\title{
Full-scale operation of a tubular ultrafiltration system in the treatment of oily waste
}

\author{
Michael Christopher Malak \\ West Virginia University
}

Follow this and additional works at: https://researchrepository.wvu.edu/etd

\section{Recommended Citation}

Malak, Michael Christopher, "Full-scale operation of a tubular ultrafiltration system in the treatment of oily waste" (1999). Graduate Theses, Dissertations, and Problem Reports. 970.

https://researchrepository.wvu.edu/etd/970

This Thesis is protected by copyright and/or related rights. It has been brought to you by the The Research Repository @ WVU with permission from the rights-holder(s). You are free to use this Thesis in any way that is permitted by the copyright and related rights legislation that applies to your use. For other uses you must obtain permission from the rights-holder(s) directly, unless additional rights are indicated by a Creative Commons license in the record and/ or on the work itself. This Thesis has been accepted for inclusion in WVU Graduate Theses, Dissertations, and Problem Reports collection by an authorized administrator of The Research Repository @ WVU. For more information, please contact researchrepository@mail.wvu.edu. 


\title{
Full-Scale Operation of a Tubular Ultrafiltration System in the Treatment of Oily Waste
}

\author{
Michael C. Malak \\ Thesis submitted to the \\ College of Engineering and Mineral Resources \\ at West Virginia University \\ in partial fulfillment of the requirements \\ for the degree of \\ Master of Science \\ in \\ Civil Engineering \\ Brian E. Reed, Ph.D., Chair \\ David Martinelli, Ph.D. \\ Roger C. Viadero Jr., Ph.D. \\ Department of Civil and Environmental Engineering \\ Morgantown, West Virginia \\ 1999
}

Keywords: Membrane Separation, Ultrafiltration, Oil-In-Water Emulsions Copyright 1999 Michael C. Malak 
TITLE PAGE i

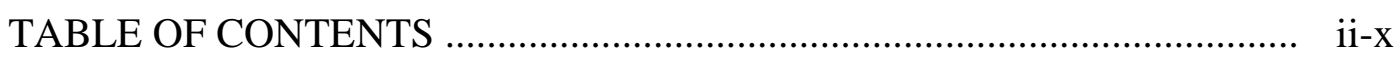

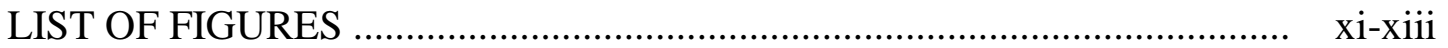

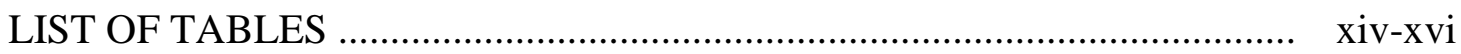

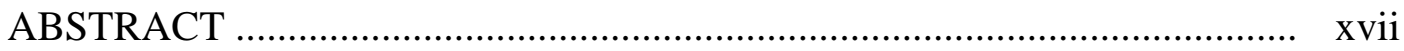

CHAPTER 1.0 INTRODUCTION ...................................................... 1-2

CHAPTER 2.0 BACKGROUND ................................................................ 3-51

MEMBRANE SEPARATION.............................................. 3-43

GENERAL TYPES OF MEMBRANE PROCESSES................. 3-6

Reverse Osmosis........................................ 4

Nanofiltration............................................ 4

Ultrafiltration......................................... $4-6$

Microfiltration.......................................... 6

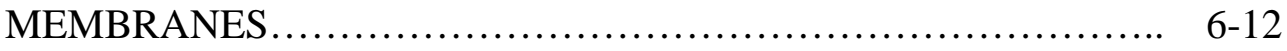

Cellulose Acetate Membranes............................... 11

Ceramic Membranes........................................... 11

CONFIGURATION OF MEMBRANE MODULES................. 11-19

Tubular.................................................... 13-14

Spiral Wound ............................................ 13-15

Hollow Fiber............................................ 16-17

Plate and Frame............................................ 16-19

MEMBRANE OPERATION MODES............................. 18-22

Recycle ............................................... 20

Semi-batch ............................................... 20-21

Batch-down .......................................... 20-22

PARTICLE FILTRATION ........................................... 23-43

Polarization Theory....................................... 26

Osmotic Pressure Model....................................... 27 
Gel Layer Model.......................................... 28

Resistance in Series Model................................. 28-29

Membrane Fouling.................................... 29-33

Mathematical Fouling Models............................. 33-43

OPERATING PARAMETERS ................................. 43-48

Flowrate.................................................... 44

Transmembrane Pressure.................................. 44-45

Temperature/Viscosity................................... 45-46

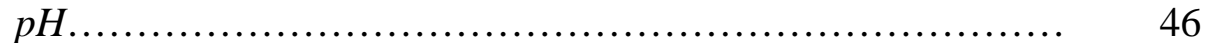

Cleaning Process.......................................... 47-48

CHARACTERISTICS OF OIL-IN-WATER EMULSIONS.......... 48-51

CHAPTER 3.0 MATERIALS AND METHODS.......................... 52-64

System Overview ........................................ $52-54$

System Operation....................................... $55-58$

Experimental Design.................................... $\quad 58-59$

Sampling Procedure...................................... 59-61

Flushing the system....................................... 61

Cleaning.............................................. 61-63

Acid Cleaning............................................ 63-64

\section{CHAPTER 4.0 RESULTS}

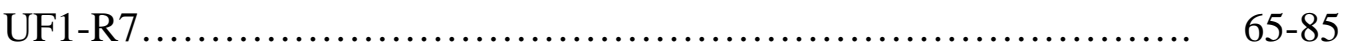

UF1-R7-SR1 ....................................... $\quad 76-79$

Permeate Flux and System Temperature................ $\quad 76$

Concentrate Oil Content and Free Oil Production......... $\quad 76$

Oil/Grease (O/G), Turbidity and Pond Effluent.......... 76

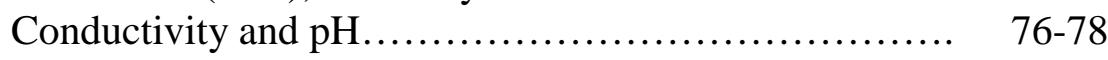

UF1-R7-SR1 Cleaning............................ $78-79$

UF1-R7-SR2 .......................................... $79-81$

Permeate Flux and System Temperature................ $\quad 79$

Concentrate Oil Content and Free Oil Production........ $\quad 79$

Oil/Grease (O/G), Turbidity and Pond Effluent........... $\quad 80$

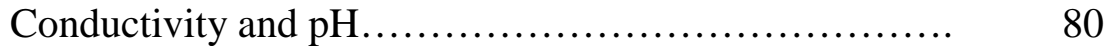

UF1-R7-SR2 Cleaning............................. 80-81

UF1-R7-SR3 ......................................... $81-83$

Permeate Flux and System Temperature................ 81

Concentrate Oil Content and Free Oil Production......... 81 
Oil/Grease (O/G), Turbidity and Pond Effluent..........

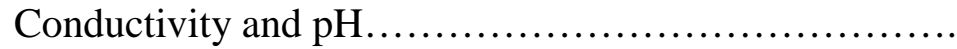

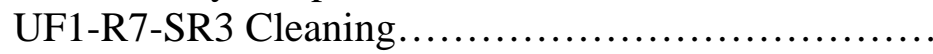

UF1-R7-SR4.

$83-85$

Permeate Flux and System Temperature............... 83

Concentrate Oil Content and Free Oil Production......... 83

Oil/Grease (O/G), Turbidity and Pond Effluent............ 84

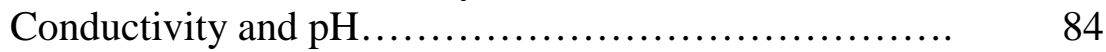

UF1-R7-SR4 Cleaning............................ $84-85$

UF1-R8

$86-120$

UF1-R8-SR1

$87-100$

Permeate Flux and System Temperature................ 99

Concentrate Oil Content and Free Oil Production........ 99

Oil/Grease $(\mathrm{O} / \mathrm{G})$, Turbidity and Pond Effluent........... 99

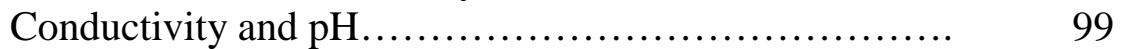

UF1-R8-SR1 Cleaning.............................. 99-100

UF1-R8-SR2 .......................................... 100-102

Permeate Flux and System Temperature................ 101

Concentrate Oil Content and Free Oil Production......... 101

Oil/Grease (O/G), Turbidity and Pond Effluent........... 101

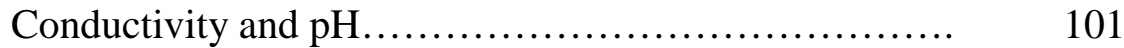

UF1-R8-SR2 Cleaning.............................. 101-102

UF1-R8-SR3 .......................................... 103-105

Permeate Flux and System Temperature................ 103

Concentrate Oil Content and Free Oil Production......... 103

Oil/Grease (O/G), Turbidity and Pond Effluent........... 103

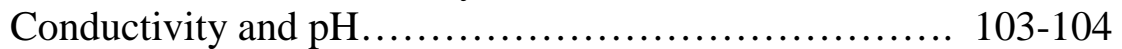

UF1-R8-SR3 Cleaning............................. 104-105

UF1-R8-SR4........................................ 105-107

Permeate Flux and System Temperature................ 105

Concentrate Oil Content and Free Oil Production......... 105

Oil/Grease (O/G), Turbidity and Pond Effluent........... 105

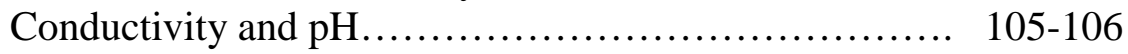

UF1-R8-SR4 Cleaning.............................. 106-107

UF1-R8-SR5 ............................................ 107-109

Permeate Flux and System Temperature................. 107

Concentrate Oil Content and Free Oil Production........ 107

Oil/Grease (O/G), Turbidity and Pond Effluent........... 108

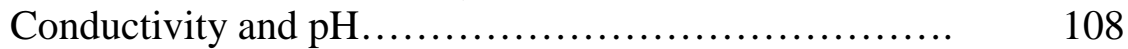


UF1-R8-SR5 Cleaning................................. 108-109

UF1-R8-SR6

$109-111$

Permeate Flux and System Temperature................. 109

Concentrate Oil Content and Free Oil Production........ 109

Oil/Grease (O/G), Turbidity and Pond Effluent........... 110

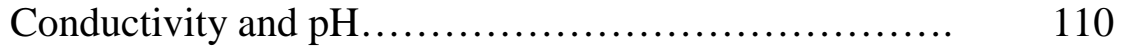

UF1-R8-SR6 Cleaning............................ 110-111

UF1-R8-SR7 ........................................... 111-113

Permeate Flux and System Temperature................. 111

Concentrate Oil Content and Free Oil Production......... 111

Oil/Grease (O/G), Turbidity and Pond Effluent........... 112

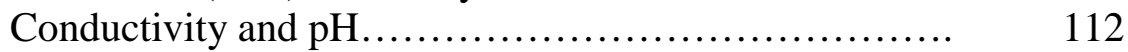

UF1-R8-SR7 Cleaning............................. 112-113

UF1-R8-SR8 .......................................... 113-115

Permeate Flux and System Temperature................. 113

Concentrate Oil Content and Free Oil Production......... 113

Oil/Grease (O/G), Turbidity and Pond Effluent........... 114

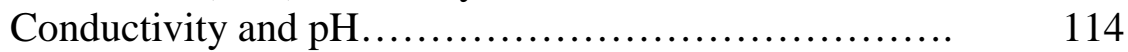

UF1-R8-SR8 Cleaning............................ 114-115

UF1-R8-SR9 ............................................... 115-117

Permeate Flux and System Temperature................. 115

Concentrate Oil Content and Free Oil Production......... 115

Oil/Grease (O/G), Turbidity and Pond Effluent........... 116

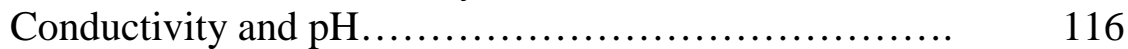

UF1-R8-SR9 Cleaning............................ 116-117

UF1-R8-SR10.......................................... 117-119

Permeate Flux and System Temperature................. 117

Concentrate Oil Content and Free Oil Production......... 117

Oil/Grease (O/G), Turbidity and Pond Effluent........... 118

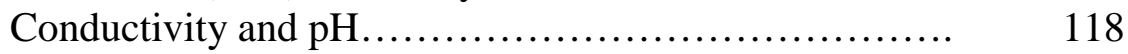

UF1-R8-SR10 Cleaning............................ 118-119

UF1-R8-SR11.............................................. 119-120

Permeate Flux and System Temperature.................. 119

Concentrate Oil Content and Free Oil Production........ 119

Oil/Grease (O/G), Turbidity and Pond Effluent........... 120

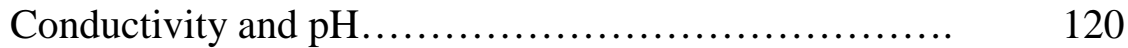

UF2-R3.

$120-142$

$\begin{array}{rr}\text { UF2-R3-SR1 } \ldots \ldots \ldots \ldots \ldots \ldots \ldots \ldots \ldots \ldots \ldots \ldots \ldots \ldots \ldots & 121-134 \\ \text { Permeate Flux and System Temperature } \ldots \ldots \ldots \ldots \ldots \ldots \ldots & 133\end{array}$ 
Concentrate Oil Content and Free Oil Production.........

Oil/Grease (O/G), Turbidity and Pond Effluent...........

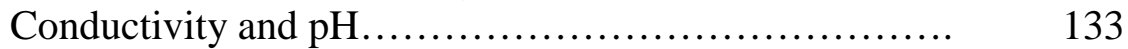

UF2-R3-SR1 Cleaning........................... 133-134

UF2-R3-SR2 ......................................... 135-137

Permeate Flux and System Temperature............... 135

Concentrate Oil Content and Free Oil Production........ 135

Oil/Grease (O/G), Turbidity and Pond Effluent.......... 135

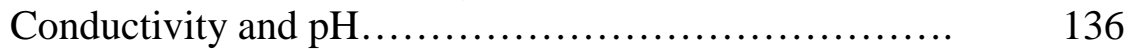

UF2-R3-SR2 Cleaning.......................... 136-137

UF2-R3-SR3 ....................................... 137-139

Permeate Flux and System Temperature............... 137

Concentrate Oil Content and Free Oil Production......... 137

Oil/Grease (O/G), Turbidity and Pond Effluent.......... 138

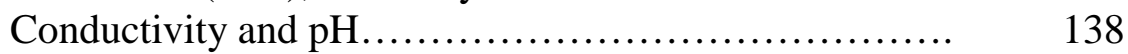

UF2-R3-SR3 Cleaning.......................... 138-139

UF2-R3-SR4 .......................................... 139-142

Permeate Flux and System Temperature.............. 140

Concentrate Oil Content and Free Oil Production......... $\quad 140$

Oil/Grease (O/G), Turbidity and Pond Effluent.......... 140

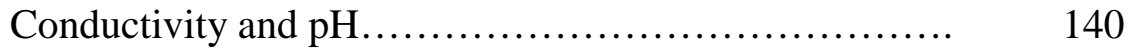

UF2-R3-SR4 Cleaning.......................... 140-142

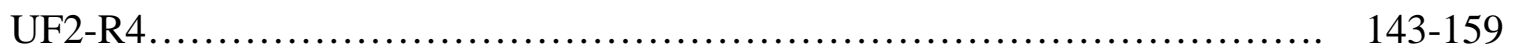

UF2-R4-SR1 ......................................... 155

Permeate Flux and System Temperature............... 155

Concentrate Oil Content and Free Oil Production........ 155

Oil/Grease (O/G), Turbidity and Pond Effluent.......... 155

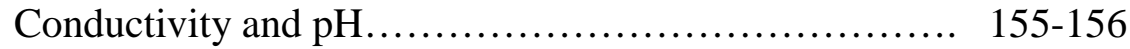

UF2-R4-SR1 Cleaning........................... 156-157

UF2-R4-SR2 ...................................... 157-159

Permeate Flux and System Temperature............... 157

Concentrate Oil Content and Free Oil Production......... 157

Oil/Grease (O/G), Turbidity and Pond Effluent.......... 157

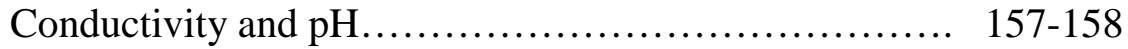

UF2-R4-SR2 Cleaning........................... 158-159 
UF2-R5.

UF2-R5-SR1

$159-176$

Permeate Flux and System Temperature................ 175

Concentrate Oil Content and Free Oil Production......... 175

Oil/Grease (O/G), Turbidity and Pond Effluent............ 175

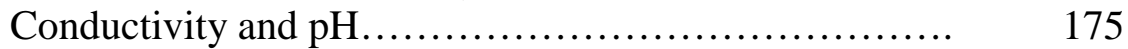

UF2-R5-SR1 Cleaning............................... 175-176

UF2-R5-SR2 ........................................ 177-178

Permeate Flux and System Temperature................ 177

Concentrate Oil Content and Free Oil Production......... 177

Oil/Grease (O/G), Turbidity and Pond Effluent........... 177

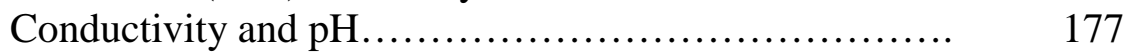

UF2-R5-SR2 Cleaning............................. 178

UF2-R5-SR3 ........................................... 179-180

Permeate Flux and System Temperature................. 179

Concentrate Oil Content and Free Oil Production......... 179

Oil/Grease (O/G), Turbidity and Pond Effluent........... 179

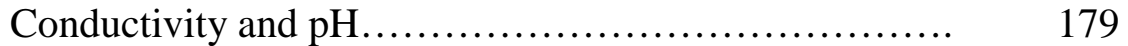

UF2-R5-SR3 Cleaning............................... 180

UF2-R5-SR4 ........................................ 181-183

Permeate Flux and System Temperature................. 181

Concentrate Oil Content and Free Oil Production......... 181

Oil/Grease (O/G), Turbidity and Pond Effluent........... 181

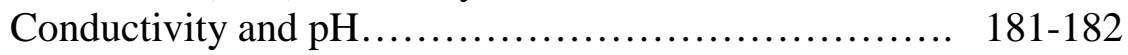

UF2-R5-SR4 Cleaning.......................... 182-183

UF2-R5-SR5 ......................................... 183-185

Permeate Flux and System Temperature................ 183

Concentrate Oil Content and Free Oil Production........ 183

Oil/Grease $(\mathrm{O} / \mathrm{G})$, Turbidity and Pond Effluent........... 183

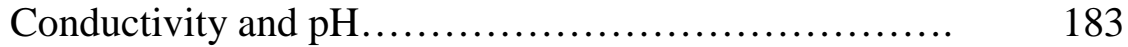

UF2-R5-SR5 Cleaning.......................... 184-185

UF2-R5-SR6......................................... 185-187

Permeate Flux and System Temperature................ 185

Concentrate Oil Content and Free Oil Production......... 185

Oil/Grease (O/G), Turbidity and Pond Effluent.......... 185

Conductivity and $\mathrm{pH}$................................ 185-186

UF2-R5-SR6 Cleaning........................... 186-187

UF2-R5-SR7 ......................................... 187-189 
Permeate Flux and System Temperature.

UF2-R5-SR8

$189-191$

Oil/Grease (O/G), Turbidity and Pond Effluent............

Conductivity and $\mathrm{pH}$

190

UF2-R5-SR8 Cleaning.

190-191

191-193

191

191

Concentrate Oil Content and Free Oil Production. ...

Oil/Grease $(\mathrm{O} / \mathrm{G})$, Turbidity and Pond Effluent. ...

Conductivity and $\mathrm{pH}$

UF2-R5-SR9 Cleaning.

UF2-R5-SR10 193-195

Permeate Flux and System Temperature. 193

Concentrate Oil Content and Free Oil Production......... Oil/Grease (O/G), Turbidity and Pond Effluent....

Conductivity and $\mathrm{pH}$. ...

UF2-R5-SR10 Cleaning.

UF2-R5-SR11....

Permeate Flux and System Temperature.

$195-196$

Concentrate Oil Content and Free Oil Production.........

Oil/Grease $(\mathrm{O} / \mathrm{G})$, Turbidity and Pond Effluent.....

Conductivity and $\mathrm{pH}$.

UF2-R5-SR11 Cleaning.

194

194

194-195

195

195

195

196

196

UF2-R5-SR12

$197-198$

Permeate Flux and System Temperature.................. 197

Concentrate Oil Content and Free Oil Production.........

Oil/Grease (O/G), Turbidity and Pond Effluent............

Conductivity and $\mathrm{pH}$ 
UF2-R5-SR13.

$199-200$

Permeate Flux and System Temperature.

199

Concentrate Oil Content and Free Oil Production........ 199

Oil/Grease (O/G), Turbidity and Pond Effluent........... 199

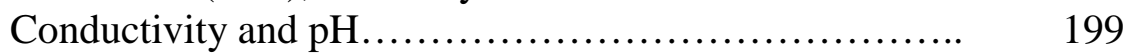

UF2-R5-SR13 Cleaning............................. 200

UF2-R5-SR14................................................ 200-202

Permeate Flux and System Temperature................. 201

Concentrate Oil Content and Free Oil Production........ 201

Oil/Grease (O/G), Turbidity and Pond Effluent............ 201

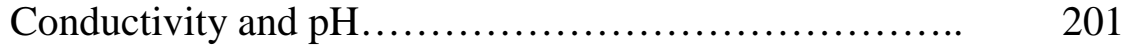

UF2-R5-SR14 Cleaning............................. 201-202

UF2-R5-SR15 ........................................ 202-204

Permeate Flux and System Temperature................ 203

Concentrate Oil Content and Free Oil Production......... 203

Oil/Grease (O/G), Turbidity and Pond Effluent............ 203

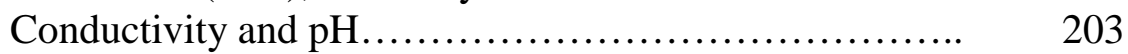

UF2-R5-SR15 Cleaning............................. 203-204

UF2-R5-SR16........................................... 204-206

Permeate Flux and System Temperature................ 205

Concentrate Oil Content and Free Oil Production........ 205

Oil/Grease (O/G), Turbidity and Pond Effluent............ 205

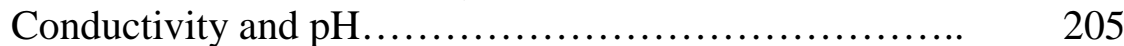

UF2-R5-SR16 Cleaning.............................. 205-206

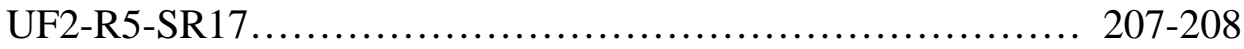

Permeate Flux and System Temperature................ 207

Concentrate Oil Content and Free Oil Production........ 207

Oil/Grease (O/G), Turbidity and Pond Effluent............ 207

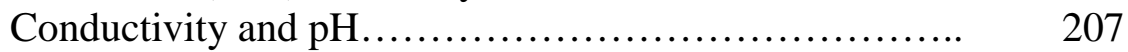

UF2-R5-SR17 Cleaning............................ 207-208

UF2-R5-SR18............................................. 209-210

Permeate Flux and System Temperature................. 209

Concentrate Oil Content and Free Oil Production........ 209

Oil/Grease (O/G), Turbidity and Pond Effluent............ 209

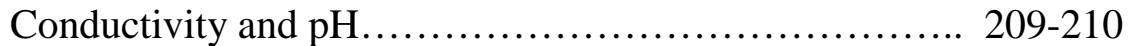

UF2-R5-SR18 Cleaning............................ 210

UF2-R5-SR19............................................ 211

Permeate Flux and System Temperature................. 211

Concentrate Oil Content and Free Oil Production........ 211

Oil/Grease $(\mathrm{O} / \mathrm{G})$, Turbidity and Pond Effluent............ 211 


\section{CHAPTER 5.0 DISCUSSION}

DEVELOPMENT OF AN OPERATING PLAN

FOR THE TUBULAR UNITS................................. 212-214

MODIFIED TREATMENT PROCESS............................. 214-225

Water Quality............................................ 215

Free Oil Production........................................ 215-216

Concentrate Oil Content.................................... 216-225

ROLE OF CONCENTRATION POLARIZTION AND

MEMBRANE FOULING ON PERMEATE FLUX................. 225-239

CHAPTER 6.0 CONCLUSION...................................... 240-241

CHAPTER $7.0 \quad$ REFERENCES..................................... 242-245 


\section{LIST OF FIGURES}

Figure (2.1) Usable Ranges of Membrane Process

Figure (2.2) A Schematic of the general Manufacturing Process of Membranes 10

Figure (2.3) A Schematic of a Tubular Membrane Module

Figure (2.4) A Schematic of a Spiral Wound Membrane Module

Figure (2.5) A Schematic of a Hollow Fiber Membrane Module

Figure (2.6) A Schematic of a Plate and Frame Membrane Module

Figure (2.7) A Schematic of Semi-batch Operation Mode

Figure (2.8) A Schematic of Batch Operation Mode

Figure (2.9) Concentration Polarization Phenomena

Figure (2.10) Operation Parameters Effecting Concentration Polarization

Figure (2.11) A Schematic of Membrane Fouling Due to Pore Plugging

Figure (2.12) The Effects of Operating Pressure on Permeate Flux

Figure (2.13) Result of the Salt Free System

Figure (2.14) Three Stage Change in Fouling Rate

Figure (2.15) A Schematic of an Emulsified Oil Droplet

Figure (3.1) Proposed Treatment Process

Figure (3.2) Profile of the Tubular UF System

Figure (3.3) Top View Membrane Configuration

Figure (4.1) Permeate Flux versus Time for UF1-R7

Figure (4.2) Permeate Turbidity versus Time for UF1-R7 
Figure (4.4) Permeate Turbidity versus Time for UF1-R8

Figure (4.5) Permeate Flux versus Time for UF2-R3

Figure (4.6) Permeate Turbidity versus Time for UF2-R3

Figure (4.7) Permeate Flux versus Time for UF2-R4

Figure (4.8) Permeate Turbidity versus Time for UF2-R4

145

Figure (4.9) Permeate Flux versus Time for UF2-R5

Figure (4.10) Permeate Turbidity versus Time for UF2-R5

162

Figure (5.1) Running Permeate Average versus Time

Figure (5.2) Current Treatment Process 215

$\begin{array}{lll}\text { Figure (5.3) Oil Mass Balance Diagram } & 218\end{array}$

Figure (5.4) Actual and Predicted Oil Contents for UF1-R7 Mass Balance 220

Figure (5.5) Actual and Predicted Oil Contents for UF1-R8 Mass Balance 221

Figure (5.6) Actual and Predicted Oil Contents for UF2-R3 Mass Balance 222

Figure (5.7) Actual and Predicted Oil Contents for UF2-R4 Mass Balance 223

Figure (5.8) Actual and Predicted Oil Contents for UF2-R5 Mass Balance 224

Figure (5.9) Actual and Predicted Permeate Flux for UF1-R7 using Model \#4

Figure (5.10) Actual and Predicted Permeate Flux for UF1-R8 (subrun 1-6) using Model \#4

Figure (5.11) Actual and Predicted Permeate Flux for UF1-R8 (subrun 7-10) using Model \#4

Figure (5.12) Actual and Predicted Permeate Flux for UF2-R3 using Model \#4 
Figure (5.13) Actual and Predicted Permeate Flux for UF2-R4 using Model \#4

Figure (5.14) Actual and Predicted Permeate Flux for UF2-R5 (Subrun 1-6) using Model \#4

Figure (5.15) Actual and Predicted Permeate Flux for UF2-R5 (Subrun 7-12) using Model \#4

Figure (5.16) Actual and Predicted Permeate Flux for UF2-R5 (Subrun 13-18) using Model \#4

Figure (5.17) Actual and Predicted Permeate Flux for UF2-R5-SR3 using Models 1, 2, 3, and 5 


\section{LIST OF TABLES}

$\underline{\text { TABLE }}$

PAGE

$\begin{array}{lll}\text { Table (2.1) Applications for Ultrafiltration } & 7\end{array}$

$\begin{array}{lll}\text { Table (2.2) Applications for Microfiltration } & 8\end{array}$

Table (2.3) Advantages and Disadvantages of Cellulose Acetate Membranes 12

Table (2.4) Mathematical Fouling Models 34

Table (2.5) Composition of Cheese Whey 36

Table (2.6) Value of $\mathrm{J}_{\mathrm{O}}$ and $\mathrm{b}$ from Cheryan and Merin experiments 39

Table (2.7) Results of Pressure and Flow Rate on the Fouling Index, b $\quad 40$

Table (4.1) Summary of Permeate Parameters for UF1-R7 68

Table (4.2) Summary of Concentrate and Pond Effluent $\quad 69$

Parameters for UF1-R7

Table (4.3) Summary of Permeate Cleaning Parameters for UF1-R7 70

Table (4.4) Summary of Concentrate Cleaning Parameters for UF1-R7 71

Table (4.5) Summary of Permeate O/G Samples for UF1-R7 72

Table (4.6) Summary of Concentrate Oil Content Samples for UF1-R7 73

Table (4.7) Summary of Skimming Samples for UF1-R7 74

Table (4.8) Summary of Free Oil Productions for UF1-R7 75

Table (4.9) Summary of Pond Effluent O/G Samples for UF1-R7 77

Table (4.10) Summary of Permeate Parameters for UF1-R8 90

Table (4.11) Summary of Concentrate and Pond Effluent 91

Parameters for UF1-R8

Table (4.12) Summary of Permeate Cleaning Parameters for UF1-R8 92

Table (4.13) Summary of Concentrate Cleaning Parameters for UF1-R8 93 
Table (4.14) Summary of Permeate O/G Samples for UF1-R8

Table (4.15) Summary of Concentrate Oil Content Samples for UF1-R8

Table (4.16) Summary of Skimming Samples for UF1-R8 96

Table (4.17) Summary of Free Oil Productions for UF1-R8 97

Table (4.18) Summary of Pond Effluent O/G Samples for UF1-R8 98

Table (4.19) Summary of Permeate Parameters for UF2-R3 124

Table (4.20) Summary of Concentrate and Pond Effluent O/G 125

Table (4.21) Summary of Permeate Cleaning Parameters for UF2-R3 126

Table (4.22) Summary of Concentrate Cleaning Parameters for UF2-R3 127

Table (4.23) Summary of Permeate O/G Samples for UF2-R3 128

Table (4.24) Summary of Concentrate Oil Content Samples for UF2-R3 129

Table (4.25) Summary of Skimming Samples for UF2-R3 130

Table (4.26) Summary of Free Oil Productions for UF2-R3 131

Table (4.27) Summary of Pond Effluent O/G Samples for UF2-R3 132

Table (4.28) Summary of Permeate Parameters for UF2-R4 146

Table (4.29) Summary of Concentrate and Pond Effluent O/G 147

Table (4.30) Summary of Permeate Cleaning Parameters for UF2-R4 148 
Table (4.31) Summary of Concentrate Cleaning Parameters for UF2-R4

Table (4.32) Summary of Permeate O/G Samples for UF2-R4 150

Table (4.33) Summary of Concentrate Oil Content Samples for UF2-R4 151

Table (4.34) Summary of Skimming Samples for UF2-R4 152

Table (4.35) Summary of Free Oil Productions for UF2-R4 153

Table (4.36) Summary of Pond Effluent O/G Samples for UF2-R4 154

Table (4.37) Summary of Permeate Parameters for UF2-R5 (Subruns 1 - 11) 163

Table (4.38) Summary of Permeate Parameters for UF2-R5 (Subruns 12 - 19) 164

Table (4.39) Summary of Concentrate and Pond Effluent O/G 165 Parameters for UF2-R5 (Subruns 1-11)

Table (4.40) Summary of Concentrate and Pond Effluent O/G 166 Parameters for UF2-R5 (Subruns 12 - 19)

Table (4.41) Permeate Cleaning Parameters for UF2-R5 (Subrun 1 - 11) 167

Table (4.42) Summary of Permeate Cleaning Parameters 168 for UF2-R5 (Subruns 12 - 19)

Table (4.43) Summary of Concentrate Cleaning Parameters for UF2-R5 169

Table (4.44) Summary of Permeate O/G Samples for UF2-R5 170

Table (4.45) Summary of Concentrate Oil Content Samples for UF2-R5 171

Table (4.46) Summary of Skimming Samples for UF2-R5 172

Table (4.47) Summary of Free Oil Productions for UF2-R5 173

Table (4.48) Summary of Pond Effluent O/G Samples for UF2-R5 174

Table (5.1) List of Fouling Indexes (k) for All Subruns 237 


\begin{abstract}
An aluminum company in West Virginia uses an oil-water (metal working fluid) in their rolling mill process for lubrication. In the past, the company collected the oilywaste into two lined waste ponds with a combined holding capacity of 5 million gallons. Separation of the oil-water mixture occurred as emulsifiers in the metal working fluid broke down. Free oil was skimmed resulting in a pond effluent, which contained 0.2 to 1.0-\% oil. Pond effluent was sprayed on a treatment field and the remaining oil was degraded naturally. The daily flow to the spray fields averaged 80,000 gallons. In 1993, concerns about direct land treatment of the waste surfaced, due to new groundwater regulations issued by the West Virginia Department of Environmental Protection. As a result, the company investigated alternatives for oily-waste treatment. The technologies studied were as follows: chemical addition dissolved air flotation (CA-DAF), biological aerated filter, tubular and rotary ultrafiltration (UF), land application, and constructed wetlands. The primary pollutant of concern was oil/grease $(\mathrm{O} / \mathrm{G})$.
\end{abstract}

Separation of the free oil in a single three million-gallon pond was selected as primary treatment. Tubular ultrafiltration was chosen as the secondary treatment process. Tubular UF was selected to treat the remaining water phase or pond effluent. Permeate from the tubular UF is sent to a hybrid constructed wetlands for polishing. Residual from the tubular UF is treated using high-shear rotary Ultrafiltration (HSR-UF). HSR-UF is able to concentrate oily-waste to $\sim 70 \%$ oil. The residual from the HSR-UF was to be disposed of off site. 


\section{CHAPTER 1}

\section{INTRODUCTION}

An aluminum company in West Virginia uses an oil-water mixture (metal working fluid) in their rolling mill process for lubrication. In the past, the company collected the oily-waste into two lined waste ponds with a combined holding capacity of 5 million gallons. Separation of the oil-water mixture occurred as emulsifiers in the metal working fluid brokedown. Free oil was skimmed resulting in a pond effluent, which contained 0.2 to $1.0 \%$ oil. Pond effluent was sprayed on a treatment field and the remaining oil was degraded naturally. The daily flow to the spray fields averaged 80,000 gallons. In 1993, concerns about direct land treatment of the waste surfaced, due to new groundwater regulations issued by the West Virginia Department of Environmental Protection. As a result, the company investigated alternatives for oily-waste treatment. The technologies studied were as follows: chemical addition dissolved air flotation (CA-DAF), biological aerated filter, tubular and rotary ultrafiltration (UF), land application, and constructed wetlands. The primary pollutant of concern was oil/grease $(\mathrm{O} / \mathrm{G})$. Separation of the free oil in a single three million gallon pond was selected as primary treatment. Tubular ultrafiltration was chosen as the secondary treatment process. Tubular UF was selected to treatment the remaining water phase or pond effluent. Permeate from the tubular UF was to be sent to a hybrid constructed wetlands for polishing. Residual from the tubular UF was to be treated using high-shear rotary Ultrafiltration (HSR-UF). HSR-UF is able to concentrate oily-waste to $~ 70 \%$ oil. The residual from the HSR-UF was to be disposed of off site. 
Following full-scale system construction, West Virginia University's Department of Civil and Environmental Engineering (WVU-CEE) was asked to startup the system and optimize performance.

\section{OBJECTIVE AND GOALS}

The objective of the entire study was to develop a standard operating plan for the entire oily-waste system. In partial fulfillment of this objective, the following goals were developed:

1. Develop operating plan for tubular UF system that optimizes system performance.

2. Determine free oil production rates.

3. Develop a mass balance model on oil for tubular UF system.

4. Investigate the role of concentration polarization on permeate flux. 


\section{Chapter 2}

\section{BACKGROUND}

In this section membrane filtration; types of membrane separation processes; configuration of membrane geometries are discussed. In addition membrane limitations and factors controlling membrane performance and membrane fouling models will be discussed.

\section{Membrane Separation}

Membrane filtration is pressure driven separation process designed to separate fluid/fluid and particle/fluid mixtures using porous membranes. The membrane allows the fluid to pass and retains the particles and other dissolved substances. The membrane acts as a barrier that separates the material according to their physical and molecular size. Particles smaller than the pores on the membranes are allowed to pass while particles of larger size are retained or rejected. Material that pass through the membrane is known as permeate, while the retained material is returned to the feed tank to be concentrated further. Permeate flux is the term used to describe the rate at which the fluid is passing through the membrane. Flux is measured as volume/membrane area-time.

\section{GENERAL TYPES OF MEMBRANE PROCESSES}

The diameter of the particle or molecular weight of the molecule that is rejected in the separation process is one way to characterize membranes, known as the molecular weight cutoff or MWCO. There are several types of membrane filtration processes including Reverse Osmosis (RO), Nanofiltration (NF), Ultrafiltration (UF), and 
Microfiltration (MF). In Figure 2.1, the usable range of each membrane processes are presented (Perry and Green, 1997).

\section{REVERSE OSMOSIS}

Reverse osmosis (RO) is a membrane separation technology that separates materials with diameters from $\sim 10^{-4}$ to $10^{-3} \mu \mathrm{m}$. The common particles that RO generally separates are metal ions and salts. As a result RO is mainly used for purifying brackish and sea waters.[Belfort, 1998] Osmosis is the diffusion of water through a semipermeable barrier from an area of low concentration to an area of higher concentration. $\mathrm{RO}$ on the other hand, is the exact opposite of osmosis. In RO, the pressure in the concentrated side of the membrane is increase above the osmotic pressure so that the water diffuses from the more concentrated side to the pure waterside of the membrane.

\section{NANOFILTRATION}

Nanofiltration (NF) is generally the same type technology as reverse osmosis. The difference is that Nanofiltration separates particles from solution that range from $\sim 10^{-3}$ to $10^{-2} \mu \mathrm{m}$. NF is often used to soften water. Dewatering of pesticides and herbicides solutions is also another common use of Nanofiltration.[Perry and Green 1997]

\section{ULTRAFILTRATION}

Ultrafiltration (UF) is the separation process at which, hydrostatic pressure is applied to the feed solution. Water and dissolved materials, which have low molecular weights, are allowed to pass through the membranes. Larger particles such as emulsified oils and other suspended materials are rejected [Goldsmith, 1974]. UF is used to separate particle sizes that range from $\sim 10^{-3}$ to $1 \mu \mathrm{m}$. Use of ultrafiltration has been successful in 


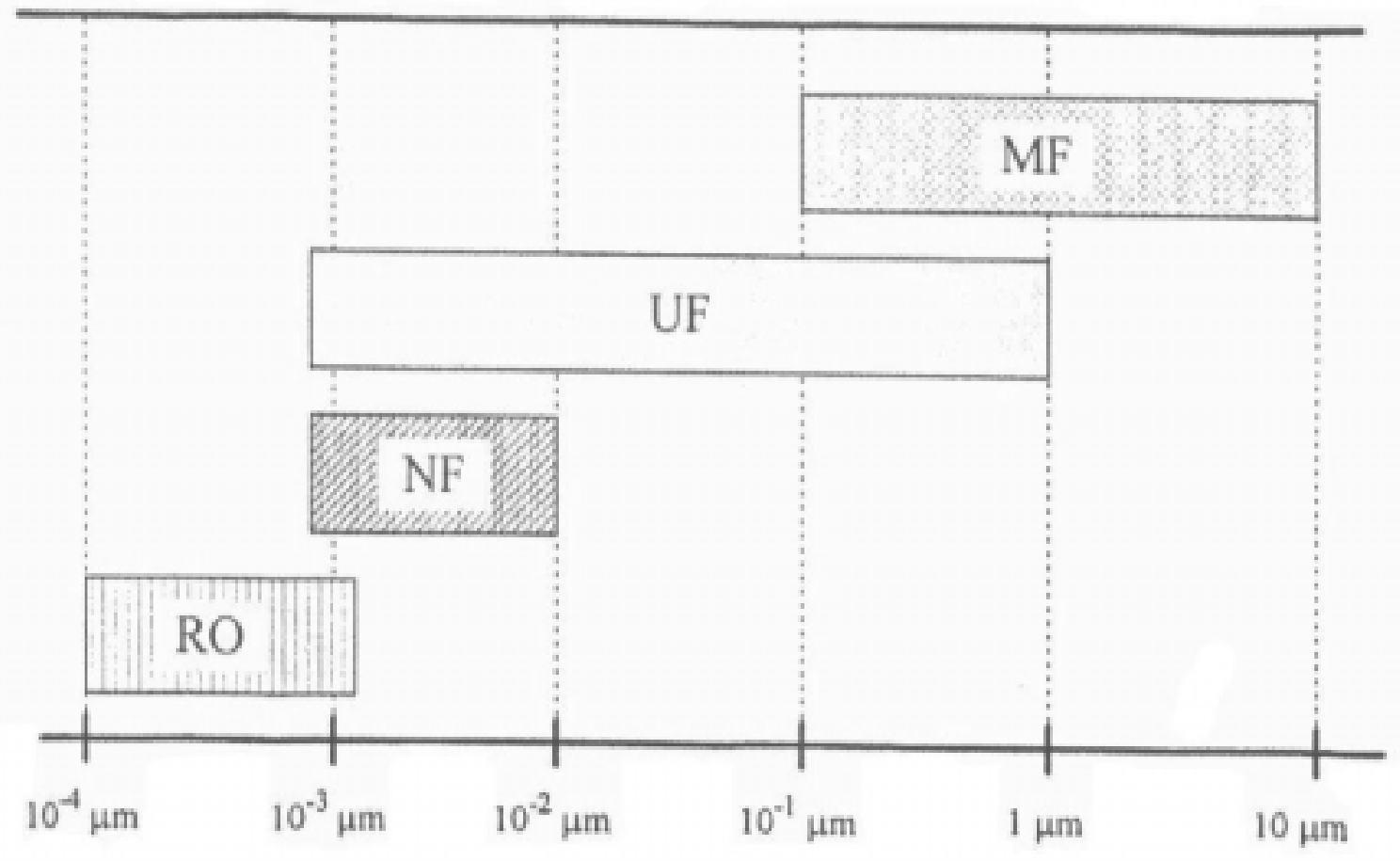

Particle Diameter

Figure 2.1 Usable Ranges of Membrane Process (Perry and Green, 1997) 
metalworking processes such as rolling mills that use emulsified oil solution for lubrication. Some other applications for Ultrafiltration are presented in Table 2.1 [Toyomoto 1992].

\section{MICROFILTRATION}

Microfiltration (MF) is similar to UF. Microfiltration like UF uses an applied pressure to drive water through a porous membrane. The difference is MF has larger pore sizes than UF. MF is used to separate materials that range in size from $\sim 10^{-1}$ to $10 \mu \mathrm{m}$. Microfiltration is often used in industries such as fermentation, medical, food and beverage and electronic. Applications of MF are presented in Table 2.2. [Toyomoto and Higuchi, 1992]

\section{MEMBRANES}

Membranes used in separation processes are classified by the molecular weight or the diameter of the particle retained by the membrane. In theory, compounds having greater molecular weight than the molecule weight cutoff (MWCO) will be retained by the membrane. Compounds with less molecular weight than the MWCO will pass through the membrane as permeate. MWCO can be misleading, in that compounds with less molecular weights than the MWCO may still be retained by the membrane because of the compounds unique shape.

Membranes must be able to withstand the mechanical, chemical and biological stresses imposed during operation. Membranes are generally made from durable polymers that are able to withstand periodic cleanings to remove foulants and other debris from the 
Table 2.1 Applications for Ultrafiltration

\begin{tabular}{||l|l||}
\hline \hline Industry & Applications \\
\hline \hline Fermentation & Sterilization and removal of micro-particles in liquid or gas \\
\hline Medical & $\begin{array}{l}\text { Transfusion filter set: hemocyte/serum separation: purification of } \\
\text { surgical water }\end{array}$ \\
\hline Electronic & $\begin{array}{l}\text { Removal of microparticles from the ultrapure water; purification of } \\
\text { chemicals and solvents }\end{array}$ \\
\hline Food and Beverage & Purification of edible oils, beverages, draft beer and draft wine \\
\hline Others & $\begin{array}{l}\text { Removal of micro-particles from solvents and oils; water purifiers } \\
\text { for home use; purification of condensed water at nuclear plants }\end{array}$ \\
\hline
\end{tabular}


Table 2.2 Applications for Microfiltration

\begin{tabular}{||l|l||}
\hline \hline Industry & Applications \\
\hline \hline Fermentation & $\begin{array}{l}\text { Production of sterilized or pyrogen-free water; } \\
\text { concentration/purification of enzymes; production of vaccines; } \\
\text { purification of fermented liquors }\end{array}$ \\
\hline Medical & Filter-type artificial kidney \\
\hline Electronic & Purification of ultrapure water \\
\hline Automobile & Recovery of electrodeposition paints \\
\hline Chemical & Purification of colloid and emulsion \\
\hline Food and beverage & $\begin{array}{l}\text { Clarification of fruit juices; production of unrefined spirits; removal } \\
\text { of dregs from soy sauce. }\end{array}$ \\
\hline
\end{tabular}


membrane's surface. The membranes are chosen by their compatibility with the waste stream, ability to retain particles and maintain performance over a long period of time.

Membrane manufacturing is important in understanding the separation and permeation mechanism of small molecules passing through a membrane. As stated before, membranes are generally made of durable natural polymers, such as cellulose or synthetic polymers such as, polycarbonate or polysulfone. In Figure 2.2, a schematic of general manufacturing of polymer membranes is presented [Cheryan, 1986]. The polymer is first mixed with suitable solvent and swelling agents. The mixture is known as cast dope. The next phase of the process is to test a small sample of the casting dope under controlled conditions to assure the casting dope makes a satisfactory membrane. The controlled test is usually performed in a glass plate. If the cast dope passes the quality control test, the entire batch is placed into the casting machine. The casting machine is the critical process in the production of membranes. Casting equipment is designed specifically for each type of membrane or module configuration. Therefore, the casting machines are usually designed and constructed by the manufacturers themselves. In generally, membranes are manufactured in flat sheets. However, membranes can be cast directly onto the module they are made for (e.g. tubular modules). The membranes then under go an annealing or drying process and are checked for performance characteristics before being constructed into the final form [Cheryan, 1986]. During the drying process, solvents in the casting evaporate forming the pores of the membrane. The membranes are then preserved in a wet storage. 


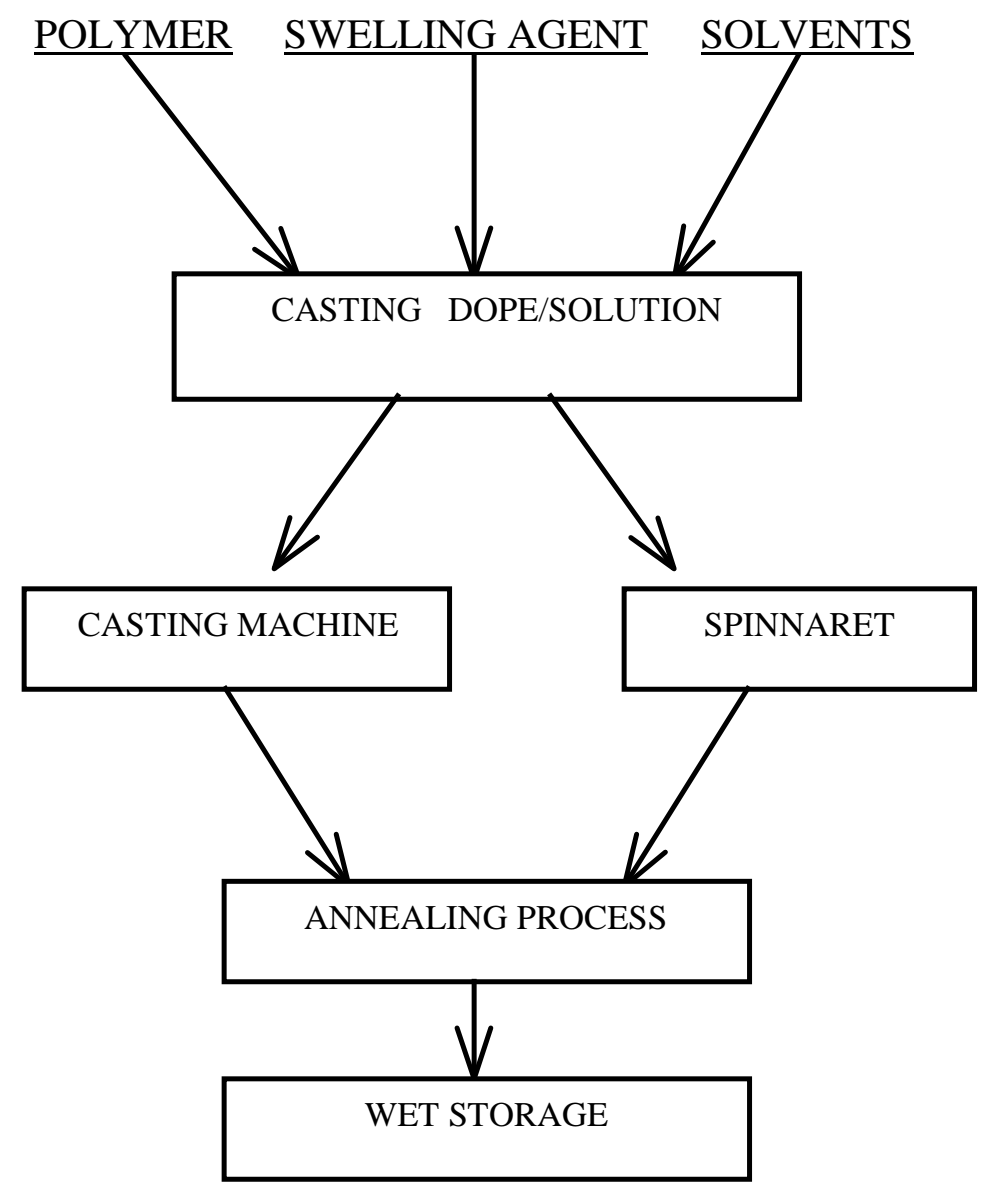

Figure 2.2 A Schematic of the general Manufacturing Process of Membranes(Cheryan, 1986) 


\section{Cellulose Acetate Membranes}

One common type of membrane used in UF applications is cellulose acetate membranes. The raw material for cellulose acetate membranes is cellulose. The major source of cellulose is wood pulp. Cellulose and its derivatives are linear, rod-like and rather inflexible molecules. These characteristics are important for RO and UF application in that these membrane processes are operated at high pressures. Therefore, the cellulose membrane material is excellent for withstanding these pressures. In Table 2.3, advantages and disadvantages of cellulose acetate membranes are presented [Cheryan, 1986].

\section{Ceramic Membranes}

Ceramic membranes are membranes that are made from inorganic mineral materials. In theory, ceramic membranes are extremely versatile, since these membranes are made of inorganic components. Unlike cellulose acetate membranes, both membrane and support structures are able to withstand wide ranges in temperature and $\mathrm{pH}$. In addition ceramic membranes are very resist to chemical and abrasion degradation. Ceramic membrane durability have been tested using strong caustic soda solutions at temperatures approaching the boiling point and no apparent damage to the membranes were observed [Cheryan, 1986]. One disadvantage of ceramic membranes is that these membranes tend to be expensive, because of their durable qualities. 
Table 2.3, Advantages and Disadvantages of Cellulose Acetate Membranes

Advantages $\quad$ Disadvantages

Cellulose acetate strong molecular structure is ideal for pressure driven membrane

Have fairly narrow temperature and $\mathrm{pH}$ ranges. (recommended max. temperature of processes. $30^{\circ} \mathrm{C}$, and $\mathrm{pH}$ range of $2-8$ perferable $3-6$ )

High permeate flux and salt rejection properties. Cellulose acetate membranes have been reported to undergo a compaction phenomena. (results in permeate flux decline)

Cellulose acetate membranes are easily manufactured. Highly susceptible to biodegradation due to the natural cellulose material.

The raw material (cellulose) is a renewable resource. Sanitizers such as chlorine, will oxide cellulose acetate, thus damaging the membrane 


\section{CONFIGURATION OF MEMBRANE MODULES}

There are many different module configurations for UF and MF used in commercial applications. The most common are tubular, spiral wound, hollow fiber and plate and frame [Belfort 1988].

\section{Tubular}

In Figure 2.3, a schematic of a tubular module is presented [MacNeil and McCoy, 1989]. A tubular membrane consists of a porous membrane that is cast as a tube on the inside of a support tube, which is in turn placed into a another tube usually made of PVC. The feed flows through the tube at a high velocity. The feed velocity has to be high enough to cause turbulence at the membrane surface. Reynolds numbers up to 130,000 have been used in tubular systems [Belfort, 1988]. The permeate is forced radially through the membrane and is collected through a port located at the end of the tube. Tubular membranes are usually between 5 and 10 feet in length and 0.5 to 1 inch in diameter. Operating pressures usually are about 90 psi for commercial units [MacNeil and MacCoy, 1989]. Tubular units are easily cleaned. Large flow channels make it easier to remove accumulated material on the membranes surface [MacNeil and McCoy, 1989] Disadvantages of tubular membranes are a low packing density.

\section{Spiral Wound}

In Figure 2.4, a schematic of the spiral wound module is presented [MacNeil and McCoy, 1989]. In the spiral wound module, several flat membranes are layered tightly together between a two plastic screen supports and then rolled. The membranes are then seal together at the edges and placed into permeate collection tube. [Belfort, 1988] The feed solution flow through the wound membrane. As it does, permeate is forced through 


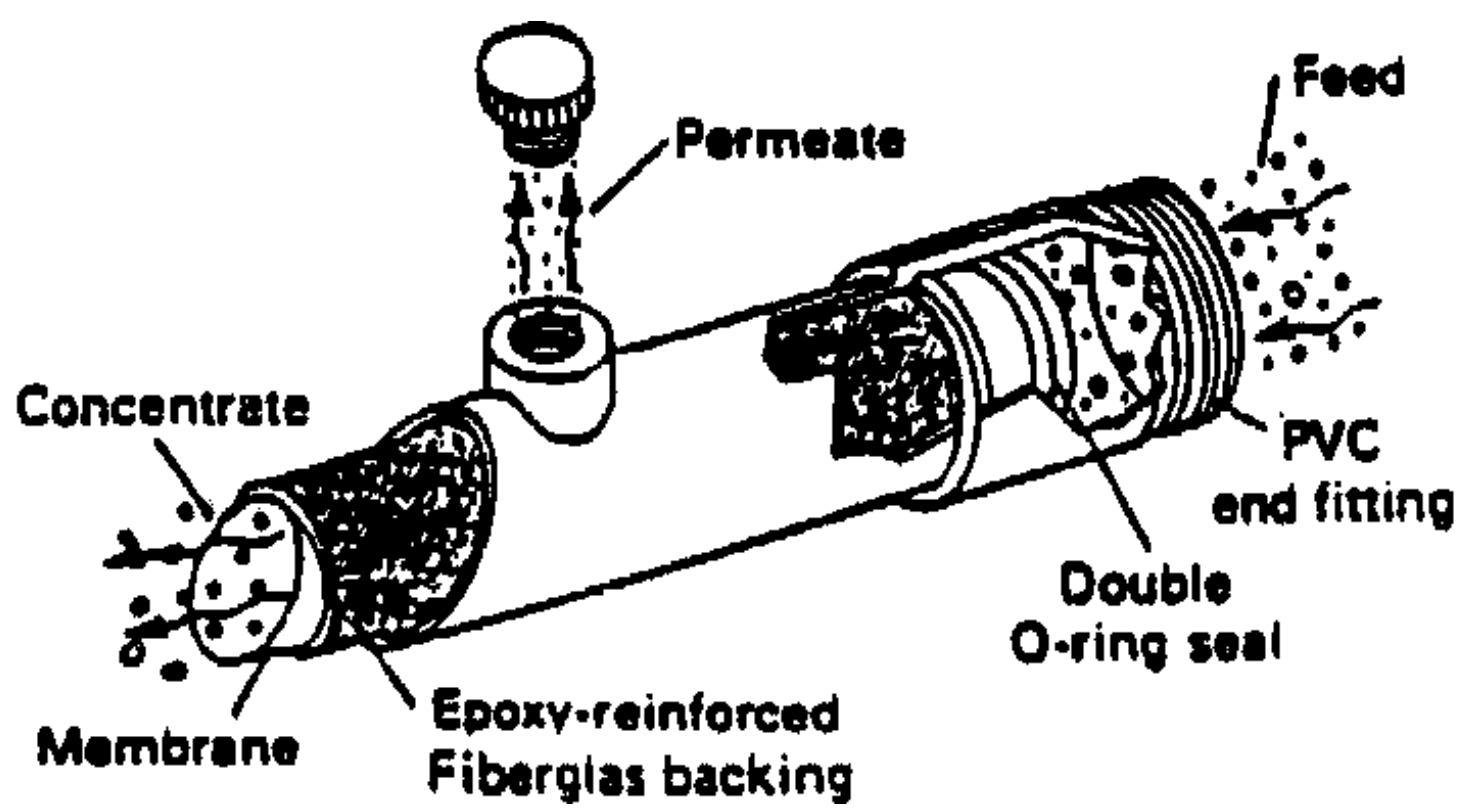

Figure 2.3 A Schematic of a Tubular Membrane Module (Perry and Green, 1997) 


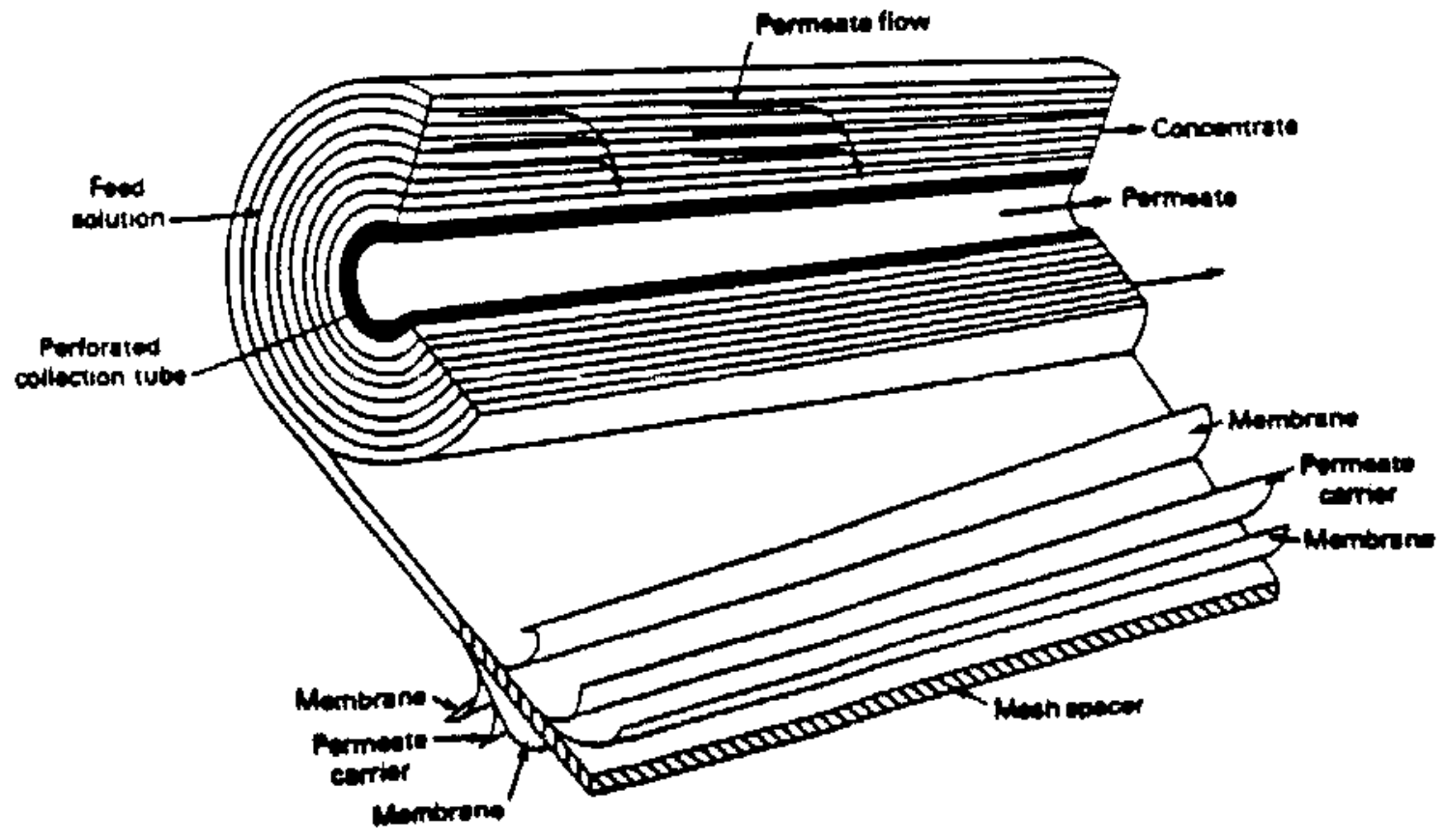

Figure 2.4. A Schematic of a Spiral Wound Membrane Module(MacNeil an McCoy, 1989) 
the porous membrane and is collected. The feed material that is rejected flows to the end of the modules and exits. Spiral wound membranes can be operated at pressure up to 150 psig. The diameters of these modules usually range from $\sim 5-20 \mathrm{~cm}$. A disadvantage to the spiral wound modules is that fouling occurs more readily than of the tubular membranes due to smaller flow channels [MacNeil and McCoy, 1989]. Spiral wound modules have been successful in some areas. Recently the spiral wound design was found to be one of the leading contenders for large scale commercial applications in the biotechnology field.[Belfort, 1988]

\section{Hollow Fiber}

In Figure 2.5, a schematic of a hollow fiber module is presented [MacNeil and McCoy, 1989]. Hollow fibers are bundled into a U-shaped arrangement for feed flow on the outside or in a straight pattern for feed flow on the inside. Opposite to tubular modules, hollow fiber membranes do not have an underlying support. For the U-shaped configuration, feed flows at high pressure across the outside of the hollow fibers. Permeate is forced radially inward through the unsupported fibers. The permeate collects in the center and flows to a collection chamber. For the straight pattern, the feed solution travels through the center bore. Permeate from the feed solution travels radially outward through the fibers. Hollow fiber membranes, similar to other membrane modules, have advantages and disadvantages. The U-shaped design is low in cost, compact and has a low water hold up. Disadvantages to the U-shaped design is that shell-side feed hollow fiber tend to plug easily and are relatively difficult to clean. The inside feed or straight configured hollow fiber design improves the possibility for cleanings, by reversing the 


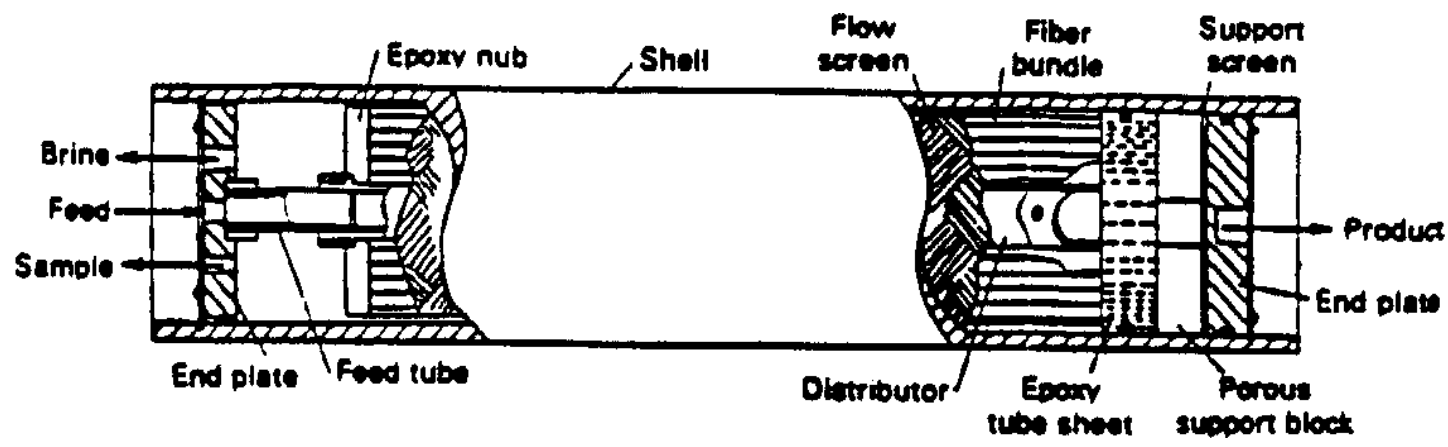

Figure 2.5. A Schematic of a Hollow Fiber Membrane Module (MacNeil and McCoy, 1989) 
flow of permeate clogged pores of the membranes are cleaned. This design is increasingly being used in the biomedical and biochemical fields.[Belfort, 1988]

\section{Plate and Frame}

In Figure 2.6, a schematic of a plate and frame module is presented [MacNeil and McCoy, 1989]. Plate and frame systems have porous membranes with disc-shape spacers between them. The spacers are used to direct feed solution along the membrane's surface radially. The membranes can be placed in series or parallel inside the housing. Permeate is collected at the outer edges of the membrane discs. The concentrate or rejected material flows to the top of the housing and returns to the feed tank. An advantages to the design is a low volume hold-up per unit membrane area. The low volume hold up per membrane area makes this design an excellent system for recovering valuable biologicals. Another advantage with the design is that replacement of membranes are quick and easy. Disadvantages include, high probability for channel clogging and difficulties in cleaning effectively. [Belfort, 1988]

\section{Membrane Operation Modes}

There are three primary separation modes used in filtration. These separation modes are (1)semi-batch or modified batch mode, (2) batch mode and (3) recycle mode. Since membrane separation technologies are volume reduction processes, the concentration factor $(\mathrm{CF})$ is an important system parameter. $\mathrm{CF}$ is defined as the ratio of feed concentration at a given time over the initial feed concentration. Concentration factors are generally expressed as $1 \mathrm{X}, 2 \mathrm{X}$, etc, and increase as the separation system treats waste. 


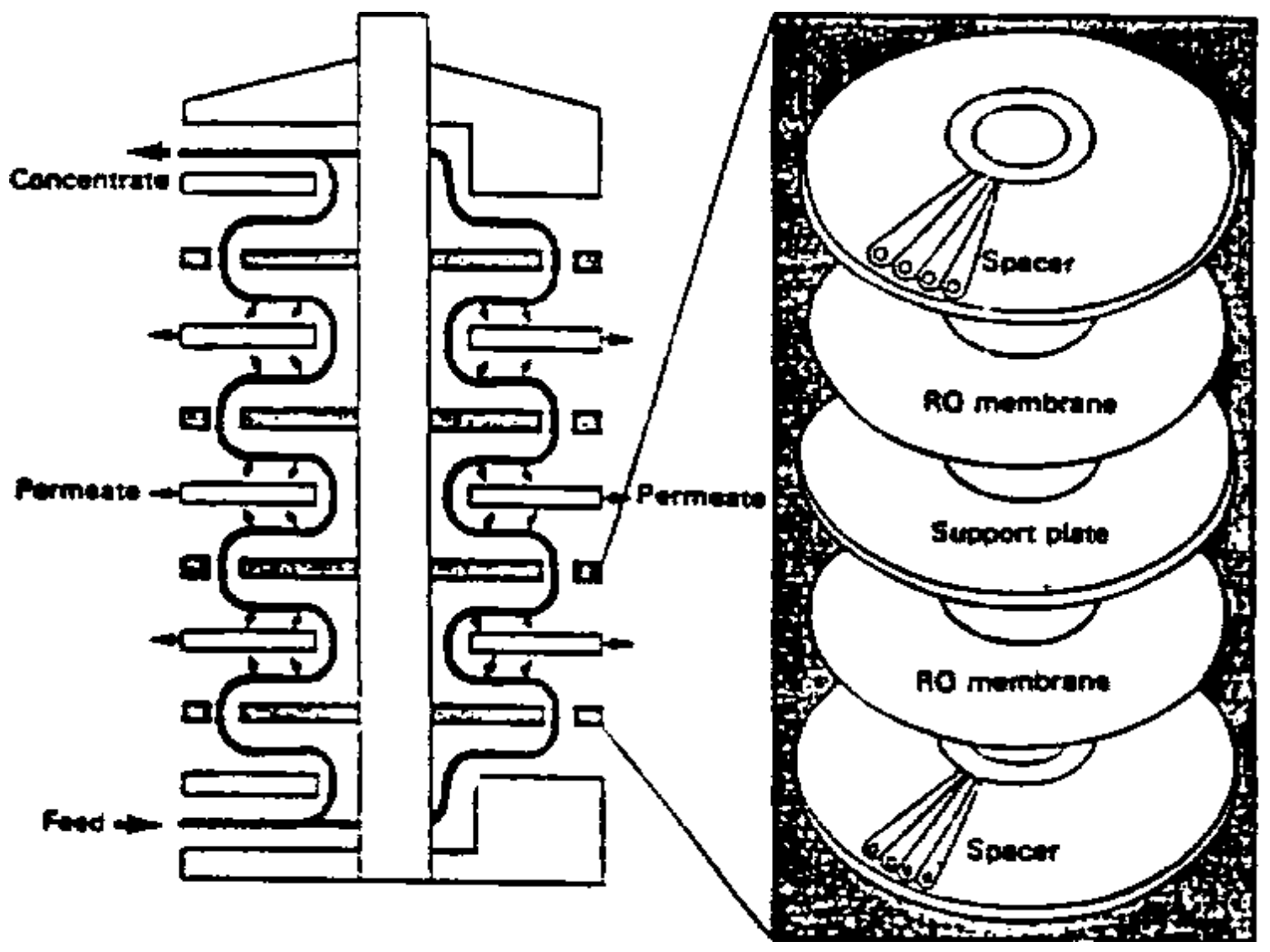

Figure 2.6 A Schematic of a Plate and Frame Membrane Module (MacNeil and McCoy, 1989) 


\section{Recycle Mode}

In the recycle mode, feed solution is pumped to the membranes from a feed tank. As the feed travels along the membrane permeate is forced through the membrane and returned back to the feed tank. The reject solution also returns to the feed tank. Thus, the solution in the feed tank remains at a constant concentration. Pilot scale laboratory studies are often operated in recycle mode to test membrane performance at constant concentrations.

\section{Semi-Batch Mode}

In Figure 2.7, a schematic of the semi-batch operation mode is presented [Koch Membrane System, 1993]. In the semi-batch mode, fresh feed solution (1X) is continuously being supplied to the feed tank and the same rate permeate is leaving the system. As a result the concentration in the feed tank increases with time. It is possible to dewater large volumes of waste, thus, reducing the amount that needs to be disposed.

\section{Batch Mode}

In Figure 2.8, a schematic of the batch mode is presented [Koch Membrane System, 1993]. In the batch mode, the feed solution is pumped to the membranes from the feed tank. Unlike the semi-batch mode, fresh $1 \mathrm{X}$ feed solution is not continuously pumped into the feed tank while permeate is removed. The concentration in the feed tank increases as the volume decreases. Batch mode is often applied after the semi-batch mode to further reduce the volume of waste that needs to be disposed of. 


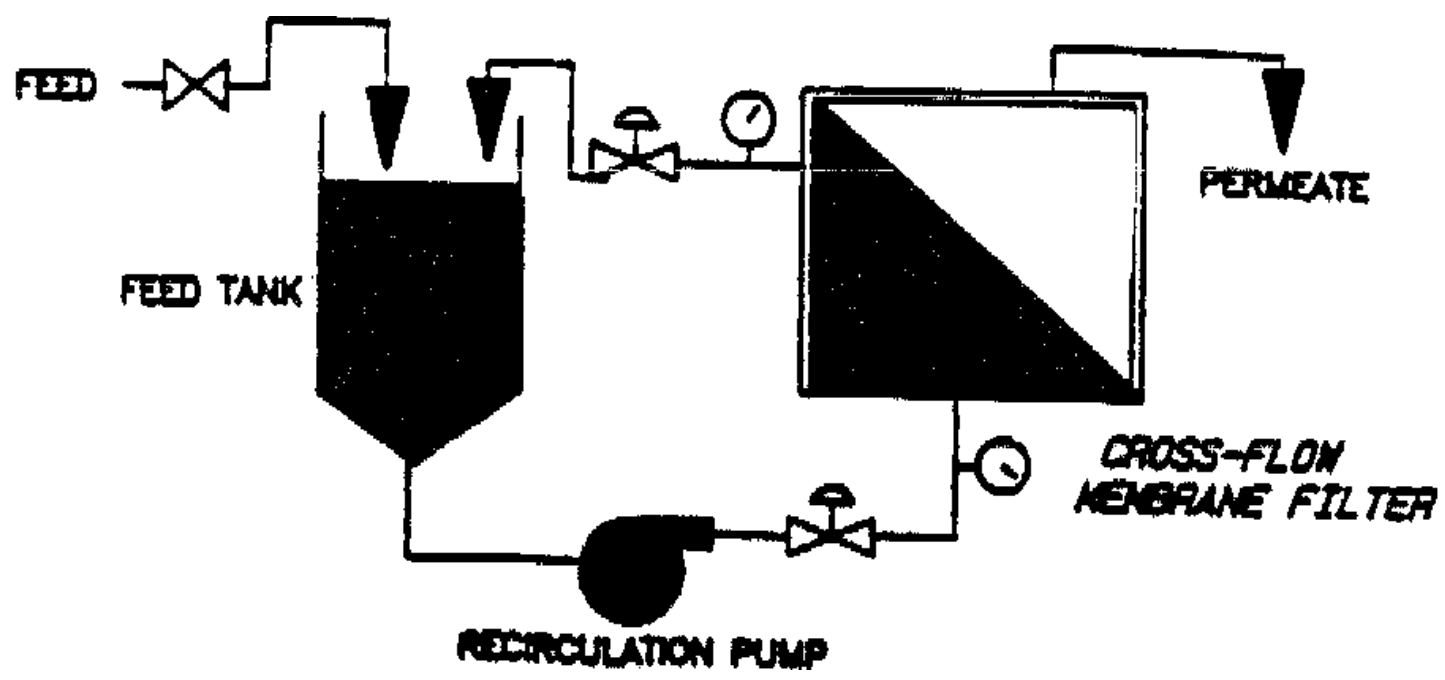

Figure 2.7 A Schematic of Semi-batch Operation Mode (Koch Membrane Systems, 1993) 


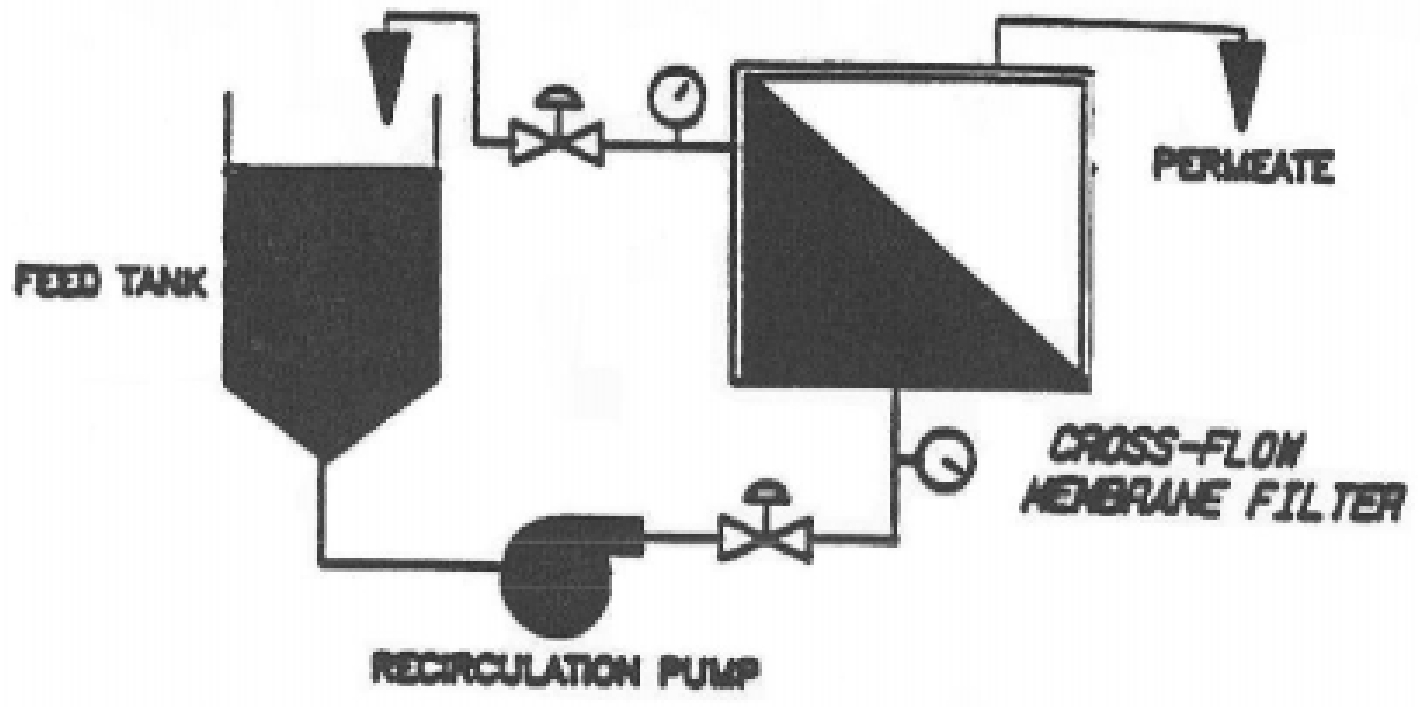

Figure 2.8 A Schematic of Batch Operation Mode( Koch Membrane Systems, 1993) 


\section{Particle Filtration}

Ultrafiltration has proven effective in many different applications, such as waste rolling mill coolant and in the recovery of electrodeposition paints. Although, commercially successful, the mechanisms of the ultrafiltration process are not fully understood. The ultrafiltration of macromolecules causes a decline in the flux passing through the membrane. Concentration polarization and the formation of a gel layer are the main causes attributed to the decline in flux. [ Jonsson and Tragardh, 1990] The gel layer is part of the concentration polarization layer. The gel layer is composed of macromolecules that have presumably reached the maximum concentration [ Toyomoto and Higuchi, 1992]. Concentration polarization is defined as the accumulation of rejected solutes at the membrane's surface. A schematic of the concentration polarization phenomena is presented in Figure 2.9 (Cheryan, 1986). Solute is brought to the membrane surface by convective transport. As water permeates through the membrane solute molecules cumulate at the membranes surface. Flux decline occurs due to an increased resistance in the concentration boundary layer. Operating parameters such as, transmembrane pressure, temperature, cross-flow velocity and feed concentration influence the effects of concentration polarization. However, concentration polarization effects should be reversible since its effected by changing operating parameters (Cheryan, 1986). A drawing of these operation parameters effecting concentration polarization is presented in Figure 2.10. As transmembrane pressure is increased, feed concentration is increased, or hydraulic turbulence is decreased, the permeate flux becomes independent of pressure. 

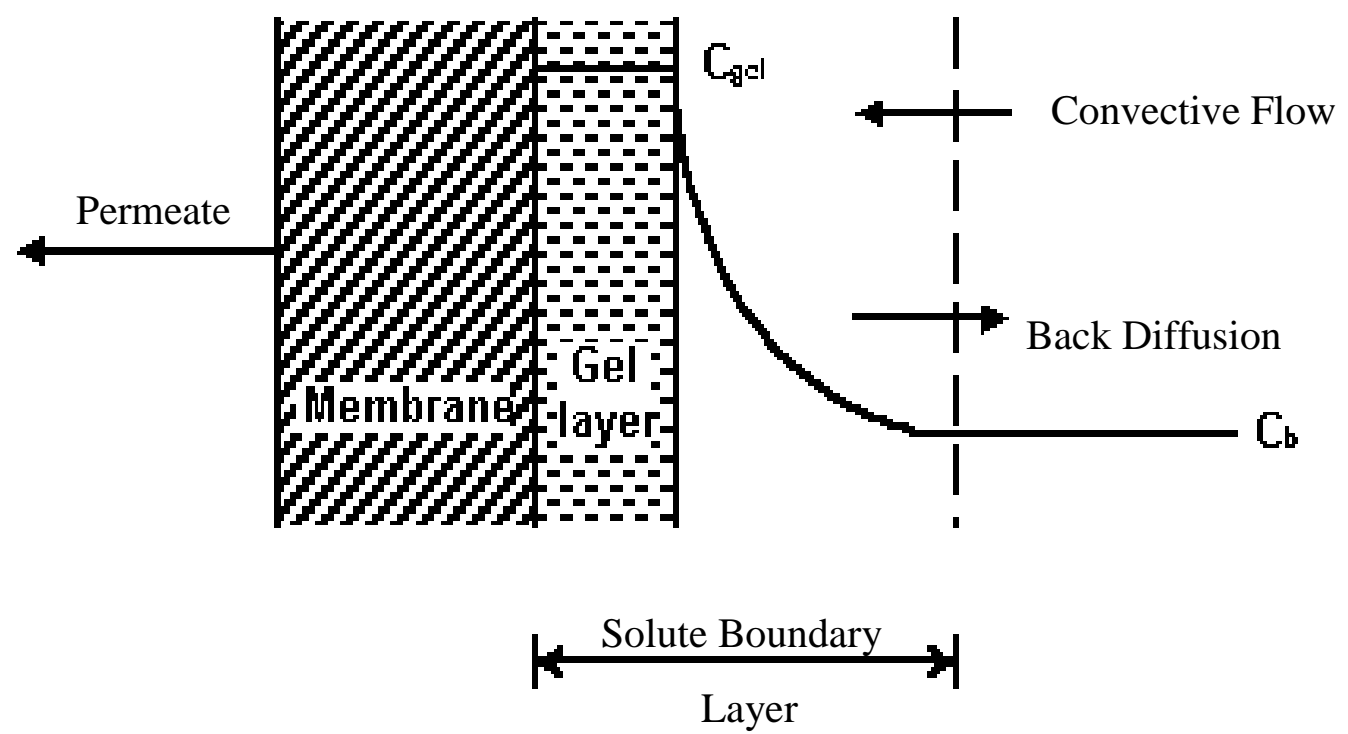

Figure 2.9 Concentration Polarization Phenomena(Cheryan, 1986) 
Permeate

Flux

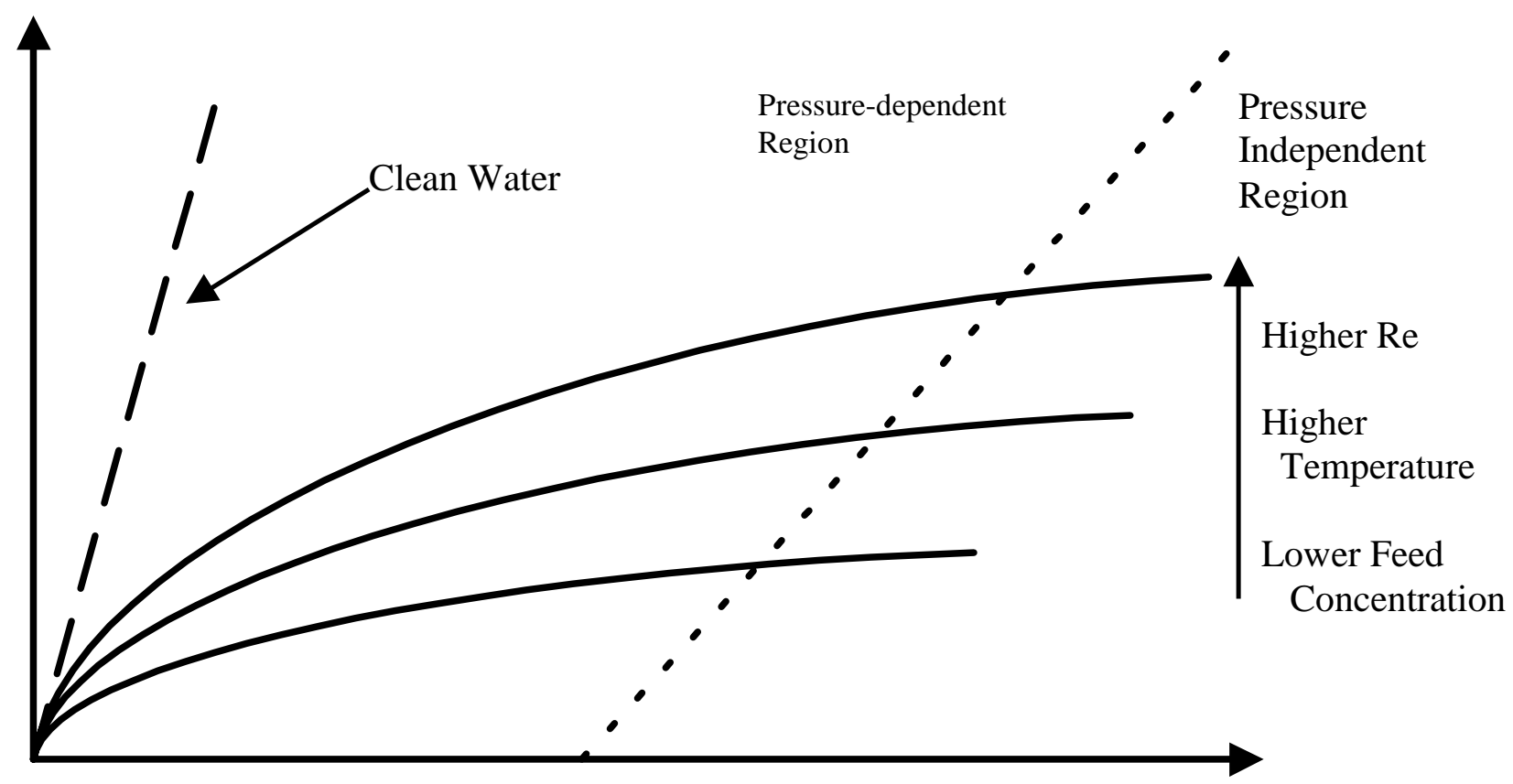

Transmembrane Pressure

Figure 2.10 Operation Parameters Effecting Concentration Polarization(Cheryan 1986) 


\section{Polarization Theory}

There are three widely accepted models that are used to explain the relationship between permeate flux and operating parameters. They are 1) the osmotic pressure model, 2) the gel layer model, 3) the resistance in series model [ Jonsson and Tragardh, 1990]. Before explaining these models a discussion of how fluid flows through membrane pores will be introduced. Fluid flow through porous membranes can be described by the Darcy

equation.

$$
\mathrm{J}=\mathrm{K} \Delta \mathrm{P} / \mu \Delta \mathrm{L}
$$

where:

$\mathrm{J}=$ permeate flux, $\mathrm{L} / \mathrm{m}^{2} \mathrm{~h}$

$\mathrm{K}=$ specific permeability, $\mathrm{m}^{2}$

$\Delta \mathrm{P}=$ transmembrane pressure, $\mathrm{Pa}$

$\mu=$ viscosity, $\mathrm{Pa} \mathrm{s}$

$\Delta \mathrm{L}=$ membrane thickness, $\mathrm{m}$

The membrane thickness, $\Delta \mathrm{L}$ is difficult to measure in an asymmetric membrane. The reason being the pores of the membranes have increasing diameters. As a result the thickness is not constant. A solution to this problem, is to combine the thickness and the specific permeability to form the hydraulic resistance of the membrane, $R_{m}=\Delta L / K$. Ultrafiltration is a separation process, therefore solutes and other particles are retained on one side of the membrane. Thus, the Darcy equation does not fully describe the flow through the membrane [ Jonsson and Tragardh, 1990] 


\section{Osmotic Pressure Model}

For typical Ultrafiltration applications of low concentration macromolecular solutions, the osmotic pressure is too small to be compared with the supplied pressure and for this reason can be neglected. For solutions with high macromolecule concentrations the osmotic pressure is also high and cannot be neglected [Toyomoto and Higuchi, 1992]. When the osmotic pressure due to solute accumulation at the membrane surface is not negligible, the Hagen-Poiseuille model often used to describe fluid flow through a membrane:

$$
\mathrm{J}=\varepsilon r^{2}\left(\Delta \mathrm{P}_{\mathrm{T}}-\Delta \pi\right) / 8 \mu \Delta \mathrm{x}
$$

Where $\mathrm{J}=$ permeate flux, $\varepsilon=$ membrane surface porosity, $\mathrm{r}=$ mean pore radius, $\Delta \mathrm{P}_{\mathrm{T}}=$ hydraulic pressure difference between the feed and the permeate, $\Delta \pi=$ osmotic pressure difference between the feed and permeate, $\mu=$ viscosity of the fluid permeating the membrane, $\Delta \mathrm{x}=$ membrane thickness. The osmotic pressure is generally small compared to the applied pressure in ultrafiltration applications such as oil in water emulsions [Cheryan, 1986]. In this case Hagen-Poiseuille Model is simplified:

$$
\mathrm{J}=\varepsilon \mathrm{r}^{2}\left(\Delta \mathrm{P}_{\mathrm{T}}\right) / 8 \mu \Delta \mathrm{x}
$$

When using Hagen-Poiseuille Model several assumptions have to be made: (1) The fluid flow through the membrane pores is fully developed laminar flow. (2) The permeate is incompressible. (3) The permeate is Newtonian, meaning viscosity of the permeate is dependent on shear stress and shear rate. (4) Permeate flow is independent of time (steady-state conditions). [Cheryan, 1986] 


\section{Gel Layer Model}

The gel layer model was the first model to explain the decrease in flux in UF applications. As stated previous, part of the concentration polarization layer is a nonfluid gel-like layer that forms at the surface of the membrane, when the solute concentration reaches the limiting value, $\mathrm{c}_{\mathrm{g}}$ (the concentration of gel layer). Equation (4) is derived from equation (3) by replacing $c_{\mathrm{W}}$ with $\mathrm{c}_{\mathrm{g}}$, which is the concentration of the solute in the gel layer [Toyomoto and Higuchi, 1990]

$$
J=K \ln \left(c_{g}-c_{p}\right) /\left(c_{b}-c_{p}\right)
$$

Usually the concentration of the gel layer $\left(c_{g}\right)$ is extremely high compared to concentration of the permeate $\left(c_{p}\right)$. As a result $c_{p}$ can be neglected and the equation is present as:

$$
\mathrm{J}=\mathrm{k} \ln \left(\mathrm{c}_{\mathrm{g}} / \mathrm{c}_{\mathrm{b}}\right)
$$

Equation (5) predicts a linear relationship between $\mathrm{J}$ and $\mathrm{c}_{\mathrm{g}}$ with $-\mathrm{k}$ being the slope of the line. Flow velocity, channel height, feed viscosity and the diffusion coefficient of the solute are all considered when determining the value of $\mathrm{k}$.

\section{Resistance in Series Model}

The resistance in series models assumes permeate flux is determined by the membrane resistance $\left(R_{m}\right)$, the concentration polarization boundary layer resistance $\left(R_{b l}\right)$, and any layer of adsorbed solute resistance $\left(R_{a}\right)$. With these assumptions, the resistance in series models is described by the following equation [Jonsson and Tragardh, 1990]: 


$$
\mathrm{J}=\Delta \mathrm{P} / \mu\left(\mathrm{R}_{\mathrm{m}}+\mathrm{R}_{\mathrm{a}}+\mathrm{R}_{\mathrm{bl}}\right)
$$

The concept of adsorptive layer resistance can be explained by realizing that some membranes might have the capacity to adsorb solutes from feed solutions. Adsorption onto the membrane walls might also occur when particles small enough to flow through the membrane pores adsorb to the membrane wall and as a result resist flow.

\section{Membrane Fouling}

Membrane fouling, similar to concentration polarization, can result in a decrease in permeate flux over time. However, membrane fouling is different from concentration polarization. For example, when the flow rate in a cross-flow membrane separation system is reduced, permeate flux will decrease. If the decrease in permeate flux is due to concentration polarization (i.e., the accumulation of solute molecules at the membrane's surface), the permeate flux should return to the initial value when the flow rate is raised. However, if the permeate flux does not increase to the initial value when the flow rate is increased, the membrane has experienced fouling.

Fouling is the term used to describe the loss of throughput of the membrane as it becomes physically and/or chemically changed by the feed solution. Membrane fouling is primarily due to pore plugging and/or solute adsorption. Fouling can be caused by a variety of compounds. Some of these foulants are 1)dissolved organics ( humic substances, biological slimes and macromolecules), 2) dissolved inorganics ( $\mathrm{CaSO}_{4}$, $\mathrm{CaCO}_{3}, \mathrm{Mg}(\mathrm{OH})_{2}$ and $\left.\mathrm{Fe}(\mathrm{OH})_{3}\right)$ and 3) particulate matter [Jonsson and Boesen, 1984] 
In the case of pore plugging, solute molecules from the feed solution are forced into the membrane pores, causing a decrease in permeate flux. In Figure 2.11, a schematic of membrane fouling due to pore plugging is presented. Pore plugging is more prevalent in a situation where the membrane is subject to low hydraulic turbulence and high transmembrane pressure. At high transmembrane pressure and low hydraulic turbulence, the solute molecules have an increased chance of being forced into the membrane pores. Some solute particles, if small enough, enter the membrane pores and adsorb onto the pore walls. The adsorbed molecules cause a decrease in effective pore diameter. The decrease in effective pore diameter causes an increase in membrane resistance, thus decreasing the permeate flux. [Jonsson and Tragardh, 1990]

Lee et al. (1984) studied the effects on operating pressure on membrane fouling using 3\% and 5\% oil/water emulsions. In Figure, 2.12 the effects of operating pressure on permeate flux are presented (Lee et al, 1984). At lower operating pressures, membrane fouling(loss of permeate) was negligible. However, permeate flux decline becomes more prevalent when the operating pressure was increased to 4 bars. Lee $e t$ al. (1984) concluded that as the pressure increased, the probability of oil droplets coming in contact with the membrane's pores increased. Additionally, some of the pores the operating pressure exceeded the capillary pressure. As a result the oil droplets were deformed and entered the membranes structure decreasing the permeate flux.

Membrane fouling is not an uncontrollable problem. The proper selection of operating conditions, membrane chemistry and cleaning methods are important factors that 


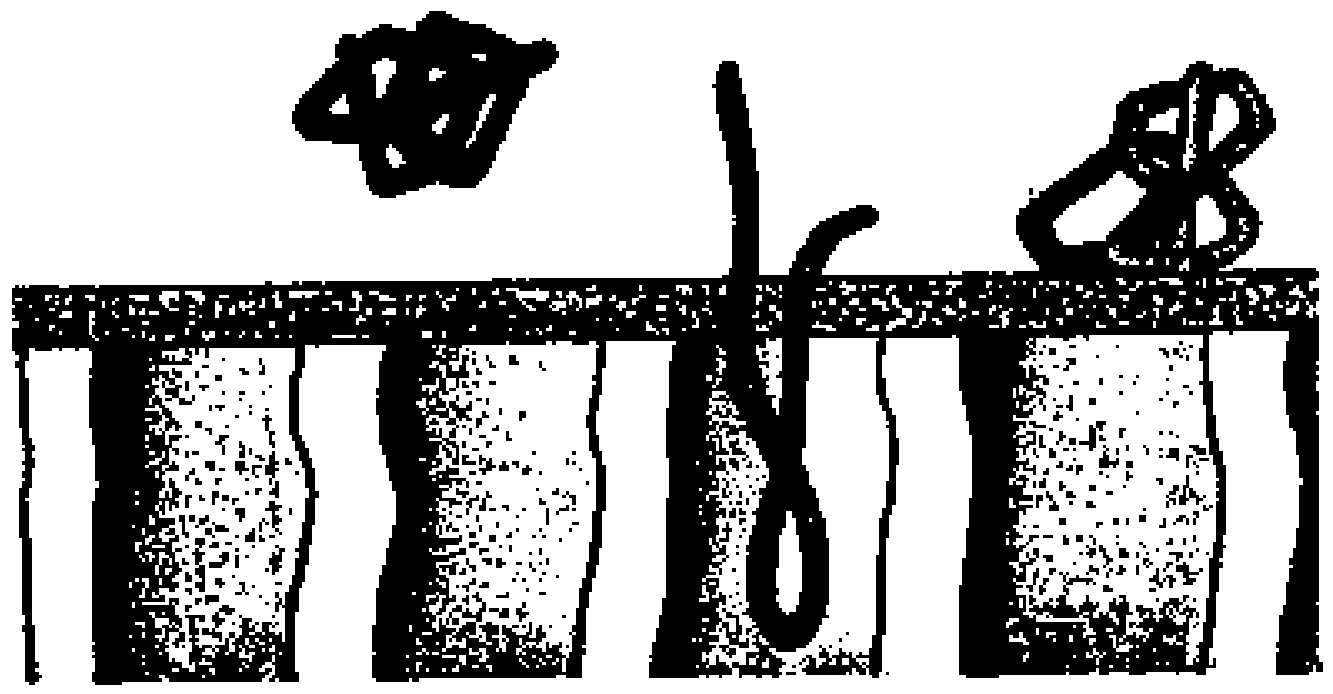

Figure 2.11, A Schematic of Membrane Fouling Due to Pore Plugging (Cheryan, 1986) 


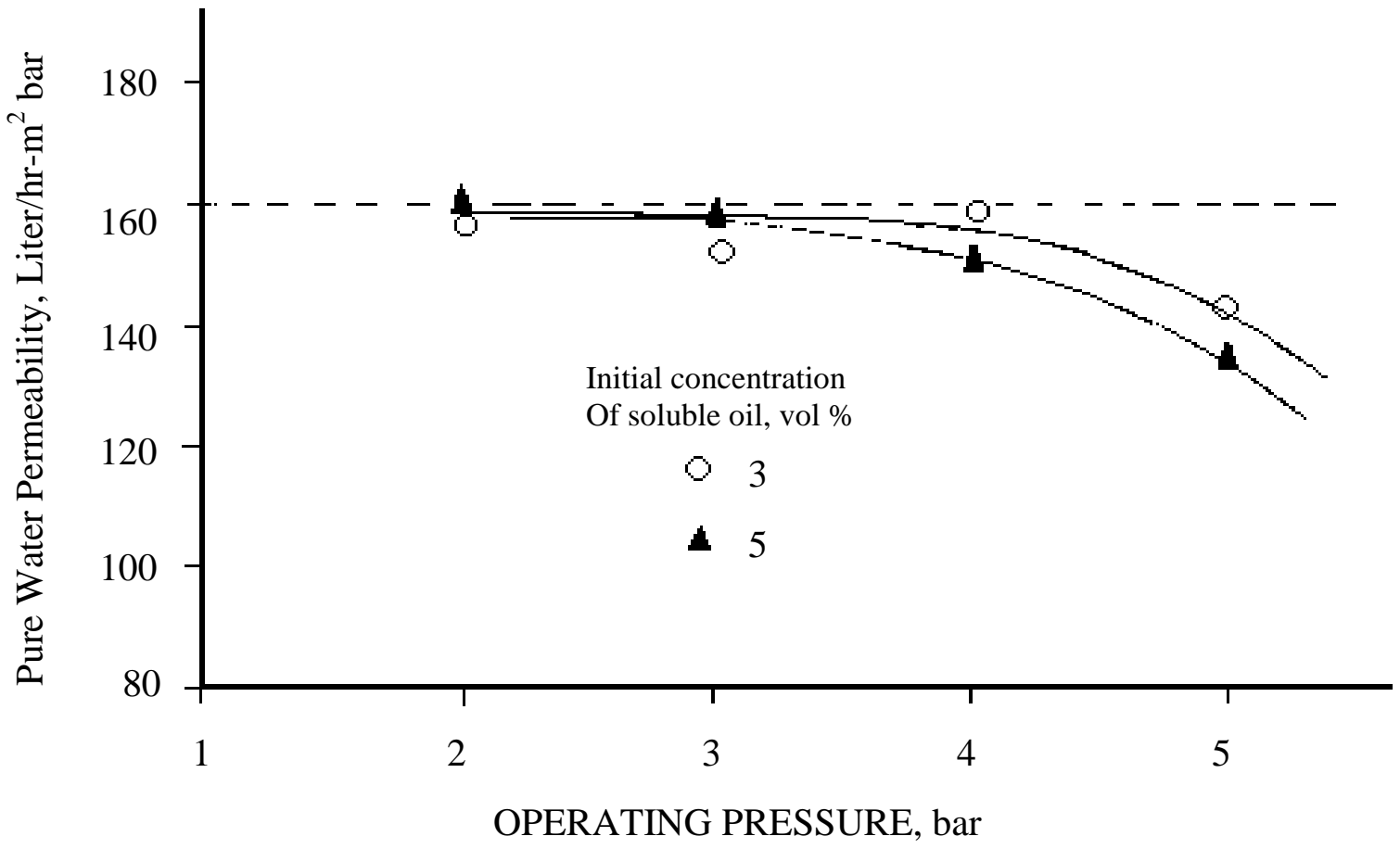

Figure, 2.12 The Effects of Operating Pressure on Permeate Flux (Lee et al. 1984) 
can minimizing permeate flux loss due to membrane fouling. For example, the operating pressure (transmembrane pressure) should be balanced to provide maximum permeate flux at minimum transmembrane pressure. An excess of pressure could cause solute molecules to deform and enter membrane pores as presented earlier in study performed by Lee et al. (1984).

Reed et al. (1997) reported that membrane fouling can be reduced by using hydrophilic and negatively charged membranes. A membrane with a negative charge may be chosen for a contaminant that is also negatively charged. The repulsive force between the contaminant and the membrane will act to decrease the amount of fouling that occurs. In addition, using a hydrophilic (water-attracting) membrane allows water to pass through the membrane's pores more readily.

The primary method of restoring permeate flux lost due to membrane fouling is membrane cleanings. Fouling which is removed through membrane cleanings is called "reversible fouling" and fouling that cannot be removed by cleanings is called "irreversible fouling." Although cleanings are used to restore permeate flux, the use of aggressive chemicals such as concentrated acidic and caustic solutions often result in shortened membrane life [Perry and Green, 1997].

\section{Mathematical Models of Fouling}

The simplest type of model relates flux to the time and/or volume permeated. In Table 2.4 a list of mathematical fouling models are presented [Cheryan, 1986/Mallevialle, 1996]. Most of the models assume that the build up of the fouling layer is a first order reaction. Additionally, the model are semi-empirical in that, the models do not help explain 
Table 2.4 Mathematical Fouling Models(Cheryan, 1986/Mallevialle, 1996)

\begin{tabular}{|c|c|}
\hline Model & Reference \\
\hline \hline $\mathrm{J}=\mathrm{J}_{\mathrm{o}} \mathrm{t}^{-\mathrm{b}}$ & $\begin{array}{c}\text { Sheppard and Thomas(1970) } \\
\text { Kuo and Cheryan (1983) }\end{array}$ \\
\hline $\mathrm{J}=\mathrm{J}_{\mathrm{o}} \mathrm{e}^{-\mathrm{bt}}$ & Sheppard and Thomas(1970) \\
\hline $\mathrm{J}=\mathrm{J}_{\mathrm{o}} \mathrm{V}^{-\mathrm{b}}$ & Merin and Cheryan (1980) \\
\hline $\mathrm{J}=\mathrm{e}^{\mathrm{a}} \mathrm{V}^{-\mathrm{b}}$ & Matthews et al. (1978) \\
\hline $\mathrm{J}=\mathrm{Jss}+\mathrm{Be}^{-\mathrm{bt}}$ & Concentration Polarization/Adsorption \\
\hline $\mathrm{J}=\mathrm{J}_{\mathrm{o}} /\left(1+\mathrm{J}_{\mathrm{o}} \mathrm{kt}\right)$ & Model \\
\hline
\end{tabular}


or understand the phenomenon itself. Also, some of the models predict that permeate flux will be zero at infinite time, which may not actually occur in practice. These models are useful in that the parameters $\left(b\right.$, fouling index, and $\mathrm{J}_{\mathrm{o}}$, initial permeate flux at time zero) correlated with operating parameters can help give some understanding of the fouling phenomenon. [Cheryan, 1986]

Cheryan and Merin studied the fouling phenomenon during ultrafiltration of cottage cheese whey. In Table 2.5, the composition of cheese whey is presented [Cheryan and Merin, 1983]. To study the effects of individual proteins in the overall fouling process, each of the major protein fractions in cheese whey were made up in the proper concentrations presented in Table 2.5. The proteins that are present in cheese whey are $\alpha-$ lactalbumin, $\beta$-lactoglobulin and bovine serum albumin. Additionally, the role of salt in the fouling process was studied. Two different aquoeus environments were studied; a whey disalystate (WD) buffer and a salt free system (SF). The WD system mimicked the original environment of the cheese whey. The model that best fit the data was based on the assumption that the amount of flux is a function of the cumulative volume permeated. The equation is as follows:

$$
\mathrm{J}=\mathrm{J}_{\mathrm{O}} \mathrm{V}^{-\mathrm{b}}
$$

Where $\mathrm{J}$ is instantaneous flux at any time $\mathrm{t}, \mathrm{J}_{\mathrm{O}}$ is the initial flux at $\mathrm{t}=0, \mathrm{~V}$ is the volume permeated, and $\mathrm{b}$ is the fouling index. [Cheryan and Merin, 1983]

During the experiment a total of eight different feeds were studied. Whey, $\alpha-$ lactalbumin, $\beta$-lactoglobulin and bovine serum albumin (BSA) were dissolved in SF and WD environments and processed in the UF system. In Figure 2.13, the results of SF system are presented. 
Table 2.5. Composition of Cheese Whey. [Cheryan and Merin, 1983]

\begin{tabular}{|c|c|}
\hline Composition & Concentration, $\%$ \\
\hline \hline Total Solids & $6.0-6.5$ \\
\hline Lactose & $4.5-5.0$ \\
\hline Salts & $0.5-0.9$ \\
\hline Fat & $0.1-0.5$ \\
\hline$\alpha$-lactalbumin (Protein) & 0.16 \\
\hline$\beta$-lactoglobulin (Protein) & 0.4 \\
\hline Bovine serum albumin (Protein) & 0.04 \\
\hline
\end{tabular}




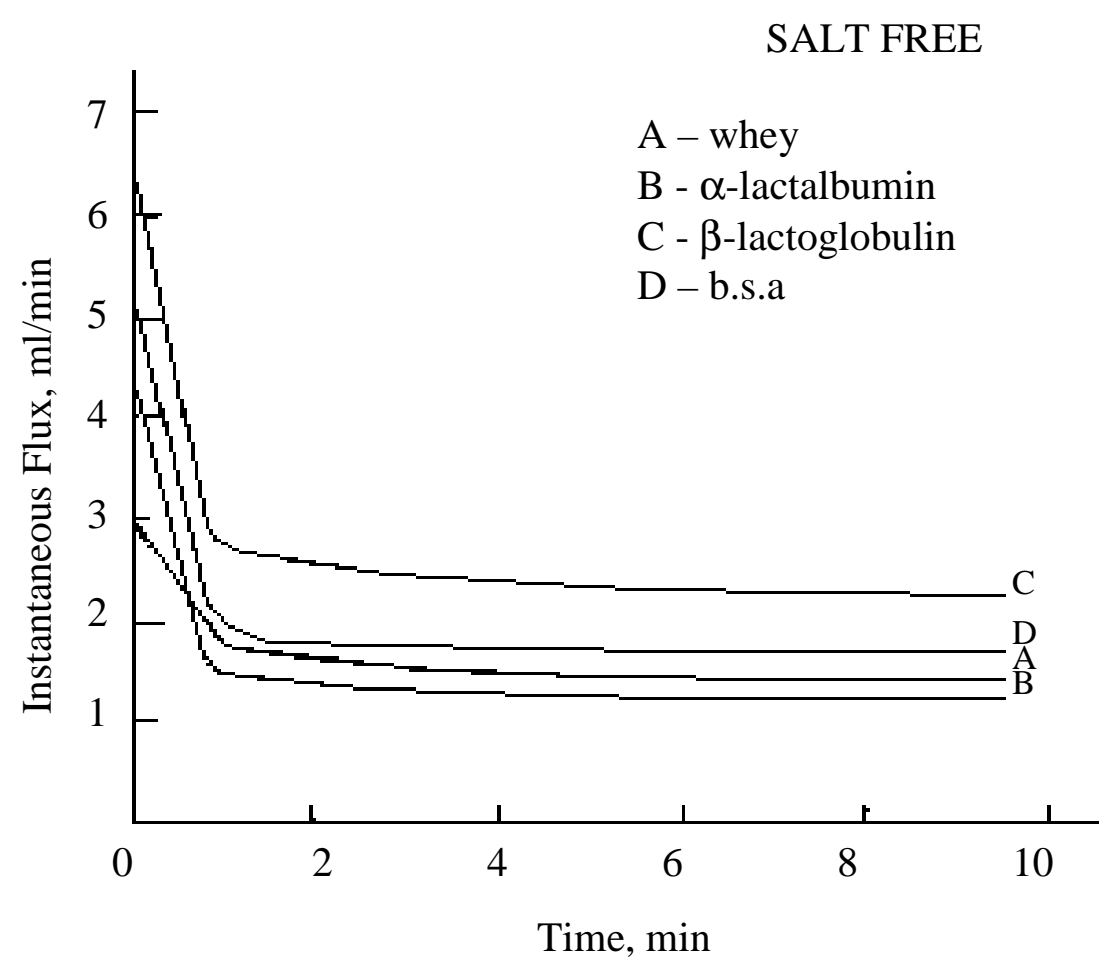

Figure 2.13. Result of the Salt Free System. [Cheryan and Merin, 1983] 
A similar set of curves were obtained in the WD system [Cheryan and Merin, 1983]. Since fouling seemed to occur immediate after UF started up, the experiments were held at 10 minutes of operational time. Fouling was found to occur in two stages: an initial rapid decline in flux followed by a more gradual decline in flux. In Table 2.6 a list of $\mathrm{J}_{\mathrm{o}}$ and b values for WD and SF system are presented [Cheryan and Merin, 1983]. In general, $\mathrm{J}_{\mathrm{O}}$ and $\mathrm{b}$ presented in Table 2.6, implies that the presence of salts have significant effects on the rate of flux decline. Additionally, $\alpha$-lactalbumin had the strongest gel-forming tendencies (lowest $\mathrm{J}_{\mathrm{O}}$ ), and $\beta$-lactoglobulin had the worst long-term fouling effects (highest $b$ values). The original whey, had the worst overall fouling due to the combined effects of the individual proteins and salts.

Kuo and Cheryan (1983) conducted a fouling study of an acid whey in a spiral wound unit. The study focused on the effects of pressure and flowrate on the fouling index, b. The experiments were conducted at pressures of 240,310 and $485 \mathrm{kPa}$. The flow rates were 3 and $10 \mathrm{~L} / \mathrm{min}$ at $240 \mathrm{kPa}, 3$ and $8 \mathrm{~L} / \mathrm{min}$ at $310 \mathrm{kPa}$, and 3 and $10 \mathrm{~L} / \mathrm{min}$ at $485 \mathrm{kPa}$. To keep feed concentration constant, a total recycle mode was used. The fouling model that was used to during the study is as follows:

$$
\mathrm{J}=\mathrm{J}_{\mathrm{O}} \mathrm{t}^{-\mathrm{b}}
$$

Where $\mathrm{J}$ is the permeate flux an any time $\mathrm{t}, \mathrm{t}$ is the operation time, Jo is the instantaneous flux at $t=0$ and $b$ is the fouling index. [Kuo and Cheryan, 1983]

A summary of the results of the experiment are presented in Table 2.7. In general, higher flow rate and intermediate transmembrane pressure of $310 \mathrm{kPa}$, reduced the rate of 
Table 2.6. Value of $\mathrm{J}_{0}$ and $\mathrm{b}$ from Cheryan and Merin experiments

\begin{tabular}{|c|c|c|c|}
\hline Protein & System & Jo & b \\
\hline \hline Whey & Native & 1.369 & 0.297 \\
& SF & 1.905 & 0.163 \\
\hline$\alpha$-lactalbumin & WD & 1.722 & 0.123 \\
& SF & 1.549 & 0.160 \\
\hline$\beta$-lactoglobulin & WD & 2.694 & 0.214 \\
& SF & 3.163 & 0.136 \\
\hline Bovine serum albumin & WD & 2.777 & 0.147 \\
& SF & 1.853 & 0.069 \\
\hline
\end{tabular}

$\mathrm{WD}=$ whey dialystate environment, $\mathrm{SF}=$ salt free environment 
Table 2.7, Results of Pressure and Flow Rate on the Fouling Index, b (Kuo \& Cheryan, 1983)

\begin{tabular}{|c|c|c|c|}
\hline$\Delta \mathbf{P}_{\mathbf{T}}(\mathbf{k P a})$ & $\mathbf{Q}(\mathbf{L} / \mathbf{m i n})$ & $\mathbf{J o}(\mathbf{L} / \mathbf{m i n})$ & $\mathbf{B}$ \\
\hline \hline 240 & 3 & 1.1234 & 0.179 \\
\hline & 10 & 1.2687 & 0.089 \\
\hline 310 & 3 & 1.1595 & 0.191 \\
\hline & 8 & 1.4067 & 0.126 \\
\hline 485 & 10 & 1.4579 & 0.076 \\
\hline & 3 & 1.2790 & 0.208 \\
\hline & 10 & 2.3446 & 0.384 \\
\hline
\end{tabular}


fouling at least in the initial stages. However, at the highest transmembrane pressure studied, high flow rate did not benefit permeate flux. In addition, $\mathrm{b}$ values decreased in general, with increasing flow rates at the low and intermediate pressure (indicating a lower fouling rate with higher flow rate). However, a sharp increase in $b$ was observed at the highest pressure. The phenomena stated above can be explained by Kuo and Cheryan fouling theory. The theory states: "The rate at which membranes foul by particulate deposition is controlled by the rate of deposition $\left(\mathrm{V}_{\mathrm{d}}\right)$ and the rate of removal of the deposited material $\left(\mathrm{V}_{\mathrm{r}}\right)$, e.g., by shear forces. If $\mathrm{V}_{\mathrm{d}}>\mathrm{V}_{\mathrm{r}}$, fouling will occur and a decline in flux will be observed. At higher flow rate, the rate at which solutes are brought in contact with the membrane is high, but the removal by shear forces is also high. The resulting effect is that the net rate of deposit $\left(\mathrm{V}_{\mathrm{d}}-\mathrm{V}_{\mathrm{r}}\right)$ is lower at low flow rates." [Kuo and Cheryan, 1983] Such a phenomenon was observed in the first 90 to 120 minutes of Kuo and Cheryan's experiments. However, after that period of time, a sudden change in the fouling rate occurred. The change in fouling rate that was observed in the experiment is presented in Figure 2.14.

The reason for the change in fouling rate was complicated. Although a total recycle of rejected material and permeate was maintained, it was theorized that small solutes, e.g. lactose and salts, which pass through the membrane, could get "trapped" in the pores. The solutes became trapped either by adsorption or "crowding". As more permeate passed through the membrane, the trapped solutes would further concentrate and would eventually crystalline and precipitate in the pores. Kuo and Cheryan observed that fouling occurred in three stages in their experiments. The three stages are as 


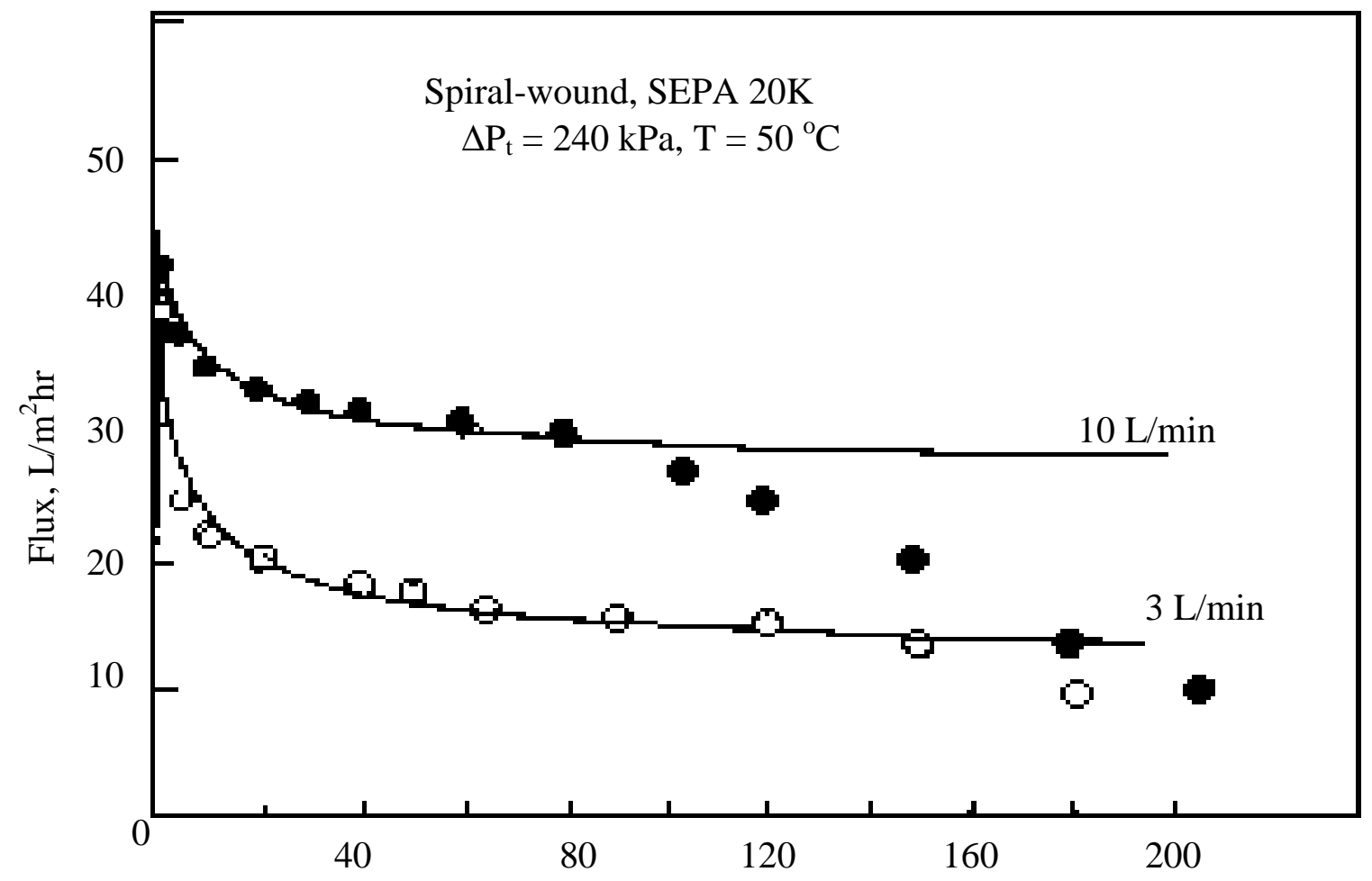

Figure 2.14 Three Stage Change in Fouling Rate, (Kuo and Cheryan, 1983) 
a relatively rapid flux decline, 2) after most of the adsorptive site are saturated, $V_{d}-V_{r}$ approached zero, thus a constant flux would be observed, 3) as the membrane continues to produced permeate, solutes trapped in the pores would become crowded, and eventually precipitate in the pores further reducing flux.

Sheppard and Thomas (1970), studied the effects of circulation velocity a commercial cellulose acetate membrane to determine performance. To model the fouling the following equation was used:

$$
\mathbf{J}=\mathrm{J}_{\mathrm{o}}\left(\mathrm{e}^{-\mathrm{bt}}\right)
$$

Where: $\mathrm{J}=$ Flux at time $\mathrm{t}$

$\mathrm{T}=$ time of operation

$\mathrm{J}_{\mathrm{o}}=$ initial flux at $\mathrm{t}=0$

$\mathrm{b}=$ fouling index

The average flux over a $1-y r$ period of operation is only $24.4 \%$ of the initial flux, when the value of $b$ is 0.3 and the average flux over a 1 -yr period of operation exceeds $90 \%$ of the initial flux only when the value of $b$ is less than 0.02 .

From the study, the mean value of the exponent, b, decreased from 0.09 to 0.026 as the axial velocity increased from 1.64 to $24 \mathrm{ft} / \mathrm{s}$. Increasing the axial velocity from 1.64 to $24 \mathrm{ft} / \mathrm{s}$ would on the average increase the average flux during the first years of the operation from 64.5 to $88 \%$ of the initial value.

\section{Operating Parameters}

The following operating parameters are important for UF systems. These operating parameters are: (1)feed cross-flowrate, (2) transmembrane pressure, (3) temperature/viscosity, (4) cleaning procedure. 


\section{Flowrate}

Volumetric flowrate is defined as the volume of wastewater pumped through the membrane unit. In a crossflow filtration system, high feed flowrates will create turbulence, which in turn reduces the influence of concentration polarization at the membrane surface. Turbulence in a membrane system is one of the simplest methods of controlling the effects of concentration polarization.

Reed et al. (1997) looked at the effects of crossflow velocity on the treatment of an oily wastewater using a tubular UF system. By increasing the crossflow velocity from

9 to $21 \mathrm{ft} / \mathrm{s}$, increased the $\mathrm{P}$ (negative charged) and $\mathrm{M}$ (non-charged) membranes fluxes from 33 to $38 \mathrm{ga} / \mathrm{ft}^{2}-\mathrm{d}$ and from 20.5 to $24 \mathrm{gal} / \mathrm{ft}^{2}$-d, respectively. The cross-flow velocity was increased by increasing the applied pressure in the system.

\section{Transmembrane Pressure}

The transmembrane pressure is the driving force in UF systems. The average transmembrane pressure is calculated by the following equation:

$$
\mathrm{P}_{\mathrm{tm}}=\left[\left(\mathrm{P}_{\text {in }}+\mathrm{P}_{\text {out }}\right) / 2\right]-\mathrm{P}_{\text {perm }}
$$

where; $\mathrm{P}_{\mathrm{tm}}$ is the average transmembrane pressure

$P_{\text {in }}$ is the pressure at the entrance of the membrane

$\mathrm{P}_{\text {out }}$ is the pressure at the exit of the membrane

$\mathrm{P}_{\text {perm }}$ is the pressure exerted on the permeate (usually zero)

Mahdi and Skold (1991) conducted UF experiments on synthetic metal working fluids to determine the effects of temperature and inlet pressure on flux. At $25{ }^{\circ} \mathrm{C}$, inlet pressure was increased from 0.2 to $0.3 \mathrm{kPa}$ and an increase in the initial flux was from 
25 to $25 \mathrm{~L} / \mathrm{m}^{2}-\mathrm{h}$. At a temperature of $30{ }^{\circ} \mathrm{C}$, an increase in inlet pressure from 0.2 to 0.3 $\mathrm{kPa}$ caused an increase in initial flux from $\sim 21$ to $30 \mathrm{~L} / \mathrm{m}^{2}-\mathrm{h}$. Studies by Applegate (1984) using a UF system, proved that higher transmembrane pressures increase productivity of membranes. Increasing the pressure from 0.5 to $33 \mathrm{psig}$, increased the permeate flow from $\sim 1.51$ to $2.27 \mathrm{~m}^{3} / \mathrm{d}$ at a crossflow velocity of $\sim 3.35 \mathrm{~m} / \mathrm{s}$.

Reed et al. (1997) performed pressure excursion experiments using a tubular UF system treating an oily waste. The transmembrane pressure was increased from 27.5 to 43.5 psi. The resulting permeate fluxes of the $\mathrm{P}$ (negative charged) and $\mathrm{M}$ (non-charged) increased from 34 to $43 \mathrm{gal} / \mathrm{ft}^{2}$-d and from 16 to $26 \mathrm{gal} / \mathrm{ft}^{2}$-d, respectively.

\section{Temperature/Viscosity}

Temperature control in UF systems is important due to some membranes being sensitive to high temperatures. Temperature also influences viscosity. As temperature of the feed is increased, feed viscosity decreases resulting in a higher permeate flux. The decrease in viscosity results in an increase in fluid flow through the membrane (Jonsson et $a$ ). Increasing temperature can proven to be beneficial in UF system, however, some membranes cannot tolerate high temperature. As a result these membrane systems are operated at lower feed temperatures. An increase in viscosity occurs with lower feed temperatures, therefore, an increase in power may be necessary to pump the fluid. Wahl et al. (1979) interviewed 21 full-scale tubular UF operators and determined that wastewater temperature ranged from 50 to $100{ }^{\circ} \mathrm{F}$ and averaged $92{ }^{\circ} \mathrm{F}$. 
Yuksel et al. (1991) reported that treatment of an aqueous phase of a demulsified mixture was sensitive to temperature changes. The critical temperature was approximately $35^{\circ} \mathrm{C}$. Operation below this temperature resulted in treatment of waste with a lower oil viscosity. The low oil viscosity resulted in increased fouling because the oil was able to pass into the filter and lower the efficiency of the filter. This effect was reversed if the temperature was increased.

Mahdi and Skold (1991) conducted a field study on a waterbased metalworking fluid using a UF system. At a constant pressure of $0.2 \mathrm{kPa}$, an increase in feed temperature from 25 to $30{ }^{\circ} \mathrm{C}$ increased permeate flux from approximately 12 to 22 $\mathrm{L} / \mathrm{m}^{2} \mathrm{~h}$. At a constant pressure of $0.3 \mathrm{kPa}$, an increase in temperature from 25 to $30{ }^{\circ} \mathrm{C}$, increased permeate flux from $\sim 22$ to $31 \mathrm{~L} / \mathrm{m}^{2} \mathrm{~h}$.

\section{pH}

The $\mathrm{pH}$ of a feed solution is an important operating parameter because some membranes may be degraded at extreme $\mathrm{pH}$ levels, depending on their material composition. Feed $\mathrm{pH}$ can also effect solute-membrane and solute-solute relationships. The $\mathrm{pH}$ of membrane cleaning solutions vary in $\mathrm{pH}$, from very acidic to very basic. Therefore, degradation of the membrane should be considered before deciding on the type of cleaner for the membrane. 


\section{Cleaning Process}

After the membranes have become fouled and permeate flux decreases to unacceptable levels the membranes are cleaned. There are several methods used for cleaning membrane systems. One method commonly used is washing the membrane with a base solution followed by an acid solution. There are 6 steps in base/acid cleaning method. These are cleaning steps are (Blank and Brady, 1993):

1. Flush system of wastewater with clean water

2. Clean system with a caustic/surfactant solution for roughly one hour. Typically the cleaning solution is a $0.1 \%$ solution, $\mathrm{pH} \sim 10,100-110^{\circ} \mathrm{F}$.

3. Flush system with warm water to remove cleaning solution.

4. Clean system with an acid solution, to remove salt deposits (at $100-120^{\circ} \mathrm{F}$ for one hour).

5. Flush the system to remove acid with warm water.

6. Perform a clean water flux to confirm cleanness of membrane

For large tubular membranes, spongeballs are sometimes used. The spongeball are sent through the membranes tubular to remove fouling. The spongeballs are effective at removing particles on the membranes surface. This type of mechanical cleaning is often used in membrane systems that treat oil and water wastes [Blank and Brady, 1993]. The spongeballs increases the contact between the oil on the membrane surface and the soap. [Pinto, 1978]. 
Another method of cleaning is backwashing. Hollow fiber membranes are capable of being backwashed. In this case, the particles that are lodged in the membrane pores and dislodged by the reversed flow through the membranes.

Zaidi et al. (1992) conducted field scale experiments using ceramic tubular filtration units to remove oil from oilfield brines. A three step process was used to clean the membranes. The three step process included: 1) a hot caustic wash, 2) a fresh water rinse, and 3) acid wash. Investigators concluded that cleaning with detergents and mechanical means did not always restore the filters original flux. Thus some fouling was considered to be irreversible.

\section{CHARACTERISTICS OF OIL-IN-WATER EMULSIONS}

The metal-working industry produces large amounts of oily wastewaters. Some the metal working processes that use large volumes of emulsified oils for lubrication and cooling include, metal rolling, forming, grinding and cutting operations. These metal working lubricants provide 1) control friction, 2) reduced tool wear and 3) improve surface quality of the workpiece. Metal working lubricants commonly consist of petroleum oil compounds, water and various additives. Petroleum oils occur naturally. These petroleum oils are refined by means of distillation, solvent extraction or molecular sieving. There are two commonly used types of metalworking lubricants. These lubricants are straight oils and emulsions [Laemmle, 1991].

Straight oils are generally made up of petroleum oil derivatives, which provide excellent friction reduction and good corrosion protection. Disadvantages of using straight oils are their poor capability to remove heat and are potential fire hazards due to 
the low flash points. Straight oils are generally used when lubrication is the major factor and cooling is the minor factor [Laemmle, 1991].

Emulsions are mixtures that consists of either simple or compound oils added to water. Two major advantages to using emulsions is the oil phase portion capability to lubricate and the water phase to cool industrial equipment. A schematic of an emulsified oil droplet is present in Figure 2.15. [Burke, 1991] In a oil-water emulsion, oil is said to be the "dispersed phase" and water is the "continuous phase." Typical oil gobule sizes from $\sim 0.2$ to $10 \mu \mathrm{m}$. Since the typical size of the emulsified oil droplets are similar in size to, or larger than, the wavelength of visible light, emulsions appear milky white. [Laemmle, 1991].

Emulsions have to be stabilized with emulsifiers because oil-in water mixtures are not thermodynamically stable. In other words, the state of lowest free energy is total separation. As a result, emulsifiers have to be added to stabilize the mixture and prevent the oil and water from separating. Emulsifiers concentrate at the oil-water interface and prevent oil globule coalescence. Emulsions can vary in stability, depending on the characteristics of the oil and the concentration and nature of the emulsifiers. Since the hydrophilic end of the oil-water emulsion is negatively charged, the net surface charge of the emulsified oil droplet is negative. The emulsified oil droplets tend to stay dispersed due to electrostatic repulsion between the emulsified oil droplets. The emulsion is then said to be kinetically stable because the state of lowest free energy if the emulsion is still total separation [Laemmle, 1991].

The ability of the oil-water emulsion to provide adequate lubrication is tied into the availability of the oil phase to lubricate. Two factors controlling availability of the oil 


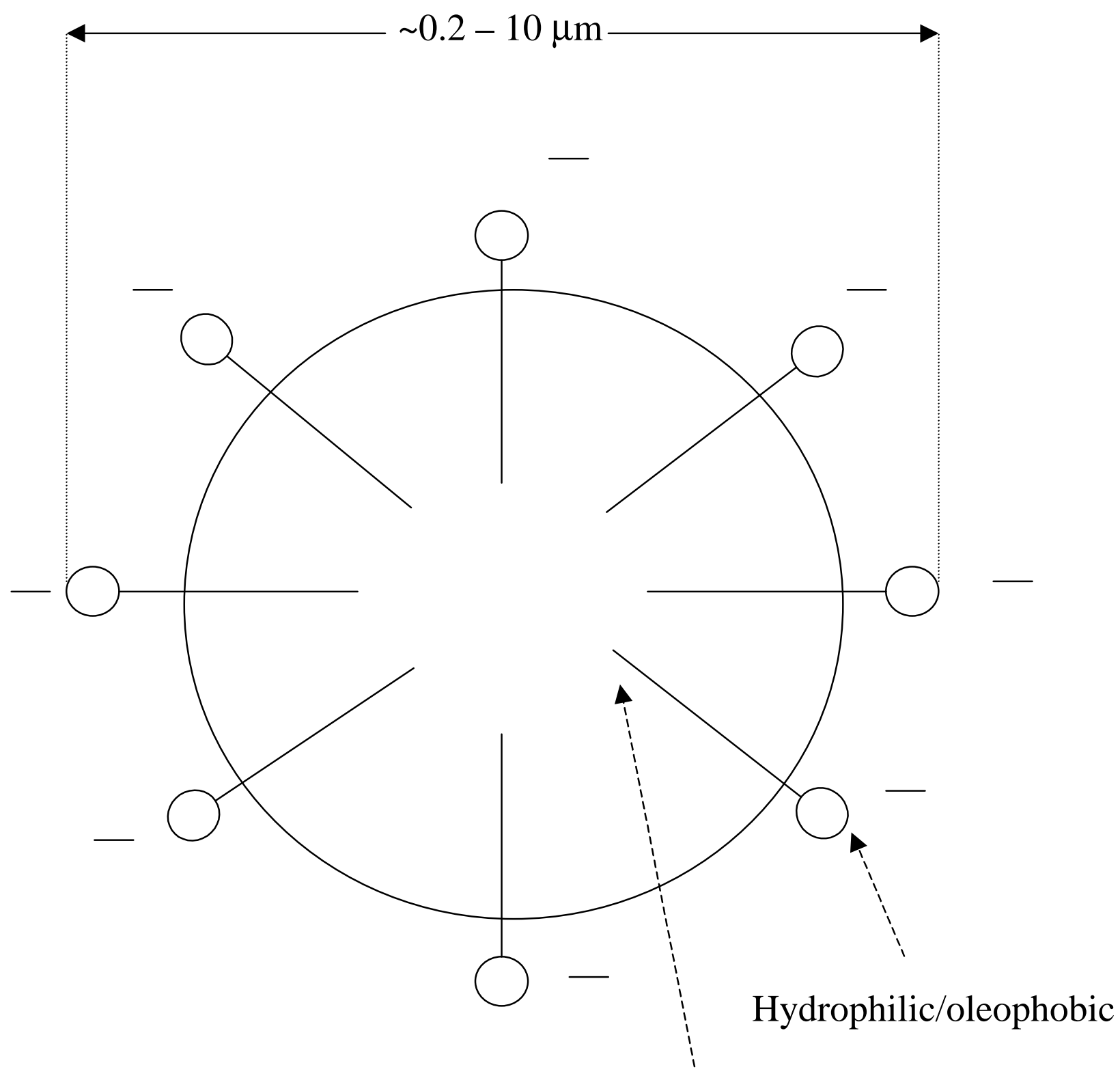

Hydrophobic/oleophilic

Figure 2.15, A Schematic of an Emulsified Oil Droplet (Burke, 1991) 
phase is emulsion stability and concentration of oil in the emulsion (percent oil). In general, the higher the percent oil, the greater is the availability of oil or lubrication. Also,

the higher the percent oil, the less stable an emulsion is. Additionally, as the oil content increases cooling capability decreases because there is less water for cooling. Unfortunately, the less stable the emulsion is, the greater the chance of rapid, often unpredictable declines in stability. The unpredictable behavior can lead to operating problems in metalworking processes. Therefore, the stability and percent oil of an emulsion must be balanced to meet the lubrication and cooling needs of the metalworking operation.

Since oil-water emulsions are kinetically stable, rather than thermodynamically stable, the "batch life" of the emulsion as to be taken into consideration. New emulsions are generally the most stable and have the least oil available for lubrication. Over time the maximum performance of the emulsion is reached as emulsifiers are depleted through biological degradation and as debris generated in the emulsion provides nucleation sites for globule coalescence. Yet, as the emulsion degrades further, the emulsion becomes very unstable and has to be disposed of. New emulsion has to be introduced into the process. Emulsion that are initially less stable have a shorter batch life than emulsions which are more stable initially [Laemmle, 1991].

Typical oil-water emulsions used in rolling mill process contain petroleum oils, emulsifiers, biocides and antifoaming agents. In general, emulsion solutions used in metalworking operations contain approximately 5 to $10 \%$ oil and approximately 90 to $95 \%$ water [Laemmle, 1991]. 


\section{CHAPTER 3}

\section{MATERIAL AND METHODS}

During the fabrication process, metal working fluid mixtures are used for lubrication. The metal working fluid or coolant consisted of a 5 percent mineral oil and 95 percent de-mineralized water. The coolant is monitored over this period and when the coolant fails to meet certain process specifications, it is pumped out of the hot line mill to a 600,000 gallon storage tank. While in the storage tank $\mathrm{pH}$ of the waste is checked to prevent treatment problems down stream of the tank. In Figure 3.1, a schematic of the treatment process is presented. If the $\mathrm{pH}$ is in the range of 4 to 8 the coolant is either pumped or gravity drained to pond \#2. Pond \#2 is a fully designed RCRA facility with double liner and leak detection. The capacity of pond \#2 is roughly 3 million gallons. While residing in pond \#2 for roughly 28 days, emulsifiers in the waste coolant breakdown. The oil that separates is skimmed off the top of the pond. The resulting water phase or pond effluent had a remaining oil content of 0.2 to1.0\%. The oily waste is then pumped by 25 horsepower Goulds pumps, to two identical concentration tanks located adjacent to the tubular ultrafiltration building. Each concentration tank is capable of holding 20,000 gallons of raw waste and is $\sim 18$ feet tall in height. The concentration tanks supply oily waste to the two tubular Ultrafiltration unit located inside the adjacent building.

Two tubular crossflow ultrafiltration skids were used in this study. In Figure 3.2, a profile on one UF skid is presented. In each skid, 736 Koch membranes were arranged into 23 rows. In each row, two banks exist, containing 16 membranes that are connected 


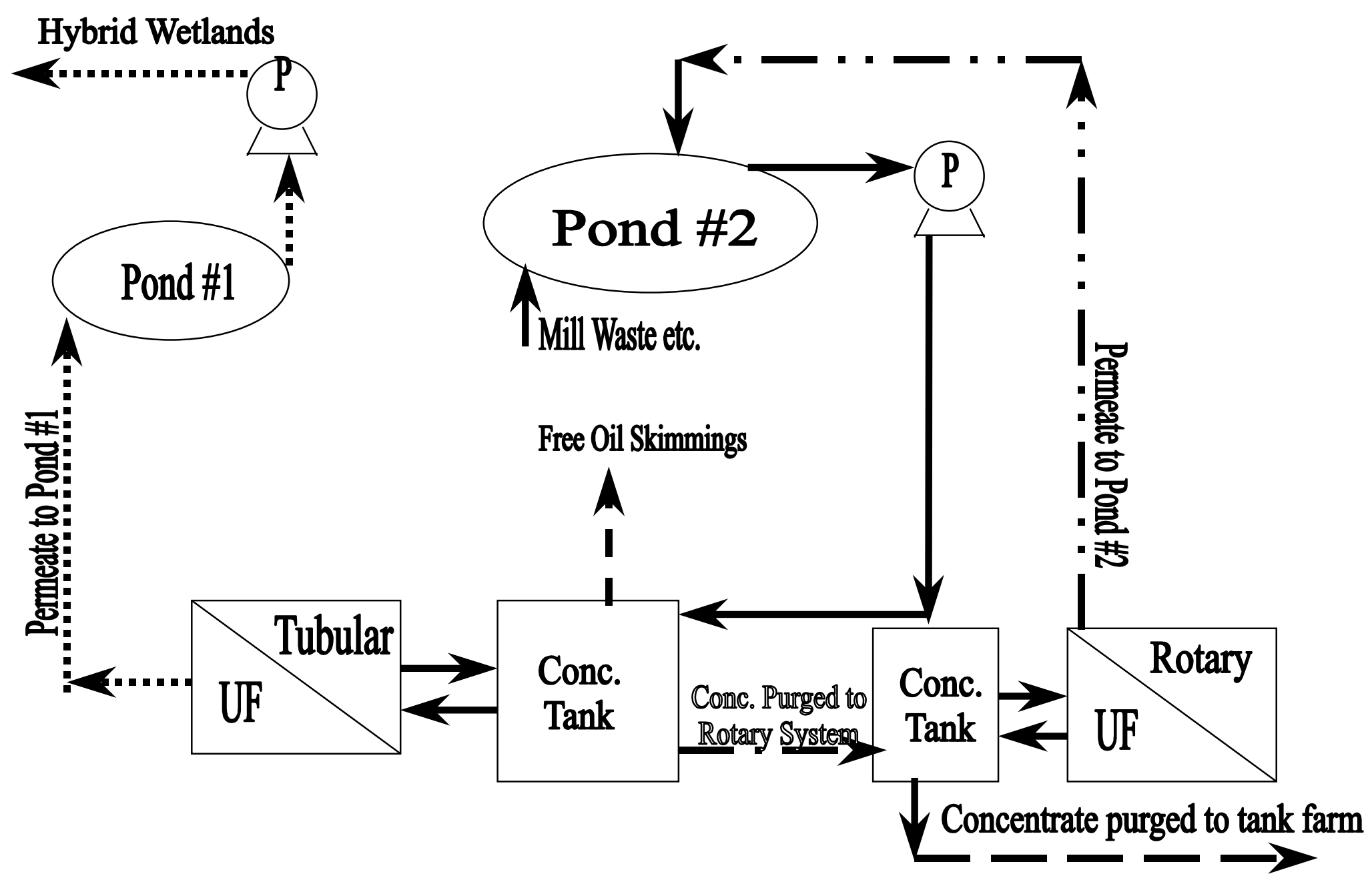

Figure 3.1 Proposed Treatment Process 


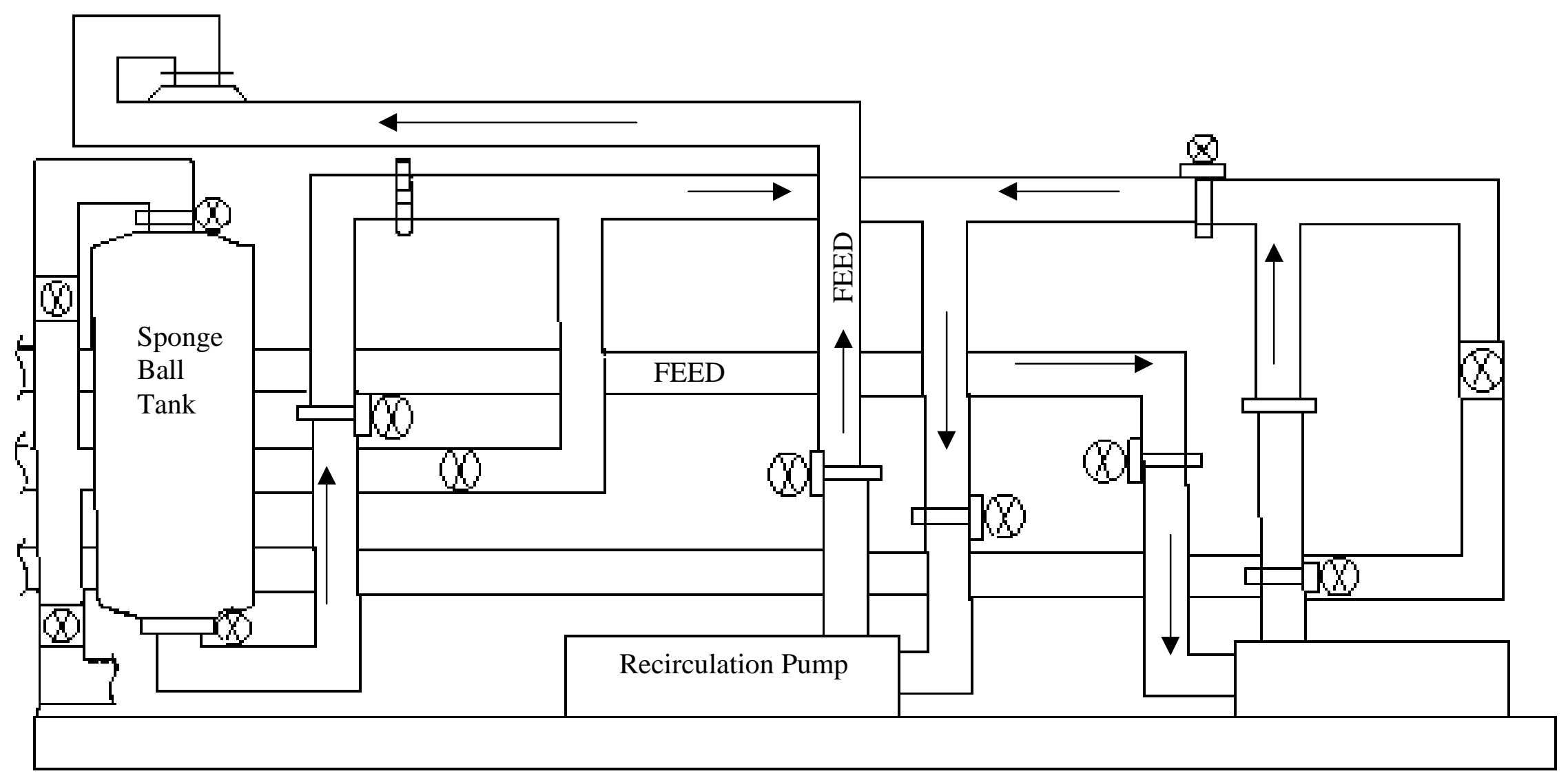

A. Figure 3.2 Profile of the Tubular UF System 
in series. The individual membranes are 9.0 feet long, with a membrane surface area of $2.2 \mathrm{ft}^{2}$. The tubular membranes are negatively charged and rated for a MWCO of 120,000. The molecular weight rating of these membranes allows water to pass through the pores on the membrane, while retarding or resisting the larger oil molecules.

\section{System Overview}

During the initial pre-start up, oily waste or pond effluent from pond \#2, is pumped to the 20,000 gallon concentration tank until the tank is filled to a level of $\sim 15$ feet. The waste is supplied to the system by a 25 horsepower Goulds open impeller centrifugal pump located on the UF skid. A larger 125 horsepower Goulds open impeller centrifugal pump receives the waste and sends the waste to two identical manifolds. From each manifolds the oily waste is sent to 23 membrane banks. In Figure 3.2, a schematic of the top view membrane configuration in each UF unit is presented. Each of the 23 membrane banks has 16 tubes or membranes connected in series. The water that passes through the membranes are channeled through permeate collection tubes. The collection tubes direct all permeate into permeate manifolds. The permeate flowrate is constantly monitored by a Bailey Fischer and Porter magnetic flowmeter. The permeate leaves the system and is discarded in to pond \#1. Pond \#1 similar to pond \#2, is a fully designed RCRA facility with double liners and leak detection.

The rejected oil that did not pass through the membrane is collected into two concentrate manifolds. From these manifolds a portion of the concentrate is directed back to the 125 horsepower pump where it is recirculated to maintain the necessary cross-flow velocity. The cross flow velocity for the systems averages $\sim 12 \mathrm{ft} / \mathrm{s}$ and 


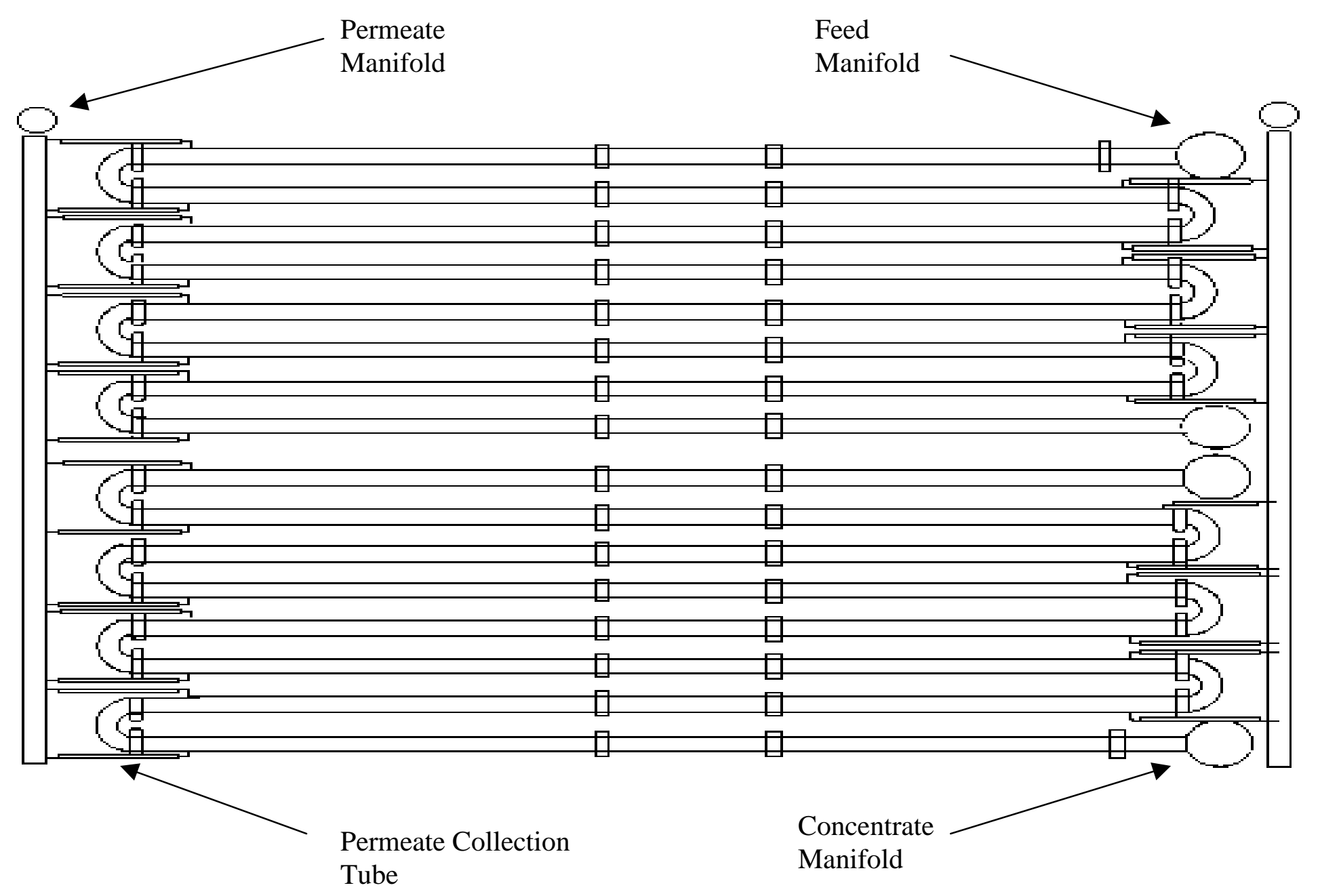

B. Figure 3.3 Top View Membrane Configuration 
Reynolds numbers $>100,000$. The portion of the concentrate that was not redirect back for recirculation, is returned to the 20,000 gallon concentration tank. In the concentration tank, the fluid returning from the system is mixed with the waste and eventually under goes the same process described above.

The process explained above is a semi-batch process. As permeate is removed the level in the concentration tank drops. The level of the oily waste inside the concentration tank is monitored by Milltronic electric level indicators. When the level inside the tank drops to the specified point of $11.0 \mathrm{ft}$, the feed pump at the pump house sends more pond effluent into the tank and fills the tank up to its initial level of $\sim 15.0 \mathrm{ft}$.

As the UF system concentrates the oily waste, an amount of free oil separates out of the solution and rises to the top of the tank forming a layer. As the process continues more and more oil accumulates at the top of the feed tank. Skim-Pak oil skimmers located in the concentration tanks skim off this layer and send it to an oil sump located at the base of the tank. From this sump, the oil is pump to storage tanks and then sold for other purposes or disposed of. Without these skimmers to extract the free oil, the sonic level indicators would start to malfunction. The oil can absorb or distort the signal being sent by the meter, resulting in inaccurate level readings.

While the system is operating, certain system parameters are observed on a PLC to monitor system performance. Recycle and concentrate pressures are monitored to assure a proper transmembrane pressure of 54 to $58 \mathrm{psi}$ are maintained. The maximum pressure allowed to be exerted by the recirculation pump is $92 \mathrm{psi}$, in order to protect the membrane from being damaged. The recirculation pressure could be controlled by a butterfly valve located on the discharged side on the pump. Concentrate pressure was 
controlled on the PLC by using Bettis pressure control valve. Recycle, concentrate and permeate flowrates were also monitored on the PLC. Concentrate temperature was measured on inline temperature probe located in the recycle stream of the system. Maximum concentrate temperature was set at $120^{\circ} \mathrm{F}$ to protect against membrane and system damage.

\section{System Operation}

An experiment or run started by filling one of the 20,000 gallon tanks with fresh 1X pond effluent from pond \#2. A run was defined as the semi-batch of the waste in the concentrate tank. A run ended when the contents in the tank were purged to storage tanks for disposal. Runs are subdivided into subruns. Subruns are defined as the interval of time the system was in operation (concentration mode) between system cleanings. Over the course of these subruns, permeate flux was monitored. The system was developed to operate at a average permeate flow of $29 \mathrm{gal} / \mathrm{min}$ or average flux of $25.8 \mathrm{gal} / \mathrm{ft}^{2}-\mathrm{d}$ each. This set point enables the systems to produce roughly 80,000 gallons of permeate per day. To assure that the demands on the system are being met, a running permeate average was updated daily. If the average permeate flow dropped below the $29 \mathrm{gal} / \mathrm{min}$ the system was shutdown and cleaned. Another parameter that was used to determine the length of a subrun was the instantaneous permeate flow. A operating set point of 18 $\mathrm{gal} / \mathrm{min}$ or $16 \mathrm{gal} / \mathrm{ft}^{2}-\mathrm{d}$ was used, because a low flow such as this is not recommended by the producer of the membranes. 
Other parameters that were monitored throughout a subrun included permeate turbidity, and $\mathrm{pH}$ and conductivity of both the concentrate and the permeate.

\section{Sampling Procedure}

While the system operated samples of the concentrate, permeate, pond effluent and skimmed oil from tanks were taken. The frequency and method of analysis for each sample taken, will be discussed in following section.

\section{Concentrate Samples:}

Concentrate samples were taken $2 \mathrm{X} /$ week while the system processed waste, to be analyzed for oil content. The sample port was located on the bottom half of the concentrate tanks. Triplicate samples were taken at the beginning and end of a subrun for QA/QC. If a subrun last for a long period of time, concentrate samples were then triplicated every $10 \%$. To determine the oil content of the concentrate samples, the analytical lab located on site, utilized an acid split solution, and consisted of saturated sodium bisulfate with 20 percent sulfuric acid. Equipment needed to perform the analysis consisted of an $8 \%$ graduate babcock bottle, $20 \mathrm{~mL}$ pipette and centrifuge. Once the samples were mixed thoroughly, $20 \mathrm{~mL}$ were extracted and placed into each of the $8 \%$ babcock bottle. Then approximately $20 \mathrm{~mL}$ of acid solution are added to each and then mixed. The babcock bottles were then placed into a heated water bath and boiled (100

${ }^{\mathrm{O}} \mathrm{C}$ ) for a minimum of 30 minutes. After 30 minutes, the babcock bottles were filled up to the bottle neck with more acid solution and placed in the centrifuge in balanced positions. The samples were then centrifuged for a minimum of 20 minutes, refilled with acid to top of graduated neck and centrifuge for an additional 20 minutes. The percent oil content 
was read directly from the bottle graduation to the nearest 0.1 percent. [Century

Aluminum Corporation Technical Dept.]

\section{Permeate Samples:}

Permeate samples a were taken roughly every twenty four hours and analyzed for turbidity, $\mathrm{pH}$, conductivity and temperature. Sample were taken from a permeate drain line that was connected into the permeate to pond \#1 manifold. Every other sample that was taken during operation, was analyzed for oil and grease. Triplicate samples were taken every $10 \%$ for QA/QC. To determine the oil and grease of the permeate samples a Freon extract test was used. The reagents and working solutions needed for the analysis was Trichlorotriflouroethane Optima Grade Freon and De-ionized water. The equipment consisted of a Horiba Oil Content Analyzer Model OCMA-220, two graduated cylinders and a waste beaker. After the analyzer readings has stabilized, $15 \mathrm{~mL}$ of the permeate sample was measured out and pour into the sample inlet located on the analyzer. The same amount of freon was measured out and poured into the same inlet. The system then automatically analyzed the amount of oil concentration present in the sample. After the instrument stabilizes the reading can be read directly from the display. The measurement range for this analysis was 0 to $200 \mathrm{ppm}$.

[Century Aluminum Corporation Technical Dept.]

\section{Pond Effluent Samples:}

Pond effluent samples were taken roughly every other day and analyzed for oil content, using the method described earlier. Samples were taken from sampling port located on a six inch feed line to the concentrate tanks. 


\section{Concentrate Tank Skimmings:}

Oil that was skimmed from the top of each concentrate tank was sampled regularly for oil content. A sample was taken from the oil sump were the skimmings collected before being sent to the storage tank area. Due to the high oil content of the skimmings acid split solutions could not be used for this analysis. A procedure utilizing a centrifuge and $15 \mathrm{~mL}$ graduated pear shaped bottle was implemented. After the skimming sample was mixed vigorously, $10 \mathrm{~mL}$ of the sample were pour into the pear shape bottle. The sample was then placed into a centrifuge in a balanced position, using a water filled blank if necessary. The samples were centrifuge for a minimum of 30 minutes. The result could be read directly on the graduated bottle. The measurement range for this analysis was from 0 to $100 \pm 0.05$ percent.

\section{Flushing the System}

After the system was shutdown a flush sequence insued. During the flush, a 4000 gallon flush tank was used. The tank was either filled with permeate from the two UF systems or with softened water. The flush lasted for a total of 4 minutes. The purpose of the flush was to remove the majority of oily-water from the system before the cleaning solution is utilized.

\section{Cleaning}

Once the system was flushed, the membranes were cleaned before the wastewater can be processed again. Cleaning removes the build-up of oil and other material from the membranes surface. Removing oil and other debris from the membranes allows for higher fluxes. 
The first stage in the preparation of cleaning was to make up the cleaning solution. Koch recommended a 0.5 - $1.0 \%$ KLD or "Koch Liquid Detergent" cleaning solution for the membranes. To reduce cleaning costs a $0.5 \%$ solution was used for the cleaning. To achieve the mixture, 6 gallons of KLD was added to $\sim 600$ gallons of softened water. Softened water was used during the cleaning for two reasons. The EDTA in the KLD soap will react with the ions the produce hard water. Thus reducing the KLD's cleaning effectiveness. Additionally, using hard water at high temperatures can cause scaling at the membranes surface. The cleaning tank used in these experiments was a 1000 gallon CIP or "Cleaning in Place" tank. Once the solution was made, the contents were mixed and heated for approximately 3 hours or until the cleaning solution reached a temperature of $130^{\circ} \mathrm{F}$. While the cleaning solution was heated, it was $\mathrm{pH}$ adjusted to 10 using Kochkleen 120.

Once the cleaning solution was heated and $\mathrm{pH}$ adjusted, the chemical clean mode is initiated. The cleaning solution had to be reheated and $\mathrm{pH}$ adjusted to $\sim 10$ again once the solution was circulated through the system. The actual cleaning was started when the concentrate temperature reached $120^{\circ} \mathrm{F}$. The system was allowed to circulate and clean for a period of 40 minutes. Over the course of the 40 minute cleaning, temperature, turbidity, $\mathrm{pH}$, conductivity and permeate flux were monitored. Permeate flux was monitored every 10 minutes. Permeate temperature, $\mathrm{pH}$, turbidity, and conductivity were monitored every 15 minutes. Cleaning feed temperature, $\mathrm{pH}$ and conductivity were monitored every 30 minutes.

After 40 minutes elapsed, the system was shutdown and prepared for a spongeball cleaning. Spongeball cleaning were instituted in order to scour and clean the pores of the 
membranes. The spongeballs, were supplied by Koch and were 0.5 inches in diameter. Once the valves were adjusted on the system for spongeball retrieval, the system under went two spongeball passes. During each pass, fifty spongeballs were allowed to travel through the system once. During the spongeball sequence, the PLC was monitored closely to note the maximum permeate flow achieved. After the spongeball sequence was performed, the valves were readjusted to the normal mode setting. The system was then cleaned for an additional 40 minutes with the same cleaning solution.

\section{Acid Cleaning}

Acid cleanings were initiated when system performance was below average. Over time metals ions clog the membrane pores and spongeballing doesn't remove them totally. As the metals ions build up, the permeate flux decline directly effecting the treatment rate. As a result, acid cleanings are instituted to remove the metals from the pores of the membranes. Acid cleanings were also implemented before starting a new run, insure that the membranes were as clean as possible to start the new run.

The acid cleanings were preformed after the system was cleaning with KLD and flushed with 4000-gallons of water. The CIP tank was drained, cleaned with hot water and refilled with 600 gallons of softened water. The water was then $\mathrm{pH}$ adjusted to $\sim 2.2$ as it heated to $120^{\circ} \mathrm{F}$. The $\mathrm{pH}$ adjustment was performed using a mixing tank located adjacent to the cleaning tank. The $\mathrm{pH}$ adjusting solution consisted of one box of the propietry carboxylic acid to 55 gallons of softened water. When the desired temperature was reached, the acid mixture was allowed to circulate through the system for one hour. Similar to the KLD cleaning, temperature, turbidity, $\mathrm{pH}$, conductivity and permeate flux 
were monitored during the acid cleaning. After one hour elapsed on the acid cleaning the system was flushed with water. The CIP tank was drained, cleaned out and refilled with softened water. A $0.3 \%$ KLD solution was made by adding 3 gallons of KLD to 600 gallons of water. The cleaning solution was then heated to $120{ }^{\circ} \mathrm{F}$ and allowed to circulate for one hour. The same parameters were monitored for this cleaning as well. 


\section{CHAPTER 4}

\section{RESULTS}

In the following section, the results that were obtained at the facility are presented. Information that will be presented in this section is as follows: characteristics of influent, permeate and concentrate, cleanings, and flux characteristics.

\section{UF1-R7}

UF1-R7 started on January 16, 1998 at 09:40 and ended on February 7, 1998 at 00:50. The run lasted for 21.2 days. The objectives of the run were: 1 ) monitor system performance, 2) estimate the volume of free oil that forms at the top of the concentrate tanks and 3) conduct an oil mass balance on the system in order to note the change occurring in the system. UF1-R7 had 4 subruns. Each subrun and cleaning is discussed separately in the following sections.

In Figure 4.1, permeate flux versus time for UF1-R7 is presented. In Figure 4.2, permeate turbidity versus time for UF1-R7 is presented. In Table 4.1, a summary of permeate operating parameters for UF1-R7 is presented. In Table 4.2, a summary of concentrate operating parameters for UF1-R7 is presented. In Table 4.3, a summary of permeate cleaning parameters for UF1-R7 is presented. In Table 4.4, a summary of concentrate cleaning parameters for UF1-R7 is presented. In Table 4.5, a summary of permeate $\mathrm{O} / \mathrm{G}$ samples analyzed for UF1-R7, is presented. In Table 4.6, a summary of concentrate oil content samples analyzed for UF1-R7, is presented. In Table 4.7, a summary of free oil skimming samples analyzed for UF1-R7, is presented. In Table 4.8, a summary of free oil production for UF1-R7 is presented. 


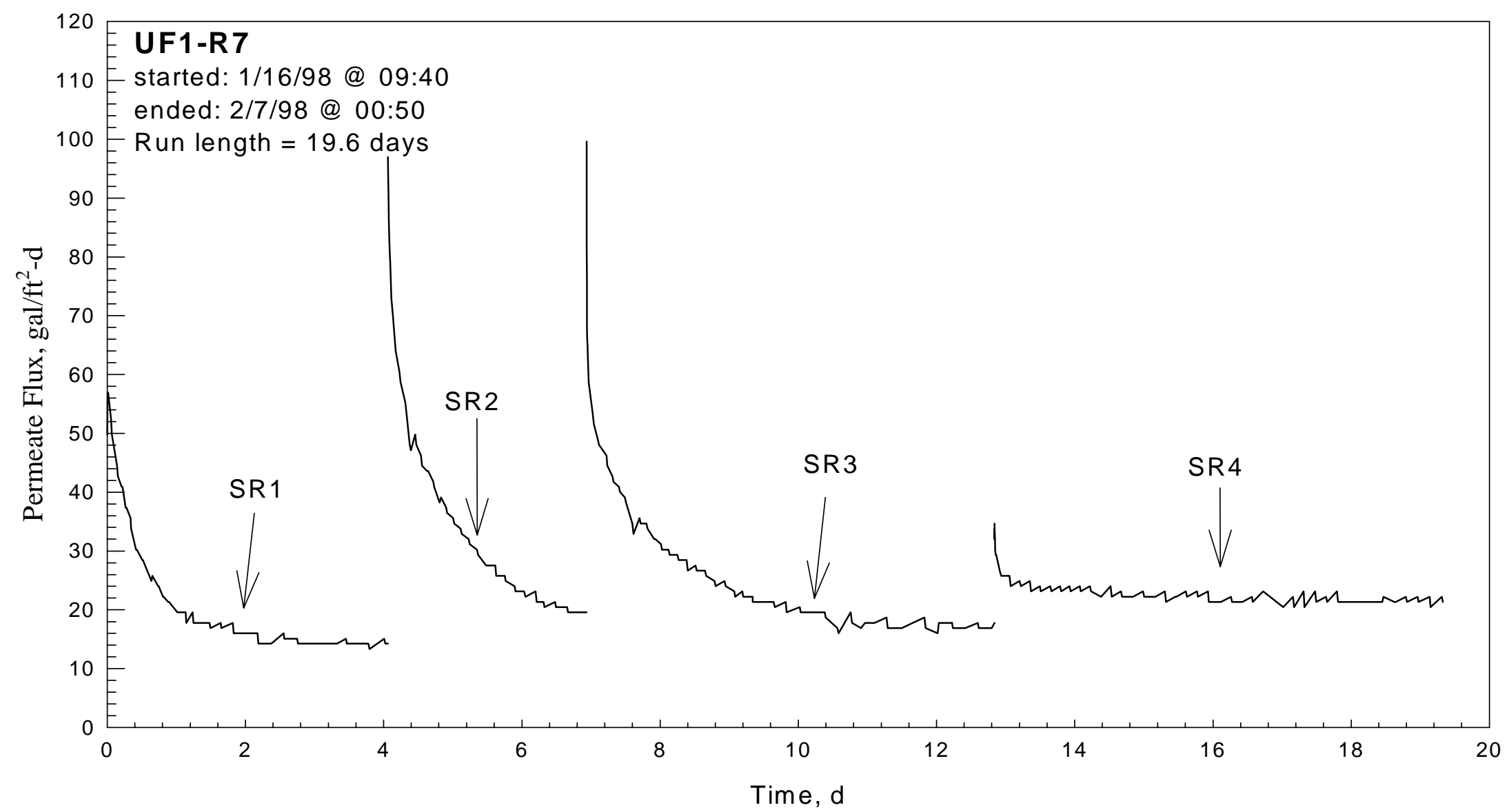

Figure 4.1 Permeate Flux versus Time for UF1-R7 


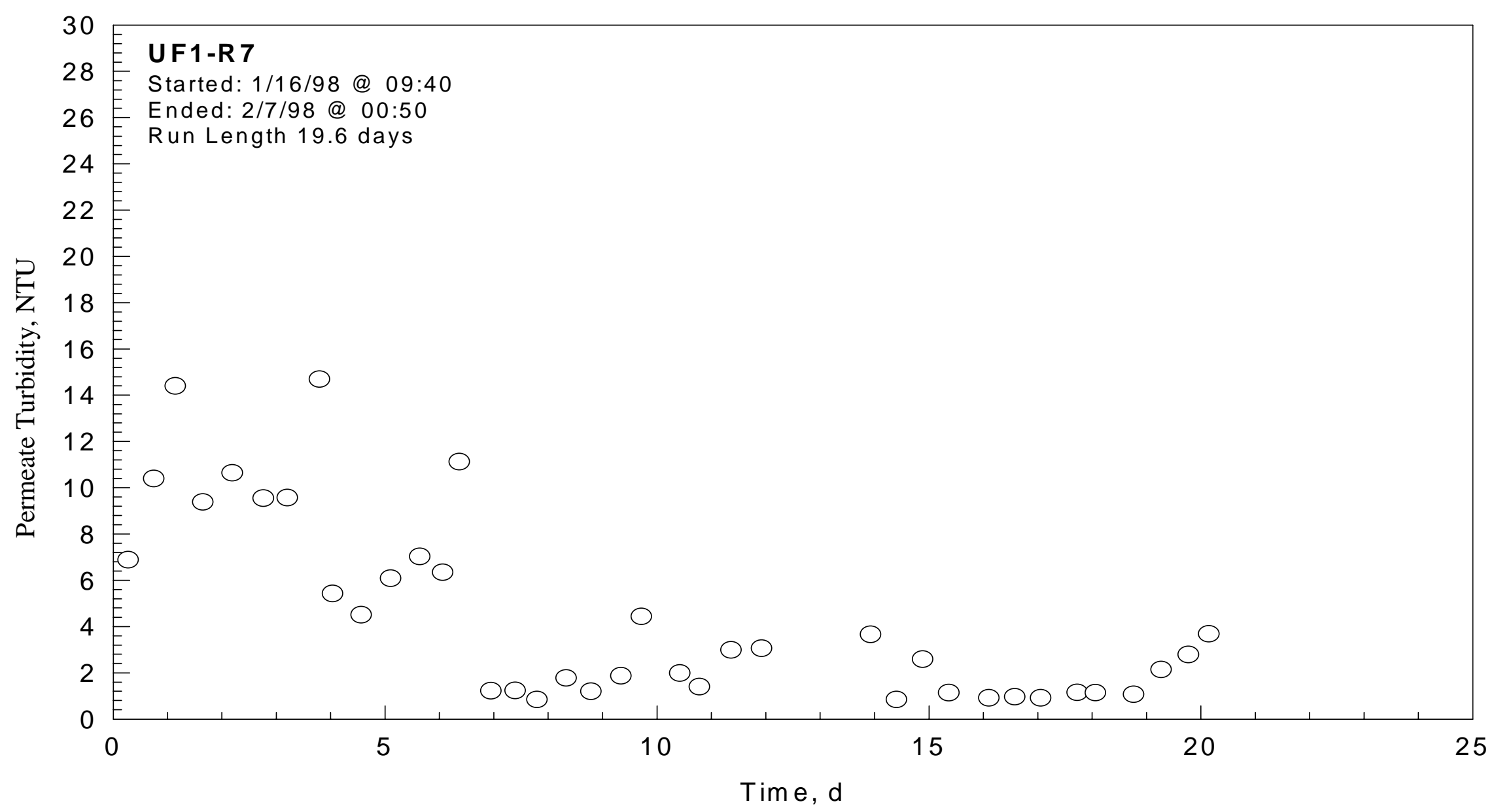

Figure 4.2 Permeate Turbidity versus Time for UF1-R7 
Table 4.1. Summary of Permeate Parameters for UF1-R7

\begin{tabular}{|c|c|c|c|c|c|c|}
\hline $\begin{array}{l}\text { Subrun } \\
\text { ID }\end{array}$ & $\begin{array}{c}\text { Flux }\left(\text { gal/ft }{ }^{2}-d\right) \\
{[\text { min - max }]} \\
\text { Avg } \pm \text { std }\end{array}$ & $\begin{array}{l}\text { Temperature }\left({ }^{{ }^{O}} \mathbf{F}\right) \\
{[\text { min }- \text { max }]} \\
\text { Avg } \pm \text { std }\end{array}$ & $\begin{array}{c}\text { Turbidity (NTU) } \\
\text { [min - max }] \\
\text { Avg } \pm \text { std }\end{array}$ & $\begin{array}{c}\mathbf{p H} \\
{[\mathrm{min}-\mathbf{m a x}]} \\
\text { Avg } \pm \text { std }\end{array}$ & $\begin{array}{c}\text { Conductivity }(\mu \mathrm{S} / \mathrm{cm}) \\
{[\mathrm{min}-\max ]} \\
\text { Avg } \pm \text { std }\end{array}$ & $\begin{array}{c}\text { O/G (mg/L) } \\
{[\mathrm{min}-\text { max }]} \\
\text { Avg } \pm \text { std }\end{array}$ \\
\hline 1 & $\begin{array}{c}{[13.3-56.9]} \\
23.2 \pm 11.8\end{array}$ & $\begin{array}{c}{[69.2-79.1]} \\
75.9 \pm 3.1\end{array}$ & $\begin{array}{c}{[6.9-14.7]} \\
10.7 \pm 2.6\end{array}$ & $\begin{array}{c}{[6.1-6.6]} \\
6.3 \pm 0.14\end{array}$ & $\begin{array}{c}{[406-685]} \\
558 \pm 65\end{array}$ & $\begin{array}{l}{[2-8]} \\
4.1 \pm 2.4\end{array}$ \\
\hline 2 & $\begin{array}{c}{[19.6-96.9]} \\
43.5 \pm 22.4\end{array}$ & $\begin{array}{c}{[71.7-76.8]} \\
74.4 \pm 2.2\end{array}$ & $\begin{array}{c}{[4.5-7.0]} \\
5.8 \pm 0.96\end{array}$ & $\begin{array}{c}{[5.4-6.0]} \\
5.8 \pm 0.24\end{array}$ & $\begin{array}{c}{[66.4-704]} \\
453 \pm 247\end{array}$ & $\begin{array}{c}{[4-6.7]} \\
5.4 \pm 1.2\end{array}$ \\
\hline 3 & $\begin{array}{c}{[16-99.6]} \\
31.2 \pm 17.8\end{array}$ & $\begin{array}{c}{[73.1-80.0]} \\
76.5 \pm 2.5\end{array}$ & $\begin{array}{c}{[0.84-11.1]} \\
2.8 \pm 2.8\end{array}$ & $\begin{array}{c}{[5.4-5.7]} \\
5.7 \pm 0.25\end{array}$ & $\begin{array}{c}{[82-759]} \\
528 \pm 186\end{array}$ & $\begin{array}{l}{[2-5]} \\
4.3 \pm 1.1\end{array}$ \\
\hline 4 & $\begin{array}{c}{[17.8-34.7]} \\
22.9 \pm 2.9\end{array}$ & $\begin{array}{c}{[73.2-78.2]} \\
76 \pm 1.4\end{array}$ & $\begin{array}{c}{[0.84-3.7]} \\
1.9 \pm 1.0\end{array}$ & $\begin{array}{c}{[4.5-6.3]} \\
5.6 \pm 0.44\end{array}$ & $\begin{array}{c}{[165-601]} \\
465 \pm 139\end{array}$ & $\begin{array}{l}{[2-6]} \\
4.4 \pm 1.5\end{array}$ \\
\hline
\end{tabular}


Table 4.2. Summary of Concentrate and Pond Effluent Parameters for UF1-R7

\begin{tabular}{|c|c|c|c|c|c|}
\hline $\begin{array}{l}\text { Subrun } \\
\text { ID }\end{array}$ & $\begin{array}{l}\text { Temperature }\left({ }^{0} \mathbf{F}\right) \\
{[\text { min }-\max ]} \\
\text { Avg } \pm \text { std }\end{array}$ & $\begin{array}{c}\mathrm{pH} \\
{[\mathrm{min}-\mathbf{m a x}]} \\
\text { Avg } \pm \text { std }\end{array}$ & $\begin{array}{c}\text { Conductivity }(\mu \mathrm{S} / \mathrm{cm}) \\
{[\mathrm{min}-\max ]} \\
\text { Avg } \pm \text { std }\end{array}$ & $\begin{array}{c}\text { Oil Content (\%) } \\
{[\text { min - max }]} \\
\text { Avg } \pm \text { std }\end{array}$ & $\begin{array}{c}\text { Pond Effluent O/G }(\mathrm{mg} / \mathrm{L}) \\
{[\min -\max ]} \\
\text { Avg } \pm \text { std }\end{array}$ \\
\hline 1 & $\begin{array}{c}{[72.8-84.7]} \\
80.5 \pm 3.8\end{array}$ & $\begin{array}{c}{[6.4-7.1]} \\
6.7 \pm 0.34\end{array}$ & $\begin{array}{c}{[531-646]} \\
585 \pm 47\end{array}$ & $\begin{array}{c}{[0.65-1.45]} \\
1.1 \pm 0.4\end{array}$ & $\begin{array}{c}{[0.4-0.6]} \\
0.5 \pm 0.1\end{array}$ \\
\hline 2 & $\begin{array}{c}{[76.0-82.0]} \\
78.9 \pm 2.7\end{array}$ & $\begin{array}{c}{[6.1-6.4]} \\
6.2 \pm 0.19\end{array}$ & $\begin{array}{c}{[177-440]} \\
308 \pm 186\end{array}$ & $\begin{array}{c}{[1.45-5.0]} \\
3.2 \pm 2.5\end{array}$ & {$[0.5]$} \\
\hline 3 & $\begin{array}{c}{[76.5-86.0]} \\
81.2 \pm 3.1\end{array}$ & $\begin{array}{c}5.7-6.1] \\
5.9 \pm 0.24\end{array}$ & $\begin{array}{c}{[18-615]} \\
404 \pm 336\end{array}$ & $\begin{array}{c}{[5.0-7.4]} \\
6.2 \pm 1.7\end{array}$ & $\begin{array}{c}0.5-1.6] \\
1.0 \pm 0.5\end{array}$ \\
\hline 4 & $\begin{array}{c}{[78.9-82.1]} \\
80.5 \pm 1.1\end{array}$ & $\begin{array}{c}{[4.9-6.1]} \\
5.5 \pm 0.44\end{array}$ & $\begin{array}{c}{[261-429]} \\
364 \pm 77\end{array}$ & $\begin{array}{c}{[7.4-9.1]} \\
8.2 \pm 0.9\end{array}$ & $\begin{array}{c}{[0.46-1.2]} \\
0.7 \pm 0.3\end{array}$ \\
\hline
\end{tabular}


Table 4.3. Summary of Permeate Cleaning Parameters for UF1-R7

\begin{tabular}{|c|c|c|c|c|c|}
\hline $\begin{array}{l}\text { Subrun } \\
\text { ID }\end{array}$ & $\begin{array}{c}\text { Flux }\left(\mathrm{gal} / \mathrm{ft}^{2}-\mathrm{d}\right) \\
{[\mathrm{min}-\max ]} \\
\text { Avg } \pm \text { std }\end{array}$ & $\begin{array}{l}\text { Temperature }\left({ }^{0} \mathrm{~F}\right) \\
{[\mathrm{min}-\mathrm{max}]} \\
\text { Avg } \pm \text { std }\end{array}$ & $\begin{array}{c}\text { Turbidity (NTU) } \\
\text { [min - max }] \\
\text { Avg } \pm \text { std }\end{array}$ & $\begin{array}{c}\text { pH } \\
{[\min -\mathbf{m a x}]} \\
\text { Avg } \pm \text { std }\end{array}$ & $\begin{array}{c}\text { Conductivity }(\mu \mathrm{S} / \mathrm{cm}) \\
{[\mathrm{min}-\max ]} \\
\text { Avg } \pm \text { std }\end{array}$ \\
\hline 1 & $\begin{array}{c}{[33.5-86.3]} \\
62.3 \pm 8.9\end{array}$ & $\begin{array}{c}{[89.2-98.0]} \\
93.3 \pm 3.9\end{array}$ & $\begin{array}{c}{[43.8-108.9]} \\
68.8 \pm 29.6\end{array}$ & $\begin{array}{c}{[6.7-6.8]} \\
6.8 \pm 0.03\end{array}$ & $\begin{array}{c}{[628-742]} \\
688 \pm 52\end{array}$ \\
\hline 2 & $\begin{array}{c}{[36.5-68.5]} \\
54.8 \pm 4.8\end{array}$ & $\begin{array}{c}{[89.2-102]} \\
95 \pm 5.2\end{array}$ & $\begin{array}{c}{[5.6-40]} \\
17.8 \pm 14\end{array}$ & $\begin{array}{c}{[5.7-6.5]} \\
6.3 \pm 0.33\end{array}$ & $\begin{array}{c}{[687-919]} \\
823 \pm 100\end{array}$ \\
\hline 3 & $\begin{array}{c}{[21.3-26.7]} \\
26.1 \pm 1.2\end{array}$ & $\begin{array}{c}{[87.7-98.0]} \\
92.8 \pm 3.0\end{array}$ & $\begin{array}{c}{[3.9-10.7]} \\
6.6 \pm 2.1\end{array}$ & $\begin{array}{c}{[4.9-6.5]} \\
5.7 \pm 0.64\end{array}$ & $\begin{array}{c}{[449-617]} \\
562 \pm 59\end{array}$ \\
\hline 4 & $\begin{array}{c}{[28.5-37.4]} \\
32.9 \pm 1.9\end{array}$ & $\begin{array}{c}{[88-98.7]} \\
93.6 \pm 3.7\end{array}$ & $\begin{array}{c}{[7.3-15.0]} \\
10.4 \pm 2.2\end{array}$ & $\begin{array}{c}{[6.5-7.0]} \\
6.7 \pm 0.12\end{array}$ & $\begin{array}{c}{[589-718]} \\
644 \pm 39\end{array}$ \\
\hline
\end{tabular}


Table 4.4. Summary of Concentrate Cleaning Parameters for UF1-R7

\begin{tabular}{|c|c|c|c||}
\hline \begin{tabular}{|c|c|} 
Subrun \\
ID
\end{tabular} & $\begin{array}{c}\left.\text { Temperature } \mathbf{(}^{\mathbf{O}} \mathbf{F}\right) \\
{[\mathbf{m i n}-\mathbf{m a x}]} \\
\text { Avg } \pm \text { std }\end{array}$ & $\begin{array}{c}\mathbf{p H} \\
{[\mathbf{m i n}-\mathbf{m a x}]} \\
\text { Avg } \pm \text { std }\end{array}$ & $\begin{array}{c}\text { Conductivity }(\boldsymbol{\mu S} / \mathbf{c m}) \\
{[\mathbf{m i n}-\mathbf{m a x}]} \\
\mathbf{A v g} \pm \mathbf{s t d}\end{array}$ \\
\hline 1 & {$[95-110]$} & {$[6.7-6.8]$} & {$[1342-1420]$} \\
& $103.5 \pm 5.5$ & $6.8 \pm 0.03$ & $1383 \pm 37$ \\
\hline 2 & {$[95-110]$} & {$[5.7-6.5]$} & {$[1482-1850]$} \\
& $102.5 \pm 5.8$ & $6.3 \pm 0.33$ & $1656 \pm 156$ \\
\hline 3 & {$[95-106.4]$} & {$[4.9-6.5]$} & {$[520-944]$} \\
& $101.5 \pm 4.8$ & $5.7 \pm 0.64$ & $761 \pm 135$ \\
\hline 4 & {$[95-107.5]$} & {$[6.5-7.0]$} & {$[968-1109$} \\
& 102.2 & $6.7 \pm 0.12$ & $1058 \pm 51$ \\
\hline \hline
\end{tabular}


Table 4.5 Summary of Permeate O/G Samples for UF1-R7

\begin{tabular}{|c|c|c|c|c|}
\hline \multirow{2}{*}{ Subrun ID } & \multirow{2}{*}{ Date/Time } & \multicolumn{3}{|c|}{ Sample Results (mg/L) } \\
\hline & & $\# 1$ & $\# 2$ & $\# 3$ \\
\hline 1 & $1 / 16 / 98(17: 20)$ & 2 & & \\
\hline 1 & 1/17/98 (04:35) & 4 & 3 & 5 \\
\hline 1 & 1/18/98 (02:08) & 6 & & \\
\hline 1 & 1/18/98 (15:02) & 3 & & \\
\hline 1 & $1 / 19 / 98(04: 45)$ & 2 & & \\
\hline 1 & 1/19/98 (15:36) & 2 & & \\
\hline 1 & $1 / 20 / 98(05: 45)$ & 8 & & \\
\hline 2 & $1 / 20 / 98(23: 15)$ & 4 & & \\
\hline 2 & $1 / 21 / 98(11: 32)$ & 6 & & \\
\hline 2 & 1/22/98 (13:27) & 5 & & \\
\hline 2 & 1/23/98 (00:32) & 7 & 7 & 6 \\
\hline 3 & 1/24/98 (01:12) & 2 & & \\
\hline 3 & 1/25/98 (02:02) & 4 & & \\
\hline 3 & 1/26/98 (01:30) & 5 & & \\
\hline 3 & $1 / 26 / 98(12: 46)$ & 4 & & \\
\hline 3 & 1/27/98 (10:00) & 5 & & \\
\hline 3 & $1 / 28 / 98(02: 57)$ & 5 & & \\
\hline 3 & 1/29/98 (02:37) & 4 & 5 & 6 \\
\hline 4 & 1/30/98 (04:21) & 5 & & \\
\hline 4 & 1/31/98 (01:08) & 3 & & \\
\hline 4 & 2/1/98 (02:07) & 4 & & \\
\hline 4 & $2 / 2 / 98(00: 39)$ & 6 & & \\
\hline 4 & 2/2/98 (23:37) & 6 & 5 & 6 \\
\hline 4 & 2/3/98 (22:25) & 5 & & \\
\hline 4 & 2/4/98 (22:37) & 6 & & \\
\hline 4 & 2/6/98 (03:39) & 5 & & \\
\hline 4 & $2 / 6 / 98 \quad(23: 38)$ & 1 & 3 & 4 \\
\hline
\end{tabular}


Table 4.6 Summary of Concentrate Oil Content Samples for UF1-R7

\begin{tabular}{|c|c|c|c|c|}
\hline Subrun ID & \multirow{2}{*}{ Date/Time } & \multicolumn{3}{|c|}{ Sample Results (\%) } \\
\cline { 3 - 5 } & & $\mathbf{\# 1}$ & $\mathbf{\# 2}$ & $\mathbf{\# 3}$ \\
\hline 1 & $1 / 15 / 98(14: 20)$ & 0.6 & 0.7 & \\
\hline 1 & $1 / 16 / 98(10: 30)$ & 0.6 & 0.6 & 0.6 \\
\hline 1 & $1 / 16 / 98(16: 32)$ & 1.2 & 1.0 & 0.9 \\
\hline 1 & $1 / 17 / 98(11: 45)$ & 0.8 & 1.0 & 0.6 \\
\hline 1 & $1 / 18 / 98(19: 40)$ & 1.6 & 1.9 & 1.4 \\
\hline 2 & $1 / 20 / 98(17: 16)$ & 2.2 & 1.4 & 1.5 \\
\hline 2 & $1 / 22 / 98(00: 29)$ & 3.9 & & \\
\hline 3 & $1 / 23 / 98(19: 10)$ & 3.4 & 5.0 & \\
\hline 3 & $1 / 26 / 98(16: 58)$ & 7.6 & 7.6 & 7.4 \\
\hline 3 & $1 / 29 / 98(07: 55)$ & 7.4 & 7.6 & 7.6 \\
\hline 4 & $2 / 2 / 98(13: 10)$ & 7.8 & 8.0 & 8.2 \\
\hline 4 & $2 / 6 / 98(16: 07)$ & 5.0 & & \\
\hline 4 & $2 / 7 / 98(00: 16)$ & 6.2 & 9.6 & 8.6 \\
\hline
\end{tabular}


Table 4.7 Summary of Skimming Samples for UF1-R7

\begin{tabular}{|c|c|c|c|c|}
\hline Subrun ID & \multirow{2}{*}{ Date/Time } & \multicolumn{3}{|c|}{ Sample Results (mg/L) } \\
\cline { 3 - 5 } & & $\# \mathbf{H 1}$ & $\mathbf{\# 2}$ & $\mathbf{\# 3}$ \\
\hline \hline 1 & $1 / 16 / 98(11: 00)$ & 4,000 & & \\
\hline 1 & $1 / 17 / 98(11: 05)$ & 6,000 & & \\
\hline 1 & $1 / 19 / 98(15: 18)$ & 5,000 & & \\
\hline 2 & $1 / 21 / 98(13: 25)$ & 5,000 & & \\
\hline 3 & $1 / 23 / 98(19: 35)$ & 5,000 & & \\
\hline 3 & $1 / 25 / 98(11: 25)$ & 16,000 & & \\
\hline 3 & $1 / 27 / 98(10: 00)$ & 14,000 & & \\
\hline 3 & $1 / 28 / 98(21: 46)$ & 6,000 & 6,000 & 7,000 \\
\hline 4 & $2 / 1 / 98(13: 20)$ & 8,000 & & \\
\hline 4 & $2 / 2 / 98(12: 15)$ & 12,000 & & \\
\hline 4 & $2 / 3 / 98(10: 50)$ & 6,000 & & \\
\hline 4 & $2 / 4 / 98(14: 20)$ & 6,000 & & \\
\hline 4 & $2 / 5 / 98(23: 39)$ & 5,000 & & \\
\hline 4 & $2 / 6 / 98(23: 16)$ & 5,000 & 4,000 & 5,000 \\
\hline
\end{tabular}


Table 4.8 Summary of Free Oil Productions for UF1-R7

\begin{tabular}{|c|c|c|c|}
\hline Subrun ID & Subrun Length, d & Total Free Oil, gal & Free Oil Production, gal/d \\
\hline 1 & 4.1 & 0.0 & 0.0 \\
\hline 2 & 2.9 & 258 & 88.9 \\
\hline 3 & 5.9 & 1,464 & 248.1 \\
\hline 4 & 8.3 & 1,752 & 211.1 \\
\hline
\end{tabular}


In Table 4.9, a summary of pond effluent samples analyzed for UF1-R7, is presented.

\section{UF1-R7-SR1}

UF1-R7-SR1 was started on January 16, 1998 at 09:40 and ended on January 20, 1998 at 12:07. The length of the subrun lasted 4.06 days. The total permeate volume produced was 134,050 gal.

\section{Permeate Flux and System Temperature}

Over the course of the subrun, the permeate flux ranged from 13.3 to $56.9 \mathrm{gal} / \mathrm{ft}^{2}-$

d. Permeate temperature ranged from 69.2 to $79.1^{\circ} \mathrm{F}$ with an average of $75.9^{\circ} \mathrm{F}$. Concentrate temperatures ranged from 72.8 to $84.7^{\circ} \mathrm{F}$ with an average of $80.5^{\circ} \mathrm{F}$.

\section{Concentrate Oil Content and Free Oil Production}

Concentrate oil content started out at around $0.65 \%$ and increased to $1.45 \%$ by the end of the experiment. The total volume of free oil that was produced during subrun \#1 was 0 gallons. The average daily free oil production was 0.0 gallons/day.

\section{Oil/Grease (O/G), Turbidity and Pond Effluent}

Permeate $\mathrm{O} / \mathrm{G}$ remained low, averaging $4.1 \mathrm{mg} / \mathrm{L}$ and ranging from 2.0 to 8.0

mg/L. Permeate turbidity ranged from 6.9 to 14.7 NTU with an average of 10.7 NTU. Pond effluent ranged from 4000 to $6000 \mathrm{mg} / \mathrm{L}$ and averaged $5000 \mathrm{mg} / \mathrm{L}$ during subrun $\# 1$.

\section{Conductivity and pH}

Permeate $\mathrm{pH}$ ranged from 6.1 to 6.6 with an average of 6.3 . Concentrate $\mathrm{pH}$ 
Table 4.9 Summary of Pond Effluent O/G Samples for UF1-R7

\begin{tabular}{|c|c|c|c|c|}
\hline Subrun ID & Date/Time & \multicolumn{3}{|c|}{ Sample Results (mg/L) } \\
\cline { 3 - 5 } & & $\# \mathbf{1}$ & $\mathbf{\# 2}$ & $\mathbf{\# 3}$ \\
\hline 1 & $1 / 16 / 98(11: 00)$ & 4,000 & & \\
\hline 1 & $1 / 17 / 98(11: 05)$ & 6,000 & & \\
\hline 1 & $1 / 19 / 98(15: 18)$ & 5,000 & & \\
\hline 2 & $1 / 21 / 98(13: 25)$ & 5,000 & & \\
\hline 3 & $1 / 23 / 98(19: 35)$ & 5,000 & & \\
\hline 3 & $1 / 25 / 98(11: 25)$ & 16,000 & & \\
\hline 3 & $1 / 27 / 98(10: 00)$ & 14,000 & & \\
\hline 3 & $1 / 28 / 98(21: 46)$ & 6,000 & 6,000 & 7,000 \\
\hline 4 & $2 / 1 / 98(13: 20)$ & 8,000 & & \\
\hline 4 & $2 / 2 / 98(12: 15)$ & 12,000 & & \\
\hline 4 & $2 / 3 / 98(10: 50)$ & 6,000 & & \\
\hline 4 & $2 / 4 / 98(14: 20)$ & 6,000 & & \\
\hline 4 & $2 / 5 / 98(23: 39)$ & 5,000 & & \\
\hline 4 & $2 / 6 / 98(23: 16)$ & 5,000 & 4,000 & 5,000 \\
\hline
\end{tabular}


ranged from 6.4 to 7.1 with an average of 6.7 . Permeate conductivity ranged from 531 to $646 \mu \mathrm{S} / \mathrm{cm}$ and averaged $585 \mu \mathrm{S} / \mathrm{cm}$. Concentrate conductivity's ranged from 406 to 685 $\mu \mathrm{S} / \mathrm{cm}$ and averaged $558 \mu \mathrm{S} / \mathrm{cm}$.

\section{UF1-R7-SR1 Cleaning}

After UF1-R7-SR1 was shutdown on January 20, 1998 at 12:07, it was cleaned at 13:00 using a $0.5 \%$ KLD cleaning solution. The cleaning solution was recycled for total of two hours. Cleaning was started at a temperature of $\sim 100{ }^{\circ} \mathrm{F}$. The system temperature was not allowed to increase above $110{ }^{\mathrm{O}} \mathrm{F}$ due to a pipe rupturing in previous experiments. If the system temperature reaches $110^{\circ} \mathrm{F}$, it is shutdown and allowed to cool, to approximately $100^{\circ} \mathrm{F}$. After which it is started again to finish the rest of the twohour cleaning. Total downtime for this cleaning was 300 minutes. Over the course of the cleaning, temperature, turbidity, $\mathrm{pH}$, conductivity and permeate flux were monitored. Permeate flux was monitored every 10 minutes. Permeate temperature, $\mathrm{pH}$, turbidity, and conductivity were monitored every 15 minutes. Concentrate temperature, $\mathrm{pH}$ and conductivity were monitored every 30 minutes. The same procedure for data collection was carried out in future cleanings.

\section{Permeate Flux and Temperature}

During the first hour and 15 minutes of the cleaning, the permeate flux ranged from 33.5 to $60.5 \mathrm{gal} / \mathrm{ft}^{2}-\mathrm{d}$ and averaged $45.9 \mathrm{gal} / \mathrm{ft}^{2}-\mathrm{d}$. Permeate temperature ranged from 89.2 to $98.0^{\circ} \mathrm{F}$ and averaged $93.3^{\circ} \mathrm{F}$. Concentrate temperature ranged from 95 to $110^{\circ} \mathrm{F}$ and averaged $103.5^{\circ} \mathrm{F}$.

The system was shutdown 75 minutes into the cleaning because the concentrate temperature reached $110^{\circ} \mathrm{F}$. The system was allowed to cool for 105 minutes and then restarted to complete the two-hour cleaning. During the second half of cleaning, the permeate flux ranged from 61.4 to $86.3 \mathrm{gal} / \mathrm{ft}^{2}-\mathrm{d}$ and averaged $78.8 \mathrm{gal} / \mathrm{ft}^{2}-\mathrm{d}$. Concentrate 
temperatures ranged from 101 to $110^{\circ} \mathrm{F}$ and averaged $105.0^{\circ} \mathrm{F}$. Permeate temperature were not taken during the second hour of cleaning due to human error.

\section{pH, Conductivity and Turbidity}

Permeate $\mathrm{pH}$ ranged from 6.7 to 6.8 with an average of 6.8 . Concentrate $\mathrm{pH}$ ranged from 6.8 to 6.9 with an average of 6.9. Permeate conductivity ranged from 628 to $742 \mu \mathrm{S} / \mathrm{cm}$ and averaged $688 \mu \mathrm{S} / \mathrm{cm}$. Concentrate conductivity ranged from 1342 to $1420 \mu \mathrm{S} / \mathrm{cm}$ and averaged $1383 \mu \mathrm{S} / \mathrm{cm}$. Permeate turbidity ranged from 43.8 to 108.9 NTU and averaged 68.8 NTU. Turbidity of only the permeate was monitored. Concentrate turbidity was over the range of the turbidity meter.

\section{UF1-R7-SR2}

UF1-R7-SR2 was started on January 20, 1998 at 17:06 and ended on January 23, 1998 at 15:07. The length of the subrun lasted 2.88 days. Subrun \#2 was shutdown because the running permeate average was reached. The total permeate volume produced was 157,440 gal.

\section{Permeate Flux and System Temperature}

Over the course of the subrun, the permeate flux ranged from 19.6 to $96.9 \mathrm{gal} / \mathrm{ft}^{2}-$

d. Permeate temperature ranged from 71.7 to $76.8^{\circ} \mathrm{F}$ with an average of $74.4^{\circ} \mathrm{F}$. Concentrate temperatures ranged from 76.0 to $82.0^{\circ} \mathrm{F}$ with an average of $78.9^{\circ} \mathrm{F}$.

\section{Concentrate Oil Content and Free Oil Production}

During subrun \#2, concentrate oil content started out at $1.45 \%$ and increased to $5.0 \%$. The total volume of free oil that was produced during subrun \#2 was 258 gallons. The average daily free oil production was 88.9 gallons/day. 


\section{Oil/Grease, Turbidity and Pond Effluent}

Permeate $\mathrm{O} / \mathrm{G}$ remained low, averaging $5.4 \mathrm{mg} / \mathrm{L}$ and ranging from 4.0 to 6.7 mg/L. Turbidity was also low, averaging 5.8 NTU and ranging from 4.5 to 7.0 NTU. Pond effluent was constant around $5000 \mathrm{mg} / \mathrm{L}$.

\section{Conductivity and pH}

Permeate $\mathrm{pH}$ ranged from 5.4 to 6.0 with an average of 5.8. Concentrate $\mathrm{pH}$ ranged from 6.1 to 6.4 with an average of 6.2 . Permeate conductivity ranged from 66.4 to $704 \mu \mathrm{S} / \mathrm{cm}$ and averaged $453 \mu \mathrm{S} / \mathrm{cm}$. Concentrate conductivity's ranged from 177 to $440 \mu \mathrm{S} / \mathrm{cm}$ and averaged $308 \mu \mathrm{S} / \mathrm{cm}$.

\section{UF1-R7-SR2 Cleaning}

After UF1-R7-SR2 was shutdown on January 23, 1998 at 15:07, it was cleaned at 15:37 using a $0.5 \%$ KLD cleaning solution. The cleaning solution was recycled for total of two hours running time. Cleaning was started at a temperature of $\sim 100{ }^{\circ} \mathrm{F}$. If the system temperature reaches $110^{\circ} \mathrm{F}$, it is shutdown and allowed to cool, to approximately $100^{\circ} \mathrm{F}$. After which it is started again to finish the rest of the two-hour cleaning. Total downtime for this cleaning was 233 minutes.

\section{Permeate Flux and Temperature}

During the first hour of the cleaning, the permeate flux ranged from 36.5 to 54.2 $\mathrm{gal} / \mathrm{ft}^{2}-\mathrm{d}$ and averaged $46.1 \mathrm{gal} / \mathrm{ft}^{2}-\mathrm{d}$. Permeate temperature ranged from 89.2 to $102{ }^{\circ} \mathrm{F}$ and averaged $95^{\circ} \mathrm{F}$. Concentrate temperature ranged from 95 to $110^{\circ} \mathrm{F}$ and averaged $102^{\circ} \mathrm{F}$ over the course of the first hour.

The system was shutdown 66 minutes into the cleaning because the concentrate temperature reached $110^{\circ} \mathrm{F}$. The system was allowed to cool for 71 minutes and then 
restarted to complete the two-hour cleaning. During the second hour of cleaning, the permeate flux ranged from 60.0 to $68.5 \mathrm{gal} / \mathrm{ft}^{2}-\mathrm{d}$ and averaged $63.4 \mathrm{gal} / \mathrm{ft}^{2}-\mathrm{d}$. Concentrate temperatures ranged from 103 to $111^{\circ} \mathrm{F}$ and averaged $107^{\circ} \mathrm{F}$. Permeate temperature were not taken during the second hour of cleaning due to human error.

\section{pH, Conductivity and Turbidity}

Permeate $\mathrm{pH}$ ranged from 5.7 to 6.5 with an average of 6.3. Concentrate $\mathrm{pH}$ ranged from 6.5 to 6.6 with an average of 6.5. Permeate conductivity ranged from 687 to $919 \mu \mathrm{S} / \mathrm{cm}$ and averaged $823 \mu \mathrm{S} / \mathrm{cm}$. Concentrate conductivity ranged from 1482 to $1850 \mu \mathrm{S} / \mathrm{cm}$ and averaged $1656 \mu \mathrm{S} / \mathrm{cm}$. Permeate turbidity ranged from 5.6 to $40.0 \mathrm{NTU}$ and averaged 17.8 NTU. Turbidity of only the permeate was monitored.

\section{UF1-R7-SR3}

UF1-R7-SR3 was started on January 23, 1998 at 19:00 and ended on January 29, 1998 at 17:05. The length of the subrun lasted 5.86 days. Subrun \#3 was shutdown because the running permeate average of $29 \mathrm{gpm}$ was reached. The total permeate volume produced was 234,960 gal.

\section{Permeate Flux and System Temperature}

Over the course of the subrun, the permeate flux ranged from 16.0 to $99.6 \mathrm{gal} / \mathrm{ft}^{2}-$

d. Permeate temperature ranged from 73.1 to $80.0^{\circ} \mathrm{F}$ with an average of $76.5^{\circ} \mathrm{F}$. Concentrate temperatures ranged from 76.5 to $86.0^{\circ} \mathrm{F}$ with an average of $81.2{ }^{\circ} \mathrm{F}$.

\section{Concentrate Oil Content and Free Oil Production}

During subrun \#3, concentrate oil content started out at $5.0 \%$ and increased to $7.4 \%$. The total volume of free oil that was produced during subrun \#3 was 1,464 gallons. The average daily free oil production was 248.1 gallons/day. 


\section{Oil/Grease, Turbidity and Pond Effluent}

Permeate $\mathrm{O} / \mathrm{G}$ remained low, averaging $4.3 \mathrm{mg} / \mathrm{L}$ and ranging from 2.0 to 5.0 mg/L. Turbidity was also low, averaging $2.8 \mathrm{NTU}$ and ranging from 0.84 to $11.1 \mathrm{NTU}$. Pond Effluent ranged from 5000 to $16,000 \mathrm{mg} / \mathrm{L}$ and averaged 10,250 mg/L.

\section{Conductivity and pH}

Permeate $\mathrm{pH}$ ranged from 5.4 to 5.7 with an average of 5.7. Concentrate $\mathrm{pH}$ ranged from 5.7 to 6.1 with an average of 5.9. Permeate conductivity ranged from 82 to $759 \mu \mathrm{S} / \mathrm{cm}$ and averaged $528 \mu \mathrm{S} / \mathrm{cm}$. Concentrate conductivity's ranged from 18 to 615 $\mu \mathrm{S} / \mathrm{cm}$ and averaged $404 \mu \mathrm{S} / \mathrm{cm}$.

\section{UF1-R7-SR3 Cleaning}

After UF1-R7-SR3 was shutdown on January 29, 1998 at 17:05, it was cleaned at 17:05 using a $0.5 \%$ KLD cleaning solution. The cleaning solution was recycled for total of two hours running time. Cleaning was started at a temperature of $\sim 100^{\circ} \mathrm{F}$. If the system temperature reaches $110^{\circ} \mathrm{F}$, it is shutdown and allowed to cool down, to approximately $100^{\circ} \mathrm{F}$. After which it is started again to finish the rest of the two-hour cleaning. Total downtime for this cleaning was 475 minutes.

\section{Permeate Flux and Temperature}

During the first hour, the permeate flux ranged from 21.3 to $25 \mathrm{gal} / \mathrm{ft}^{2}-\mathrm{d}$ and averaged $23.2 \mathrm{gal} / \mathrm{ft}^{2}$-d. Permeate temperature ranged from 87.7 to $94.3^{\circ} \mathrm{F}$ and averaged $90.1^{\circ} \mathrm{F}$. Concentrate temperature ranged from 95 to $110^{\circ} \mathrm{F}$ and averaged $102.3^{\circ} \mathrm{F}$ over the course of the first hour.

The system was shutdown 60 minutes into the cleaning because the concentrate temperature reached $110^{\circ} \mathrm{F}$. The system was allowed to cool for 73 minutes and then restarted to complete the two-hour cleaning. During the second hour of cleaning, the 
permeate flux ranged from 26.7 to $30.2 \mathrm{gal} / \mathrm{ft}^{2}-\mathrm{d}$ and averaged $29.0 \mathrm{gal} / \mathrm{ft}^{2}-\mathrm{d}$. Concentrate temperatures ranged from 94.6 to $106.4^{\circ} \mathrm{F}$ and averaged $100.8^{\circ} \mathrm{F}$. Permeate temperature ranged from 90.8 to $98.0^{\circ} \mathrm{F}$ with an average of $95.4^{\circ} \mathrm{F}$.

\section{pH, Conductivity and Turbidity}

Permeate $\mathrm{pH}$ ranged from 4.9 to 6.5 with an average of 5.7. Concentrate $\mathrm{pH}$

ranged from 5.3 to 6.6 with an average of 5.9. Permeate conductivity ranged from 449 to $617 \mu \mathrm{S} / \mathrm{cm}$ and averaged $562 \mu \mathrm{S} / \mathrm{cm}$. Concentrate conductivity ranged from 520 to 944 $\mu \mathrm{S} / \mathrm{cm}$ and averaged $761 \mu \mathrm{S} / \mathrm{cm}$. Permeate turbidity ranged from 3.9 to $10.7 \mathrm{NTU}$ and averaged 6.6 NTU.

\section{UF1-R7-SR4}

UF1-R7-SR4 was started on January 30, 1998 at 02:00 and ended on February 7, 1998 at 00:50. The length of the subrun lasted 8.27 days. The total permeate volume produced was 292,650 gal. Subrun \#4 marked the end of UF1-R7. After the system was shutdown, the concentrate in the feed tanks was purged to the tank farm.

\section{Permeate Flux and System Temperature}

Over the course of the subrun, the permeate flux ranged from 17.8 to $34.7 \mathrm{gal} / \mathrm{ft}^{2}-$ d. Permeate temperature ranged from 73.2 to $78.2^{\circ} \mathrm{F}$ with an average of $76.0^{\circ} \mathrm{F}$. Concentrate temperatures ranged from 78.9 to $82.1^{\circ} \mathrm{F}$ with an average of $80.5^{\circ} \mathrm{F}$.

\section{Concentrate Oil Content and Free Oil Production}

During subrun \#4, concentrate oil content started out at $7.4 \%$ and increased to $9.1 \%$. The total volume of free oil that was produced during subrun \#4 was 1,752 gallons. The average daily free oil production was 211.1 gallons/day. 


\section{Oil/Grease, Turbidity and Pond Effluent}

Permeate $\mathrm{O} / \mathrm{G}$ remained low, averaging $4.4 \mathrm{mg} / \mathrm{L}$ and ranging from 2.0 to 6.0 $\mathrm{mg} / \mathrm{L}$. Turbidity was also low, averaging $1.9 \mathrm{NTU}$ and ranging from 0.8 to $3.7 \mathrm{NTU}$. Pond effluent O/G ranged from 6000 to $12000 \mathrm{mg} / \mathrm{L}$ and averaged $6800 \mathrm{mg} / \mathrm{L}$.

\section{Conductivity and $\mathrm{pH}$}

Permeate $\mathrm{pH}$ ranged from 4.5 to 6.3 with an average of 5.6. Concentrate $\mathrm{pH}$ ranged from 4.9 to 6.1 with an average of 5.5. Permeate conductivity ranged from 165 to $601 \mu \mathrm{S} / \mathrm{cm}$ and averaged $465 \mu \mathrm{S} / \mathrm{cm}$. Concentrate conductivity's ranged from 261 to $429 \mu \mathrm{S} / \mathrm{cm}$ and averaged $364 \mu \mathrm{S} / \mathrm{cm}$.

\section{UF1-R7-SR4 Cleaning}

After UF1-R7-SR4 was shutdown on February 7, 1998 at 00:50, it was cleaned at 02:00 using a $0.5 \%$ KLD cleaning solution. The cleaning solution was recycled for total of two hours running time. Cleaning was started at a temperature of $\sim 100^{\circ} \mathrm{F}$. If the system temperature reaches $110^{\circ} \mathrm{F}$, it is shutdown and allowed to cool, to approximately $100{ }^{\circ} \mathrm{F}$. After which it is started again to finish the rest of the two-hour cleaning. Total downtime for this cleaning was 1170 minutes.

\section{Permeate Flux and Temperature}

During the first hour, the permeate flux ranged from 28.5 to $32.9 \mathrm{gal} / \mathrm{ft}^{2}-\mathrm{d}$ and averaged $30.6 \mathrm{gal} / \mathrm{ft}^{2}$-d. Permeate temperature ranged from 88.0 to $97.1^{\circ} \mathrm{F}$ and averaged $92.8^{\circ} \mathrm{F}$. Concentrate temperature ranged from 95 to $106.4^{\circ} \mathrm{F}$ and averaged $100.9^{\circ} \mathrm{F}$ over the course of the first hour.

The system was shutdown 60 minutes into the cleaning because the concentrate temperature reached $110^{\circ} \mathrm{F}$. The system was allowed to cool for 60 minutes and then restarted to complete the two-hour cleaning. During the second hour of cleaning, the 
permeate flux ranged from 32.9 to $37.4 \mathrm{gal} / \mathrm{ft}^{2}-\mathrm{d}$ and averaged $35.2 \mathrm{gal} / \mathrm{ft}^{2}-\mathrm{d}$. Permeate temperatures ranged from 89.4 to $98.7^{\circ} \mathrm{F}$ with an average of $94.3^{\circ} \mathrm{F}$. Concentrate temperatures ranged from 98.2 to $107.5^{\circ} \mathrm{F}$ and averaged $102.8^{\circ} \mathrm{F}$.

\section{pH, Conductivity and Turbidity}

Permeate $\mathrm{pH}$ ranged from 6.5 to 7.0 with an average of 6.7 . Concentrate $\mathrm{pH}$ ranged from 6.3 to 7.1 with an average of 6.8. Permeate conductivity ranged from 589 to $718 \mu \mathrm{S} / \mathrm{cm}$ and averaged $644 \mu \mathrm{S} / \mathrm{cm}$. Concentrate conductivity ranged from 968 to 1109 $\mu \mathrm{S} / \mathrm{cm}$ and averaged $1058 \mu \mathrm{S} / \mathrm{cm}$. Permeate turbidity ranged from 7.3 to $15.0 \mathrm{NTU}$ and averaged 10.4 NTU.

\section{UF1-R7-SR4 Acid Cleaning}

After a regular cleaning and flush was performed on the system, an acid cleaning was implemented for one-hour. The acid cleaning started once the 600 gallons of softened water was $\mathrm{pH}$ adjusted to $\sim 2.2$.

\section{Permeate Flux and Temperature}

During the acid cleaning, the permeate flux ranged from 33.8 to $39.1 \mathrm{gal} / \mathrm{ft}^{2}-\mathrm{d}$ and averaged $36.5 \mathrm{gal} / \mathrm{ft}^{2}-\mathrm{d}$. Permeate temperature ranged from 75.3 to $91.0^{\circ} \mathrm{F}$ and averaged $84.2^{\circ} \mathrm{F}$. Concentrate temperature ranged from 84 to $100^{\circ} \mathrm{F}$ and averaged $92.8^{\circ} \mathrm{F}$.

\section{pH, Conductivity and Turbidity}

Permeate $\mathrm{pH}$ ranged from 2.6 to 3.6 with an average of 3.0. Concentrate $\mathrm{pH}$ ranged from 2.7 to 3.3 with an average of 2.9. Permeate conductivity ranged from 757 to 
$1201 \mu \mathrm{S} / \mathrm{cm}$ and averaged $1091 \mu \mathrm{S} / \mathrm{cm}$. Concentrate conductivity ranged from 1332 to $2500 \mu \mathrm{S} / \mathrm{cm}$ and averaged $1616 \mu \mathrm{S} / \mathrm{cm}$. Permeate turbidity ranged from 4.9 to $22.4 \mathrm{NTU}$ and averaged $8.8 \mathrm{NTU}$.

\section{UF1-R7-SR4 Cleaning After Acid}

After the acid cleaning and flush, the system was then cleaned again using a 0.3 $\%$ KLD solution for one-hour.

\section{Permeate Flux and Temperature}

During the second regular cleaning, the permeate flux ranged from 37.4 to 44.5 $\mathrm{gal} / \mathrm{ft}^{2}-\mathrm{d}$ and averaged $40.8 \mathrm{gal} / \mathrm{ft}^{2}-\mathrm{d}$. Permeate temperature ranged from 89.2 to $98.0^{\circ} \mathrm{F}$ and averaged $94.5^{\circ} \mathrm{F}$. Concentrate temperature ranged from 95 to $107^{\circ} \mathrm{F}$ and averaged $101^{\circ} \mathrm{F}$.

\section{pH, Conductivity and Turbidity}

Permeate $\mathrm{pH}$ ranged from 4.4 to 4.6 with an average of 4.5 . Concentrate $\mathrm{pH}$ ranged from 4.4 to 4.5 with an average of 4.5 . Permeate conductivity ranged from 380 to $419 \mu \mathrm{S} / \mathrm{cm}$ and averaged $399 \mu \mathrm{S} / \mathrm{cm}$. Concentrate conductivity ranged from 618 to $673 \mu$ S/cm and averaged $647 \mu \mathrm{S} / \mathrm{cm}$. Permeate turbidity ranged from 5.4 to $7.2 \mathrm{NTU}$ and averaged 6.0 NTU.

\section{UF1-R8}

UF1-R8 started on February 7, 1998 at 20:20 and ended on June 25, 1998 at 07:02. The run lasted for 125 days. The objectives of the run were: 1) monitor system 
performance, 2) estimate the volume of free oil that forms at the top of the concentrate tanks and 3) conduct an oil mass balance on the system in order to note the change occurring in the system.

In Figure 4.3, permeate flux versus time for UF1-R8 is presented. In Figure 4.4, permeate turbidity versus time for UF1-R8 is presented. In Table 4.10, a summary of permeate operating parameters for UF1-R8 is presented. In Table 4.11, a summary of operating concentrate parameters for UF1-R8 is presented. In Table 4.12, a summary of permeate cleaning parameters for UF1-R8 is presented. In Table 4.13, a summary of concentrate cleaning parameters for UF1-R8 is presented. In Table 4.14, a summary of permeate O/G samples analyzed for UF1-R8, is presented. In Table 4.15, a summary of concentrate oil content samples analyzed for UF1-R8, is presented. In Table 4.16, a summary of free oil skimming samples analyzed for UF1-R8, is presented. In Table 4.17, a summary of free oil production for UF1-R8 is presented. In Table 4.18, a summary of pond effluent samples analyzed for UF1-R8, is presented.

\section{UF1-R8-SR1}

UF1-R8-SR1 was started on February 7, 1998 at 20:20 and ended on February 18, 1998 at 00:00. The length of the subrun lasted 10.1 days. The system allowed to operate even though the permeate flux was lower than normal. The system was operated until the spongeball cleaning system was repaired. The total permeate volume produced was 364,800 gal. 


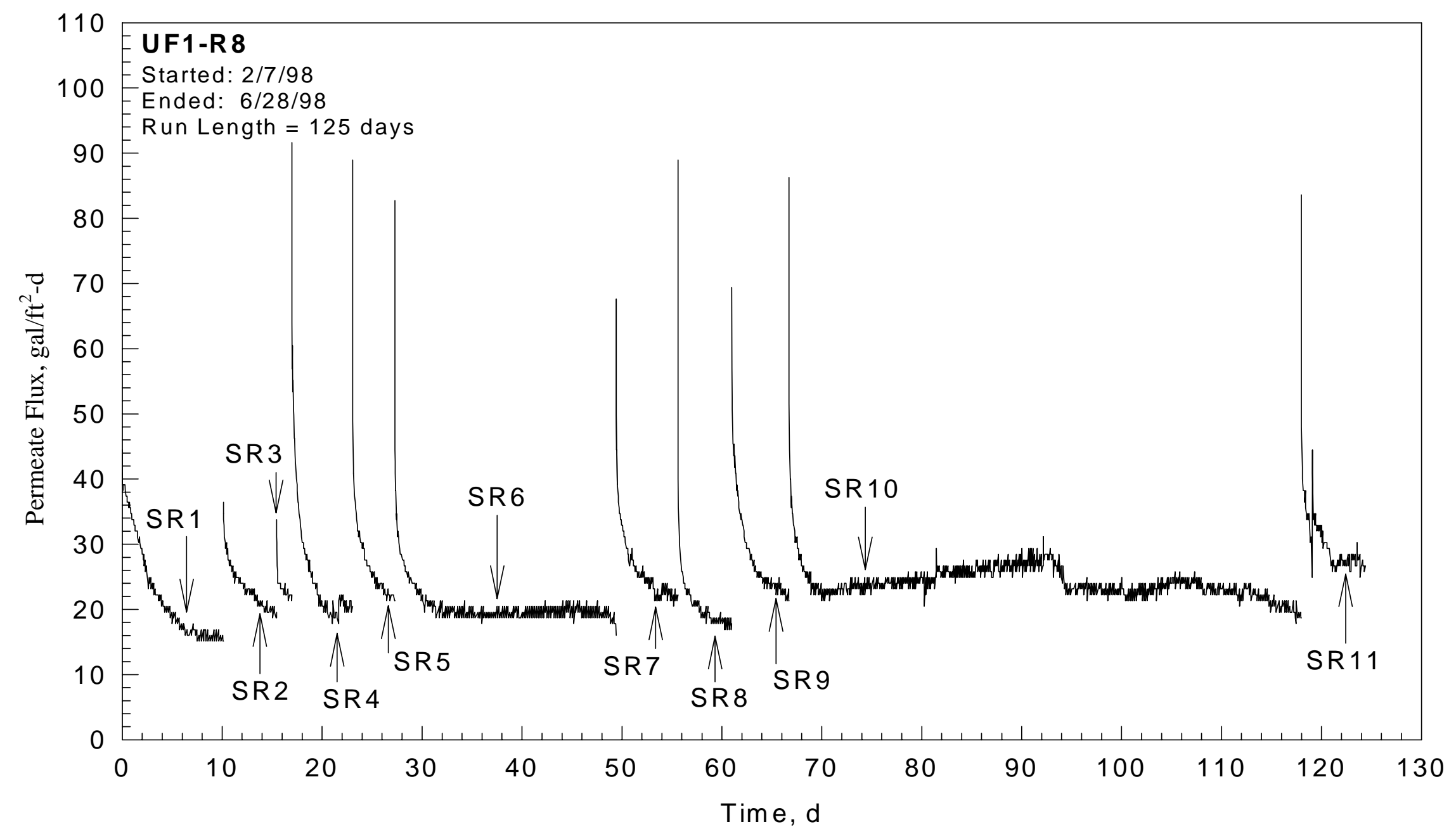

C. Figure 4.3 Permeate Flux versus Time for UF1-R8 


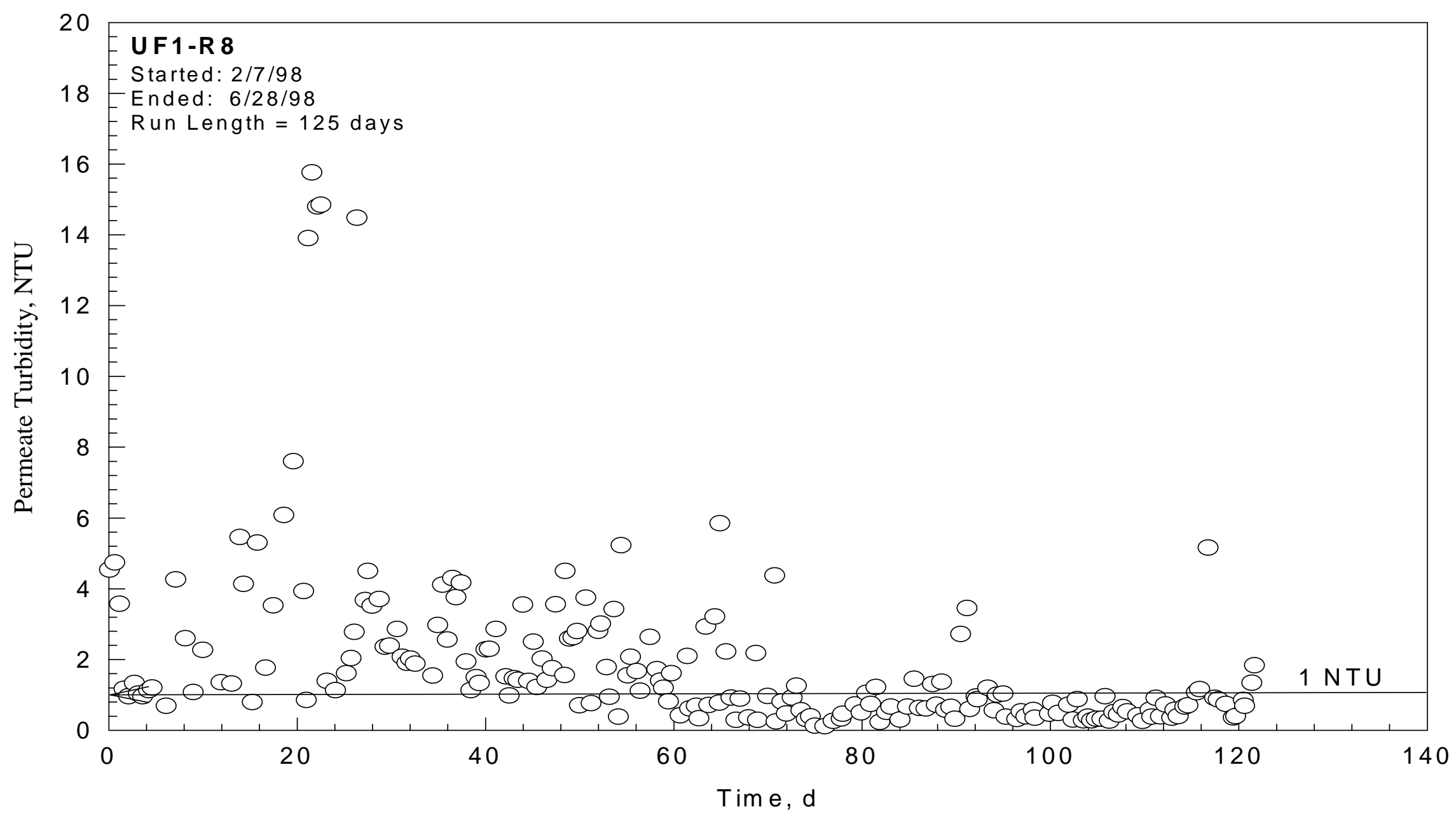

Figure 4.4 Permeate Turbidity versus Time for UF1-R8 
Table 4.10. Summary of Permeate Parameters for UF1-R8

\begin{tabular}{|c|c|c|c|c|c|c|}
\hline $\begin{array}{l}\text { Subrun } \\
\text { ID }\end{array}$ & $\begin{array}{c}\left.\text { Flux (gal/ft' }{ }^{2}-\mathbf{d}\right) \\
{[\mathrm{min}-\mathbf{m a x}]} \\
\text { Avg } \pm \text { std }\end{array}$ & $\begin{array}{l}\text { Temperature }\left({ }^{0} \mathbf{F}\right) \\
\quad[\min -\max ] \\
\text { Avg } \pm \text { std }\end{array}$ & $\begin{array}{c}\text { Turbidity (NTU) } \\
\text { [min - max }] \\
\text { Avg } \pm \text { std }\end{array}$ & $\begin{array}{c}\text { pH } \\
{[\min -\max ]} \\
\text { Avg } \pm \text { std }\end{array}$ & $\begin{array}{c}\text { Conductivity }(\mu \mathrm{S} / \mathrm{cm}) \\
{[\mathrm{min}-\max ]} \\
\text { Avg } \pm \text { std }\end{array}$ & $\begin{array}{c}\text { O/G (mg/L) } \\
{[\mathrm{min}-\max ]} \\
\text { Avg } \pm \text { std } \\
\end{array}$ \\
\hline 1 & $\begin{array}{c}{[15.1-44.5]} \\
24.8 \pm 8.6\end{array}$ & $\begin{array}{c}{[67.5-79.8]} \\
76.3 \pm 3.5\end{array}$ & $\begin{array}{c}{[0.69-4.7]} \\
2.1 \pm 1.5\end{array}$ & $\begin{array}{c}{[5.2-5.9]} \\
5.5 \pm 5.5\end{array}$ & $\begin{array}{c}{[87-501]} \\
403 \pm 107\end{array}$ & $\begin{array}{c}{[2.3-5.0]} \\
3.8 \pm 1.0\end{array}$ \\
\hline 2 & $\begin{array}{c}{[18.7-36.5]} \\
23.9 \pm 4.0\end{array}$ & $\begin{array}{c}{[75.7-79.6]} \\
77.6 \pm 1.8\end{array}$ & $\begin{array}{c}{[1.3-5.5]} \\
2.6 \pm 1.9\end{array}$ & $\begin{array}{c}{[4.3-6.4]} \\
5.1 \pm 0.9\end{array}$ & $\begin{array}{c}{[467-637]} \\
529 \pm 94\end{array}$ & $\begin{array}{l}{[4-5]} \\
4.5 \pm 0.7\end{array}$ \\
\hline 3 & $\begin{array}{c}{[21.3-33.8]} \\
24.6 \pm 3.5\end{array}$ & $\begin{array}{c}{[76.0-76.5]} \\
76.3 \pm 0.35\end{array}$ & $\begin{array}{c}{[0.79-4.1]} \\
2.5 \pm 2.4\end{array}$ & $\begin{array}{c}{[5.7-5.8]} \\
5.8 \pm 0.10\end{array}$ & $\begin{array}{c}{[439-491]} \\
465 \pm 37\end{array}$ & $\begin{array}{c}{[4]} \\
4 \pm 0.0\end{array}$ \\
\hline 4 & $\begin{array}{c}{[17.8-91.6]} \\
29.7 \pm 13.4\end{array}$ & $\begin{array}{c}{[72.9-76.5]} \\
75.6 \pm 1.4\end{array}$ & $\begin{array}{c}{[0.85-7.6]} \\
4.2 \pm 2.4\end{array}$ & $\begin{array}{c}{[4.1-5.5]} \\
5.2 \pm 0.48\end{array}$ & $\begin{array}{c}{[268-431]} \\
361 \pm 50\end{array}$ & $\begin{array}{c}{[6]} \\
6 \pm 0.0\end{array}$ \\
\hline 5 & $\begin{array}{c}{[19.6-88.9]} \\
28.6 \pm 10.8\end{array}$ & $\begin{array}{c}{[71.8-78.2]} \\
74.7 \pm 1.8\end{array}$ & $\begin{array}{c}{[1.1-17.5]} \\
8.0 \pm 7.4\end{array}$ & $\begin{array}{c}{[4.5-6.4]} \\
5.6 \pm 0.58\end{array}$ & $\begin{array}{c}{[207-382]} \\
300 \pm 57\end{array}$ & $\begin{array}{c}{[5]} \\
5 \pm 0.0\end{array}$ \\
\hline 6 & $\begin{array}{c}{[16.0-82.7]} \\
21.7 \pm 6.4\end{array}$ & $\begin{array}{c}{[71.8-81.5]} \\
78.4 \pm 2.5\end{array}$ & $\begin{array}{c}{[0.98-14.5]} \\
2.7 \pm 2.2\end{array}$ & $\begin{array}{c}{[4.4-6.3]} \\
5.1 \pm 0.5\end{array}$ & $\begin{array}{c}{[111-391]} \\
287 \pm 77\end{array}$ & $\begin{array}{l}{[1-5]} \\
2.8 \pm 1.7\end{array}$ \\
\hline 7 & $\begin{array}{c}{[20.5-67.6]} \\
27.7 \pm 7.7\end{array}$ & $\begin{array}{c}{[73.9-79.6]} \\
77.4 \pm 1.8\end{array}$ & $\begin{array}{c}{[0.4-4.5]} \\
2.3 \pm 1.3\end{array}$ & $\begin{array}{c}{[4.8-5.7]} \\
5.3 \pm 0.3\end{array}$ & $\begin{array}{c}{[236-604]} \\
350 \pm 109\end{array}$ & $\begin{array}{c}{[3-4]} \\
3.5 \pm 0.7\end{array}$ \\
\hline 8 & $\begin{array}{c}{[16.9-88.9]} \\
23.0 \pm 10.4\end{array}$ & $\begin{array}{c}{[73.7-82.6]} \\
79.4 \pm 2.8\end{array}$ & $\begin{array}{c}{[0.8-5.2]} \\
1.9 \pm 1.3\end{array}$ & $\begin{array}{c}{[5.1-6.3]} \\
5.4 \pm 0.3\end{array}$ & $\begin{array}{c}{[285-450]} \\
410 \pm 110\end{array}$ & $\begin{array}{c}{[3-5]} \\
3.7 \pm 1.2\end{array}$ \\
\hline 9 & $\begin{array}{c}{[21.3-69.4]} \\
30.0 \pm 9.1\end{array}$ & $\begin{array}{c}{[75.8-80.9]} \\
78.3 \pm 1.7\end{array}$ & $\begin{array}{c}{[0.3-3.2]} \\
1.3 \pm 1.1\end{array}$ & $\begin{array}{c}{[5.0-5.4]} \\
5.2 \pm 0.1\end{array}$ & $\begin{array}{c}{[138-464]} \\
312 \pm 109\end{array}$ & $\begin{array}{l}{[1-3]} \\
2.0 \pm 1.4\end{array}$ \\
\hline 10 & $\begin{array}{c}{[20.5-86.3]} \\
25.6 \pm 6.9\end{array}$ & $\begin{array}{c}{[78.3-89.7]} \\
83.6 \pm 2.7\end{array}$ & $\begin{array}{c}{[0.11-5.8]} \\
0.80 \pm 0.9\end{array}$ & $\begin{array}{c}{[4.8-6.1]} \\
5.5 \pm 0.3\end{array}$ & $\begin{array}{c}{[101-687]} \\
341 \pm 122\end{array}$ & $\begin{array}{l}{[1-9]} \\
3.9 \pm 2.5\end{array}$ \\
\hline 11 & $\begin{array}{c}{[24.9-83.6]} \\
31.9 \pm 8.9 \\
\end{array}$ & $\begin{array}{c}{[85.8-90.3]} \\
87.6 \pm 2.3 \\
\end{array}$ & $\begin{array}{c}{[228-476]} \\
346 \pm 82 \\
\end{array}$ & $\begin{array}{c}{[4.8-7.1]} \\
5.4 \pm 0.4 \\
\end{array}$ & $\begin{array}{c}{[228-476]} \\
346 \pm 116 \\
\end{array}$ & $\begin{array}{c}{[2-5]} \\
3.2 \pm 1.1 \\
\end{array}$ \\
\hline
\end{tabular}


Table 4.11. Summary of Concentrate and Pond Effluent Parameters for UF1-R8

\begin{tabular}{|c|c|c|c|c|c|}
\hline $\begin{array}{l}\text { Subrun } \\
\text { ID }\end{array}$ & $\begin{array}{l}\text { Temperature }\left({ }^{0} \mathrm{~F}\right) \\
{[\mathrm{min}-\max ]} \\
\text { Avg } \pm \text { std }\end{array}$ & $\begin{array}{c}\text { pH } \\
{[\underset{\min }{\text { Avg } \pm \text { max }]}}\end{array}$ & $\begin{array}{c}\text { Conductivity }(\mu \mathrm{S} / \mathrm{cm}) \\
{[\mathrm{min}-\max ]} \\
\text { Avg } \pm \text { std }\end{array}$ & $\begin{array}{l}\text { Oil Content (\%) } \\
\text { [min - max }] \\
\text { Avg } \pm \text { std }\end{array}$ & $\begin{array}{c}\text { Pond Effluent } \mathrm{O} / \mathrm{G}(\mathrm{mg} / \mathrm{L}) \\
{[\min -\max ]} \\
\text { Avg } \pm \text { std }\end{array}$ \\
\hline 1 & $\begin{array}{c}70.8-84.3] \\
79.8 \pm 4.0\end{array}$ & $\begin{array}{c}{[5.2-5.6]} \\
5.4 \pm 0.15\end{array}$ & $\begin{array}{c}110-470] \\
302 \pm 134\end{array}$ & $\begin{array}{c}{[0.67-2.6]} \\
1.6 \pm 1.4\end{array}$ & $\begin{array}{c}{[0.6-0.7]} \\
0.63\end{array}$ \\
\hline 2 & $\begin{array}{c}{[79.2-82.6]} \\
81.3 \pm 1.5\end{array}$ & $\begin{array}{c}{[4.4-5.3]} \\
4.8 \pm 0.62\end{array}$ & $\begin{array}{c}{[104-373]} \\
238 \pm 191\end{array}$ & $\begin{array}{c}2.6-3.6] \\
3.1 \pm 0.7\end{array}$ & $\begin{array}{c}{[0.6-0.7]} \\
0.65\end{array}$ \\
\hline 3 & $\begin{array}{c}{[79.8-81.9]} \\
80.9 \pm 1.5\end{array}$ & $\begin{array}{c}6.1] \\
6.1 \pm 0.0\end{array}$ & $\begin{array}{c}{[292]} \\
292 \pm 0.0\end{array}$ & $\begin{array}{c}{[3.6-4.0]} \\
3.8 \pm 0.3\end{array}$ & $\begin{array}{c}{[0.6]} \\
0.6\end{array}$ \\
\hline 4 & $\begin{array}{c}{[75.7-80.7]} \\
79.6 \pm 2.0\end{array}$ & $\begin{array}{c}{[5.2-5.9]} \\
5.5 \pm 0.47\end{array}$ & $\begin{array}{c}{[183-534]} \\
359 \pm 248\end{array}$ & $\begin{array}{c}{[4.0-5.4]} \\
4.7 \pm 0.9 \\
\end{array}$ & $\begin{array}{c}0.6] \\
0.6 \\
\end{array}$ \\
\hline 5 & $\begin{array}{c}{[77.9-80.8]} \\
79.0 \pm 1.0\end{array}$ & $\begin{array}{c}{[5.3-6.3]} \\
5.9 \pm 0.44 \\
\end{array}$ & $\begin{array}{c}{[147-333]} \\
247 \pm 90\end{array}$ & $\begin{array}{c}{[5.4-6.8]} \\
6.1 \pm 1.0 \\
\end{array}$ & $\begin{array}{c}{[0.7]} \\
0.7 \\
\end{array}$ \\
\hline 6 & $\begin{array}{c}{[76.0-85.0]} \\
81.9 \pm 2.2\end{array}$ & $\begin{array}{c}{[4.6-6.2]} \\
5.3 \pm 0.4\end{array}$ & $\begin{array}{c}{[204-501]} \\
355 \pm 105\end{array}$ & $\begin{array}{c}{[6.8-11.5]} \\
8.9 \pm 2.4\end{array}$ & $\begin{array}{c}{[0.6-0.7]} \\
0.68 \\
\end{array}$ \\
\hline 7 & $\begin{array}{c}{[78.3-79.6]} \\
81.1 \pm 1.6\end{array}$ & $\begin{array}{c}{[5.2-6.0]} \\
5.4 \pm 0.3 \\
\end{array}$ & $\begin{array}{c}170-486] \\
354 \pm 110 \\
\end{array}$ & $\begin{array}{c}{[11.5-11.0]} \\
10.6 \pm 1.0\end{array}$ & $\begin{array}{c}0.7-0.8] \\
0.73 \\
\end{array}$ \\
\hline 8 & $\begin{array}{r}{[80-86]} \\
83.3 \pm 2.2 \\
\end{array}$ & $\begin{array}{c}5.3-5.6] \\
5.4 \pm 0.1 \\
\end{array}$ & $\begin{array}{c}267-492] \\
415 \pm 110 \\
\end{array}$ & $\begin{array}{c}{[11.0-10.5]} \\
10.8 \pm 0.5\end{array}$ & $\begin{array}{c}0.7-0.9] \\
0.8 \\
\end{array}$ \\
\hline 9 & $\begin{array}{c}{[78.1-83.6]} \\
81.5 \pm 1.6 \\
\end{array}$ & $\begin{array}{c}{[5.2-5.4]} \\
5.3 \pm 0.1 \\
\end{array}$ & $\begin{array}{c}{[212-431]} \\
342 \pm 109\end{array}$ & $\begin{array}{c}{[8.8-9.8]} \\
9.3 \pm 0.7 \\
\end{array}$ & $\begin{array}{r}0.8] \\
0.8 \\
\end{array}$ \\
\hline 10 & $\begin{array}{c}80.7-92.4] \\
87.3 \pm 2.9\end{array}$ & $\begin{array}{c}{[4.9-5.9]} \\
5.5 \pm 0.3\end{array}$ & $\begin{array}{c}{[220-523]} \\
406 \pm 72\end{array}$ & $\begin{array}{c}{[10.2-3.0]} \\
8.9 \pm 3.6\end{array}$ & $\begin{array}{c}{[0.3-0.8]} \\
0.72\end{array}$ \\
\hline 11 & $\begin{array}{c}91.2-92] \\
91.5 \pm 0.2 \\
\end{array}$ & $\begin{array}{c}{[5.2-5.5]} \\
5.4 \pm 0.3 \\
\end{array}$ & $\begin{array}{c}{[441-555]} \\
498 \pm 89\end{array}$ & $\begin{array}{c}{[3.0-4.5]} \\
3.7 \pm 0.7 \\
\end{array}$ & $\begin{array}{c}0.7-0.9] \\
0.83 \\
\end{array}$ \\
\hline
\end{tabular}


Table 4.12. Summary of Permeate Cleaning Parameters for UF1-R8

\begin{tabular}{|c|c|c|c|c|c|}
\hline $\begin{array}{l}\text { Subrun } \\
\text { ID }\end{array}$ & $\begin{array}{c}\left.\text { Flux (gal/ft' }{ }^{2}-\mathbf{d}\right) \\
{[\mathrm{min}-\max ]} \\
\text { Avg } \pm \text { std }\end{array}$ & $\begin{array}{l}\text { Temperature }\left({ }^{\mathrm{O}} \mathrm{F}\right) \\
{[\mathrm{min}-\mathrm{max}]} \\
\text { Avg } \pm \text { std }\end{array}$ & $\begin{array}{c}\text { Turbidity (NTU) } \\
\text { [min - max }] \\
\text { Avg } \pm \text { std }\end{array}$ & $\begin{array}{c}\text { pH } \\
{[\min -\max ]} \\
\text { Avg } \pm \text { std }\end{array}$ & $\begin{array}{c}\text { Conductivity }(\mu \mathrm{S} / \mathrm{cm}) \\
{[\mathrm{min}-\max ]} \\
\operatorname{Avg} \pm \text { std }\end{array}$ \\
\hline 1 & $\begin{array}{c}{[24.0-43.5]} \\
35.2 \pm 6.0\end{array}$ & $\begin{array}{c}{[80.4-97.6]} \\
89.6 \pm 6.1\end{array}$ & $\begin{array}{c}{[5.6-44.9]} \\
14.8 \pm 13.9 \\
\end{array}$ & $\begin{array}{c}{[6.0-6.1]} \\
6.0 \pm 0.1 \\
\end{array}$ & $\begin{array}{c}{[522-639]} \\
581 \pm 46\end{array}$ \\
\hline 2 & $\begin{array}{c}{[32.0-35.6]} \\
33.9 \pm 0.7\end{array}$ & $\begin{array}{c}{[91.5-98.4]} \\
96.3 \pm 2.5\end{array}$ & $\begin{array}{c}{[3.7-9.7]} \\
4.9 \pm 2.4\end{array}$ & NA & $\begin{array}{c}{[454-617]} \\
537 \pm 58 \\
\end{array}$ \\
\hline 3 & $\begin{array}{c}{[103.2-128.1]} \\
115.9 \pm 1.7\end{array}$ & $\begin{array}{c}{[90.1-97.5]} \\
93.9 \pm 1.9\end{array}$ & $\begin{array}{c}{[2.2-4.1]} \\
3.1 \pm 0.8\end{array}$ & $\begin{array}{c}{[8.8-9.2]} \\
9.1 \pm 0.2\end{array}$ & $\begin{array}{c}{[723-802]} \\
770 \pm 27\end{array}$ \\
\hline 4 & $\begin{array}{c}{[76.5-115.6]} \\
95.1 \pm 2.0\end{array}$ & $\begin{array}{c}{[110-112.8]} \\
111.9 \pm 1.6\end{array}$ & $\begin{array}{c}{[3.6-8.3]} \\
4.8 \pm 2.0\end{array}$ & $\begin{array}{c}{[6.5-6.7]} \\
6.6 \pm 0.10\end{array}$ & $\begin{array}{c}{[507-592]} \\
560 \pm 35\end{array}$ \\
\hline 5 & $\begin{array}{c}{[80-108.5]} \\
92.5 \pm 2.4\end{array}$ & $\begin{array}{c}{[110.6-114.1]} \\
111.8 \pm 1.1\end{array}$ & $\begin{array}{c}{[3.2-9.5]} \\
6.1 \pm 2.3 \\
\end{array}$ & $\begin{array}{c}{[8.5-9.5]} \\
9.1 \pm 0.5\end{array}$ & $\begin{array}{c}{[479-1430]} \\
957 \pm 428\end{array}$ \\
\hline 6 & $\begin{array}{c}{[65.8-97.8]} \\
81.1 \pm 3.3\end{array}$ & $\begin{array}{c}{[109-112.9]} \\
110.9 \pm 2.0\end{array}$ & $\begin{array}{c}{[2.9-6.3]} \\
4.4 \pm 1.6\end{array}$ & $\begin{array}{c}{[5.4-5.9]} \\
5.7 \pm 0.2\end{array}$ & $\begin{array}{c}{[281-614]} \\
453 \pm 158\end{array}$ \\
\hline 7 & $\begin{array}{c}{[57.8-99.6]} \\
78.6 \pm 3.4\end{array}$ & $\begin{array}{c}{[114.3-119.2]} \\
116.2 \pm 1.2\end{array}$ & $\begin{array}{c}{[2.0-5.6]} \\
3.8 \pm 1.9\end{array}$ & $\begin{array}{c}{[8.4-9.2]} \\
8.9 \pm 0.4\end{array}$ & $\begin{array}{c}{[353-714]} \\
544 \pm 173 \\
\end{array}$ \\
\hline 8 & $\begin{array}{c}{[119.2-140.5]} \\
129.5 \pm 3.5\end{array}$ & $\begin{array}{c}{[114.1-119.2]} \\
115.1 \pm 1.2\end{array}$ & $\begin{array}{c}{[0.6-6.0]} \\
1.6 \pm 2.2 \\
\end{array}$ & $\begin{array}{c}{[9.3-9.9]} \\
9.6 \pm 0.4\end{array}$ & $\begin{array}{c}{[1285-2260]} \\
1773 \pm 481\end{array}$ \\
\hline 9 & $\begin{array}{c}{[88.9-126.3]} \\
106.5 \pm 2.6\end{array}$ & $\begin{array}{c}{[89.1-111.1]} \\
99.8 \pm 0.9\end{array}$ & $\begin{array}{c}{[1.6-3.0]} \\
2.2 \pm 0.6\end{array}$ & $\begin{array}{c}{[6.2-6.3]} \\
6.3 \pm 0.04\end{array}$ & $\begin{array}{c}{[733-874]} \\
819 \pm 60\end{array}$ \\
\hline 10 & $\begin{array}{c}{[69.4-103.2]} \\
86.2 \pm 1.1\end{array}$ & $\begin{array}{c}{[111.8-118.2]} \\
114.5 \pm 4.2\end{array}$ & $\begin{array}{c}{[1.0-6.5]} \\
2.7 \pm 2.6\end{array}$ & $\begin{array}{c}{[9.4-9.6]} \\
9.5 \pm 0.1\end{array}$ & $\begin{array}{c}{[922-1144]} \\
1041 \pm 94\end{array}$ \\
\hline 11 & $\begin{array}{c}72.4-128.0] \\
88.3 \pm 2.3 \\
\end{array}$ & $\begin{array}{c}111.4-118.2] \\
115.2 \pm 2.2 \\
\end{array}$ & $\begin{array}{c}{[1.2-7.5]} \\
2.2 \pm 1.2 \\
\end{array}$ & $\begin{array}{c}{[9.5-9.8]} \\
9.6 \pm 0.1 \\
\end{array}$ & $\begin{array}{c}{[858-1211]} \\
1069 \pm 56\end{array}$ \\
\hline
\end{tabular}


Table 4.13. Summary of Concentrate Cleaning Parameters for UF1-R8

\begin{tabular}{|c|c|c|c|}
\hline $\begin{array}{l}\text { Subrun } \\
\text { ID }\end{array}$ & $\begin{array}{l}\text { Temperature }\left({ }^{0} \mathbf{F}\right) \\
{[\min -\max ]} \\
\text { Avg } \pm \text { std }\end{array}$ & $\begin{array}{c}\mathbf{p H} \\
{[\min -\max ]} \\
\text { Avg } \pm \text { std } \\
\end{array}$ & $\begin{array}{c}\text { Conductivity }(\mu \mathrm{S} / \mathrm{cm}) \\
{[\mathrm{min}-\max ]} \\
\text { Avg } \pm \text { std }\end{array}$ \\
\hline 1 & $\begin{array}{c}{[82.5-106.7]} \\
95.7 \pm 7.7\end{array}$ & $\begin{array}{c}6.3-6.7] \\
6.4 \pm 0.2\end{array}$ & $\begin{array}{c}{[1345-1542]} \\
1443 \pm 93\end{array}$ \\
\hline 2 & $\begin{array}{c}98-107] \\
104 \pm 3.5 \\
\end{array}$ & NA & $\begin{array}{c}{[827-1245]} \\
1036 \pm 173 \\
\end{array}$ \\
\hline 3 & $\begin{array}{c}{[94.4-105.3]} \\
100 \pm 2.2\end{array}$ & $\begin{array}{c}{[9.0-9.2]} \\
9.1 \pm 0.1\end{array}$ & $\begin{array}{c}{[1798-1970]} \\
1876 \pm 65\end{array}$ \\
\hline 4 & $\begin{array}{c}{[117.4-124.3]} \\
121 \pm 2.8\end{array}$ & $\begin{array}{c}{[6.7-6.9]} \\
6.8 \pm 0.10\end{array}$ & $\begin{array}{c}{[924-1411]} \\
1162 \pm 253\end{array}$ \\
\hline 5 & $\begin{array}{c}119.7-124.9] \\
121.2 \pm 1.5 \\
\end{array}$ & $\begin{array}{c}{[8.5-9.6]} \\
9.1 \pm 0.5 \\
\end{array}$ & $\begin{array}{c}{[985-2300]} \\
1725 \pm 641 \\
\end{array}$ \\
\hline 6 & $\begin{array}{c}{[118-124.9]} \\
120 \pm 1.6 \\
\end{array}$ & $\begin{array}{c}{[6.0-6.3]} \\
6.2 \pm 0.2 \\
\end{array}$ & $\begin{array}{c}{[264-1043]} \\
776 \pm 348 \\
\end{array}$ \\
\hline 7 & $\begin{array}{c}{[121-128.8]} \\
123.2 \pm 2.2\end{array}$ & $\begin{array}{c}{[8.5-9.3]} \\
8.9 \pm 0.4\end{array}$ & $\begin{array}{c}{[712-1425]} \\
1113 \pm 343\end{array}$ \\
\hline 8 & $\begin{array}{c}{[120.5-128.8]} \\
123.4 \pm 2.4\end{array}$ & $\begin{array}{c}{[9.3-10.0]} \\
9.7 \pm 0.4\end{array}$ & $\begin{array}{c}{[1973-2920]} \\
2419 \pm 468 \\
\end{array}$ \\
\hline 9 & $\begin{array}{c}96-122.5] \\
108.6 \pm 2.1\end{array}$ & $\begin{array}{c}{[6.4-6.5]} \\
6.5 \pm 0.1\end{array}$ & $\begin{array}{c}{[1228-1433]} \\
1358 \pm 113\end{array}$ \\
\hline 10 & $\begin{array}{c}{[121-126]} \\
122.8 \pm 3.3\end{array}$ & $\begin{array}{c}{[9.5-9.6]} \\
9.5 \pm 0.1\end{array}$ & $\begin{array}{c}{[959-2230]} \\
1615 \pm 620\end{array}$ \\
\hline 11 & $\begin{array}{c}{[120-125]} \\
123.3 \pm 2.6\end{array}$ & $\begin{array}{c}{[9.6-10.0]} \\
9.7 \pm 1.2\end{array}$ & $\begin{array}{c}{[1025-2330]} \\
1725 \pm 255\end{array}$ \\
\hline
\end{tabular}


Table 4.14 Summary of Permeate O/G Samples for UF1-R8

\begin{tabular}{|c|c|c|c|c|}
\hline \multirow[t]{2}{*}{ Subrun ID } & \multirow[t]{2}{*}{ Date/Time } & \multicolumn{3}{|c|}{ Sample Results (mg/L) } \\
\hline & & $\# 1$ & $\# 2$ & $\# 3$ \\
\hline 1 & $2 / 7 / 98(22: 37)$ & 2 & 3 & 2 \\
\hline 1 & 2/8/98 (23:35) & 3 & & \\
\hline 1 & $2 / 9 / 98 \quad(22: 33)$ & 4 & & \\
\hline 1 & $2 / 11 / 98(01: 11)$ & 5 & & \\
\hline 1 & 2/12/98 (03:03) & 4 & & \\
\hline 1 & 2/13/98 (22:59) & 3 & & \\
\hline 1 & $2 / 16 / 98(00: 38)$ & 4 & 5 & 5 \\
\hline 2 & $2 / 19 / 98(02: 43)$ & 5 & & \\
\hline 2 & 2/23/98 (01:18) & 4 & & \\
\hline 3 & 2/25/98 (01:56) & 6 & & \\
\hline 4 & $3 / 2 / 98(21: 23)$ & 6 & & \\
\hline 5 & $3 / 7 / 98(02: 50)$ & 5 & & \\
\hline 5 & 3/11/98 (04:39) & 5 & & \\
\hline 6 & 3/15/98 (04:00) & 3 & 3 & 3 \\
\hline 6 & $3 / 21 / 98(12: 23)$ & 2 & & \\
\hline 6 & 3/23/98 (09:05) & 1 & & \\
\hline 6 & $3 / 29 / 98(18: 24)$ & 3 & & \\
\hline 6 & $3 / 30 / 98(19: 02)$ & 3 & & \\
\hline 6 & 4/2/98 (07:02) & 5 & & \\
\hline 7 & 4/5/98 (09:40) & 4 & & \\
\hline 7 & 4/9/98 (13:10) & 3 & & \\
\hline 8 & 4/11/98 (10:15) & 3 & & \\
\hline 8 & 4/14/98 (04:21) & 5 & 5 & 5 \\
\hline 8 & 4/15/98 (15:32) & 3 & & \\
\hline 9 & 4/19/98 (01:30) & 3 & & \\
\hline 9 & $4 / 21 / 98(19: 55)$ & 1 & & \\
\hline 10 & 4/23/98 (19:05) & 8 & & \\
\hline 10 & 4/27/98 (05:16) & 4 & & \\
\hline 10 & 4/30/98 (12:04) & 1 & & \\
\hline 10 & 5/3/98 (01:50) & 2 & & \\
\hline 10 & 5/6/98 (15:30) & 3 & & \\
\hline 10 & $5 / 10 / 98(14: 16)$ & 4 & 3 & 4 \\
\hline 10 & 5/13/98 (02:02) & 5 & & \\
\hline 10 & $5 / 21 / 98(16: 14)$ & 9 & & \\
\hline 10 & $5 / 29 / 989 \quad(09: 45)$ & 3 & & \\
\hline 10 & $6 / 5 / 98 \quad(11: 45)$ & 2 & & \\
\hline 10 & 6/11/98 (23:01) & 2 & & \\
\hline 11 & 6/19/98 (14:11) & 5 & & \\
\hline 11 & 6/21/98 (03:40) & 4 & & \\
\hline 11 & $6 / 24 / 98(11: 30)$ & 3 & & \\
\hline
\end{tabular}


Table 4.15 Summary of Concentrate Oil Content Samples for UF1-R8

\begin{tabular}{|c|c|c|c|c|}
\hline \multirow[t]{2}{*}{ Subrun ID } & \multirow[t]{2}{*}{ Date/Time } & \multicolumn{3}{|c|}{ Sample Results (\%) } \\
\hline & & $\# 1$ & $\# 2$ & \#3 \\
\hline 1 & 2/7/98 (20:00) & 0.7 & 0.6 & 0.7 \\
\hline 1 & $2 / 10 / 98(22: 35)$ & 2.4 & & \\
\hline 1 & 2/13/98 (23:39) & 2.3 & & \\
\hline 1 & $2 / 17 / 98(23: 50)$ & 2.6 & 2.8 & 2.4 \\
\hline 2 & 2/18/98 (03:05) & 2.7 & 2.4 & 2.6 \\
\hline 2 & $2 / 23 / 98(10: 56)$ & 3.6 & 3.6 & 3.6 \\
\hline 3 & 2/25/98 (06:46) & 4.1 & 4.0 & 4.1 \\
\hline 3 & $2 / 28 / 98(16: 25)$ & 4.3 & & \\
\hline 4 & 3/6/98 (17:30) & 5.4 & & \\
\hline 5 & $3 / 12 / 98(05: 40)$ & 6.8 & 6.8 & 6.6 \\
\hline 6 & $3 / 19 / 98(11: 32)$ & 9.0 & & \\
\hline 6 & 4/3/98 (02:03) & 11.5 & 11.1 & 11.5 \\
\hline 7 & 4/10/98 (10:12) & 11.0 & & \\
\hline 8 & 4/16/98 (01:50) & 10.5 & & \\
\hline 9 & 4/17/98 (12:20) & 8.8 & & \\
\hline 9 & 4/23/98 (08:40) & 9.8 & & \\
\hline 10 & 4/23/98 (18:32) & 10.2 & 10.5 & 10.2 \\
\hline 10 & 4/24/98 (08:23) & 12.3 & & \\
\hline 10 & 4/29/98 (05:26) & 12.8 & & \\
\hline 10 & 4/30/98 (12:56) & 9.5 & & \\
\hline 10 & 5/6/98 (13:55) & 9.6 & & \\
\hline 10 & 5/12/98 (02:01) & 11.9 & & \\
\hline 10 & 5/13/98 (11:22) & 12.0 & 12.1 & 11.8 \\
\hline 10 & $5 / 22 / 98(09: 35)$ & 4.5 & & \\
\hline 10 & $5 / 28 / 98(11: 01)$ & 6.5 & & \\
\hline 10 & 5/30/98 (08:44) & 8.8 & & \\
\hline 10 & $6 / 6 / 98(12: 45)$ & 9.3 & & \\
\hline 10 & $6 / 10 / 98(12: 22)$ & 2.5 & & \\
\hline 10 & $6 / 16 / 98(10: 30)$ & 3.0 & 3.2 & 3.0 \\
\hline 11 & 6/25/98 (06:57) & 4.5 & & \\
\hline
\end{tabular}


Table 4.16 Summary of Skimming Samples for UF1-R8

\begin{tabular}{|c|c|c|c|c|}
\hline \multirow[t]{2}{*}{ Subrun ID } & \multirow[t]{2}{*}{ Date/Time } & \multicolumn{3}{|c|}{ Sample Results (\%) } \\
\hline & & $\# 1$ & $\# 2$ & $\# 3$ \\
\hline 1 & 2/8/98 (12:04) & 99 & & \\
\hline 1 & $2 / 17 / 98(23: 00)$ & 100 & & \\
\hline 2 & 2/19/98 (03:00) & 100 & & \\
\hline 2 & $2 / 21 / 98(15: 30)$ & 98 & & \\
\hline 3 & $2 / 26 / 98(11: 01)$ & 100 & 99 & 100 \\
\hline 4 & $3 / 7 / 98 \quad(05: 30)$ & 100 & & \\
\hline 5 & $3 / 13 / 98(12: 20)$ & 99 & & \\
\hline 6 & $3 / 23 / 98(11: 22)$ & 99 & & \\
\hline 6 & $3 / 28 / 98(10: 10)$ & 98 & & \\
\hline 7 & 4/8/98 (09:30) & 100 & & \\
\hline 8 & 4/15/98 (10:45) & 100 & & \\
\hline 9 & 4/21/98 (08:40) & 99 & & \\
\hline 10 & $4 / 25 / 98(12: 20)$ & 98 & & \\
\hline 10 & 4/30/98 (16:20) & 98 & & \\
\hline 10 & $5 / 15 / 98(11: 19)$ & 100 & 100 & 98 \\
\hline 10 & $5 / 27 / 98(13: 31)$ & 100 & & \\
\hline 10 & $6 / 5 / 98 \quad(09: 59)$ & 100 & & \\
\hline 11 & 6/19/98 (09:05) & 99 & & \\
\hline
\end{tabular}


Table 4.17 Summary of Free Oil Productions for UF1-R8

\begin{tabular}{|c|c|c|c||}
\hline Subrun ID & Subrun Length, d & Total Free Oil, gal & Free Oil Production, gal/d \\
\hline \hline 1 & 10.1 & 2,056 & 203.6 \\
\hline 2 & 5.2 & 1,267 & 243.7 \\
\hline 3 & 1.5 & 316 & 210.7 \\
\hline 4 & 6.1 & 1,679 & 275.2 \\
\hline 5 & 5.3 & 2,304 & 434.7 \\
\hline 6 & 22.4 & 4,936 & 221.3 \\
\hline 7 & 6.2 & 2,316 & 373.5 \\
\hline 8 & 5.4 & 1,589 & 294.3 \\
\hline 9 & 5.7 & 2,068 & 362.8 \\
\hline 10 & 51.3 & 26,823 & 522.8 \\
\hline 11 & 6.5 & 4,130 & 635.4 \\
\hline
\end{tabular}


Table 4.18 Summary of Pond Effluent O/G Samples for UF1-R8

\begin{tabular}{|c|c|c|c|c|}
\hline \multirow[t]{2}{*}{ Subrun ID } & \multirow[t]{2}{*}{ Date/Time } & \multicolumn{3}{|c|}{ Sample Results (mg/L) } \\
\hline & & $\# 1$ & $\# 2$ & $\# 3$ \\
\hline 1 & $2 / 7 / 98(19: 45)$ & 6,000 & & \\
\hline 1 & $2 / 10 / 98(14: 30)$ & 6,000 & & \\
\hline 1 & 2/13/98 (14:00) & 7,000 & & \\
\hline 1 & $2 / 15 / 98(13: 45)$ & 6,000 & & \\
\hline 2 & $2 / 20 / 98(02: 55)$ & 6,000 & & \\
\hline 2 & 2/22/98 (04:32) & 7,000 & & \\
\hline 3 & $2 / 24 / 98(21: 53)$ & 6,000 & & \\
\hline 4 & $3 / 1 / 98(00: 15)$ & 6,000 & & \\
\hline 4 & $3 / 2 / 98(21: 15)$ & 6,000 & 6,000 & 6,000 \\
\hline 4 & $3 / 5 / 98(04: 10)$ & 6,000 & & \\
\hline 5 & 3/9/98 (03:25) & 6,000 & & \\
\hline 6 & 3/13/98 (23:10) & 6,000 & & \\
\hline 6 & $3 / 25 / 98(15: 30)$ & 7,000 & & \\
\hline 6 & $3 / 29 / 98(09: 50)$ & 6,000 & & \\
\hline 7 & 4/6/98 (05:30) & 7,000 & & \\
\hline 7 & 4/9/98 (15:11) & 7,000 & & \\
\hline 8 & 4/12/98 (08:05) & 8,000 & & \\
\hline 8 & 4/15/98 (16:40) & 7,000 & & \\
\hline 9 & 4/19/98 (16:50) & 7,000 & 6,000 & 7,000 \\
\hline 10 & 4/24/98 (01:20) & 7,000 & & \\
\hline 10 & 4/28/98 (09:00) & 9,000 & & \\
\hline 10 & 5/1/98 (11:13) & 8,000 & & \\
\hline 10 & 5/6/98 (21:05) & 30,000 & & \\
\hline 10 & 5/9/98 (12:20) & 3,000 & & \\
\hline 10 & 5/19/98 (23:30) & 8,000 & & \\
\hline 10 & $5 / 22 / 98(16: 00)$ & 9,000 & 9,000 & 8,000 \\
\hline 10 & 5/26/98 (09:10) & 7,000 & & \\
\hline 10 & 6/3/98 (14:35) & 8,000 & & \\
\hline 10 & 6/13/98 (05:10) & 9,000 & & \\
\hline 11 & $6 / 19 / 98(07: 05)$ & 8,000 & & \\
\hline 11 & $6 / 24 / 98(07: 43)$ & 8,000 & & \\
\hline
\end{tabular}




\section{Permeate Flux and System Temperature}

Over the course of the subrun, the permeate flux ranged from 15.1 to $61.4 \mathrm{gal} / \mathrm{ft}^{2}-$ d. Permeate temperature ranged from 68.1 to $77.9^{\circ} \mathrm{F}$ with an average of $74.1^{\circ} \mathrm{F}$. Concentrate temperatures ranged from 72.0 to $83.4^{\circ} \mathrm{F}$ with an average of $78.8^{\circ} \mathrm{F}$.

\section{Concentrate Oil Content and Free Oil Production}

Concentrate oil content started out at $0.67 \%$ and increased to $2.6 \%$ over the course of subrun \#1. The total volume of free oil that was produced during subrun \#1 was 2,056 gallons. The average daily free oil production was 203.6 gallons/day.

\section{Oil/Grease, Turbidity and Pond Effluent}

Permeate $\mathrm{O} / \mathrm{G}$ remained low, averaging $3.8 \mathrm{mg} / \mathrm{L}$ and ranging from 2.3 to 5.0 mg/L. Turbidity was also low, averaging $2.1 \mathrm{NTU}$ and ranging from 0.69 to $4.7 \mathrm{NTU}$. Pond effluent ranged from 6000 to $7000 \mathrm{mg} / \mathrm{L}$ and averaged $6300 \mathrm{mg} / \mathrm{L}$.

\section{Conductivity and pH}

Permeate $\mathrm{pH}$ ranged from 5.2 to 5.9 with an average of 5.5. Concentrate $\mathrm{pH}$

ranged from 5.2 to 5.6 with an average of 5.4. Permeate conductivity ranged from 87.0 to $501 \mu \mathrm{S} / \mathrm{cm}$ and averaged $403 \mu \mathrm{S} / \mathrm{cm}$. Concentrate conductivity ranged from 110 to $470 \mu \mathrm{S} / \mathrm{cm}$ and averaged $302 \mu \mathrm{S} / \mathrm{cm}$.

\section{UF1-R8-SR1 Cleaning}

After UF1-R8-SR1 was shutdown on February 18, 1998 at 00:00, it was cleaned at $01: 00$ using a $0.5 \%$ KLD cleaning solution. The cleaning solution was recycled for total of two hours running time. Cleaning was started at a temperature of $\sim 80^{\circ} \mathrm{F}$. The 
temperature was not to exceed $110^{\circ} \mathrm{F}$. Holes were found in the CIP tank, from the heater located at the bottom of the tank. As a result the heater was not used during this cleaning. The cleaning water was recirculated and heated by the system pumps. Total downtime for this cleaning was 180 minutes.

\section{Permeate Flux and Temperature}

During the cleaning, the permeate flux ranged from 24.0 to $43.5 \mathrm{gal} / \mathrm{ft}^{2}-\mathrm{d}$ and averaged $35.2 \mathrm{gal} / \mathrm{ft}^{2}-\mathrm{d}$. Permeate temperature ranged from 80.4 to $97.6^{\circ} \mathrm{F}$ and averaged $89.6^{\circ} \mathrm{F}$. Concentrate temperature ranged from 82.5 to $106.7^{\circ} \mathrm{F}$ and averaged $95.7^{\circ} \mathrm{F}$ over the course of the cleaning.

\section{pH, Conductivity and Turbidity}

Permeate $\mathrm{pH}$ ranged from 6.0 to 6.1 with an average of 6.0. Concentrate $\mathrm{pH}$

ranged from 6.3 to 6.7 with an average of 6.4. Permeate conductivity ranged from 522 to $639 \mu \mathrm{S} / \mathrm{cm}$ and averaged $581 \mu \mathrm{S} / \mathrm{cm}$. Concentrate conductivity ranged from 1345 to $1542 \mu \mathrm{S} / \mathrm{cm}$ and averaged $1443 \mu \mathrm{S} / \mathrm{cm}$. Permeate turbidity ranged from 5.6 to $44.9 \mathrm{NTU}$ and averaged 14.8 NTU.

\section{UF1-R8-SR2}

UF1-R8-SR2 was started on February 18, 1998 at 03:00 and ended on February 23, 1998 at 10:56. The length of the subrun lasted 5.24 days. Major downtime was expected for valve replacement. As a result the system was shutdown and cleaned in order to restore a high permeate flow. The total permeate volume produced was 202,520 gal. 


\section{Permeate Flux and System Temperature}

Over the course of the subrun, the permeate flux ranged from 18.7 to $36.5 \mathrm{gal} / \mathrm{ft}^{2}-$

d. Permeate temperature ranged from 75.7 to $79.6{ }^{\circ} \mathrm{F}$ with an average of $77.6^{\circ} \mathrm{F}$. Concentrate temperatures ranged from 79.2 to $82.6^{\circ} \mathrm{F}$ with an average of $81.3^{\circ} \mathrm{F}$.

\section{Concentrate Oil Content and Free Oil Production}

Concentrate oil content started out at $2.6 \%$ and increased to $3.6 \%$ over the course of subrun \#2. The total volume of free oil that was produced during subrun \#2 was 1,267 gallons. The average daily free oil production was 243.7 gallons/day.

\section{Oil/Grease, Turbidity and Pond Effluent}

Permeate $\mathrm{O} / \mathrm{G}$ remained low, averaging $4.5 \mathrm{mg} / \mathrm{L}$ and ranging from 4.0 to 5.0 mg/L. Turbidity was also low, averaging 2.6 NTU and ranging from 1.3 to 5.5 NTU. Pond effluent ranged from 6000 to $7000 \mathrm{mg} / \mathrm{L}$ and averaged $6500 \mathrm{mg} / \mathrm{L}$.

\section{Conductivity and pH}

Permeate $\mathrm{pH}$ ranged from 4.3 to 6.4 with an average of 5.1. Concentrate $\mathrm{pH}$ ranged from 4.4 to 5.3 with an average of 4.8. Permeate conductivity ranged from 467 to $637 \mu \mathrm{S} / \mathrm{cm}$ and averaged $529 \mu \mathrm{S} / \mathrm{cm}$. Concentrate conductivity's ranged from 104 to 373 $\mu \mathrm{S} / \mathrm{cm}$ and averaged $238 \mu \mathrm{S} / \mathrm{cm}$.

\section{UF1-R8-SR2 Cleaning}

After UF1-R8-SR2 was shutdown on February 23, 1998 at 10:56, it was cleaned at $15: 12$ using a $0.5 \%$ KLD cleaning solution. The cleaning solution was recycled for total of two hours running time. Cleaning was started at a temperature of $\sim 100^{\circ} \mathrm{F}$. If the system temperature reaches $110^{\circ} \mathrm{F}$, it is shutdown and allowed to cool down, to 
approximately $100^{\circ} \mathrm{F}$. After which it is started again to finish the rest of the two-hour cleaning. The CIP tank heater was not used during the cleaning because the heating coils were melting holes in the bottom. The heater will not be used until the new tank arrives. As a result the downtime is longer than normal because the water does not heat up as fast. Total downtime for this cleaning was 440 minutes.

\section{Permeate Flux and Temperature}

During the first hour, the permeate flux ranged from 32.0 to $34.7 \mathrm{gal} / \mathrm{ft}^{2}-\mathrm{d}$ and averaged $33.3 \mathrm{gal} / \mathrm{ft}^{2}-\mathrm{d}$. Permeate temperature ranged from 91.5 to $99.3{ }^{\circ} \mathrm{F}$ and averaged $95.6^{\circ} \mathrm{F}$. Concentrate temperature ranged from 98 to $109^{\circ} \mathrm{F}$ and averaged $103^{\circ} \mathrm{F}$ over the course of the first hour.

The system was shutdown 60 minutes into the cleaning because the concentrate temperature reached $110^{\circ} \mathrm{F}$. The system was allowed to cool for 62 minutes and then restarted to complete the two-hour cleaning. During the second hour of cleaning, the permeate flux ranged from 33.8 to $35.6 \mathrm{gal} / \mathrm{ft}^{2}-\mathrm{d}$ and averaged $34.5 \mathrm{gal} / \mathrm{ft}^{2}-\mathrm{d}$. Concentrate temperatures ranged from 103 to $107^{\circ} \mathrm{F}$ and averaged $105^{\circ} \mathrm{F}$. Permeate temperature ranged from 95.6 to $98.4^{\circ} \mathrm{F}$ with an average of $97^{\circ} \mathrm{F}$.

\section{pH, Conductivity and Turbidity}

Permeate and concentrate $\mathrm{pH}$ were not taken during this cleaning because the $\mathrm{pH}$ probe was not functioning properly. Permeate conductivity ranged from 454 to $617 \mu \mathrm{S} / \mathrm{cm}$ and averaged $536.5 \mu \mathrm{S} / \mathrm{cm}$. Concentrate conductivity ranged from 827 to $1245 \mu \mathrm{S} / \mathrm{cm}$ and averaged $1036 \mu \mathrm{S} / \mathrm{cm}$. Permeate turbidity ranged from 3.7 to $9.7 \mathrm{NTU}$ and averaged 4.9 NTU. 


\section{UF1-R8-SR3}

UF1-R8-SR3 was started on February 23, 1998 at 18:16 and ended on February 25, 1998 at 06:46. The length of the subrun lasted 1.52 days. The subrun was shut down so that a new stainless steel header could be installed and bad valves replaced. The total permeate volume produced was 58,270 gal.

\section{Permeate Flux and System Temperature}

Over the course of the subrun, the permeate flux ranged from 21.3 to $33.8 \mathrm{gal} / \mathrm{ft}^{2}-$ d. Permeate temperature ranged from 76.0 to $76.5^{\circ} \mathrm{F}$ with an average of $76.3^{\circ} \mathrm{F}$. Concentrate temperatures ranged from 79.8 to $81.9^{\circ} \mathrm{F}$ with an average of $80.9^{\circ} \mathrm{F}$.

\section{Concentrate Oil Content and Free Oil Production}

Concentrate oil content started out at $3.6 \%$ and increased to $4.0 \%$ over the course of subrun \#3. The total volume of free oil that was produced during subrun \#3 was 316 gallons. The average daily free oil production was 210.7 gallons/day.

\section{Oil/Grease, Turbidity and Pond Effluent}

Permeate O/G remained low, around $4 \mathrm{mg} / \mathrm{L}$. Turbidity was also low, averaging 2.5 NTU and ranging from 0.79 to 4.1 NTU. Pond effluent remained constant at 6000 $\mathrm{mg} / \mathrm{L}$.

\section{Conductivity and pH}

Permeate $\mathrm{pH}$ ranged from 5.7 to 5.8 with an average of 5.8. Concentrate $\mathrm{pH}$ was constant at 6.1. Permeate conductivity ranged from 439 to $491 \mu \mathrm{S} / \mathrm{cm}$ and averaged 465 $\mu \mathrm{S} / \mathrm{cm}$. Concentrate conductivity's was constant at $292 \mu \mathrm{S} / \mathrm{cm}$ 


\section{UF1-R8-SR3 Cleaning}

After UF1-R8-SR3 was shutdown on February 25, 1998 at 06:46, it was cleaned on February 28, 1998 at 12:00 using a 0.5 \% KLD cleaning solution. There was several days of downtime due in installation of a new header. The cleaning solution was recycled for total of two hours running time. The CIP tank was cracked again so the flush tank was used for the cleaning. As a result the temperature cleaning solution could not be pre-heated before the cleaning. The solution was recycled for awhile to heat in up as much as possible. The cleaning temperature started out $\sim 90^{\circ} \mathrm{F}$. Total downtime for this cleaning was 240 minutes.

\section{Permeate Flux and Temperature}

During the first hour, the permeate flux ranged from 103.2 to $109.4 \mathrm{gal} / \mathrm{ft}^{2}-\mathrm{d}$ and averaged $105.8 \mathrm{gal} / \mathrm{ft}^{2}-\mathrm{d}$. Permeate temperature ranged from 90.1 to $94.7^{\circ} \mathrm{F}$ and averaged $92.2^{\circ} \mathrm{F}$. Concentrate temperature ranged from 94.4 to $101.1^{\circ} \mathrm{F}$ and averaged $97.8^{\circ} \mathrm{F}$ over the course of the first hour.

The system was then shutdown and the valves were adjusted for a spongeball sequence. During the first spongeball pass the flux increased to $114.7 \mathrm{gal} / \mathrm{ft}^{2}-\mathrm{d}$. The second spongeball pass yielded a flux of $114.7 \mathrm{gal} / \mathrm{ft}^{2}-\mathrm{d}$.

During the second hour of cleaning, the permeate flux ranged from 124.5 to $128.1 \mathrm{gal} / \mathrm{ft}^{2}-\mathrm{d}$ and averaged $125.9 \mathrm{gal} / \mathrm{ft}^{2}-\mathrm{d}$. Concentrate temperatures ranged from 93.9 to $97.5^{\circ} \mathrm{F}$ and averaged $95.5^{\circ} \mathrm{F}$. Permeate temperature ranged from 99 to $105.3^{\circ} \mathrm{F}$ with an average of $102.2^{\circ} \mathrm{F}$.

\section{pH, Conductivity and Turbidity}

Permeate $\mathrm{pH}$ ranged from 8.8 to 9.2 with an average of 9.1. Concentrate $\mathrm{pH}$ ranged from 9.0 to 9.2 with an average of 9.1 . Permeate conductivity ranged from 723 to $802 \mu \mathrm{S} / \mathrm{cm}$ and averaged $770 \mu \mathrm{S} / \mathrm{cm}$. Concentrate conductivity ranged from 1798 to 
$1970 \mu \mathrm{S} / \mathrm{cm}$ and averaged $1876 \mu \mathrm{S} / \mathrm{cm}$. Permeate turbidity ranged from 2.2 to $4.1 \mathrm{NTU}$ and averaged 3.1 NTU.

\section{UF1-R8-SR4}

UF1-R8-SR4 was started on February 28, 1998 at 16:00 and ended on March 6, 1998 at 17:30. The length of the subrun lasted 6.1 days. Subrun \#4 was ended because the permeate running average reached $29 \mathrm{gal} / \mathrm{min}$. The total permeate volume produced was 256,390 gal.

\section{Permeate Flux and System Temperature}

Over the course of the subrun, the permeate flux ranged from 17.8 to $91.6 \mathrm{gal} / \mathrm{ft}^{2}-$ d. Permeate temperature ranged from 72.9 to $76.5^{\circ} \mathrm{F}$ with an average of $75.6^{\circ} \mathrm{F}$. Concentrate temperatures ranged from 75.7 to $80.7^{\circ} \mathrm{F}$ with an average of $79.6^{\circ} \mathrm{F}$.

\section{Concentrate Oil Content and Free Oil Production}

Concentrate oil content started out at $4.0 \%$ and increased to $5.4 \%$ over the course of subrun \#4. The total volume of free oil that was produced during subrun \#4 was 1,679 gallons. The average daily free oil production was 275.2 gallons/day.

\section{Oil/Grease, Turbidity and Pond Effluent}

Permeate O/G remained low, around $6 \mathrm{mg} / \mathrm{L}$. Turbidity was also low, averaging 4.2 NTU and ranging from 0.85 to 7.6 NTU. Pond effluent remained constant at 6000 $\mathrm{mg} / \mathrm{L}$.

\section{Conductivity and pH}

Permeate $\mathrm{pH}$ ranged from 4.1 to 5.5 with an average of 5.2. Concentrate $\mathrm{pH}$ ranged from 5.2 to 5.9 and averaged 5.5. Permeate conductivity ranged from 268 to 431 
$\mu \mathrm{S} / \mathrm{cm}$ and averaged $361 \mu \mathrm{S} / \mathrm{cm}$. Concentrate conductivity's ranged from 183.3 to $534 \mu$ S/cm and averaged $359 \mu \mathrm{S} / \mathrm{cm}$.

\section{UF1-R8-SR4 Cleaning}

After UF1-R8-SR4 was shutdown on March 6, 1998 at 17:30, it was cleaned at 20:10 using a $0.5 \%$ KLD cleaning solution. The new stainless steel CIP tank was used to clean with. Once the water was heated to $\sim 115^{\circ} \mathrm{F}$, unit \#1 was cleaned for 40 minutes. After 40 minutes elapsed, the system was shutdown and prepared for two spongeball passes. After the spongeball sequence the system was cleaned for an additional 40 minutes. Total downtime for this cleaning was 270 minutes.

\section{Permeate Flux and Temperature}

During the first regular cleaning, the permeate flux ranged from 76.5 to $80.0 \mathrm{gal} / \mathrm{ft}^{2}-\mathrm{d}$ and averaged $78.4 \mathrm{gal} / \mathrm{ft}^{2}-\mathrm{d}$. Permeate temperature ranged from 110 to $112.8^{\circ} \mathrm{F}$ and averaged $111.9^{\circ} \mathrm{F}$. Concentrate temperature ranged from 117.4 to $124.3^{\circ} \mathrm{F}$ and averaged $121^{\circ} \mathrm{F}$.

The system was then shutdown and the valves were adjusted for a spongeball sequence. During the first spongeball pass the flux increased to $115.8 \mathrm{gal} / \mathrm{ft}^{2}-\mathrm{d}$. The second spongeball pass yielded a flux of $126.2 \mathrm{gal} / \mathrm{ft}^{2}-\mathrm{d}$.

During the second 40 minutes of cleaning, the permeate flux ranged from 110.3 to $115.6 \mathrm{gal} / \mathrm{ft}^{2}-\mathrm{d}$ and averaged $111.7 \mathrm{gal} / \mathrm{ft}^{2}-\mathrm{d}$. Concentrate temperatures ranged from 117.5 to $121^{\circ} \mathrm{F}$ and averaged $119.3{ }^{\circ} \mathrm{F}$. Permeate temperature ranged from 108.1 to 110.9 ${ }^{\circ} \mathrm{F}$ and averaged $109.5^{\circ} \mathrm{F}$. 


\section{pH, Conductivity and Turbidity}

Permeate $\mathrm{pH}$ ranged from 6.5 to 6.7 with an average of 6.6. Concentrate $\mathrm{pH}$ ranged from 6.7 to 6.9 with an average of 6.8 . Permeate conductivity ranged from 507 to $592 \mu \mathrm{S} / \mathrm{cm}$ and averaged $560 \mu \mathrm{S} / \mathrm{cm}$. Concentrate conductivity ranged from 924 to $1411 \mu \mathrm{S} / \mathrm{cm}$ and averaged $1162 \mu \mathrm{S} / \mathrm{cm}$. Permeate turbidity ranged from 3.6 to $8.3 \mathrm{NTU}$ and averaged 4.8 NTU.

\section{UF1-R8-SR5}

UF1-R8-SR5 was started on March 6, 1998 at 22:00 and ended on March 12, 1998 at 05:45. The length of the subrun lasted 5.30 days. Subrun \#5 was ended because the permeate running average reached $29 \mathrm{gal} / \mathrm{min}$. The total permeate volume produced was 225,490 gal.

\section{Permeate Flux and System Temperature}

Over the course of the subrun, the permeate flux ranged from 19.6 to $88.9 \mathrm{gal} / \mathrm{ft}^{2}-$ d. Permeate temperature ranged from 71.8 to $78.2^{\circ} \mathrm{F}$ with an average of $74.7^{\circ} \mathrm{F}$. Concentrate temperatures ranged from 77.9 to $80.8^{\circ} \mathrm{F}$ with an average of $79.0{ }^{\circ} \mathrm{F}$.

\section{Concentrate Oil Content and Free Oil Production}

Concentrate oil content started out at $5.4 \%$ and increased to $6.8 \%$ during subrun \#5. The total volume of free oil that was produced during subrun \#5 was 2,304 gallons. The average daily free oil production was 434.7 gallons/day. 


\section{Oil/Grease, Turbidity and Pond Effluent}

Permeate $\mathrm{O} / \mathrm{G}$ remained low, around $5 \mathrm{mg} / \mathrm{L}$. Turbidity was also low, averaging 8.0 NTU and ranging from 1.1 to 17.5 NTU. Pond effluent remained constant at 7000 $\mathrm{mg} / \mathrm{L}$.

\section{Conductivity and pH}

Permeate $\mathrm{pH}$ ranged from 4.5 to 6.4 with an average of 5.6. Concentrate $\mathrm{pH}$ ranged from 5.3 to 6.3 and averaged 5.9. Permeate conductivity ranged from 207 to 382 $\mu \mathrm{S} / \mathrm{cm}$ and averaged $300 \mu \mathrm{S} / \mathrm{cm}$. Concentrate conductivity's ranged from 147 to $333 \mu$ S/cm and averaged $247 \mu \mathrm{S} / \mathrm{cm}$.

\section{UF1-R8-SR5 Cleaning}

After UF1-R8-SR5 was shutdown on March 12, 1998 at 05:45, it was cleaned at 10:10 using a $0.5 \%$ KLD cleaning solution. Once the cleaning solution was heated to $115^{\circ} \mathrm{F}$ and the $\mathrm{pH}$ increased to $\sim 10$, unit \#1 was cleaned for 40 minutes. After 40 minutes elapsed, the system was shutdown and prepared for two spongeball passes. After the spongeball sequence the system was cleaned for an additional 40 minutes. Total downtime for this cleaning was 435 minutes.

\section{Permeate Flux and Temperature}

During the first regular cleaning, the permeate flux ranged from 80 to $83.6 \mathrm{gal} / \mathrm{ft}^{2}$ $\mathrm{d}$ and averaged $81.8 \mathrm{gal} / \mathrm{ft}^{2}-\mathrm{d}$. Permeate temperature ranged from 110.6 to $111.4{ }^{\circ} \mathrm{F}$ and averaged $111.1^{\circ} \mathrm{F}$. Concentrate temperature ranged from 119.7 to $122.5^{\circ} \mathrm{F}$ and averaged $121^{\circ} \mathrm{F}$.

The system was then shutdown and the valves were adjusted for a spongeball sequence. During the first spongeball pass the flux increased to $117.4 \mathrm{gal} / \mathrm{ft}^{2}-\mathrm{d}$. The second spongeball pass yielded a flux of $132.2 \mathrm{gal} / \mathrm{ft}^{2}-\mathrm{d}$. 
During the second 40 minutes of cleaning, the permeate flux ranged from 97.8 to $108.5 \mathrm{gal} / \mathrm{ft}^{2}-\mathrm{d}$ and averaged $103.2 \mathrm{gal} / \mathrm{ft}^{2}-\mathrm{d}$. Concentrate temperatures ranged from 111.3 to $114.1^{\circ} \mathrm{F}$ and averaged $112.5^{\circ} \mathrm{F}$. Permeate temperature ranged from 117.5 to $124.9^{\circ} \mathrm{F}$ and averaged $121.4^{\circ} \mathrm{F}$.

\section{pH, Conductivity and Turbidity}

Permeate $\mathrm{pH}$ ranged from 8.5 to 9.5 with an average of 9.1. Concentrate $\mathrm{pH}$ ranged from 8.5 to 9.6 with an average of 9.1 . Permeate conductivity ranged from 479 to $1430 \mu \mathrm{S} / \mathrm{cm}$ and averaged $957 \mu \mathrm{S} / \mathrm{cm}$. Concentrate conductivity ranged from 985 to $2300 \mu \mathrm{S} / \mathrm{cm}$ and averaged $1725 \mu \mathrm{S} / \mathrm{cm}$. Permeate turbidity ranged from 3.2 to $9.5 \mathrm{NTU}$ and averaged 6.1 NTU.

\section{UF1-R8-SR6}

UF1-R8-SR6 was started on March 12, 1998 at 13:00 and ended on April 4, 1998 at $01: 10$. The length of the subrun lasted 22.4 days. The system was allowed to run because the instantaneous permeate flow steady out into the mid to lower twenties. The total permeate volume produced was 761,940 gal.

\section{Permeate Flux and System Temperature}

Over the course of the subrun, the permeate flux ranged from 18 to $93 \mathrm{gal} / \mathrm{ft}^{2}-\mathrm{d}$. Permeate temperature ranged from 71.8 to $81.5^{\circ} \mathrm{F}$ with an average of $78.4^{\circ} \mathrm{F}$. Concentrate temperatures ranged from 76.0 to $85.0^{\circ} \mathrm{F}$ with an average of $81.9^{\circ} \mathrm{F}$.

\section{Concentrate Oil Content and Free Oil Production}

Concentrate oil content started out at $6.8 \%$ and increased to $11.5 \%$ during subrun \#6. The total volume of free oil that was produced during subrun \#6 was 4,936 gallons. The average daily free oil production was 221.3 gallons/day. 


\section{Oil/Grease, Turbidity and Pond Effluent}

Permeate $\mathrm{O} / \mathrm{G}$ ranged from 1 to $5 \mathrm{mg} / \mathrm{L}$ and averaged $2.8 \mathrm{mg} / \mathrm{L}$. Permeate turbidity ranged from 0.98 to 14.5 NTU and averaged 2.7 NTU. Pond effluent oil content ranged from 6,000 to $7,000 \mathrm{mg} / \mathrm{L}$ and averaged $6800 \mathrm{mg} / \mathrm{L}$.

\section{Conductivity and pH}

Permeate $\mathrm{pH}$ ranged from 4.4 to 6.3 with an average of 5.1. Concentrate $\mathrm{pH}$ ranged from 4.6 to 6.2 and averaged 5.3. Permeate conductivity ranged from 111 to $391 \mu$ S/cm and averaged $287 \mu \mathrm{S} / \mathrm{cm}$. Concentrate conductivity's ranged from 204 to 501 $\mu \mathrm{S} / \mathrm{cm}$ and averaged $355 \mu \mathrm{S} / \mathrm{cm}$.

\section{UF1-R8-SR6 Cleaning}

After UF1-R8-SR6 was shutdown on April 4, 1998 at 01:10, it was cleaned at 02:33 using a $0.5 \%$ KLD cleaning solution. The $\mathrm{pH}$ of the cleaning solution was not raised to 10 because of time and personal available at the time.

\section{Permeate Flux and Temperature}

During the first regular cleaning, the permeate flux ranged from 65.8 to 71.1 $\mathrm{gal} / \mathrm{ft}^{2}-\mathrm{d}$ and averaged $69.0 \mathrm{gal} / \mathrm{ft}^{2}-\mathrm{d}$. Permeate temperature ranged from 109 to $112.9^{\circ} \mathrm{F}$ and averaged $110.9^{\circ} \mathrm{F}$. Concentrate temperature ranged from 118 to $122^{\circ} \mathrm{F}$ and averaged $120^{\circ} \mathrm{F}$.

The system was then shutdown and the valves were adjusted for a spongeball sequence. During the first spongeball pass the flux increased to $92.5 \mathrm{gal} / \mathrm{ft}^{2}-\mathrm{d}$. The second spongeball pass yielded a flux of $108.5 \mathrm{gal} / \mathrm{ft}^{2}-\mathrm{d}$. The third spongeball pass yielded a permeate flux of $113.8 \mathrm{gal} / \mathrm{ft}^{2}-\mathrm{d}$. 
During the second cleaning after spongeballs, the permeate flux ranged from 90.7 to $97.8 \mathrm{gal} / \mathrm{ft}^{2}-\mathrm{d}$ and averaged $93.1 \mathrm{gal} / \mathrm{ft}^{2}-\mathrm{d}$. Concentrate temperatures ranged from 114 to $124.9^{\circ} \mathrm{F}$ and averaged $116.9^{\circ} \mathrm{F}$. Permeate temperature ranged around $108.1^{\circ} \mathrm{F}$

\section{pH, Conductivity and Turbidity}

Permeate $\mathrm{pH}$ ranged from 5.4 to 5.9 with an average of 5.7. Concentrate $\mathrm{pH}$ ranged from 6.0 to 6.3 with an average of 6.2. Permeate conductivity ranged from 281 to $614 \mu \mathrm{S} / \mathrm{cm}$ and averaged $453 \mu \mathrm{S} / \mathrm{cm}$. Concentrate conductivity ranged from 264 to 1043 $\mu \mathrm{S} / \mathrm{cm}$ and averaged $776 \mu \mathrm{S} / \mathrm{cm}$. Permeate turbidity ranged from 2.9 to $6.3 \mathrm{NTU}$ and averaged 4.4 NTU.

\section{UF1-R8-SR7}

UF1-R8-SR7 was started on April 4, 1998 at 04:17 and ended on April 10, 1998 at 10:12. The length of the subrun lasted 6.2 days. The system was shutdown because the running permeate average reached $29 \mathrm{gpm}$. The total permeate volume produced was 263,600 gal.

\section{Permeate Flux and System Temperature}

Over the course of the subrun, the permeate flux ranged from 20.5 to $67.6 \mathrm{gal} / \mathrm{ft}^{2}-$

d. Permeate temperature ranged from 73.9 to $79.6{ }^{\circ} \mathrm{F}$ with an average of $77.4^{\circ} \mathrm{F}$. Concentrate temperatures ranged from 78.3 to $79.6^{\circ} \mathrm{F}$ with an average of $81.1^{\circ} \mathrm{F}$.

\section{Concentrate Oil Content and Free Oil Production}

Concentrate oil content started out at $11.3 \%$ and decreased to $11.0 \%$ during subrun \#7. The total volume of free oil that was produced during subrun \#7 was 2,316 gallons. The average daily free oil production was 373.5 gallons/day. 


\section{Oil/Grease, Turbidity and Pond Effluent}

Permeate $\mathrm{O} / \mathrm{G}$ ranged from 3 to $4 \mathrm{mg} / \mathrm{L}$ and averaged $3.5 \mathrm{mg} / \mathrm{L}$. Permeate turbidity ranged from 0.38 to 4.5 NTU and averaged 2.3 NTU. Pond effluent oil content ranged from 7000 to $8000 \mathrm{mg} / \mathrm{L}$ and averaged $7300 \mathrm{mg} / \mathrm{L}$.

\section{Conductivity and pH}

Permeate $\mathrm{pH}$ ranged from 4.8 to 5.7 with an average of 5.3. Concentrate $\mathrm{pH}$ ranged from 5.2 to 6.0 and averaged 5.4. Permeate conductivity ranged from 236 to 425 $\mu \mathrm{S} / \mathrm{cm}$ and averaged $350 \mu \mathrm{S} / \mathrm{cm}$. Concentrate conductivity's ranged from 170 to 486 $\mu \mathrm{S} / \mathrm{cm}$ and averaged $354 \mu \mathrm{S} / \mathrm{cm}$.

\section{UF1-R8-SR7 Cleaning}

After UF1-R8-SR7 was shutdown on April 10, 1998 at 10:12, it was cleaned at $12: 30$ using a $0.5 \%$ KLD cleaning solution. The $\mathrm{pH}$ of the cleaning solution was raised to $\sim 9.3$.

\section{Permeate Flux and Temperature}

During the first regular cleaning, the permeate flux ranged from 57.8 to 59.6 $\mathrm{gal} / \mathrm{ft}^{2}-\mathrm{d}$ and averaged $58.7 \mathrm{gal} / \mathrm{ft}^{2}-\mathrm{d}$. Permeate temperature ranged from 114.3 to $115^{\circ} \mathrm{F}$ and averaged $114.6^{\circ} \mathrm{F}$. Concentrate temperature ranged from 121 to $124^{\circ} \mathrm{F}$ and averaged $123^{\circ} \mathrm{F}$.

The system was then shutdown and the valves were adjusted for a spongeball sequence. During the first spongeball pass the flux increased to $177.8 \mathrm{gal} / \mathrm{ft}^{2}-\mathrm{d}$. The second spongeball pass yielded the same result.

During the second cleaning after spongeballs, the permeate flux ranged from 97.8 to $99.6 \mathrm{gal} / \mathrm{ft}^{2}-\mathrm{d}$ and averaged $98.5 \mathrm{gal} / \mathrm{ft}^{2}$-d. Concentrate temperatures ranged from 114.2 
to $128.8^{\circ} \mathrm{F}$ and averaged $123.4^{\circ} \mathrm{F}$. Permeate temperature ranged around 115.6 to 119.2 ${ }^{\circ} \mathrm{F}$ and averaged $117.8^{\circ} \mathrm{F}$.

\section{pH, Conductivity and Turbidity}

Permeate $\mathrm{pH}$ ranged from 8.4 to 9.2 with an average of 8.9 . Concentrate $\mathrm{pH}$

ranged from 8.5 to 9.3 with an average of 8.9. Permeate conductivity ranged from 353 to $714 \mu \mathrm{S} / \mathrm{cm}$ and averaged $544 \mu \mathrm{S} / \mathrm{cm}$. Concentrate conductivity ranged from 712 to 1425 $\mu \mathrm{S} / \mathrm{cm}$ and averaged $1113 \mu \mathrm{S} / \mathrm{cm}$. Permeate turbidity ranged from 2.0 to $5.6 \mathrm{NTU}$ and averaged 3.8 NTU.

\section{UF1-R8-SR8}

UF1-R8-SR8 was started on April 10, 1998 at 15:30 and ended on April 16, 1998 at $02: 17$. The length of the subrun lasted 5.4 days. The system was shutdown because a new spongeball pipeline was going to be installed. The total permeate volume produced was 186,810 gal.

\section{Permeate Flux and System Temperature}

Over the course of the subrun, the permeate flux ranged from 16.9 to $88.9 \mathrm{gal} / \mathrm{ft}^{2}-$ d. Permeate temperature ranged from 73.7 to $82.6{ }^{\circ} \mathrm{F}$ with an average of $79.4{ }^{\circ} \mathrm{F}$. Concentrate temperatures ranged from 80.0 to $86.0^{\circ} \mathrm{F}$ with an average of $83.3^{\circ} \mathrm{F}$.

\section{Concentrate Oil Content and Free Oil Production}

Concentrate oil content started out at $11.2 \%$ and decreased to $10.5 \%$ during subrun \#8. The total volume of free oil that was produced during subrun \#8 was 1,589 gallons. The average daily free oil production was 294.3 gallons/day. 


\section{Permeate Oil/Grease, Turbidity and Pond Effluent}

Permeate $\mathrm{O} / \mathrm{G}$ ranged from 3 to $5 \mathrm{mg} / \mathrm{L}$ and averaged $3.7 \mathrm{mg} / \mathrm{L}$. Permeate turbidity ranged from 0.8 to $5.2 \mathrm{NTU}$ and averaged 1.9 NTU. Pond effluent oil content ranged from 7000 to $9000 \mathrm{mg} / \mathrm{L}$ and averaged $8000 \mathrm{mg} / \mathrm{L}$.

\section{Conductivity and $\mathrm{pH}$}

Permeate $\mathrm{pH}$ ranged from 5.1 to 6.3 with an average of 5.4. Concentrate $\mathrm{pH}$ ranged from 5.3 to 5.6 and averaged 5.4. Permeate conductivity ranged from 285 to $267 \mu \mathrm{S} / \mathrm{cm}$ and averaged $410 \mu \mathrm{S} / \mathrm{cm}$. Concentrate conductivity's ranged from 267 to $492 \mu \mathrm{S} / \mathrm{cm}$ and averaged $415 \mu \mathrm{S} / \mathrm{cm}$.

\section{UF1-R8-SR8 Cleaning}

After UF1-R8-SR8 was shutdown on April 16, 1998 at 02:17, it was cleaned at 04:40 using a $0.5 \% \mathrm{KLD}$ cleaning solution. The $\mathrm{pH}$ of the cleaning solution was raised to $\sim 10$.

\section{Permeate Flux and Temperature}

During the first regular cleaning, the permeate flux ranged from 119.2 to 128.1 $\mathrm{gal} / \mathrm{ft}^{2}-\mathrm{d}$ and averaged $123.8 \mathrm{gal} / \mathrm{ft}^{2}-\mathrm{d}$. Permeate temperature ranged from 114.1 to 115.5 ${ }^{\circ} \mathrm{F}$ and averaged $114.7^{\circ} \mathrm{F}$. Concentrate temperature ranged from 120.5 to $125^{\circ} \mathrm{F}$ and averaged $123.1^{\circ} \mathrm{F}$.

The system was then shutdown and the valves were adjusted for a spongeball sequence. During the first spongeball pass the flux increased to $154.7 \mathrm{gal} / \mathrm{ft}^{2}-\mathrm{d}$. The second spongeball pass yielded $165.4 \mathrm{gal} / \mathrm{ft}^{2}-\mathrm{d}$. Third and fourth spongeball passes yields permeate fluxes of 181.4 and $177.9 \mathrm{gal} / \mathrm{ft}^{2}-\mathrm{d}$ respectively.

During the second cleaning after spongeballs, the permeate flux ranged from 133.4 to $140.5 \mathrm{gal} / \mathrm{ft}^{2}-\mathrm{d}$ and averaged $135.2 \mathrm{gal} / \mathrm{ft}^{2}-\mathrm{d}$. Concentrate temperatures ranged 
from 117.7 to $128.8^{\circ} \mathrm{F}$ and averaged $123.8^{\circ} \mathrm{F}$. Permeate temperature ranged around 112.2 to $119.2^{\circ} \mathrm{F}$ and averaged $115.5^{\circ} \mathrm{F}$.

\section{pH, Conductivity and Turbidity}

Permeate $\mathrm{pH}$ ranged from 9.3 to 9.9 with an average of 9.6. Concentrate $\mathrm{pH}$ ranged from 9.3 to 10.0 with an average of 9.7. Permeate conductivity ranged from 1285 to $2260 \mu \mathrm{S} / \mathrm{cm}$ and averaged $1773 \mu \mathrm{S} / \mathrm{cm}$. Concentrate conductivity ranged from 1973 to $2920 \mu \mathrm{S} / \mathrm{cm}$ and averaged $2419 \mu \mathrm{S} / \mathrm{cm}$. Permeate turbidity ranged from 0.6 to $6.0 \mathrm{NTU}$ and averaged 1.6 NTU.

\section{UF1-R8-SR9}

UF1-R8-SR9 was started on April 17, 1998 at 16:20 and ended on April 23, 1998 at 08:53. The length of the subrun lasted 5.7 days. At the end of the subrun, the permeate running average was $30.9 \mathrm{gal} / \mathrm{min}$. The total permeate volume produced was 263,620 gal. The system was shutdown because of a severe leak in an end connect.

\section{Permeate Flux and System Temperature}

Over the course of the subrun, the permeate flux ranged from 21.3 to $69.4 \mathrm{gal} / \mathrm{ft}^{2}-$ d. Permeate temperature ranged from 75.8 to $80.9^{\circ} \mathrm{F}$ with an average of $78.3^{\circ} \mathrm{F}$. Concentrate temperatures ranged from 78.1 to $83.6^{\circ} \mathrm{F}$ with an average of $81.5^{\circ} \mathrm{F}$.

\section{Concentrate Oil Content and Free Oil Production}

Concentrate oil content started out at $10.5 \%$ and decreased to $9.8 \%$ for subrun \#9. The total volume of free oil that was produced during subrun \#9 was 2,068 gallons. The average daily free oil production was 362.8 gallons/day. 


\section{Permeate Oil/Grease, Turbidity and Pond Effluent}

Permeate $\mathrm{O} / \mathrm{G}$ ranged from 1 to $3 \mathrm{mg} / \mathrm{L}$ and averaged $2 \mathrm{mg} / \mathrm{L}$. Permeate turbidity ranged from 0.3 to $3.2 \mathrm{NTU}$ and averaged 1.3 NTU. Pond effluent oil content ranged at $8000 \mathrm{mg} / \mathrm{L}$.

\section{Conductivity and pH}

Permeate $\mathrm{pH}$ ranged from 5.0 to 5.4 with an average of 5.2. Concentrate $\mathrm{pH}$ ranged from 5.2 to 5.4 and averaged 5.3. Permeate conductivity ranged from 138 to 464 $\mu \mathrm{S} / \mathrm{cm}$ and averaged $312 \mu \mathrm{S} / \mathrm{cm}$. Concentrate conductivity's ranged from 212 to 431 $\mu \mathrm{S} / \mathrm{cm}$ and averaged $342 \mu \mathrm{S} / \mathrm{cm}$.

\section{UF1-R8-SR9 Cleaning}

After UF1-R8-SR9 was shutdown on April 23, 1998 at 08:53, it was cleaned at 14:40 using a $0.5 \%$ KLD cleaning solution. The cleaning did not follow the same format and procedure as the cleanings performed previously. During this cleaning the system was cleaned for 20 minutes and then the new spongeball screen was tested out by adjusting the valves and performing three spongeball passes. Three spongeball passes were implemented. The spongeballs were then retrieved to see if the number put in equal the number that came out. After the small test, the system was cleaned for an addition half hour.

\section{Permeate Flux and Temperature}

During the first 20 minutes of cleaning, the permeate flux remained constant at $88.9 \mathrm{gal} / \mathrm{ft}^{2}-\mathrm{d}$. Permeate temperature was only taken once during the first cleaning and ranged at $89.1^{\circ} \mathrm{F}$. Concentrate temperature ranged from 96 to $100{ }^{\circ} \mathrm{F}$ and averaged $97.9^{\circ} \mathrm{F}$. 
The system was then shutdown and the valves were adjusted for a spongeball sequence. During the first spongeball pass the flux increased to $115.6 \mathrm{gal} / \mathrm{ft}^{2}-\mathrm{d}$. The second spongeball pass yielded $124.5 \mathrm{gal} / \mathrm{ft}^{2}$-d. The third spongeball pass yielded a permeate flux of $131.6 \mathrm{gal} / \mathrm{ft}^{2}-\mathrm{d}$.

During the second cleaning after spongeballs, the permeate flux ranged from 120.9 to $126.3 \mathrm{gal} / \mathrm{ft}^{2}-\mathrm{d}$ and averaged $124 \mathrm{gal} / \mathrm{ft}^{2}-\mathrm{d}$. Concentrate temperatures ranged from 116 to $122.5^{\circ} \mathrm{F}$ and averaged $119.2^{\circ} \mathrm{F}$. Permeate temperature ranged around 109.7 to $111.1^{\circ} \mathrm{F}$ and averaged $110.4^{\circ} \mathrm{F}$.

\section{pH, Conductivity and Turbidity}

Permeate $\mathrm{pH}$ ranged from 6.2 to 6.3 with an average of 6.3 . Concentrate $\mathrm{pH}$ ranged from 6.4 to 6.5 with an average of 6.5. Permeate conductivity ranged from 733 to $874 \mu \mathrm{S} / \mathrm{cm}$ and averaged $819 \mu \mathrm{S} / \mathrm{cm}$. Concentrate conductivity ranged from 1228 to $1433 \mu \mathrm{S} / \mathrm{cm}$ and averaged $1358 \mu \mathrm{S} / \mathrm{cm}$. Permeate turbidity ranged from 1.6 to $3.0 \mathrm{NTU}$ and averaged $2.2 \mathrm{NTU}$.

\section{UF1-R8-SR10}

UF1-R8-SR10 was started on April 23, 1998 at 19:00 and ended on June 16, 1998 at 10:39. The length of the subrun lasted 51.3 days.

\section{Permeate Flux and System Temperature}

Over the course of the subrun, the permeate flux ranged from 20.5 to $86.3 \mathrm{gal} / \mathrm{ft}^{2}-$ d. Permeate temperature ranged from 73.7 to $82.6^{\circ} \mathrm{F}$ with an average of $79.4^{\circ} \mathrm{F}$. Concentrate temperatures ranged from 80.7 to $92.4^{\circ} \mathrm{F}$ with an average of $87.3^{\circ} \mathrm{F}$. 


\section{Concentrate Oil Content and Free Oil Production}

Concentrate oil content started out at $10.2 \%$ and decreased to $3.0 \%$ during subrun \#10. The total volume of free oil that was produced during subrun \#10 was 26,823 gallons. The average daily free oil production was 522.8 gallons/day.

\section{Permeate Oil/Grease, Turbidity and Pond Effluent}

Permeate $\mathrm{O} / \mathrm{G}$ ranged from 1 to $9 \mathrm{mg} / \mathrm{L}$ and averaged $3.9 \mathrm{mg} / \mathrm{L}$. Permeate turbidity ranged from 0.11 to $5.8 \mathrm{NTU}$ and averaged 0.80 NTU. Pond effluent oil content ranged from 3000 to $8000 \mathrm{mg} / \mathrm{L}$ and averaged $7200 \mathrm{mg} / \mathrm{L}$.

\section{Conductivity and pH}

Permeate $\mathrm{pH}$ ranged from 4.8 to 6.1 with an average of 5.5. Concentrate $\mathrm{pH}$ ranged from 4.9 to 5.9 and averaged 5.5. Permeate conductivity ranged from 101 to $687 \mu \mathrm{S} / \mathrm{cm}$ and averaged $341 \mu \mathrm{S} / \mathrm{cm}$. Concentrate conductivity's ranged from 220 to $523 \mu \mathrm{S} / \mathrm{cm}$ and averaged $406 \mu \mathrm{S} / \mathrm{cm}$.

\section{UF1-R8-SR10 Cleaning}

After UF1-R8-SR10 was shutdown on June 16, 1998 at 10:39, it was cleaned at 11:00 using a $0.5 \%$ KLD cleaning solution. The $\mathrm{pH}$ of the cleaning solution was raised to $\sim 10$.

\section{Permeate Flux and Temperature}

During the first regular cleaning, the permeate flux ranged from 69.4 to 71.1

$\mathrm{gal} / \mathrm{ft}^{2}-\mathrm{d}$ and averaged $70.3 \mathrm{gal} / \mathrm{ft}^{2}-\mathrm{d}$. Permeate temperature ranged from 111.8 to $117.2^{\circ}$ $\mathrm{F}$ and averaged $114.5^{\circ} \mathrm{F}$. Concentrate temperature ranged from 121 to $124^{\circ} \mathrm{F}$ and averaged $122.5^{\circ} \mathrm{F}$. 
The system was then shutdown and the valves were adjusted for a spongeball sequence. During the first spongeball pass the flux increased to $154.7 \mathrm{gal} / \mathrm{ft}^{2}-\mathrm{d}$. The second spongeball pass yielded $165.4 \mathrm{gal} / \mathrm{ft}^{2}-\mathrm{d}$. Third and fourth spongeball passes yields permeate fluxes of 181.4 and $177.9 \mathrm{gal} / \mathrm{ft}^{2}-\mathrm{d}$ respectively.

During the second cleaning after spongeballs, the permeate flux ranged from 100.5 to $103.2 \mathrm{gal} / \mathrm{ft}^{2}-\mathrm{d}$ and averaged $102.1 \mathrm{gal} / \mathrm{ft}^{2}-\mathrm{d}$. Concentrate temperatures ranged from 120 to $124{ }^{\circ} \mathrm{F}$ and averaged $123^{\circ} \mathrm{F}$. Permeate temperature ranged around 118.2 to $110.7^{\circ} \mathrm{F}$ and averaged $114.5^{\circ} \mathrm{F}$.

\section{pH, Conductivity and Turbidity}

Permeate $\mathrm{pH}$ ranged from 9.4 to 9.6 with an average of 9.5. Concentrate $\mathrm{pH}$ ranged from 9.4 to 9.6 with an average of 9.5. Permeate conductivity ranged from 922 to $1144 \mu \mathrm{S} / \mathrm{cm}$ and averaged $1041 \mu \mathrm{S} / \mathrm{cm}$. Concentrate conductivity ranged from 959 to $2230 \mu \mathrm{S} / \mathrm{cm}$ and averaged $1615 \mu \mathrm{S} / \mathrm{cm}$. Permeate turbidity ranged from 0.99 to $6.5 \mathrm{NTU}$ and averaged $2.7 \mathrm{NTU}$.

\section{UF1-R8-SR11}

UF1-R8-SR11 was started on June 18, 1998 at 14:20 and ended on June 25, 1998 at 07:02. The length of the subrun lasted 6.5 days. Subrun \#11 was shutdown, because large thunderstorms filled the settling pond. Subrun \#11 marked the end of the experiments for unit \#1. After the system was shutdown, the concentrate in the feed tanks was purged to the tank farm. 


\section{Permeate Flux and System Temperature}

Over the course of the subrun, the permeate flux ranged from 24.9 to $83.6 \mathrm{gal} / \mathrm{ft}^{2}-$

d. Permeate temperature ranged from 85.8 to $90.3{ }^{\circ} \mathrm{F}$ with an average of $87.6^{\circ} \mathrm{F}$. Concentrate temperatures ranged from 91.2 to $92.0^{\circ} \mathrm{F}$ with an average of $91.5^{\circ} \mathrm{F}$.

\section{Concentrate Oil Content and Free Oil Production}

Concentrate oil content started out at $3.0 \%$ and decreased to $4.5 \%$ during subrun \#11. The total volume of free oil that was produced during subrun \#11 was 4,130 gallons. The average daily free oil production was 635.4 gallons/day.

\section{Permeate Oil/Grease, Turbidity and Pond Effluent}

Permeate $\mathrm{O} / \mathrm{G}$ ranged from 2 to $5 \mathrm{mg} / \mathrm{L}$ and averaged $3.2 \mathrm{mg} / \mathrm{L}$. Permeate turbidity ranged from 0.36 to 5.2 NTU and averaged 1.3 NTU. Pond effluent oil content ranged from 7000 to $9000 \mathrm{mg} / \mathrm{L}$ and averaged $8300 \mathrm{mg} / \mathrm{L}$.

\section{pH, Conductivity and Turbidity}

Permeate $\mathrm{pH}$ ranged from 4.8 to 7.1 with an average of 5.4. Concentrate $\mathrm{pH}$ ranged from 5.2 to 5.5 and averaged 5.4. Permeate conductivity ranged from 228 to $476 \mu \mathrm{S} / \mathrm{cm}$ and averaged $346 \mu \mathrm{S} / \mathrm{cm}$. Concentrate conductivity's ranged from 441 to $555 \mu \mathrm{S} / \mathrm{cm}$ and averaged $498 \mu \mathrm{S} / \mathrm{cm}$.

\section{UF2-R3}

UF2-R3 started on January 16, 1998 at 01:10 and ended February 5, 1998 at 04:30. The run lasted for 18.1 days. The objectives of the run were: 1) monitor system performance, 2) estimate the volume of free oil that forms at the top of the concentrate 
tanks and 3) conduct an oil mass balance on the system in order to note the change occurring in the system.

In Figure 4.5, permeate flux versus time for UF2-R3 is presented. In Figure 4.6, permeate turbidity versus time for UF2-R3 is presented. In Table 4.19, a summary of permeate operating parameters for UF2-R3 is presented. In Table 4.20, a summary of concentrate operating parameters for UF2-R3 is presented. In Table 4.21, a summary of permeate cleaning parameters for UF2-R3 is presented. In Table 4.22, a summary of concentrate cleaning parameters for UF2-R3 is presented. In Table 4.23, a summary of permeate $\mathrm{O} / \mathrm{G}$ samples analyzed for UF2-R3, is presented. In Table 4.24 , a summary of concentrate oil content samples analyzed for UF2-R3, is presented. In Table 4.25, a summary of free oil skimming samples analyzed for UF2-R3, is presented. In Table 4.26, a summary of free oil production for UF2-R3 is presented. In Table 4.27, a summary of pond effluent samples analyzed for UF2-R3, is presented.

\section{UF2-R3-SR1}

UF2-R3-SR1 was started on January 16, 1998 at 01:10 and ended on January 21, 1998 at 00:20. The length of the subrun lasted 4.96 days. The objectives of this subrun were to estimate the volume of free oil that forms at the top of the concentrate tanks and conduct an oil mass balance on the system. The total permeate volume produced was 211,890 gal. Subrun \#2 was stopped because the running average reached the low set point of $29 \mathrm{gal} / \mathrm{min}$. 


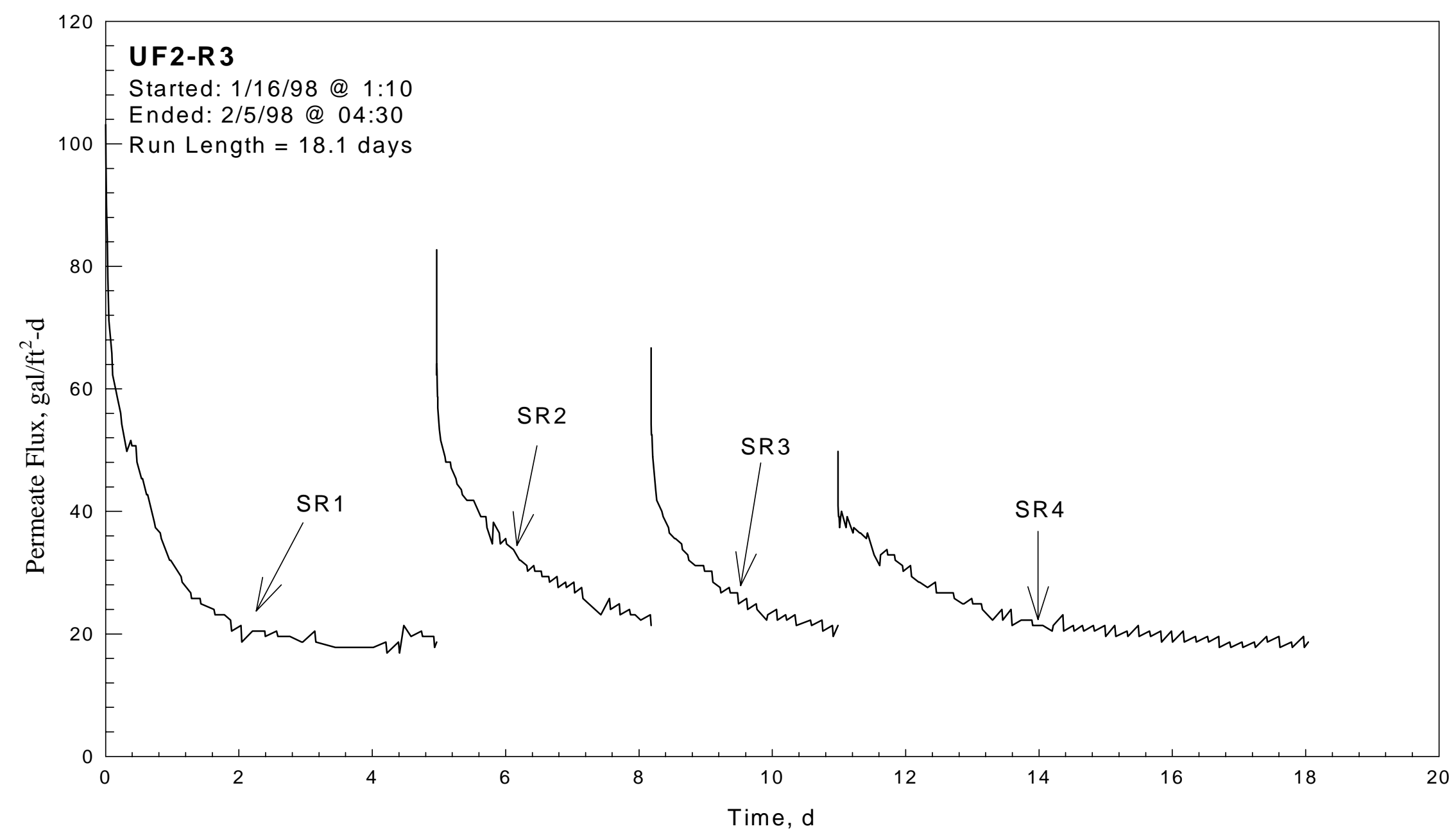

D. Figure 4.5 Permeate Flux versus Time for UF2-R3 


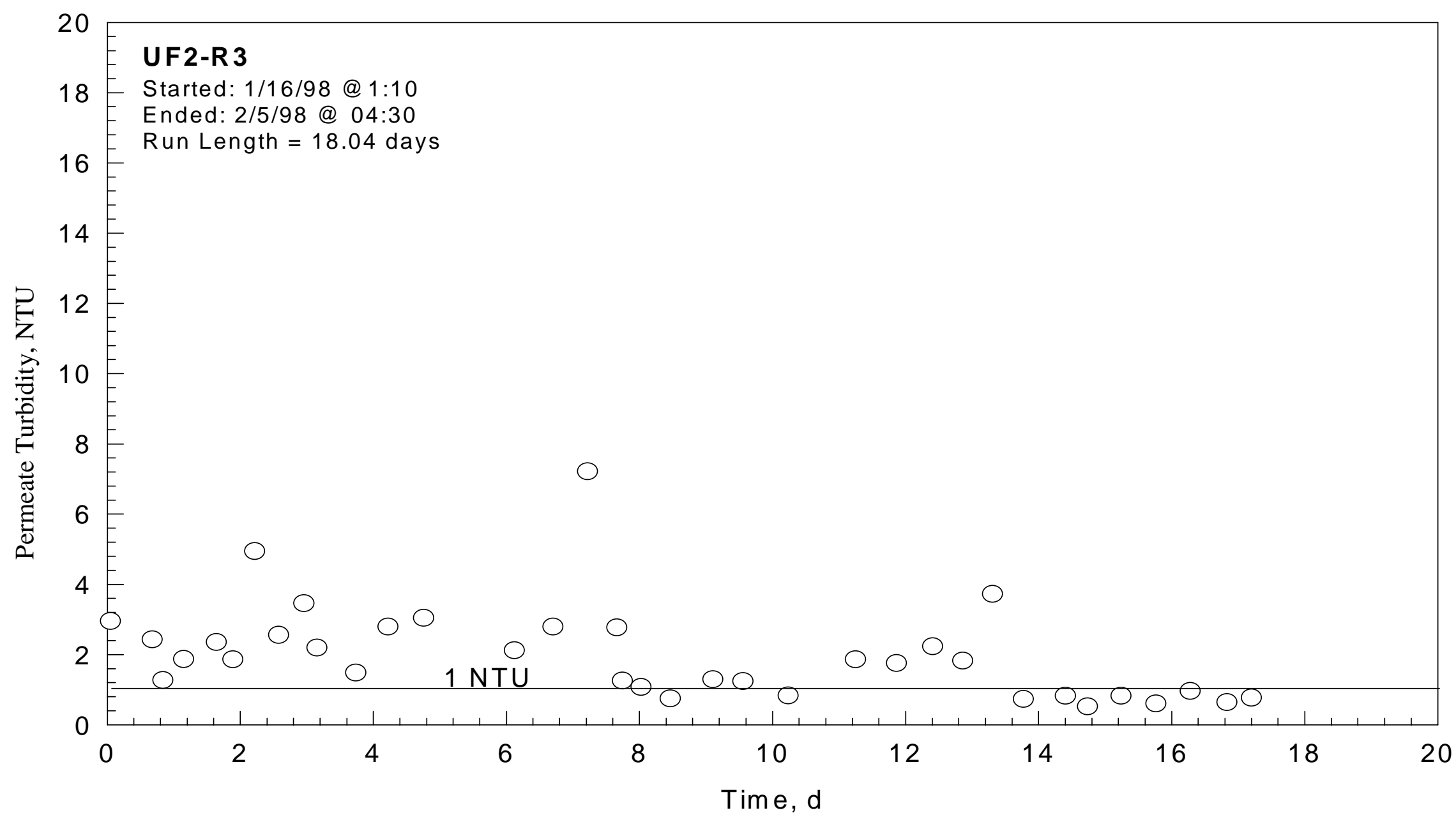

Figure 4.6 Permeate Turbidity versus Time for UF2-R3 
Table 4.19. Summary of Permeate Parameters for UF2-R3

\begin{tabular}{|c|c|c|c|c|c|c|}
\hline $\begin{array}{l}\text { Subrun } \\
\text { ID }\end{array}$ & $\begin{array}{c}\text { Flux }\left(\mathrm{gal} / \mathbf{f t}^{2}-\mathbf{d}\right) \\
{[\mathrm{min}-\max ]} \\
\text { Avg } \pm \text { std }\end{array}$ & $\begin{array}{l}\text { Temperature }\left({ }^{0} \mathbf{F}\right) \\
{[\min -\max ]} \\
\text { Avg } \pm \text { std }\end{array}$ & $\begin{array}{c}\text { Turbidity (NTU) } \\
{[\text { min }-\max ]} \\
\text { Avg } \pm \text { std }\end{array}$ & $\begin{array}{c}\text { pH } \\
{[\min -\max ]} \\
\text { Avg } \pm \text { std }\end{array}$ & $\begin{array}{c}\text { Conductivity }(\mu \mathrm{S} / \mathrm{cm}) \\
{[\min -\max ]} \\
\text { Avg } \pm \text { std }\end{array}$ & $\begin{array}{c}\text { O/G (mg/L) } \\
{[\mathrm{min}-\max ]} \\
\text { Avg } \pm \text { std }\end{array}$ \\
\hline 1 & $\begin{array}{c}{[16.9-103.2]} \\
34.2 \pm 21.5\end{array}$ & $\begin{array}{c}71.2-78.7] \\
75.7 \pm 2.3\end{array}$ & $\begin{array}{c}{[1.3-4.9]} \\
2.6 \pm 1.0\end{array}$ & $\begin{array}{c}{[5.9-6.6]} \\
6.3 \pm 0.2\end{array}$ & $\begin{array}{c}{[202-697]} \\
518 \pm 152\end{array}$ & $\begin{array}{c}{[1-5.7]} \\
3.9 \pm 1.6\end{array}$ \\
\hline 2 & $\begin{array}{c}{[21.3-82.7]} \\
38.3 \pm 13.6\end{array}$ & $\begin{array}{c}{[72.5-75.1]} \\
73.9 \pm 1.2\end{array}$ & $\begin{array}{c}{[2.1-7.2]} \\
3.4 \pm 1.9\end{array}$ & $\begin{array}{c}{[5.4-6.1]} \\
5.8 \pm 0.3\end{array}$ & $\begin{array}{c}{[361-708]} \\
504 \pm 148\end{array}$ & $\begin{array}{l}{[2-5]} \\
3.7 \pm 1.2\end{array}$ \\
\hline 3 & $\begin{array}{c}{[19.6-66.7]} \\
31.0 \pm 10.5\end{array}$ & $\begin{array}{c}{[72.5-76.9]} \\
74 \pm 1.6\end{array}$ & $\begin{array}{c}0.75-1.3] \\
1.1 \pm 0.23 \\
\end{array}$ & $\begin{array}{c}{[5.4-5.9]} \\
5.6 \pm 0.2 \\
\end{array}$ & $\begin{array}{c}{[512-656]} \\
536 \pm 53\end{array}$ & $\begin{array}{l}{[3-5]} \\
3.7 \pm 1.2\end{array}$ \\
\hline 4 & $\begin{array}{c}17.8-99.8] \\
25.3 \pm 7.3\end{array}$ & $\begin{array}{c}73.6-77.5] \\
75.6 \pm 1.2\end{array}$ & $\begin{array}{c}{[0.52-9.8]} \\
1.9 \pm 2.4\end{array}$ & $\begin{array}{c}{[4.5-6.0]} \\
5.4 \pm 0.5\end{array}$ & $\begin{array}{c}{[168-630]} \\
496 \pm 134\end{array}$ & $\begin{array}{l}{[2-6]} \\
4.0 \pm 1.3\end{array}$ \\
\hline
\end{tabular}


Table 4.20. Summary of Concentrate and Pond Effluent O/G Parameters for UF2-R3

\begin{tabular}{|c|c|c|c|c|c|}
\hline $\begin{array}{l}\text { Subrun } \\
\text { ID }\end{array}$ & $\begin{array}{l}\text { Temperature }\left({ }^{{ }^{O}} \mathbf{F}\right) \\
{[\min -\max ]} \\
\text { Avg } \pm \text { std }\end{array}$ & $\begin{array}{c}\text { pH } \\
{[\min -\text { max }]} \\
\text { Avg } \pm \text { std }\end{array}$ & $\begin{array}{c}\text { Conductivity }(\mu \mathrm{S} / \mathrm{cm}) \\
{[\mathrm{min}-\max ]} \\
\text { Avg } \pm \text { std }\end{array}$ & $\begin{array}{c}\text { Oil Content (\%) } \\
{[\mathrm{min}-\max ]} \\
\text { Avg } \pm \text { std } \\
\end{array}$ & $\begin{array}{c}\text { Pond Effluent O/G (mg/L) } \\
{[\text { min - max }]} \\
\text { Avg } \pm \text { std }\end{array}$ \\
\hline 1 & $\begin{array}{c}{[76-84.7]} \\
80.6 \pm 2.6\end{array}$ & $\begin{array}{c}{[5.7-6.5]} \\
6.2 \pm 0.3\end{array}$ & $\begin{array}{c}188-584] \\
476 \pm 147\end{array}$ & $\begin{array}{c}{[0.86-5.7]} \\
3.1 \pm 2.1\end{array}$ & $\begin{array}{c}0.3-1.2] \\
0.6 \pm 0.5\end{array}$ \\
\hline 2 & $\begin{array}{c}77-79.5] \\
78.1 \pm 1.1 \\
\end{array}$ & $\begin{array}{c}{[5.1-6.2]} \\
5.8 \pm 0.5 \\
\end{array}$ & $\begin{array}{c}388-680] \\
568 \pm 125 \\
\end{array}$ & $\begin{array}{c}{[5.7-9.6]} \\
7.6 \pm 2.7 \\
\end{array}$ & $\begin{array}{c}{[0.5-0.6]} \\
0.55 \pm 0.07\end{array}$ \\
\hline 3 & $\begin{array}{c}{[76.3-81.1]} \\
78.6 \pm 1.8 \\
\end{array}$ & $\begin{array}{c}{[5.7-6.1]} \\
5.9 \pm 0.2 \\
\end{array}$ & $\begin{array}{c}152-536] \\
372 \pm 198 \\
\end{array}$ & $\begin{array}{c}1.6-10.1] \\
5.8 \pm 6.0 \\
\end{array}$ & $\begin{array}{c}{[1.2-3.4]} \\
2.3 \pm 1.6 \\
\end{array}$ \\
\hline 4 & $\begin{array}{c}77-82.3] \\
80 \pm 1.5 \\
\end{array}$ & $\begin{array}{c}{[4.8-5.8]} \\
5.5 \pm 0.4\end{array}$ & $\begin{array}{c}198-636] \\
446 \pm 181 \\
\end{array}$ & $\begin{array}{c}10.1-9.8] \\
8.3 \pm 2.1 \\
\end{array}$ & $\begin{array}{c}{[0.6-3.1]} \\
1.3 \pm 0.9\end{array}$ \\
\hline
\end{tabular}


Table 4.21. Summary of Permeate Cleaning Parameters for UF2-R3

\begin{tabular}{|c|c|c|c|c|c|}
\hline $\begin{array}{l}\text { Subrun } \\
\text { ID }\end{array}$ & $\begin{array}{c}\text { Flux }\left(\text { gal/ft }{ }^{2}-d\right) \\
{[\min -\text { max }]} \\
\text { Avg } \pm \text { std }\end{array}$ & $\begin{array}{l}\text { Temperature }\left({ }^{\circ} \mathrm{F}\right) \\
{[\mathrm{min}-\max ]} \\
\text { Avg } \pm \text { std }\end{array}$ & $\begin{array}{l}\text { Turbidity (NTU) } \\
\text { [min - max] } \\
\text { Avg } \pm \text { std }\end{array}$ & $\begin{array}{c}\text { pH } \\
{[\underset{\min }{\text { Avg } \pm \text { max }]}}\end{array}$ & $\begin{array}{c}\text { Conductivity }(\mu \mathrm{S} / \mathrm{cm}) \\
{[\mathrm{min}-\max ]} \\
\text { Avg } \pm \text { std }\end{array}$ \\
\hline 1 & $\begin{array}{c}{[33.7-77.4]} \\
54.6 \pm 3.8\end{array}$ & $\begin{array}{c}{[86.8-96.9]} \\
92.1 \pm 2.9\end{array}$ & $\begin{array}{c}{[4.2-9.1]} \\
6.5 \pm 1.9\end{array}$ & $\begin{array}{c}5.4-6.9] \\
6.8 \pm 0.4\end{array}$ & $\begin{array}{c}{[718-885]} \\
809 \pm 60\end{array}$ \\
\hline 2 & $\begin{array}{c}{[42.7-67.6]} \\
56.4 \pm 4.5\end{array}$ & $\begin{array}{c}{[90.7-99.2]} \\
95.8 \pm 3.4\end{array}$ & $\begin{array}{c}{[2.5-9.3]} \\
4.1 \pm 2.2\end{array}$ & $\begin{array}{c}{[6.5-6.9]} \\
6.7 \pm 0.1\end{array}$ & $\begin{array}{c}{[609-903]} \\
789 \pm 86\end{array}$ \\
\hline 3 & $\begin{array}{c}{[33.8-53.4]} \\
43.1 \pm 1.5\end{array}$ & $\begin{array}{c}{[89.4-99.6]} \\
95.8 \pm 3.8\end{array}$ & $\begin{array}{c}{[2.9-19.0]} \\
8.3 \pm 5.4\end{array}$ & $\begin{array}{c}{[6.3-6.7]} \\
6.5 \pm 0.1\end{array}$ & $\begin{array}{c}636-864] \\
758 \pm 83\end{array}$ \\
\hline 4 & $\begin{array}{c}{[26.7-67.6]} \\
47.9 \pm 3.5\end{array}$ & $\begin{array}{c}89.7-97.2] \\
94 \pm 2.0\end{array}$ & $\begin{array}{c}{[4.4-38.8]} \\
13.1 \pm 12.8\end{array}$ & $\begin{array}{c}{[5.9-6.2]} \\
6.1 \pm 0.1\end{array}$ & $\begin{array}{c}{[762-880]} \\
835 \pm 41\end{array}$ \\
\hline
\end{tabular}


Table 4.22. Summary of Concentrate Cleaning Parameters for UF2-R3

\begin{tabular}{||c|c|c|c|}
\hline $\begin{array}{l}\text { Subrun } \\
\text { ID }\end{array}$ & $\begin{array}{c}\text { Temperature }\left({ }^{\mathbf{O}} \mathbf{F}\right) \\
{[\mathbf{m i n}-\mathbf{m a x}]} \\
\mathbf{A v g} \pm \text { std }\end{array}$ & $\begin{array}{c}\mathbf{p H} \\
{[\mathbf{m i n}-\mathbf{m a x}]} \\
\mathbf{A v g} \pm \mathbf{s t d}\end{array}$ & $\begin{array}{c}\text { Conductivity }(\boldsymbol{\mu S} \mathbf{S} \mathbf{c m}) \\
{[\mathbf{m i n}-\mathbf{m a x}]} \\
\mathbf{A v g} \pm \text { std }\end{array}$ \\
\hline 1 & {$[94.7-107]$} & {$[5.7-6.8]$} & {$[1209-1528]$} \\
& $101.3 \pm 2.7$ & $6.3 \pm 0.4$ & $1398 \pm 122$ \\
\hline 2 & {$[99.2-109.3]$} & {$[6.7-6.8]$} & {$[1266-1809]$} \\
& $104 \pm 3.4$ & $6.7 \pm 0.1$ & $1523 \pm 236$ \\
\hline 3 & {$[98.1-110.1]$} & {$[6.3-6.7]$} & {$[1060-1402]$} \\
& $104.7 \pm 3.7$ & $6.5 \pm 0.1$ & $1241 \pm 150$ \\
\hline 4 & {$[96.8-108.9]$} & {$[5.9-6.4]$} & {$[1751-1912]$} \\
& $103 \pm 2.8$ & $6.2 \pm 0.1$ & $1835 \pm 62$ \\
\hline
\end{tabular}


Table 4.23 Summary of Permeate O/G Samples for UF2-R3

\begin{tabular}{|c|c|c|c|c|}
\hline \multirow[t]{2}{*}{ Subrun ID } & \multirow[t]{2}{*}{ Date/Time } & \multicolumn{3}{|c|}{ Sample Results $(\mathrm{mg} / \mathrm{L})$} \\
\hline & & $\# 1$ & $\# 2$ & $\# 3$ \\
\hline 1 & 1/16/98 (02:21) & 4 & & \\
\hline 1 & 1/16/98 (19:06) & & & \\
\hline 1 & 1/17/98 (04:03) & 5 & & \\
\hline 1 & 1/17/98 (16:36) & & & \\
\hline 1 & 1/18/98 (06:26) & 6 & 6 & 5 \\
\hline 1 & 1/18/98 (15:08) & & & \\
\hline 1 & 1/19/98 (04:52) & 3 & & \\
\hline 1 & 1/19/98 (18:50) & & & \\
\hline 1 & 1/20/98 (06:27) & 4 & & \\
\hline 1 & 1/20/98 (19:10) & 1 & & \\
\hline 2 & 1/21/98 (11:51) & 4 & & \\
\hline 2 & 1/22/98 (00:38) & & & \\
\hline 2 & 1/22/98 (13:00) & 2 & & \\
\hline 2 & 1/23/98 (02:56) & 3 & & \\
\hline 2 & $1 / 23 / 98(15: 21)$ & 5 & & \\
\hline 2 & 1/24/98(02:00) & 4 & 5 & 5 \\
\hline 3 & $1 / 24 / 98(17: 28)$ & 3 & & \\
\hline 3 & 1/24/98 (00:14) & & & \\
\hline 3 & 1/25/98 (11:04) & 3 & & \\
\hline 3 & 1/26/98 (02:20) & & & \\
\hline 3 & 1/26/98 (13:06) & 5 & & \\
\hline 3 & 1/27/98 (03:44) & & & \\
\hline 4 & 1/29/98 (11:10) & 4 & & \\
\hline 4 & $1 / 29 / 98(23: 41)$ & & & \\
\hline 4 & 1/30/98 (14:27) & 4 & & \\
\hline 4 & 1/31/98 (03:33) & 3 & 3 & 3 \\
\hline 4 & $1 / 31 / 98(14: 22)$ & & & \\
\hline 4 & $2 / 1 / 98(01: 10)$ & 3 & & \\
\hline 4 & 2/1/98 (12:08) & & & \\
\hline 4 & $2 / 2 / 98(03: 14)$ & 5 & & \\
\hline 4 & 2/2/98 (11:16) & & & \\
\hline 4 & $2 / 2 / 98(23: 22)$ & 6 & & \\
\hline 4 & 2/3/98 (11:54) & & & \\
\hline 4 & 2/4/98 (00:16) & 2 & & \\
\hline 4 & 2/4/98 (13:30) & & & \\
\hline 4 & 2/4/98 (22:33) & 4 & 5 & 5 \\
\hline
\end{tabular}


Table 4.24 Summary of Concentrate Oil Content Samples for UF2-R3

\begin{tabular}{|c|c|c|c|c|}
\hline Subrun ID & \multirow{2}{*}{ Date/Time } & \multicolumn{3}{|c|}{ Sample Results (\%) } \\
\cline { 3 - 5 } & & $\mathbf{A 1}$ & $\mathbf{\# 2}$ & $\mathbf{\# 3}$ \\
\hline \hline 1 & $1 / 16 / 98(01: 20)$ & 0.9 & 0.9 & 0.8 \\
\hline 1 & $1 / 16 / 98(09: 02)$ & 1.4 & 1.2 & 1.3 \\
\hline 1 & $1 / 16 / 98(21: 15)$ & 2.2 & 2.1 & 2.4 \\
\hline 1 & $1 / 17 / 98(22: 30)$ & 2.1 & 2.5 & 2.2 \\
\hline 1 & $1 / 19 / 98(00: 05)$ & 3.1 & 3.6 & 4.1 \\
\hline 2 & $1 / 20 / 98(06: 27)$ & 3.7 & 4.1 & 3.7 \\
\hline 2 & $1 / 21 / 98(04: 42)$ & 6.6 & 6.3 & 4.3 \\
\hline 2 & $1 / 22 / 98(00: 36)$ & 5.2 & & \\
\hline 2 & $1 / 22 / 98(18: 15)$ & 3.2 & & \\
\hline 3 & $1 / 24 / 98(09: 35)$ & 9.5 & 8.4 & 9.6 \\
\hline 3 & $1 / 24 / 98(15: 50)$ & 1.3 & 1.5 & 1.9 \\
\hline 3 & $1 / 26 / 98(23: 45)$ & 8.5 & 7.4 & 10.1 \\
\hline 4 & $1 / 27 / 98(09: 00)$ & 10.0 & 9.8 & 10.7 \\
\hline 4 & $1 / 28 / 98(03: 20)$ & 6.8 & 6.8 & 5.9 \\
\hline 4 & $1 / 29 / 98(04: 22)$ & 7.6 & & \\
\hline 4 & $1 / 31 / 98(04: 16)$ & & & \\
\hline 4 & $2 / 2 / 98(11: 55)$ & 9.8 & 9.6 & 10.0 \\
\hline & $2 / 5 / 98(04: 20)$ & 9.8 & 9.7 & 9.9 \\
\hline
\end{tabular}


Table 4.25 Summary of Skimming Samples for UF2-R3

\begin{tabular}{|c|c|c|c|c|}
\hline Subrun ID & Date/Time & \multicolumn{3}{|c|}{ Sample Results (\%) } \\
\cline { 3 - 5 } & & $\mathbf{\# 1}$ & $\mathbf{\# 2}$ & $\mathbf{\# 3}$ \\
\hline \hline 1 & $1 / 16 / 98(02: 33)$ & 80 & & \\
\hline 2 & $1 / 24 / 98(23: 15)$ & 100 & & \\
\hline 3 & $1 / 25 / 98(00: 30)$ & 100 & & \\
\hline 3 & $1 / 25 / 98(14: 20)$ & 100 & & \\
\hline 3 & $1 / 26 / 98(16: 46)$ & 100 & & \\
\hline 3 & $1 / 27 / 98(17: 05)$ & 99 & & \\
\hline 3 & $1 / 28 / 98(23: 04)$ & 100 & & \\
\hline 3 & $1 / 28 / 98(23: 53)$ & 99 & & \\
\hline 4 & $1 / 29 / 98(16: 36)$ & 99 & & \\
\hline 4 & $1 / 30 / 98(07: 39)$ & 99 & & \\
\hline 4 & $1 / 30 / 98(15: 00)$ & 99 & & \\
\hline 4 & $1 / 31 / 98(15: 13)$ & 98 & & \\
\hline 4 & $2 / 1 / 98(17: 28)$ & 100 & & \\
\hline 4 & $2 / 2 / 98(04: 08)$ & 99 & & \\
\hline 4 & $2 / 2 / 98(11: 40)$ & 99 & & \\
\hline 4 & $2 / 3 / 98(04: 57)$ & 100 & & \\
\hline 4 & $2 / 3 / 98(12: 12)$ & 100 & & \\
\hline 4 & $2 / 4 / 98(04: 50)$ & 99 & & \\
\hline 4 & $2 / 4 / 98(14: 00)$ & 100 & & \\
\hline 4 & $2 / 5 / 98(07: 13)$ & 100 & & \\
\hline
\end{tabular}


Table 4.26 Summary of Free Oil Productions for UF2-R3

\begin{tabular}{|c|c|c|c|}
\hline Subrun ID & Subrun Length, & Total Free Oil, gal & Free Oil Production, gal/d \\
\hline 1 & 5.0 & 164 & 32.8 \\
\hline 2 & 3.2 & 313 & 97.8 \\
\hline 3 & 2.8 & 1,949 & 696.1 \\
\hline 4 & 7.1 & 1,951 & 274.8 \\
\hline
\end{tabular}


Table 4.27 Summary of Pond Effluent O/G Samples for UF2-R3

\begin{tabular}{|c|c|c|c|c|}
\hline \multirow{2}{*}{ Subrun ID } & \multirow{2}{*}{ Date/Time } & \multicolumn{3}{|c|}{ Sample Results (mg/L) } \\
\cline { 3 - 5 } & & $\mathbf{\# 1}$ & $\mathbf{\# 2}$ & $\mathbf{\# 3}$ \\
\hline 1 & $1 / 16 / 98(12: 10)$ & 4,000 & & \\
\hline 1 & $1 / 17 / 98(11: 20)$ & 3,000 & & \\
\hline 1 & $1 / 19 / 98(18: 30)$ & 12,000 & & \\
\hline 2 & $1 / 21 / 98(13: 32)$ & 5,000 & & \\
\hline 2 & $1 / 23 / 98(18: 35)$ & 6,000 & & \\
\hline 3 & $1 / 25 / 98(10: 55)$ & 18,000 & & \\
\hline 3 & $1 / 27 / 98(07: 20)$ & 34,000 & & \\
\hline 4 & $1 / 29 / 98(11: 00)$ & 31,000 & & \\
\hline 4 & $1 / 31 / 98(10: 30)$ & 14,000 & & \\
\hline 4 & $2 / 1 / 98(11: 48)$ & 11,000 & & \\
\hline 4 & $2 / 2 / 98(11: 05)$ & 10,000 & & \\
\hline 4 & $2 / 3 / 98(11: 40)$ & 6,000 & 7,000 & 6,000 \\
\hline 4 & $2 / 4 / 98(13: 18)$ & 8,000 & & \\
\hline
\end{tabular}




\section{Permeate Flux and System Temperature}

Over the course of the subrun, the permeate flux ranged from 16.9 to 103.2 gal/ $/ \mathrm{ft}^{2}$-d. Permeate temperature ranged from 71.2 to $78.7^{\circ} \mathrm{F}$ with an average of $75.7^{\circ} \mathrm{F}$. Concentrate temperatures ranged from 76.0 to $84.7^{\circ} \mathrm{F}$ with an average of $80.6^{\circ} \mathrm{F}$.

\section{Concentrate Oil Content and Free Oil Production}

During subrun \#1, concentrate oil content started at $0.4 \%$ oil and increased to 1.2 $\%$ oil. The total volume of free oil that was produced during subrun \#1 was 164 gallons. The average daily free oil production was 32.8 gallons/day.

\section{Permeate Oil/Grease, Turbidity and Pond Effluent}

Permeate $\mathrm{O} / \mathrm{G}$ remained low, averaging $3.8 \mathrm{mg} / \mathrm{L}$ and ranging from 1.0 to 5.7 $\mathrm{mg} / \mathrm{L}$. Turbidity was also low, averaging $2.5 \mathrm{NTU}$ and ranging from 1.3 to $4.9 \mathrm{NTU}$. Pond effluent $\mathrm{O} / \mathrm{G}$ ranged from 3,000 to $12,000 \mathrm{mg} / \mathrm{L}$ and averaged 6,333.

\section{Conductivity and $\mathrm{pH}$}

Permeate $\mathrm{pH}$ ranged from 5.9 to 6.6 with an average of 6.3. Concentrate $\mathrm{pH}$ ranged from 5.7 to 6.5 with an average of 6.2. Permeate conductivity ranged from 188 to $584 \mu \mathrm{S} / \mathrm{cm}$ and averaged $476 \mu \mathrm{S} / \mathrm{cm}$. Concentrate conductivity's ranged from 202 to 697 $\mu \mathrm{S} / \mathrm{cm}$ and averaged $518 \mu \mathrm{S} / \mathrm{cm}$.

\section{UF2-R3-SR1 Cleaning}

After UF2-R3-SR1 was shutdown on January 21, 1998 at 00:20 it was cleaned at 00:50, with a $0.5 \%$ KLD cleaning solution. Once the cleaning water was heated to 
$\sim 100^{\circ} \mathrm{F}$, the system was cleaned for one hour under the regular cleaning cycle. After one hour elapsed, the system was shutdown and prepared for a spongeball sequence. Once the valves were adjusted on the system for spongeball retrieval, the system under went two spongeball passes. After the spongeball sequence was performed, the valves were readjusted to the normal mode setting. The system was then cleaned for an additional hour with the same cleaning solution. The total downtime for the cleaning was 250 minutes.

\section{Permeate Flux and System Temperature}

During the first hour of cleaning the permeate flux ranged from 33.7 to 45.0 $\mathrm{gal} / \mathrm{ft}^{2}-\mathrm{d}$ and averaged $39.0 \mathrm{gal} / \mathrm{ft}^{2}-\mathrm{d}$. Permeate temperature during the first hour of cleaning ranged from 86.8 to $94.0^{\circ} \mathrm{F}$ and averaged $90.3^{\circ} \mathrm{F}$. Concentrate temperature ranged from 94.7 to $102^{\circ} \mathrm{F}$ and averaged $98.6^{\circ} \mathrm{F}$.

After one hour, the system was shutdown and the valves were adjusted for the spongeball sequence. During the first pass of spongeballs, the permeate flux increased to $97.8 \mathrm{gal} / \mathrm{ft}^{2}-\mathrm{d}$. The second pass of spongeballs yielded a permeate flux of $90.7 \mathrm{gal} / \mathrm{ft}^{2}-\mathrm{d}$. After two spongeball passes were performed the system was cleaned for an additional hour.

In the second hour of regular cleaning, the permeate flux ranged from 66.7 to $77.4 \mathrm{gal} / \mathrm{ft}^{2}-\mathrm{d}$ with an average of $70.1 \mathrm{gal} / \mathrm{ft}^{2}-\mathrm{d}$. Permeate temperature ranged from 90.2 to $96.9^{\circ} \mathrm{F}$ with an average of $93.9^{\circ} \mathrm{F}$. Concentrate temperature ranged from 101 to $107^{\circ} \mathrm{F}$ with an average of $104^{\circ} \mathrm{F}$.

\section{pH, Conductivity and Turbidity}

Permeate $\mathrm{pH}$ over the course of the cleaning ranged from 5.4 to 7.0 and averaged 6.8. Concentrate $\mathrm{pH}$ ranged from 5.7 to 6.8 and averaged 6.3. Permeate conductivity averaged $809 \mu \mathrm{S} / \mathrm{cm}$ and ranged from 718 to $885 \mu \mathrm{S} / \mathrm{cm}$. Concentrate conductivity 
averaged $1398 \mu \mathrm{S} / \mathrm{cm}$ and ranged from 1209 to $1528 \mu \mathrm{S} / \mathrm{cm}$. Permeate turbidity ranged from 4.2 to $9.1 \mathrm{NTU}$ and averaged $6.5 \mathrm{NTU}$.

\section{UF2-R3-SR2}

UF2-R3-SR2 was started on January 21, 1998 at 04:30 and ended on January 24, 1998 at 09:40. The length of the subrun lasted 3.2 days. The total permeate volume produced was 168,230 gal. Subrun \#2 was stopped before a running average of 29 $\mathrm{gal} / \mathrm{min}$ was reached because the instantaneous permeate flow was had reached 24 $\mathrm{gal} / \mathrm{min}$. The system is expected to be shutdown for a long period of time in the near future for valve replacements. Thus, the system was shutdown, cleaned and restarted, to restore high permeate flow, in order to decrease high pond level concerns, during the future shutdown.

\section{Permeate Flux and System Temperature}

Over the course of the subrun, the permeate flux ranged from 21.3 to $82.7 \mathrm{gal} / \mathrm{ft}^{2}-$

d. Permeate temperature ranged from 72.5 to $75.1^{\circ} \mathrm{F}$ with an average of $73.9^{\circ} \mathrm{F}$. Concentrate temperatures ranged from 77.0 to $79.5^{\circ} \mathrm{F}$ with an average of $78.1^{\circ} \mathrm{F}$.

\section{Concentrate Oil Content and Free Oil Production}

During subrun \#2 the concentrate oil content started out at $6.6 \%$ and increased to $9.6 \%$ at the end. The total volume of free oil that was produced during subrun \#2 was 313 gallons. The average daily free oil production was 97.8 gallons/day. 


\section{Permeate Oil/Grease, Turbidity and Pond Effluent}

Permeate $(\mathrm{O} / \mathrm{G})$ remained low, averaging $3.7 \mathrm{mg} / \mathrm{L}$ and ranging from 2.0 to 5.0 $\mathrm{mg} / \mathrm{L}$. Turbidity was also low, averaging 3.4 NTU and ranging from 2.1 to $7.2 \mathrm{NTU}$. Pond effluent samples ranged from 5000 to $6000 \mathrm{mg} / \mathrm{L}$ and ranged $5500 \mathrm{mg} / \mathrm{L}$.

\section{Conductivity and $\mathrm{pH}$}

Permeate $\mathrm{pH}$ ranged from 5.4 to 6.1 with an average of 5.8. Concentrate $\mathrm{pH}$ ranged from 5.1 to 6.2 with an average of 5.8. Permeate conductivity ranged from 361 to $708 \mu \mathrm{S} / \mathrm{cm}$ and averaged $504 \mu \mathrm{S} / \mathrm{cm}$. Concentrate conductivity's ranged from 388 to 680 $\mu \mathrm{S} / \mathrm{cm}$ and averaged $568 \mu \mathrm{S} / \mathrm{cm}$.

\section{UF2-R3-SR2 Cleaning}

After UF2-R3-SR2 was shutdown on January 24, 1998 at 09:40 it was cleaned at 11:00, with a $0.5 \%$ KLD cleaning solution. Once the cleaning water was heated to $\sim 100^{\circ} \mathrm{F}$, the system was cleaned for one hour under the regular cleaning cycle. After one hour elapsed, the system was shutdown and prepared for a spongeball sequence. Once the valves were adjusted on the system for spongeball retrieval, the system under went two spongeball passes. After the spongeball sequence was performed, the valves were readjusted to the normal mode setting. The system was then cleaned for an additional hour with the same cleaning solution. The total downtime for the cleaning was 350 minutes.

\section{Permeate Flux and System Temperature}

During the first hour of cleaning the permeate flux ranged from 42.7 to 50.7 $\mathrm{gal} / \mathrm{ft}^{2}-\mathrm{d}$ and averaged $47.1 \mathrm{gal} / \mathrm{ft}^{2}-\mathrm{d}$. Permeate temperature during the first hour of cleaning ranged from 90.7 to $99.4^{\circ} \mathrm{F}$ and averaged $95.8^{\circ} \mathrm{F}$. Concentrate temperature ranged from 99.2 to $109.3{ }^{\circ} \mathrm{F}$ and averaged $104.4^{\circ} \mathrm{F}$. 
After one hour, the system was shutdown and the valves were adjusted for the spongeball sequence. During the first pass of spongeballs, the permeate flux increased to $117.4 \mathrm{gal} / \mathrm{ft}^{2}-\mathrm{d}$. The second pass of spongeballs yielded a permeate flux of $111.2 \mathrm{gal} / \mathrm{ft}^{2}-$ d. After two spongeball passes were performed the system was cleaned for an additional hour.

In the second hour of regular cleaning, the permeate flux ranged from 64.0 to 67.6 $\mathrm{gal} / \mathrm{ft}^{2}-\mathrm{d}$ with an average of $65.6 \mathrm{gal} / \mathrm{ft}^{2}-\mathrm{d}$. Permeate temperature ranged from 92.2 to $99.2^{\circ} \mathrm{F}$ with an average of $95.8^{\circ} \mathrm{F}$. Concentrate temperature ranged from 99.1 to $109{ }^{\circ} \mathrm{F}$ with an average of $104.3^{\circ} \mathrm{F}$.

\section{pH, Conductivity and Turbidity}

Permeate $\mathrm{pH}$, over the course of the cleaning ranged from 6.5 to 6.9 and averaged 6.7. Concentrate $\mathrm{pH}$ ranged from 6.7 to 6.8 and averaged 6.72. Permeate conductivity averaged $789 \mu \mathrm{S} / \mathrm{cm}$ and ranged from 609 to $903 \mu \mathrm{S} / \mathrm{cm}$. Concentrate conductivity averaged $1523 \mu \mathrm{S} / \mathrm{cm}$ and ranged from 1266 to $1809 \mu \mathrm{S} / \mathrm{cm}$. Permeate turbidity ranged from 2.5 to 9.2 NTU and averaged 4.1 NTU.

\section{UF2-R3-SR3}

UF2-R3-SR3 was started on January 24, 1998 at 15:30 and ended on January 27, 1998 at 09:15. The length of the subrun lasted 2.8 days. The total permeate volume produced was 124,430 gal. The system was shutdown, because the permeate running average reached the $29 \mathrm{gal} / \mathrm{min}$ set point.

\section{Permeate Flux and System Temperature}

Over the course of the subrun, the permeate flux ranged from 19.6 to $66.7 \mathrm{gal} / \mathrm{ft}^{2}-$ d. Permeate temperature ranged from 72.2 to $76.9^{\circ} \mathrm{F}$ with an average of $74.0^{\circ} \mathrm{F}$. Concentrate temperatures ranged from 76.3 to $81.1^{\circ} \mathrm{F}$ with an average of $78.6^{\circ} \mathrm{F}$. 


\section{Concentrate Oil Content and Free Oil Production}

Concentrate oil content started out at $1.6 \%$ and increased to $10.1 \%$ by the end of subrun \#3. The total volume of free oil that was produced during subrun \#3 was 1,949 gallons. The average daily free oil production was 696.1 gallons/day.

\section{Permeate Oil/Grease, Turbidity and Pond Effluent}

Permeate $\mathrm{O} / \mathrm{G}$ remained low, averaging $3.7 \mathrm{mg} / \mathrm{L}$ and ranging from 3.0 to 5.0

mg/L. Turbidity was also low, averaging $1.1 \mathrm{NTU}$ and ranging from 0.75 to $1.3 \mathrm{NTU}$. Pond Effluent ranged from 12,000 to 34,000 mg/L and averaged 23,000 mg/L.

\section{Conductivity and pH}

Permeate $\mathrm{pH}$ ranged from 5.4 to 5.9 with an average of 5.6. Concentrate $\mathrm{pH}$ ranged from 5.7 to 6.1 with an average of 5.9. Permeate conductivity ranged from 512 to $656 \mu \mathrm{S} / \mathrm{cm}$ and averaged $536 \mu \mathrm{S} / \mathrm{cm}$. Concentrate conductivity's ranged from 152 to 536 $\mu \mathrm{S} / \mathrm{cm}$ and averaged $372 \mu \mathrm{S} / \mathrm{cm}$.

\section{UF2-R3-SR3 Cleaning}

After UF2-R3-SR3 was shutdown on January 27, 1998 at 09:15 it was cleaned at $10: 45$, with a $0.5 \%$ KLD cleaning solution. Once the cleaning water was heated to $\sim 100{ }^{\circ} \mathrm{F}$, the system was cleaned for one hour under the regular cleaning cycle. The total downtime for the cleaning was 2445 minutes. An acid cleaning was preformed after subrun \#3 ended. Therefore a large downtime occurred. 


\section{Permeate Flux and System Temperature}

During the first hour of cleaning the permeate flux ranged from 33.8 to 36.5 $\mathrm{gal} / \mathrm{ft}^{2}-\mathrm{d}$ and averaged $34.9 \mathrm{gal} / \mathrm{ft}^{2}-\mathrm{d}$. Permeate temperature during the first hour of cleaning ranged from 89.4 to $100.8^{\circ} \mathrm{F}$ and averaged $95.4{ }^{\circ} \mathrm{F}$. Concentrate temperature ranged from 98.1 to $109.9{ }^{\circ} \mathrm{F}$ and averaged $104^{\circ} \mathrm{F}$.

After one hour, the system was shutdown and the valves were adjusted for the spongeball sequence. During the first pass of spongeballs, the permeate flux increased to $69.4 \mathrm{gal} / \mathrm{ft}^{2}-\mathrm{d}$. The second pass of spongeballs yielded a permeate flux of $88.9 \mathrm{gal} / \mathrm{ft}^{2}-\mathrm{d}$. After two spongeball passes were performed the system was cleaned for an additional hour.

In the second hour of regular cleaning, the permeate flux ranged from 49.8 to 53.4 $\mathrm{gal} / \mathrm{ft}^{2}-\mathrm{d}$ with an average of $51.2 \mathrm{gal} / \mathrm{ft}^{2}-\mathrm{d}$. Permeate temperature ranged from 92.2 to $99.6^{\circ} \mathrm{F}$ with an average of $96.2^{\circ} \mathrm{F}$. Concentrate temperature ranged from 99.9 to $110.1^{\circ} \mathrm{F}$ with an average of $105.4^{\circ} \mathrm{F}$.

\section{pH, Conductivity and Turbidity}

Permeate $\mathrm{pH}$ over the course of the cleaning ranged from 6.3 to 6.7 and averaged 6.5. Concentrate $\mathrm{pH}$ ranged from 6.3 to 6.7 and averaged 6.5. Permeate conductivity averaged $758 \mu \mathrm{S} / \mathrm{cm}$ and ranged from 636 to $864 \mu \mathrm{S} / \mathrm{cm}$. Concentrate conductivity averaged $1241 \mu \mathrm{S} / \mathrm{cm}$ and ranged from 1060 to $1402 \mu \mathrm{S} / \mathrm{cm}$. Permeate turbidity ranged from 2.9 to $19.0 \mathrm{NTU}$ and averaged 8.3 NTU.

\section{UF2-R3-SR4}

UF2-R3-SR4 was started on January 29, 1998 at 03:00 and ended on February 5, 1998 at 04:30. The length of the subrun lasted 7.06 days. The total permeate volume produced was 277,940 gal. Subrun \#4 running average was far below the $29 \mathrm{gal} / \mathrm{min}$ set point, because the average never reached the system average. The permeate flow only 
started out around $50 \mathrm{gal} / \mathrm{min}$. and dropped to the mid twenties a day and a half into the subrun run. The system was not shutdown, because the instantaneous permeate flow never reached $18 \mathrm{gal} / \mathrm{min}$. Subrun \#4 marked the end of UF2-R3. After the system was shutdown the concentrate in the feed tank was purged to the tank farm.

\section{Permeate Flux and System Temperature}

Over the course of the subrun, the permeate flux ranged from 17.8 to $49.8 \mathrm{gal} / \mathrm{ft}^{2}-$ d. Permeate temperature ranged from 73.6 to $77.5^{\circ} \mathrm{F}$ with an average of $75.6^{\circ} \mathrm{F}$. Concentrate temperatures ranged from 77.0 to $82.3^{\circ} \mathrm{F}$ with an average of $80.0^{\circ} \mathrm{F}$.

\section{Concentrate Oil Content and Free Oil Production}

Concentrate Oil content started out at $10.1 \%$ and decreased to $9.8 \%$ during subrun \#4. The total volume of free oil that was produced during subrun \#4 was 1,951 gallons. The average daily free oil production was 274.8 gallons/day.

\section{Permeate Oil/Grease, Turbidity and Pond Effluent}

Permeate $\mathrm{O} / \mathrm{G}$ remained low, averaging $4.0 \mathrm{mg} / \mathrm{L}$ and ranging from 2.0 to 6.0 mg/L. Turbidity was also low, averaging 1.9 NTU and ranging from 0.5 to 9.8 NTU. Pond effluent $\mathrm{O} / \mathrm{G}$ ranged from 6,333 to $31,000 \mathrm{mg} / \mathrm{L}$ over the course of the subrun.

\section{Conductivity and pH}

Permeate $\mathrm{pH}$ ranged from 4.5 to 6.0 with an average of 5.4. Concentrate $\mathrm{pH}$ ranged from 4.8 to 5.8 with an average of 5.5. Permeate conductivity ranged from 168 to $630 \mu \mathrm{S} / \mathrm{cm}$ and averaged $496 \mu \mathrm{S} / \mathrm{cm}$. Concentrate conductivity's ranged from 198 to $636 \mu \mathrm{S} / \mathrm{cm}$ and averaged $446 \mu \mathrm{S} / \mathrm{cm}$. 


\section{UF2-R3-SR4 Cleaning}

After UF2-R3-SR4 was shutdown on February 5, 1998 at 04:30, it was cleaned at 04:40 using a $0.5 \%$ KLD cleaning solution. Once the cleaning water was heated to $\sim 100^{\circ} \mathrm{F}$, the system was cleaned for one hour under the regular cleaning cycle. The total downtime for the cleaning was 2151 minutes.

\section{Permeate Flux and System Temperature}

During the first hour of cleaning the permeate flux ranged from 26.7 to 40.9 $\mathrm{gal} / \mathrm{ft}^{2}-\mathrm{d}$ and averaged $37.0 \mathrm{gal} / \mathrm{ft}^{2}-\mathrm{d}$. Permeate temperature during the first hour of cleaning ranged from 89.7 to $95.9^{\circ} \mathrm{F}$ and averaged $93.7^{\circ} \mathrm{F}$. Concentrate temperature ranged from 96.8 to $104.5^{\circ} \mathrm{F}$ and averaged $101.4^{\circ} \mathrm{F}$.

After one hour, the system was shutdown and the valves were adjusted for the spongeball sequence. During the first pass of spongeballs, the permeate flux increased to $64.9 \mathrm{gal} / \mathrm{ft}^{2}-\mathrm{d}$. The second pass of spongeballs yielded a permeate flux of $87.2 \mathrm{gal} / \mathrm{ft}^{2}-\mathrm{d}$. After two spongeball passes were performed the system was cleaned for an additional hour.

In the second hour of regular cleaning, the permeate flux ranged from 64.9 to $67.6 \mathrm{gal} / \mathrm{ft}^{2}-\mathrm{d}$ with an average of $65.8 \mathrm{gal} / \mathrm{ft}^{2}-\mathrm{d}$. Permeate temperature ranged from 94.8 to $97.2^{\circ} \mathrm{F}$ with an average of $95.7^{\circ} \mathrm{F}$. Concentrate temperature ranged from 101.3 to $108.9^{\circ} \mathrm{F}$ with an average of $104.6^{\circ} \mathrm{F}$.

\section{pH, Conductivity and Turbidity}

Permeate $\mathrm{pH}$, over the course of the cleaning ranged from 5.9 to 6.2 and averaged 6.1. Concentrate $\mathrm{pH}$ ranged from 5.9 to 6.4 and averaged 6.2. Permeate conductivity averaged $835 \mu \mathrm{S} / \mathrm{cm}$ and ranged from 762 to $880 \mu \mathrm{S} / \mathrm{cm}$. Concentrate conductivity averaged $1835 \mu \mathrm{S} / \mathrm{cm}$ and ranged from 1751 to $1912 \mu \mathrm{S} / \mathrm{cm}$. Permeate turbidity ranged from 4.4 to 38.8 NTU and averaged 13.1 NTU. 


\section{UF2-R3-SR4 Acid Cleaning}

After a regular cleaning and flush was performed on the system, an acid cleaning was implemented for one-hour. The acid cleaning started once the 600 gallons of softened water was $\mathrm{pH}$ adjusted to $\sim 2.2$.

\section{Permeate Flux and Temperature}

During the acid cleaning, the permeate flux ranged from 54.2 to $60.5 \mathrm{gal} / \mathrm{ft}^{2}-\mathrm{d}$ and averaged $56.8 \mathrm{gal} / \mathrm{ft}^{2}-\mathrm{d}$. Permeate temperature ranged from 82.9 to $88.2^{\circ} \mathrm{F}$ and averaged $85.5^{\circ} \mathrm{F}$. Concentrate temperature ranged from 85.0 to $98.0^{\circ} \mathrm{F}$ and averaged $91.3^{\circ} \mathrm{F}$.

\section{pH, Conductivity and Turbidity}

Permeate $\mathrm{pH}$ ranged from 2.7 to 3.1 with an average of 2.9. Concentrate $\mathrm{pH}$ ranged from 2.5 to 3.0 with an average of 2.7 . Permeate conductivity ranged from 98 to $879 \mu \mathrm{S} / \mathrm{cm}$ and averaged $507 \mu \mathrm{S} / \mathrm{cm}$. Concentrate conductivity ranged from 136 to 1255 $\mu \mathrm{S} / \mathrm{cm}$ and averaged $600 \mu \mathrm{S} / \mathrm{cm}$. Permeate turbidity ranged from 3.3 to $9.7 \mathrm{NTU}$ and averaged 5.8 NTU.

\section{UF2-R3-SR4 Cleaning After Acid}

After the acid cleaning and flush, the system was then cleaned again using a 0.3 $\%$ KLD solution for one-hour.

\section{Permeate Flux and Temperature}

During the second regular cleaning, the permeate flux ranged from 69.4 to 77.4 $\mathrm{gal} / \mathrm{ft}^{2}-\mathrm{d}$ and averaged $70.4 \mathrm{gal} / \mathrm{ft}^{2}-\mathrm{d}$. Permeate temperature ranged from 85.4 to $93.0^{\circ} \mathrm{F}$ 
and averaged $90.4^{\circ} \mathrm{F}$. Concentrate temperature ranged from 95 to $102{ }^{\circ} \mathrm{F}$ and averaged $98.5^{\circ} \mathrm{F}$.

\section{pH, Conductivity and Turbidity}

Permeate $\mathrm{pH}$ ranged from 4.5 to 5.1 with an average of 5.1. Concentrate $\mathrm{pH}$ ranged from 5.1 to 5.2 with an average of 5.5. Permeate conductivity ranged from 174 to $315 \mu \mathrm{S} / \mathrm{cm}$ and averaged $261 \mu \mathrm{S} / \mathrm{cm}$. Concentrate conductivity ranged from 325 to $424 \mu$ S/cm and averaged $366 \mu \mathrm{S} / \mathrm{cm}$. Permeate turbidity ranged from 3.0 to $10.9 \mathrm{NTU}$ and averaged 4.9 NTU.

\section{UF2-R4}

UF2-R4 started on February 6, 1998 at 16:20 and February 10, 1998 at 14:00. The run lasted for 7.8 days. The objectives of the run were: 1) monitor system performance, 2) estimate the volume of free oil that forms at the top of the concentrate tanks and 3) conduct an oil mass balance on the system in order to note the change occurring in the system.

In Figure 4.7, permeate flux versus time for UF2-R4 is presented. In Figure 4.8, permeate turbidity versus time for UF2-R4 is presented. In Table 4.28, a summary of permeate operating parameters for UF2-R4 is presented. In Table 4.29, a summary of concentrate operating parameters for UF2-R4 is presented. In Table 4.30, a summary of permeate cleaning parameters for UF2-R4 is presented. In Table 4.31, a summary of concentrate cleaning parameters for UF2-R4 is presented. In Table 4.32, a summary of 
permeate $\mathrm{O} / \mathrm{G}$ samples analyzed for UF2-R4, is presented. In Table 4.33 , a summary of concentrate oil content samples analyzed for UF2-R4, is presented. In Table 4.34, a summary of free oil skimming samples analyzed for UF2-R4, is presented. In Table 4.35, a summary of free oil production for UF2-R4 is presented. In Table 4.36, a summary of pond effluent samples analyzed for UF2-R4, is presented. 


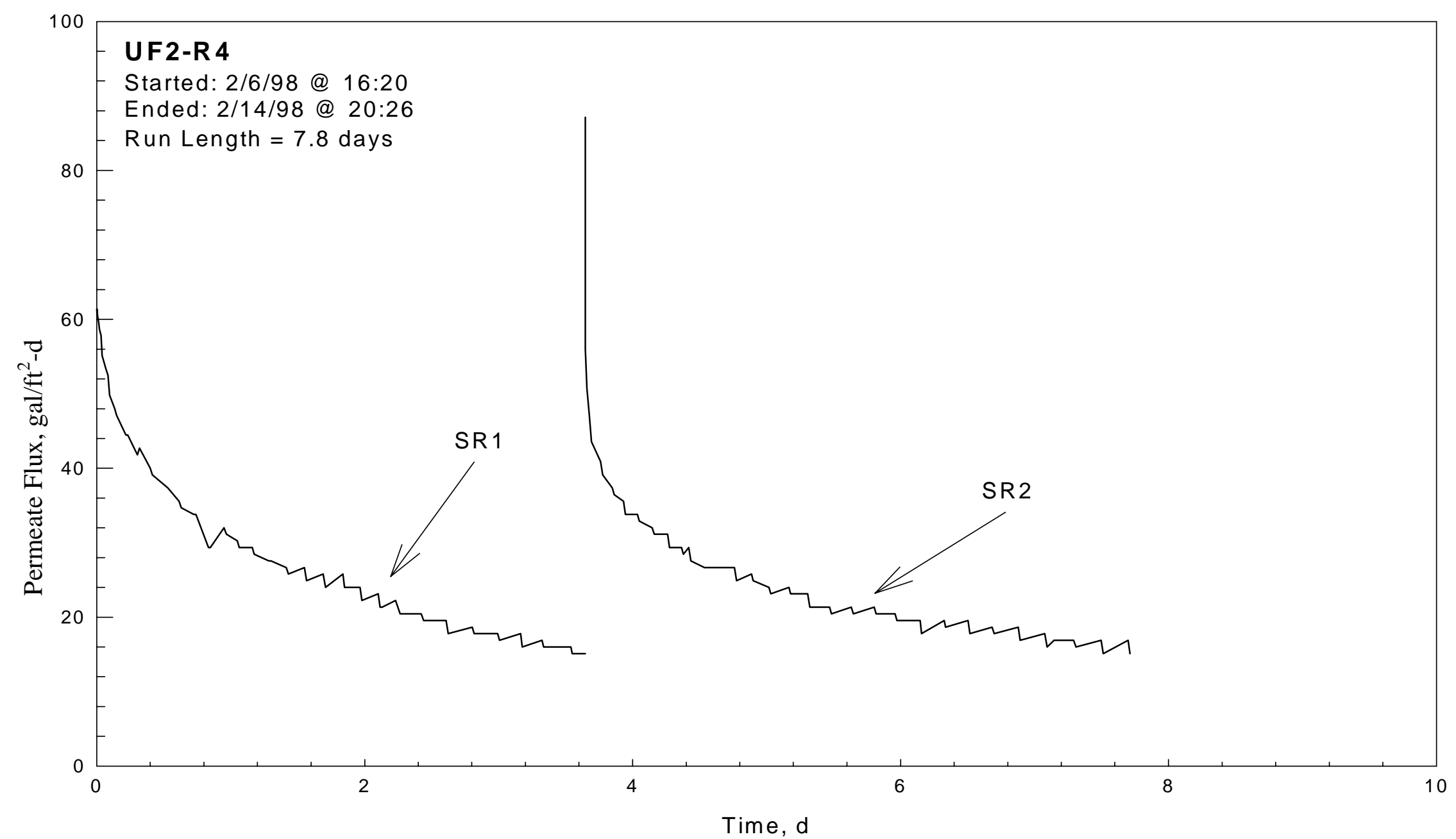

Figure 4.7 Permeate Flux versus Time for UF2-R4 


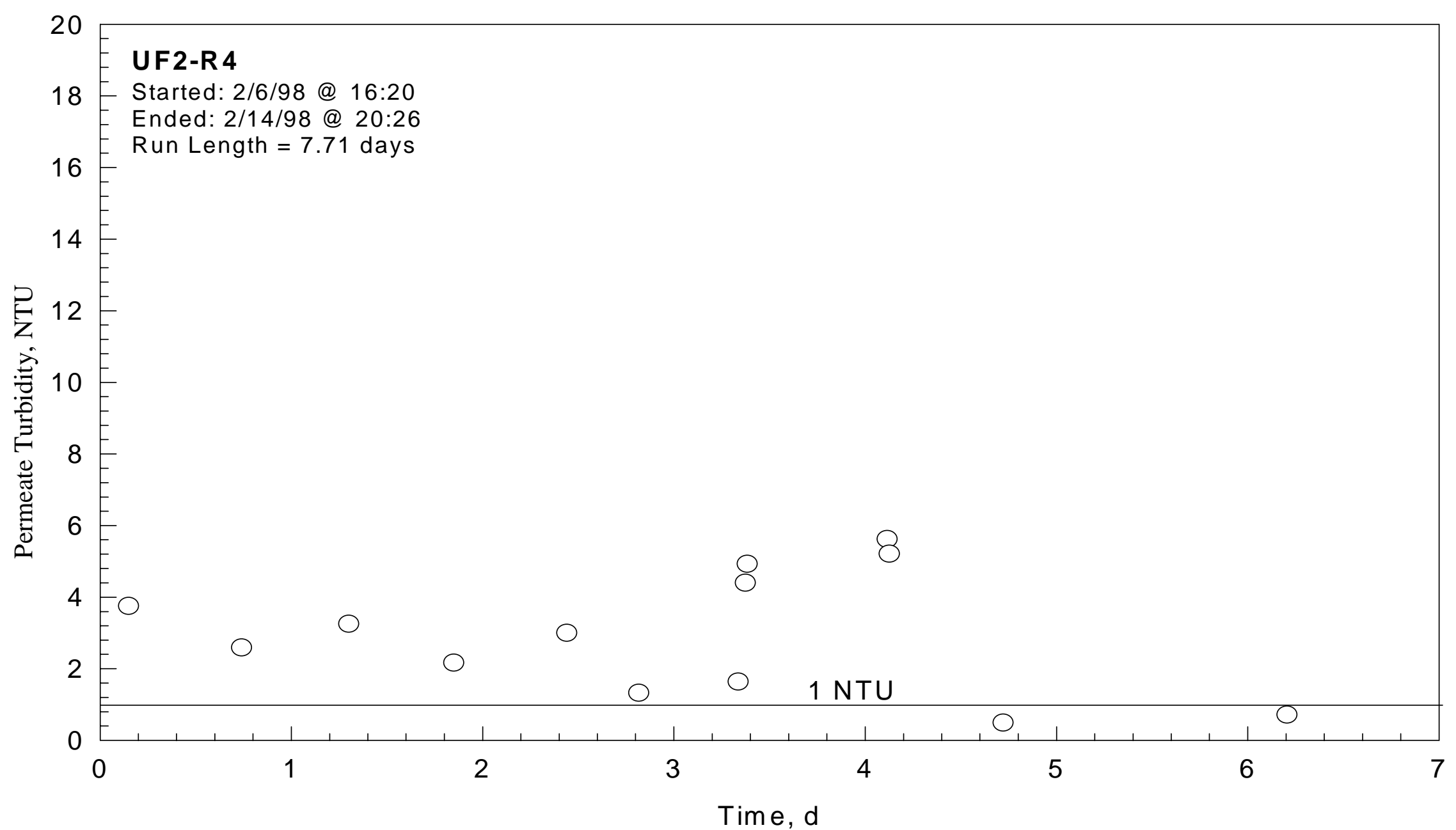

Figure 4.8 Permeate Turbidity versus Time for UF2-R4 
Table 4.28. Summary of Permeate Parameters for UF2-R4

\begin{tabular}{|c|c|c|c|c|c|c|}
\hline $\begin{array}{l}\text { Subrun } \\
\text { ID }\end{array}$ & $\begin{array}{c}\text { Flux }\left(\mathrm{gal} / \mathbf{f t}^{2}-\mathrm{d}\right) \\
{[\mathrm{min}-\mathbf{m a x}]} \\
\text { Avg } \pm \text { std }\end{array}$ & $\begin{array}{l}\text { Temperature }\left({ }^{0} \mathbf{F}\right) \\
{[\text { min }- \text { max }]} \\
\text { Avg } \pm \text { std }\end{array}$ & $\begin{array}{c}\text { Turbidity (NTU) } \\
{[\text { min - max }]} \\
\text { Avg } \pm \text { std }\end{array}$ & $\begin{array}{c}\mathbf{p H} \\
{[\min -\mathbf{m a x}]} \\
\operatorname{Avg} \pm \text { std } \\
\end{array}$ & $\begin{array}{c}\text { Conductivity }(\mu \mathrm{S} / \mathrm{cm}) \\
{[\mathrm{min}-\max ]} \\
\text { Avg } \pm \text { std }\end{array}$ & $\begin{array}{c}\text { O/G (mg/L) } \\
{[\mathrm{min}-\max ]} \\
\text { Avg } \pm \text { std } \\
\end{array}$ \\
\hline 1 & $\begin{array}{c}{[15.1-61.4]} \\
32.3 \pm 14.2\end{array}$ & $\begin{array}{c}{[68.1-77.9]} \\
74.1 \pm 3.4\end{array}$ & $\begin{array}{c}{[1.3-3.8]} \\
2.5 \pm 0.9\end{array}$ & $\begin{array}{c}{[5.2-5.7]} \\
5.6 \pm 0.23\end{array}$ & $\begin{array}{c}{[91-425]} \\
208 \pm 188\end{array}$ & $\begin{array}{l}{[2-3]} \\
2.3 \pm 0.6\end{array}$ \\
\hline 2 & $\begin{array}{c}{[15.1-87.2]} \\
27.6 \pm 12.7\end{array}$ & $\begin{array}{c}{[74.8-78.6]} \\
77.0 \pm 1.5\end{array}$ & $\begin{array}{c}{[0.5-5.6]} \\
3.6 \pm 2.3\end{array}$ & $\begin{array}{c}{[5.4-5.5]} \\
5.5 \pm 0.1\end{array}$ & $\begin{array}{c}{[61-473]} \\
376 \pm 156\end{array}$ & $\begin{array}{c}{[3-4]} \\
3.8 \pm 0.5 \\
\end{array}$ \\
\hline
\end{tabular}


Table 4.29. Summary of Concentrate and Pond Effluent O/G Parameters for UF2-R4

\begin{tabular}{|c|c|c|c|c|c|}
\hline $\begin{array}{l}\text { Subrun } \\
\text { ID }\end{array}$ & $\begin{array}{l}\text { Temperature }\left({ }^{0} \mathbf{F}\right) \\
{[\text { min }-\max ]} \\
\text { Avg } \pm \text { std }\end{array}$ & $\begin{array}{c}\mathbf{p H} \\
{[\min -\max ]} \\
\text { Avg } \pm \text { std } \\
\end{array}$ & $\begin{array}{c}\text { Conductivity }(\mu \mathrm{S} / \mathrm{cm}) \\
{[\mathrm{min}-\max ]} \\
\text { Avg } \pm \text { std }\end{array}$ & $\begin{array}{c}\text { Oil Content (\%) } \\
{[\text { min - max }]} \\
\text { Avg } \pm \text { std }\end{array}$ & $\begin{array}{c}\text { Pond Effluent O/G (mg/L) } \\
{[\text { min }- \text { max }]} \\
\text { Avg } \pm \text { std }\end{array}$ \\
\hline 1 & $\begin{array}{c}{[72-83.4]} \\
78.8 \pm 3.9\end{array}$ & $\begin{array}{c}{[5.2-6.5]} \\
5.8 \pm 0.65\end{array}$ & $\begin{array}{c}{[244-475]} \\
385 \pm 78\end{array}$ & $\begin{array}{c}{[0.4-5.2]} \\
2.5 \pm 2.4\end{array}$ & {$[0.6]$} \\
\hline 2 & $\begin{array}{c}{[78.4-83.5]} \\
81.1 \pm 2.0\end{array}$ & $\begin{array}{c}{[5.6-5.6]} \\
5.6\end{array}$ & $\begin{array}{c}{[361-486]} \\
424 \pm 88\end{array}$ & $\begin{array}{c}{[2.2-2.7]} \\
2.5 \pm 0.4\end{array}$ & $\begin{array}{c}{[0.5-0.6]} \\
0.6 \pm 0.4\end{array}$ \\
\hline
\end{tabular}


Table 4.30. Summary of Permeate Cleaning Parameters for UF2-R4

\begin{tabular}{|c|c|c|c|c|c|}
\hline $\begin{array}{l}\text { Subrun } \\
\text { ID }\end{array}$ & $\begin{array}{c}\text { Flux }\left(\mathrm{gal} / \mathrm{ft}^{2}-\mathrm{d}\right) \\
{[\mathrm{min}-\max ]} \\
\text { Avg } \pm \text { std } \\
\end{array}$ & $\begin{array}{l}\text { Temperature }\left({ }^{0} \mathbf{F}\right) \\
{[\text { min }- \text { max }]} \\
\text { Avg } \pm \text { std }\end{array}$ & $\begin{array}{c}\text { Turbidity (NTU) } \\
\text { [min - max }] \\
\text { Avg } \pm \text { std }\end{array}$ & $\begin{array}{c}\text { pH } \\
{[\min -\max ]} \\
\text { Avg } \pm \text { std } \\
\end{array}$ & $\begin{array}{c}\text { Conductivity }(\mu \mathrm{S} / \mathrm{cm}) \\
{[\mathrm{min}-\max ]} \\
\text { Avg } \pm \text { std }\end{array}$ \\
\hline 1 & $\begin{array}{c}28.6-64.0] \\
47.2 \pm 4.7\end{array}$ & $\begin{array}{c}93-100.2] \\
97.1 \pm 2.8\end{array}$ & $\begin{array}{c}{[3.3-37.9]} \\
10.2 \pm 10.8\end{array}$ & $\begin{array}{c}{[6.1-6.3]} \\
6.2 \pm 0.1\end{array}$ & $\begin{array}{c}{[554-722]} \\
617 \pm 59\end{array}$ \\
\hline 2 & $\begin{array}{c}{[77.4-96.0]} \\
86.7 \pm 2.0\end{array}$ & $\begin{array}{c}105-111.9] \\
108.5 \pm 2.2 \\
\end{array}$ & $\begin{array}{c}{[2.0-3.9]} \\
2.9 \pm 0.7 \\
\end{array}$ & $\begin{array}{c}{[5.1-5.3]} \\
5.2 \pm 0.1 \\
\end{array}$ & $\begin{array}{c}{[535-810]} \\
620 \pm 61\end{array}$ \\
\hline
\end{tabular}


Table 4.31. Summary of Concentrate Cleaning Parameters for UF2-R4

\begin{tabular}{||l|c|c|c||}
\hline $\begin{array}{l}\text { Subrun } \\
\text { ID }\end{array}$ & $\begin{array}{c}\text { Temperature }\left(^{\mathbf{O}} \mathbf{F}\right) \\
{[\mathbf{m i n}-\mathbf{m a x}]} \\
\text { Avg } \pm \text { std }\end{array}$ & $\begin{array}{c}\mathbf{p H} \\
{[\mathbf{m i n}-\mathbf{m a x}]} \\
\mathbf{A v g} \pm \text { std }\end{array}$ & $\begin{array}{c}\text { Conductivity }(\mu \mathrm{S} / \mathbf{c m}) \\
{[\mathbf{m i n}-\mathbf{m a x}]} \\
\text { Avg } \pm \text { std }\end{array}$ \\
\hline 1 & {$[98.7-109.2]$} & {$[6.1-6.5]$} & {$[703-1141]$} \\
& $104 \pm 3.5$ & $6.3 \pm 0.2$ & $903 \pm 205$ \\
\hline 2 & {$[115.7-123.4]$} & {$[5.3-5.4]$} & {$[730-1260]$} \\
& $118.9 \pm 2.5$ & $5.3 \pm 0.01$ & $913 \pm 210$ \\
\hline
\end{tabular}


Table 4.32 Summary of Permeate O/G Samples for UF2-R4

\begin{tabular}{|c|c|c|c|c|}
\hline Subrun ID & \multirow{2}{*}{ Date/Time } & \multicolumn{3}{|c|}{ Sample Results (mg/L) } \\
\cline { 3 - 5 } & & $\mathbf{\# 1}$ & $\mathbf{\# 2}$ & $\mathbf{\# 3}$ \\
\hline \hline 1 & $2 / 6 / 98(19: 55)$ & 2 & & \\
\hline 1 & $2 / 7 / 98(23: 33)$ & 2 & & \\
\hline 1 & $2 / 9 / 98(11: 56)$ & 3 & & \\
\hline 2 & $2 / 10 / 98(15: 08)$ & 4 & & \\
\hline 2 & $2 / 11 / 98(10: 36)$ & 4 & & \\
\hline 2 & $2 / 12 / 98(11: 48)$ & 4 & 3 & 2 \\
\hline 2 & $2 / 13 / 98(21: 36)$ & 4 & & \\
\hline
\end{tabular}


Table 4.33 Summary of Concentrate Oil Content Samples for UF2-R4

\begin{tabular}{|c|c|c|c|c||}
\hline Subrun ID & \multirow{2}{*}{ Date/Time } & \multicolumn{3}{|c|}{ Sample Results (\%) } \\
\cline { 3 - 5 } & & $\mathbf{\# 1}$ & $\mathbf{\# 2}$ & $\mathbf{\# 3}$ \\
\hline 1 & $2 / 6 / 98(16: 00)$ & 0.5 & 0.4 & 0.4 \\
\hline 1 & $2 / 8 / 98(19: 28)$ & 2.0 & 1.9 & 2.1 \\
\hline 1 & $2 / 10 / 98(09: 10)$ & 4.8 & 5.1 & 5.3 \\
\hline 2 & $2 / 10 / 98(14: 15)$ & 2.2 & 2.5 & 2.0 \\
\hline 2 & $2 / 14 / 98(20: 26)$ & 2.7 & & \\
\hline
\end{tabular}


Table 4.34 Summary of Skimming Samples for UF2-R4

\begin{tabular}{|c|c|c|c|c|}
\hline Subrun ID & \multirow{2}{*}{ Date/Time } & \multicolumn{3}{|c|}{ Sample Results (\%) } \\
\cline { 3 - 5 } & & $\mathbf{\# 1}$ & $\mathbf{\# 2}$ & $\mathbf{\# 3}$ \\
\hline 2 & $2 / 10 / 98(18: 26)$ & 99 & & \\
\hline 2 & $2 / 11 / 98(01: 54)$ & 100 & & \\
\hline 2 & $2 / 13 / 98(12: 55)$ & 100 & & \\
\hline 2 & $2 / 14 / 98(08: 42)$ & 99 & & \\
\hline 2 & $2 / 15 / 98(11: 45)$ & 100 & & \\
\hline
\end{tabular}


Table 4.35 Summary of Free Oil Productions for UF2-R4

\begin{tabular}{|c|c|c|c|}
\hline Subrun ID & Subrun Length, $d$ & Total Free Oil, gal & Free Oil Production, gal/d \\
\hline \hline 1 & 3.7 & 0.0 & 0.0 \\
\hline 2 & 4.1 & 1,999 & 487.6 \\
\hline
\end{tabular}


Table 4.36 Summary of Pond Effluent O/G Samples for UF2-R4

\begin{tabular}{|c|c|c|c|c|}
\hline Subrun ID & \multirow{2}{*}{ Date/Time } & \multicolumn{3}{|c|}{ Sample Results (\%) } \\
\cline { 3 - 5 } & & $\mathbf{H 1}$ & $\mathbf{\# 2}$ & $\mathbf{\# 3}$ \\
\hline 1 & $2 / 6 / 98(15: 50)$ & 5,000 & & \\
\hline 1 & $2 / 7 / 98(15: 40)$ & 5,000 & & \\
\hline 2 & $2 / 10 / 98(14: 54)$ & 6,000 & & \\
\hline 2 & $2 / 13 / 98(12: 15)$ & 6,000 & 6,000 & 7,000 \\
\hline
\end{tabular}




\section{UF2-R4-SR1}

UF2-R4-SR1 was started on February 6, 1998 at 16:20 and ended on February 10, 1998 at 08:50. The length of the subrun lasted 3.65 days. The total permeate volume produced was $157,870 \mathrm{gal}$. The running average never reached $29 \mathrm{gal} / \mathrm{min}$. Therefore the instantaneous permeate flow set point of $18 \mathrm{gal} / \mathrm{min}$ was used.

\section{Permeate Flux and System Temperature}

Over the course of the subrun, the permeate flux ranged from 15.1 to $61.4 \mathrm{gal} / \mathrm{ft}^{2}-$

d. Permeate temperature ranged from 68.1 to $77.9^{\circ} \mathrm{F}$ with an average of $74.1^{\circ} \mathrm{F}$. Concentrate temperatures ranged from 72.0 to $83.4^{\circ} \mathrm{F}$ with an average of $78.8^{\circ} \mathrm{F}$.

\section{Concentrate Oil Content and Free Oil Production}

Concentrate oil content started out at $0.4 \%$ and increased to $5.2 \%$ during subrun \#1. The total volume of free oil that was produced during subrun \#1 was 0 gallons. The average daily free oil production was 0.0 gallons/day.

\section{Permeate Oil/Grease, Turbidity and Pond Effluent}

Permeate $\mathrm{O} / \mathrm{G}$ remained low, averaging $2.3 \mathrm{mg} / \mathrm{L}$ and ranging from 2.0 to 3.0 mg/L. Turbidity was also low, averaging 2.5 NTU and ranging from 1.3 to 3.8 NTU. Pond effluent O/G was constant around 6,000 mg/L.

\section{Conductivity and pH}

Permeate $\mathrm{pH}$ ranged from 5.2 to 5.7 with an average of 5.6. Concentrate $\mathrm{pH}$ ranged from 5.2 to 6.5 with an average of 5.8. Permeate conductivity ranged from 288 to 
$475 \mu \mathrm{S} / \mathrm{cm}$ and averaged $385 \mu \mathrm{S} / \mathrm{cm}$. Concentrate conductivity's ranged from 91 to $425 \mu$ S/cm and averaged $208 \mu \mathrm{S} / \mathrm{cm}$.

\section{UF2-R4-SR1 Cleaning}

After UF2-R4-SR1 was shutdown on February 10, 1998 at 08:50 it was cleaned at 10:00, with a $0.5 \%$ KLD cleaning solution. The total downtime for the cleaning was 240 minutes.

\section{Permeate Flux and System Temperature}

During the first hour of cleaning the permeate flux ranged from 28.6 to 41.8 $\mathrm{gal} / \mathrm{ft}^{2}-\mathrm{d}$ and averaged $35.1 \mathrm{gal} / \mathrm{ft}^{2}-\mathrm{d}$. Permeate temperature during the first hour of cleaning ranged from 93 to $100.2^{\circ} \mathrm{F}$ and averaged $97.1^{\circ} \mathrm{F}$. Concentrate temperature ranged from 98.7 to $109.2^{\circ} \mathrm{F}$ and averaged $104{ }^{\circ} \mathrm{F}$.

After one hour, the system was shutdown and the valves were adjusted for the spongeball sequence. During the first pass of spongeballs, the permeate flux increased to $110.4 \mathrm{gal} / \mathrm{ft}^{2}-\mathrm{d}$. The second pass of spongeballs yielded a permeate flux of $114.5 \mathrm{gal} / \mathrm{ft}^{2}-$ d. After two spongeball passes were performed the system was cleaned for an additional hour.

In the second hour of regular cleaning, the permeate flux ranged from 56.9 to $64.0 \mathrm{gal} / \mathrm{ft}^{2}-\mathrm{d}$ with an average of $59.3 \mathrm{gal} / \mathrm{ft}^{2}-\mathrm{d}$. Permeate temperature ranged from 97.6 to $98.1^{\circ} \mathrm{F}$ with an average of $95.4^{\circ} \mathrm{F}$. Concentrate temperature ranged from 98.1 to $108.1^{\circ} \mathrm{F}$ with an average of $102.7^{\circ} \mathrm{F}$.

\section{pH, Conductivity and Turbidity}

Permeate $\mathrm{pH}$ over the course of the cleaning ranged from 6.1 to 6.3 and averaged

6.2. Concentrate $\mathrm{pH}$ ranged from 6.1 to 6.5 and averaged 6.3. Permeate conductivity averaged $617 \mu \mathrm{S} / \mathrm{cm}$ and ranged from 554 to $722 \mu \mathrm{S} / \mathrm{cm}$. Concentrate conductivity 
averaged $903 \mu \mathrm{S} / \mathrm{cm}$ and ranged from 703 to $1141 \mu \mathrm{S} / \mathrm{cm}$. Permeate turbidity ranged from 3.3 to $37.9 \mathrm{NTU}$ and averaged 10.2 NTU.

\section{UF2-R4-SR2}

UF2-R4-SR2 was started on February 10, 1998 at 14:00 and ended on February 14, 1998 at 20:26. The length of the subrun lasted 4.07 days. The total permeate volume produced was $157,670 \mathrm{gal}$. The running average was allowed to pass the $29 \mathrm{gal} / \mathrm{min}$ set point because the average reached the set point within two an a half days. The subrun ended because of a pipe rupture above the feed manifolds for the membranes. UF2-R4SR2 marked the ended of the run. Due to the pipe rupture, the system was down for several days. As a result, it was decided to acid clean the system and start with fresh pond effluent.

\section{Permeate Flux and System Temperature}

Over the course of the subrun, the permeate flux ranged from 15.1 to $87.2 \mathrm{gal} / \mathrm{ft}^{2}-$

d. Permeate temperature ranged from 74.8 to $78.6^{\circ} \mathrm{F}$ with an average of $77.0^{\circ} \mathrm{F}$. Concentrate temperatures ranged from 78.4 to $83.5^{\circ} \mathrm{F}$ with an average of $81.1^{\circ} \mathrm{F}$.

\section{Concentrate Oil Content and Free Oil Production}

Concentrate oil content started out at $2.2 \%$ and increased to $2.7 \%$ by the end of subrun \#2. The total volume of free oil that was produced during subrun \#2 was 1,999 gallons. The average daily free oil production was 487.6 gallons/day. 


\section{Permeate Oil/Grease, Turbidity and Pond Effluent}

Permeate $\mathrm{O} / \mathrm{G}$ remained low, averaging $3.8 \mathrm{mg} / \mathrm{L}$ and ranging from 3.0 to 4.0 $\mathrm{mg} / \mathrm{L}$. Turbidity was also low, averaging 3.6 NTU and ranging from 0.49 to 5.6 NTU. Pond effluent $\mathrm{O} / \mathrm{G}$ ranged from 5,000 to 6,000 mg/L and averaged 6,000 mg/L.

\section{Conductivity and pH}

Permeate $\mathrm{pH}$ ranged from 5.4 to 5.5 with an average of 5.5. Concentrate $\mathrm{pH}$ remained constant at 5.6. Permeate conductivity ranged from 61.4 to $473 \mu \mathrm{S} / \mathrm{cm}$ and averaged $376 \mu \mathrm{S} / \mathrm{cm}$. Concentrate conductivity's ranged from 361 to $486 \mu \mathrm{S} / \mathrm{cm}$ and averaged $424 \mu \mathrm{S} / \mathrm{cm}$.

\section{UF2-R4-SR2 Cleaning}

After UF2-R4-SR2 was shutdown on February 14, 1998 at 20:26 it was cleaned on February 20, 1998 at 21:30, with a $0.5 \%$ KLD cleaning solution. UF \#2 was not cleaned for several days after the shutdown because a new stainless steel header was being built to replace the old cracked header. Once the new header was installed the system was cleaned. As a result of the new header, the system could be cleaned at 120 ${ }^{\circ} \mathrm{F}$. Once the cleaning water was heated to $\sim 115^{\circ} \mathrm{F}$, the system was cleaned for one hour under the regular cleaning cycle. After one hour elapsed, the system was shutdown and prepared for a spongeball sequence. Once the valves were adjusted on the system for spongeball retrieval, the system under went two spongeball passes. After the spongeball sequence was performed, the valves were readjusted to the normal mode setting. The system was then cleaned for an additional hour with the same cleaning solution. The total downtime for just the cleaning was 150 minutes. 


\section{Permeate Flux and System Temperature}

During the first hour of cleaning the permeate flux ranged from 77.4 to 81.8 $\mathrm{gal} / \mathrm{ft}^{2}-\mathrm{d}$ and averaged $79.3 \mathrm{gal} / \mathrm{ft}^{2}-\mathrm{d}$. Permeate temperature during the first hour of cleaning ranged from 105 to $108.7^{\circ} \mathrm{F}$ and averaged $107.3^{\circ} \mathrm{F}$. Concentrate temperature ranged from 115.7 to $120.5^{\circ} \mathrm{F}$ and averaged $118.3^{\circ} \mathrm{F}$.

After one hour, the system was shutdown and the valves were adjusted for the spongeball sequence. During the first pass of spongeballs, the permeate flux increased to $113.4 \mathrm{gal} / \mathrm{ft}^{2}-\mathrm{d}$. The second pass of spongeballs yielded a permeate flux of $115.3 \mathrm{gal} / \mathrm{ft}^{2}-$

d. After two spongeball passes were performed the system was cleaned for an additional hour.

In the second hour of regular cleaning, the permeate flux ranged from 91.6 to $96.0 \mathrm{gal} / \mathrm{ft}^{2}-\mathrm{d}$ with an average of $94.0 \mathrm{gal} / \mathrm{ft}^{2}-\mathrm{d}$. Permeate temperature ranged from 105.6 to $111.9^{\circ} \mathrm{F}$ with an average of $109.8^{\circ} \mathrm{F}$. Concentrate temperature ranged from 114.8 to $123.4^{\circ} \mathrm{F}$ with an average of $119.5^{\circ} \mathrm{F}$.

\section{pH, Conductivity and Turbidity}

Permeate $\mathrm{pH}$ over the course of the cleaning ranged from 5.1 to 5.3 and averaged 5.2. Concentrate $\mathrm{pH}$ ranged from 5.3 to 5.4 and averaged 5.3. Permeate conductivity averaged $620 \mu \mathrm{S} / \mathrm{cm}$ and ranged from 535 to $810 \mu \mathrm{S} / \mathrm{cm}$. Concentrate conductivity averaged $913 \mu \mathrm{S} / \mathrm{cm}$ and ranged from 730 to $1260 \mu \mathrm{S} / \mathrm{cm}$. Permeate turbidity ranged from 2.0 to $3.9 \mathrm{NTU}$ and averaged $2.9 \mathrm{NTU}$.

\section{UF2-R5}

UF2-R5 started on February 21, 1998 at 00:00 and June 25, 1998 at 10:40. The run lasted for 110 days. The objectives of the run were: 1) monitor system performance, 
2) estimate the volume of free oil that forms at the top of the concentrate tanks and 3) conduct an oil mass balance on the system in order to note the change occurring in the system.

In Figure 4.9, permeate flux versus time for UF2-R5 is presented. In Figure 4.10, permeate turbidity versus time for UF2-R5 is presented. In Table 4.37, a summary of permeate operating parameters for UF2-R5 (Subruns 1-11) is presented. In Table 4.38, a summary of permeate operating parameters for UF2-R5 (Subruns 12-19) is presented. In Table 4.39, a summary of concentrate operating parameters for UF2-R5 (Subruns 1-11) is presented. In Table 4.40, a summary of concentrate operating parameters for UF2-R5 (Subruns 12-19) is presented. In Table 4.41, a summary of permeate cleaning parameters for UF2-R5 (subruns 1-11) is presented. In Table 4.42, a summary of permeate cleaning parameters for UF2-R5 (subruns 12-19) is presented. In Table 4.43, a summary of concentrate cleaning parameters for UF2-R5 is presented. In Table 4.44, a summary of permeate O/G samples analyzed for UF2-R5, is presented. In Table 4.45, a summary of concentrate oil content samples analyzed for UF2-R5, is presented. In Table 4.46, a summary of free oil skimming samples analyzed for UF2-R5, is presented. In Table 4.47, a summary of free oil production for UF2-R5 is presented. In Table 4.48, a summary of pond effluent samples analyzed for UF2-R5, is presented.

\section{UF2-R5-SR1}

UF2-R5-SR1 was started on February 21, 1998 at 00:00 and ended on February 21, 1998 at 17:32. The length of the subrun lasted 0.68 days. The total permeate volume produced was 24,640 gal. Subrun \#1 ended during the same day it was started because the permeate flow declined into the teens not even a half a day into the subrun. . 


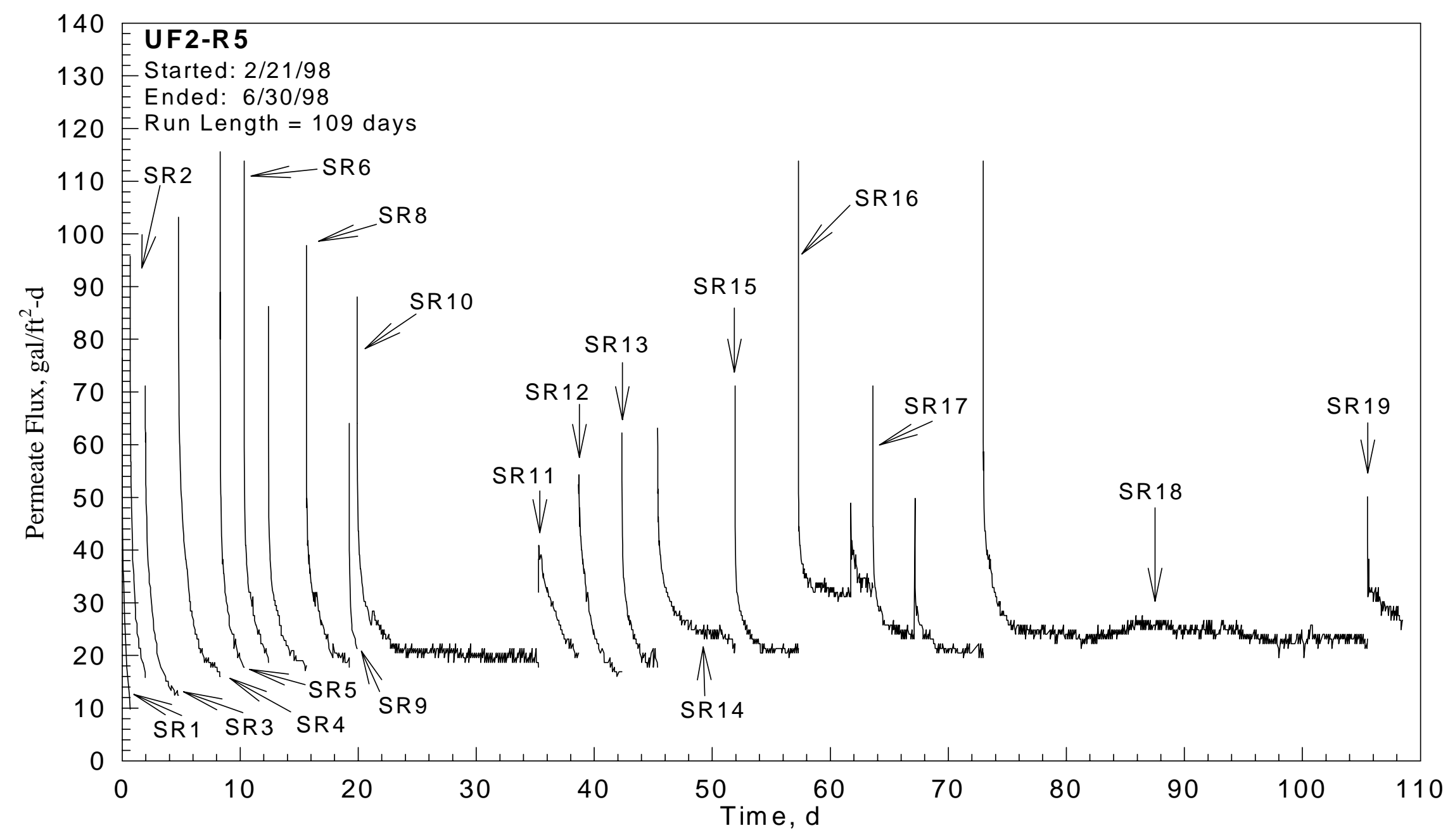

Figure 4.9 Permeate Flux versus Time for UF2-R5 


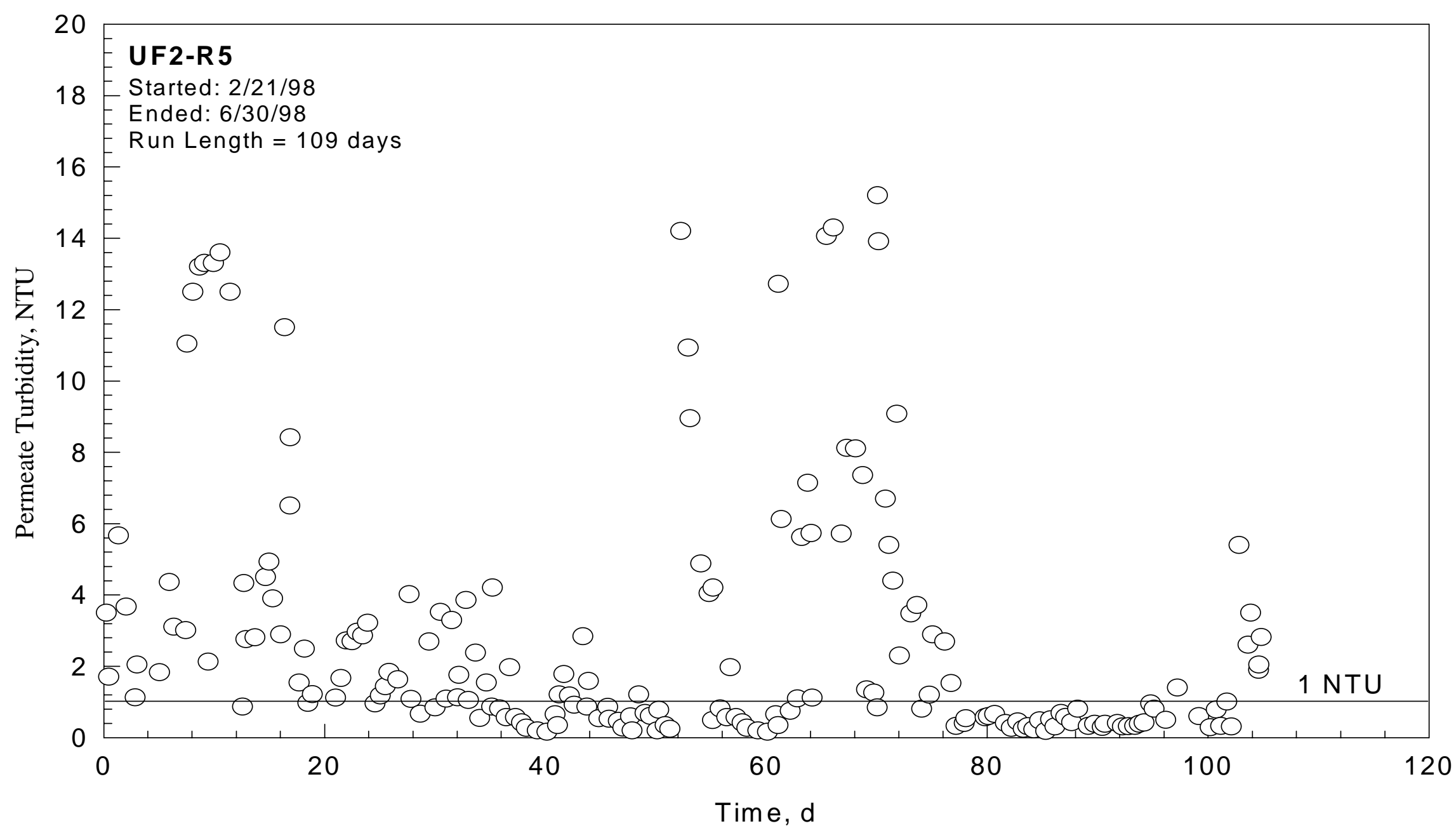

Figure 4.10 Permeate Turbidity versus Time for UF2-R5 
Table 4.37. Summary of Permeate Parameters for UF2-R5 (Subruns 1 - 11)

\begin{tabular}{|c|c|c|c|c|c|c|}
\hline $\begin{array}{l}\text { Subrun } \\
\text { ID }\end{array}$ & $\begin{array}{c}\text { Flux }\left(\mathrm{gal} / \mathbf{f t}^{2}-\mathbf{d}\right) \\
{[\min -\max ]} \\
\text { Avg } \pm \text { std }\end{array}$ & $\begin{array}{l}\text { Temperature }\left({ }^{0} \mathrm{~F}\right) \\
{[\mathrm{min}-\max ]} \\
\text { Avg } \pm \text { std }\end{array}$ & $\begin{array}{c}\text { Turbidity (NTU) } \\
\text { [min - max }] \\
\text { Avg } \pm \text { std }\end{array}$ & $\begin{array}{c}\mathbf{p H} \\
{[\min -\mathbf{m a x}]} \\
\text { Avg } \pm \text { std }\end{array}$ & $\begin{array}{c}\text { Conductivity }(\mu \mathrm{S} / \mathrm{cm}) \\
{[\min -\max ]} \\
\text { Avg } \pm \text { std }\end{array}$ & $\begin{array}{c}\mathrm{O} / \mathrm{G}(\mathrm{mg} / \mathrm{L}) \\
{[\mathrm{min}-\mathrm{max}]} \\
\text { Avg } \pm \text { std }\end{array}$ \\
\hline 1 & $\begin{array}{c}{[10.2-79.9]} \\
32.9 \pm 21.1\end{array}$ & $\begin{array}{c}68.7] \\
68.7\end{array}$ & $\begin{array}{c}{[3.5]} \\
3.5 \pm 0.0\end{array}$ & $\begin{array}{c}{[4.5]} \\
4.5 \pm 0.01\end{array}$ & $\begin{array}{c}{[206-360]} \\
283 \pm 109\end{array}$ & $\begin{array}{c}{[5]} \\
5 \pm 0.0\end{array}$ \\
\hline 2 & $\begin{array}{c}{[15.8-95.8]} \\
44.9 \pm 24.0\end{array}$ & $\begin{array}{c}{[74.5-78.2]} \\
76.4 \pm 2.6\end{array}$ & $\begin{array}{c}{[1.7-5.7]} \\
3.7 \pm 2.8\end{array}$ & $\begin{array}{c}{[4.5-6.5]} \\
5.5 \pm 1.4\end{array}$ & $\begin{array}{c}{[517]} \\
517\end{array}$ & $\begin{array}{c}{[5]} \\
5 \pm 0.0\end{array}$ \\
\hline 3 & $\begin{array}{c}{[12.5-71.1]} \\
32.8 \pm 18.8\end{array}$ & $\begin{array}{c}{[73.6-76.6]} \\
75.6 \pm 2.8\end{array}$ & $\begin{array}{c}{[1.1-3.7]} \\
2.4 \pm 1.8\end{array}$ & $\begin{array}{c}{[5.8-6.1]} \\
5.9 \pm 0.2\end{array}$ & $\begin{array}{c}{[490]} \\
490\end{array}$ & $\begin{array}{c}{[3]} \\
3 \pm 0.0\end{array}$ \\
\hline 4 & $\begin{array}{c}{[16.0-103.2]} \\
35.5 \pm 20.7\end{array}$ & $\begin{array}{c}{[73.2-77.9]} \\
76.2 \pm 2.6\end{array}$ & $\begin{array}{c}{[1.8-4.4]} \\
2.7 \pm 1.4\end{array}$ & $\begin{array}{c}{[5.1-5.9]} \\
5.4 \pm 0.4\end{array}$ & $\begin{array}{c}{[341-436]} \\
390 \pm 48\end{array}$ & $\begin{array}{c}{[3]} \\
3 \pm 0.0\end{array}$ \\
\hline 5 & $\begin{array}{c}{[17.8-115.6]} \\
37.4 \pm 22.4\end{array}$ & $\begin{array}{c}{[73.4-75.8]} \\
74.6 \pm 1.7\end{array}$ & $\begin{array}{c}{[3.0-3.1]} \\
3.1 \pm 0.1\end{array}$ & $\begin{array}{c}{[5.4-5.5]} \\
5.4 \pm 0.04\end{array}$ & $\begin{array}{c}331] \\
331\end{array}$ & $\begin{array}{c}{[5]} \\
5 \pm 0.0\end{array}$ \\
\hline 6 & $\begin{array}{c}{[18.7-113.8]} \\
33.2 \pm 17.5\end{array}$ & $\begin{array}{c}{[73.1-78.9]} \\
76.0 \pm 2.5\end{array}$ & $\begin{array}{c}{[2.1-16.6]} \\
11.8 \pm 5.8\end{array}$ & $\begin{array}{c}{[5.5-5.7]} \\
5.6 \pm 0.1\end{array}$ & $\begin{array}{c}{[238-349]} \\
306 \pm 45\end{array}$ & $\begin{array}{c}{[5]} \\
5 \pm 0.0\end{array}$ \\
\hline 7 & $\begin{array}{c}{[32.3-86.3]} \\
49.5 \pm 17.8\end{array}$ & $\begin{array}{c}{[75.3-78.0]} \\
80.3 \pm 1.1\end{array}$ & $\begin{array}{c}{[0.87-17.8]} \\
13.4 \pm 8.4\end{array}$ & $\begin{array}{c}{[5.0-6.0]} \\
5.5 \pm 0.5\end{array}$ & $\begin{array}{c}{[277-390]} \\
354 \pm 52\end{array}$ & $\begin{array}{c}{[3-5]} \\
4 \pm 1.4\end{array}$ \\
\hline 8 & $\begin{array}{c}{[17.8-97.8]} \\
30.9 \pm 14.4\end{array}$ & $\begin{array}{c}{[70.0-75.7]} \\
73.4 \pm 1.9\end{array}$ & $\begin{array}{c}2.8-4.9] \\
3.7 \pm 0.9\end{array}$ & $\begin{array}{c}{[5.1-6.2]} \\
5.5 \pm 0.4\end{array}$ & $\begin{array}{c}{[278-388]} \\
322 \pm 37\end{array}$ & $\begin{array}{c}{[4]} \\
4 \pm 0.0\end{array}$ \\
\hline 9 & $\begin{array}{c}{[19.6-64.0]} \\
29.3 \pm 11.4\end{array}$ & $\begin{array}{c}{[76.1-77.3]} \\
76.7 \pm 0.9\end{array}$ & $\begin{array}{c}{[24.1-121.6]} \\
72.9 \pm 68.9\end{array}$ & $\begin{array}{c}{[4.9-5.4]} \\
5.1 \pm 0.4\end{array}$ & $\begin{array}{c}{[376]} \\
376\end{array}$ & $\begin{array}{c}5] \\
5 \pm 0.0\end{array}$ \\
\hline 10 & $\begin{array}{c}{[17.8-88.0]} \\
23.3 \pm 8.0\end{array}$ & $\begin{array}{c}{[74.8-82.0]} \\
78.4 \pm 1.9\end{array}$ & $\begin{array}{c}{[4.2-6.3]} \\
5.0 \pm 0.5\end{array}$ & $\begin{array}{c}{[4.2-6.3]} \\
5.0 \pm 0.5\end{array}$ & $\begin{array}{c}{[202-499]} \\
354 \pm 113\end{array}$ & $\begin{array}{r}1-4] \\
3 \pm 1.4\end{array}$ \\
\hline 11 & $\begin{array}{c}{[19.6-40.9]} \\
29.5 \pm 6.2\end{array}$ & $\begin{array}{c}{[74.0-79.4]} \\
75.9 \pm 1.8\end{array}$ & $\begin{array}{c}{[5.0-5.6]} \\
5.3 \pm 0.2\end{array}$ & $\begin{array}{c}{[5.0-5.6]} \\
5.3 \pm 0.2\end{array}$ & $\begin{array}{c}{[304-444]} \\
356 \pm 66\end{array}$ & $\begin{array}{l}{[3-4]} \\
3.5 \pm 0.7\end{array}$ \\
\hline
\end{tabular}


Table 4.38. Summary of Permeate Parameters for UF2-R5 (Subruns 12 - 19)

\begin{tabular}{|c|c|c|c|c|c|c|}
\hline $\begin{array}{l}\text { Subrun } \\
\text { ID }\end{array}$ & $\begin{array}{c}\left.\text { Flux (gal/ft }{ }^{2}-d\right) \\
{[\min -\max ]} \\
\text { Avg } \pm \text { std }\end{array}$ & $\begin{array}{l}\text { Temperature }\left({ }^{\mathrm{O}} \mathbf{F}\right) \\
{[\mathrm{min}-\mathrm{max}]} \\
\text { Avg } \pm \text { std }\end{array}$ & $\begin{array}{c}\text { Turbidity (NTU) } \\
\text { [min - max }] \\
\text { Avg } \pm \text { std }\end{array}$ & $\begin{array}{c}\text { pH } \\
{[\min -\max ]} \\
\text { Avg } \pm \text { std }\end{array}$ & $\begin{array}{c}\text { Conductivity }(\mu \mathrm{S} / \mathrm{cm}) \\
{[\min -\max ]} \\
\text { Avg } \pm \text { std }\end{array}$ & $\begin{array}{c}\text { O/G (mg/L) } \\
{[\mathrm{min}-\max ]} \\
\text { Avg } \pm \text { std }\end{array}$ \\
\hline 12 & $\begin{array}{c}16.0-54.2] \\
29.6 \pm 11.9\end{array}$ & $\begin{array}{c}74.3-80.7] \\
78.5 \pm 2.3\end{array}$ & $\begin{array}{c}{[5.0-5.7]} \\
5.3 \pm 0.2\end{array}$ & $\begin{array}{c}{[5.0-5.7]} \\
5.3 \pm 0.2\end{array}$ & $\begin{array}{c}{[324-442]} \\
401 \pm 53\end{array}$ & $\begin{array}{l}{[3-4]} \\
3.5 \pm 0.7\end{array}$ \\
\hline 13 & $\begin{array}{c}{[17.8-67.3]} \\
26.3 \pm 9.7\end{array}$ & $\begin{array}{c}{[78.9-82.2]} \\
81 . \pm 1.2\end{array}$ & $\begin{array}{c}{[5.1-5.5]} \\
5.3 \pm 0.2\end{array}$ & $\begin{array}{c}{[5.1-5.5]} \\
5.3 \pm 0.2\end{array}$ & $\begin{array}{c}{[348-428]} \\
388 \pm 27\end{array}$ & $\begin{array}{l}{[3-4]} \\
3.5 \pm 0.7\end{array}$ \\
\hline 14 & $\begin{array}{c}20.5-63.1] \\
28.9 \pm 8.1\end{array}$ & $\begin{array}{c}77.1-82.8] \\
79.3 \pm 1.8\end{array}$ & $\begin{array}{c}{[5.0-5.5]} \\
5.2 \pm 0.2\end{array}$ & $\begin{array}{c}{[5.0-5.6]} \\
5.2 \pm 0.2\end{array}$ & $\begin{array}{c}{[166-463]} \\
345 \pm 95\end{array}$ & $\begin{array}{l}{[3-4]} \\
3.5 \pm 0.7\end{array}$ \\
\hline 15 & $\begin{array}{c}19.6-71.1] \\
24.6 \pm 7.6\end{array}$ & $\begin{array}{c}78.7-81.8] \\
80.4 \pm 1.0\end{array}$ & $\begin{array}{c}{[4.5-5.4]} \\
5.0 \pm 0.3\end{array}$ & $\begin{array}{c}{[4.5-5.4]} \\
5.0 \pm 0.3\end{array}$ & $\begin{array}{c}{[279-398]} \\
302 \pm 36\end{array}$ & $\begin{array}{c}{[2-6]} \\
4 \pm 2.0\end{array}$ \\
\hline 16 & $\begin{array}{c}{[30.2-113.8]} \\
36.2 \pm 9.0\end{array}$ & $\begin{array}{c}{[77.8-81.1]} \\
79.6 \pm 1.1\end{array}$ & $\begin{array}{c}{[4.7-6.2]} \\
5.1 \pm 0.5\end{array}$ & $\begin{array}{c}{[4.7-6.2]} \\
5.1 \pm 0.6\end{array}$ & $\begin{array}{c}{[196-361]} \\
281 \pm 63\end{array}$ & $\begin{array}{r}{[2-4]} \\
3 \pm 1.4\end{array}$ \\
\hline 17 & $\begin{array}{c}19.6-71.1] \\
25.7 \pm 7.6\end{array}$ & $\begin{array}{c}{[78.4-87.0]} \\
84.1 \pm 2.1\end{array}$ & $\begin{array}{c}{[5.1-5.8]} \\
5.5 \pm 0.2\end{array}$ & $\begin{array}{c}{[5.1-5.8]} \\
5.5 \pm 0.2\end{array}$ & $\begin{array}{c}{[217-433]} \\
350 \pm 89\end{array}$ & $\begin{array}{l}{[3-6]} \\
4.3 \pm 1.5\end{array}$ \\
\hline 18 & $\begin{array}{c}{[19.6-113.8]} \\
26.1 \pm 7.9\end{array}$ & $\begin{array}{c}{[80.1-89.8]} \\
85.3 \pm 2.4\end{array}$ & $\begin{array}{c}{[5.2-6.2]} \\
5.6 \pm 0.2\end{array}$ & $\begin{array}{c}{[5.2-6.2]} \\
5.6 \pm 0.2\end{array}$ & $\begin{array}{c}{[207-523]} \\
421 \pm 101\end{array}$ & $\begin{array}{l}{[1-8]} \\
3.8 \pm 3.1\end{array}$ \\
\hline 19 & $\begin{array}{c}{[24.9-49.8]} \\
30.6 \pm 3.9\end{array}$ & $\begin{array}{c}{[87.2-90.1]} \\
88.4 \pm 1.4\end{array}$ & $\begin{array}{c}{[4.8-5.1]} \\
4.9 \pm 0.1\end{array}$ & $\begin{array}{c}{[4.8-5.1]} \\
5.1 \pm 0.1\end{array}$ & $\begin{array}{c}{[422-432]} \\
427 \pm 7\end{array}$ & $\begin{array}{c}5] \\
5 \pm 0.0\end{array}$ \\
\hline
\end{tabular}


Table 4.39. Summary of Concentrate and Pond Effluent O/G Parameters for UF2-R5 (Subruns 1-11)

\begin{tabular}{|c|c|c|c|c|c|}
\hline $\begin{array}{l}\text { Subrun } \\
\text { ID }\end{array}$ & $\begin{array}{l}\text { Temperature }\left({ }^{0} \mathbf{F}\right) \\
{[\min -\max ]} \\
\text { Avg } \pm \text { std }\end{array}$ & $\begin{array}{c}\mathbf{p H} \\
{[\min -\max ]} \\
\text { Avg } \pm \text { std } \\
\end{array}$ & $\begin{array}{c}\text { Conductivity }(\mu \mathrm{S} / \mathrm{cm}) \\
{[\mathrm{min}-\max ]} \\
\text { Avg } \pm \text { std } \\
\end{array}$ & $\begin{array}{c}\text { Oil Content (\%) } \\
{[\min -\max ]} \\
\text { Avg } \pm \text { std } \\
\end{array}$ & $\begin{array}{c}\text { Pond Effluent O/G }(\mathrm{mg} / \mathrm{L}) \\
\text { [min - max }] \\
\text { Avg } \\
\end{array}$ \\
\hline 1 & $\begin{array}{c}{[72.7]} \\
72.7 \pm 0.0\end{array}$ & $\begin{array}{c}4.6-4.7] \\
4.6 \pm 0.01\end{array}$ & $\begin{array}{c}442] \\
442\end{array}$ & $\begin{array}{c}{[0.6-1.4]} \\
1.0 \pm 0.6\end{array}$ & $\begin{array}{c}{[0.6]} \\
0.6\end{array}$ \\
\hline 2 & $\begin{array}{c}{[78.2-83.6]} \\
80.9 \pm 3.8\end{array}$ & $\begin{array}{c}{[6.3]} \\
6.3\end{array}$ & $\begin{array}{c}{[442-605]} \\
524 \pm 115\end{array}$ & $\begin{array}{c}{[1.4-2.2]} \\
1.8 \pm 0.6\end{array}$ & $\begin{array}{c}{[0.6]} \\
0.6\end{array}$ \\
\hline 3 & $\begin{array}{c}{[78.6-82.7]} \\
80.7 \pm 2.9\end{array}$ & $\begin{array}{c}{[4.8]} \\
4.8\end{array}$ & $\begin{array}{c}{[443-475]} \\
459 \pm 23\end{array}$ & $\begin{array}{c}{[2.2-3.5]} \\
2.8 \pm 0.7\end{array}$ & $\begin{array}{c}{[0.5-0.6]} \\
0.55\end{array}$ \\
\hline 4 & $\begin{array}{c}{[75.7-83.6]} \\
80.8 \pm 4.5\end{array}$ & $\begin{array}{c}5.7] \\
5.7\end{array}$ & $\begin{array}{c}{[556]} \\
556\end{array}$ & $\begin{array}{c}3.4-4.0] \\
3.7 \pm 0.4\end{array}$ & $\begin{array}{c}{[0.6]} \\
0.6\end{array}$ \\
\hline 5 & $\begin{array}{c}{[77.9-80.8]} \\
79.4 \pm 2.1\end{array}$ & $\begin{array}{c}6.7] \\
6.7\end{array}$ & $\begin{array}{c}{[486]} \\
486\end{array}$ & $\begin{array}{c}{[4.0-4.8]} \\
4.4 \pm 0.6\end{array}$ & $\begin{array}{c}0.6] \\
0.6\end{array}$ \\
\hline 6 & $\begin{array}{c}{[78.2-82.9]} \\
80.4 \pm 2.0\end{array}$ & $\begin{array}{c}{[5.5-6.0]} \\
5.8 \pm 0.4\end{array}$ & $\begin{array}{c}{[212-422]} \\
317 \pm 149\end{array}$ & $\begin{array}{c}{[4.8-5.2]} \\
5.0 \pm 0.3\end{array}$ & $\begin{array}{c}0.5] \\
0.5\end{array}$ \\
\hline 7 & $\begin{array}{c}79-81.6] \\
80.3 \pm 1.1 \\
\end{array}$ & $\begin{array}{c}{[5.2-5.8]} \\
5.6 \pm 0.3 \\
\end{array}$ & $\begin{array}{c}{[309-352]} \\
325 \pm 24\end{array}$ & $\begin{array}{c}{[5.2-6.4]} \\
5.8 \pm 0.8 \\
\end{array}$ & $\begin{array}{c}{[0.6]} \\
0.6\end{array}$ \\
\hline 8 & $\begin{array}{c}{[75.0-80.7]} \\
77.9 \pm 2.0\end{array}$ & $\begin{array}{c}{[5.0-6.4]} \\
5.7 \pm 0.6\end{array}$ & $\begin{array}{c}{[234-352]} \\
307 \pm 51\end{array}$ & $\begin{array}{c}{[6.4-7.1]} \\
6.8 \pm 0.5\end{array}$ & $\begin{array}{c}{[0.6]} \\
0.6\end{array}$ \\
\hline 9 & $\begin{array}{c}79.5-80] \\
79.8 \pm 0.4\end{array}$ & $\begin{array}{c}{[5.7]} \\
5.7\end{array}$ & $\begin{array}{c}{[376]} \\
376\end{array}$ & $\begin{array}{c}{[7.1-7.2]} \\
7.2 \pm 0.1\end{array}$ & $\begin{array}{c}0.6] \\
0.6\end{array}$ \\
\hline 10 & $\begin{array}{c}{[78.7-86.1]} \\
82.3 \pm 2.0\end{array}$ & $\begin{array}{c}{[4.7-5.4]} \\
5.2 \pm 0.2\end{array}$ & $\begin{array}{c}{[202-499]} \\
354 \pm 113\end{array}$ & $\begin{array}{c}{[7.2-10.0]} \\
8.5 \pm 1.4\end{array}$ & $\begin{array}{c}{[0.6-0.8]} \\
0.7\end{array}$ \\
\hline 11 & $\begin{array}{c}{[77.0-83.0]} \\
79.8 \pm 2.1\end{array}$ & $\begin{array}{c}{[5.0-5.3]} \\
5.1 \pm 0.2\end{array}$ & $\begin{array}{c}{[304-444]} \\
356 \pm 66\end{array}$ & $\begin{array}{c}{[9.9-10.0]} \\
9.9 \pm 0.1\end{array}$ & $\begin{array}{c}0.7] \\
0.7\end{array}$ \\
\hline
\end{tabular}


Table 4.40. Summary of Concentrate and Pond Effluent O/G Parameters for UF2-R5 (Subruns 12 - 19)

\begin{tabular}{|c|c|c|c|c|c|}
\hline $\begin{array}{l}\text { Subrun } \\
\text { ID }\end{array}$ & $\begin{array}{l}\text { Temperature }\left({ }^{0} \mathbf{F}\right) \\
{[\min -\max ]} \\
\text { Avg } \pm \text { std }\end{array}$ & $\begin{array}{c}\mathbf{p H} \\
{[\min -\max ]} \\
\text { Avg } \pm \text { std } \\
\end{array}$ & $\begin{array}{c}\text { Conductivity }(\mu \mathrm{S} / \mathrm{cm}) \\
{[\mathrm{min}-\max ]} \\
\text { Avg } \pm \text { std } \\
\end{array}$ & $\begin{array}{c}\text { Oil Content (\%) } \\
{[\min -\max ]} \\
\text { Avg } \pm \text { std } \\
\end{array}$ & $\begin{array}{c}\text { Pond Effluent O/G (mg/L) } \\
{[\text { min - max }]} \\
\text { Avg } \\
\end{array}$ \\
\hline 12 & $\begin{array}{c}777.7-86.2] \\
82.8 \pm 3.0\end{array}$ & $\begin{array}{c}5.1-5.7] \\
5.4 \pm 0.2\end{array}$ & $\begin{array}{c}{[324-442]} \\
401 \pm 53\end{array}$ & $\begin{array}{c}10.0-9.8] \\
9.9 \pm 0.1\end{array}$ & $\begin{array}{c}0.7] \\
0.7\end{array}$ \\
\hline 13 & $\begin{array}{c}{[81.3-86.9]} \\
84.5 \pm 2.0\end{array}$ & $\begin{array}{c}{[5.3-5.6]} \\
5.4 \pm 0.2\end{array}$ & $\begin{array}{c}{[401-484]} \\
460 \pm 39\end{array}$ & $\begin{array}{c}9.8-7.8] \\
8.8 \pm 1.4\end{array}$ & $\begin{array}{c}{[0.6-0.7]} \\
0.67\end{array}$ \\
\hline 14 & $\begin{array}{c}{[81.0-86.0]} \\
82.9 \pm 1.4\end{array}$ & $\begin{array}{c}5.2-6.1] \\
5.4 \pm 0.4\end{array}$ & $\begin{array}{c}{[207-481]} \\
360 \pm 97\end{array}$ & $\begin{array}{c}8.4-12.0] \\
10.1 \pm 1.8\end{array}$ & $\begin{array}{c}{[0.7]} \\
0.7\end{array}$ \\
\hline 15 & $\begin{array}{c}82.3-86.3] \\
84.5 \pm 1.4\end{array}$ & $\begin{array}{c}{[5.2-5.4]} \\
5.3 \pm 0.1\end{array}$ & $\begin{array}{c}{[376-421]} \\
403 \pm 24\end{array}$ & $\begin{array}{c}{[12.0-18.0]} \\
15.9 \pm 3.6\end{array}$ & $\begin{array}{c}0.7-0.8] \\
0.75\end{array}$ \\
\hline 16 & $\begin{array}{c}{[81.6-84.8]} \\
83.1 \pm 1.0\end{array}$ & $\begin{array}{c}{[4.9-6.4]} \\
5.2 \pm 0.6\end{array}$ & $\begin{array}{c}{[188-462]} \\
309 \pm 118\end{array}$ & $\begin{array}{c}{[18.0-11.0]} \\
12.3 \pm 1.8\end{array}$ & $\begin{array}{c}{[0.7-0.9]} \\
0.8\end{array}$ \\
\hline 17 & $\begin{array}{c}{[82.0-91.2]} \\
88.1 \pm 2.5\end{array}$ & $\begin{array}{c}{[5.3-5.8]} \\
5.5 \pm 0.1\end{array}$ & $\begin{array}{c}{[217-433]} \\
350 \pm 89\end{array}$ & $\begin{array}{c}{[11.0-9.9]} \\
10.2 \pm 0.6\end{array}$ & $\begin{array}{c}{[0.7]} \\
0.7\end{array}$ \\
\hline 18 & $\begin{array}{c}{[84.0-93.6]} \\
89.9 \pm 2.2\end{array}$ & $\begin{array}{c}{[5.3-5.8]} \\
5.6 \pm 0.2\end{array}$ & $\begin{array}{c}{[207-523]} \\
421 \pm 101\end{array}$ & $\begin{array}{c}{[4.5-3.2]} \\
3.8 \pm 0.7\end{array}$ & $\begin{array}{c}{[0.6-0.8]} \\
0.74\end{array}$ \\
\hline 19 & $\begin{array}{c}{[93.2-94.5]} \\
94.1 \pm 1.0\end{array}$ & $\begin{array}{c}{[5.1-5.2]} \\
5.1 \pm 0.03\end{array}$ & $\begin{array}{c}{[422-432]} \\
427 \pm 7\end{array}$ & $\begin{array}{c}{[3.2-4.0]} \\
3.6 \pm 0.5\end{array}$ & $\begin{array}{c}{[0.8]} \\
0.8\end{array}$ \\
\hline
\end{tabular}


Table 4.41. Permeate Cleaning Parameters for UF2-R5 (Subrun 1 - 11)

\begin{tabular}{|c|c|c|c|c|c|}
\hline $\begin{array}{l}\text { Subrun } \\
\text { ID }\end{array}$ & $\begin{array}{c}\left.\text { Flux (gal/ft' }{ }^{2}-\mathbf{d}\right) \\
{[\mathrm{min}-\max ]} \\
\text { Avg } \pm \text { std }\end{array}$ & $\begin{array}{l}\text { Temperature }\left({ }^{0} \mathbf{F}\right) \\
{[\text { min }- \text { max }]} \\
\text { Avg } \pm \text { std }\end{array}$ & $\begin{array}{c}\text { Turbidity (NTU) } \\
\text { [min - max }] \\
\text { Avg } \pm \text { std }\end{array}$ & $\begin{array}{c}\text { pH } \\
{[\min -\max ]} \\
\text { Avg } \pm \text { std } \\
\end{array}$ & $\begin{array}{c}\text { Conductivity }(\mu \mathrm{S} / \mathrm{cm}) \\
{[\mathrm{min}-\max ]} \\
\text { Avg } \pm \text { std }\end{array}$ \\
\hline 1 & $\begin{array}{c}73.5-98.5] \\
85.8 \pm 1.8\end{array}$ & $\begin{array}{c}{[107.2-114.8]} \\
111.2 \pm 2.8\end{array}$ & $\begin{array}{c}{[2.0-14.6]} \\
5.4 \pm 4.1\end{array}$ & $\begin{array}{c}{[4.9-5.6]} \\
5.2 \pm 0.2\end{array}$ & $\begin{array}{c}660-1109] \\
992 \pm 142\end{array}$ \\
\hline 2 & $\begin{array}{c}{[64.2-82.7]} \\
77.4 \pm 2.0\end{array}$ & $\begin{array}{c}{[107.9-112.9]} \\
111.2 \pm 1.6 \\
\end{array}$ & $\begin{array}{c}{[4.3-9.3]} \\
6.1 \pm 1.9\end{array}$ & NA & $\begin{array}{c}{[716-984]} \\
833 \pm 109 \\
\end{array}$ \\
\hline 3 & $\begin{array}{c}{[46.2-85.4]} \\
70.4 \pm 4.1\end{array}$ & $\begin{array}{c}{[105.3-110.6]} \\
108.4 \pm 1.7\end{array}$ & $\begin{array}{c}{[2.6-15.5]} \\
7.7 \pm 5.7 \\
\end{array}$ & $\begin{array}{c}{[5.5-5.7]} \\
5.6 \pm 0.1\end{array}$ & $\begin{array}{c}{[712-845]} \\
781 \pm 49\end{array}$ \\
\hline 4 & $\begin{array}{c}{[37.4-102.3]} \\
76.35 \pm 8.87\end{array}$ & $\begin{array}{c}{[62.6-82.9]} \\
75.1 \pm 3.5\end{array}$ & $\begin{array}{c}{[4.1-9.1]} \\
6.6 \pm 2.0\end{array}$ & $\begin{array}{c}{[5.3-6.6]} \\
6.3 \pm 0.5\end{array}$ & $\begin{array}{c}{[176-249]} \\
223 \pm 26\end{array}$ \\
\hline 5 & $\begin{array}{c}{[66.7-142.3]} \\
90.6 \pm 13.1\end{array}$ & $\begin{array}{c}{[80.9-91.9]} \\
86.7 \pm 2.0\end{array}$ & $\begin{array}{c}{[4.2-6.2]} \\
5.2 \pm 0.9\end{array}$ & $\begin{array}{c}{[6.7-6.9]} \\
6.8 \pm 0.1 \\
\end{array}$ & $\begin{array}{c}{[267-309]} \\
291 \pm 15\end{array}$ \\
\hline 6 & $\begin{array}{c}{[62.3-115.6]} \\
90.4 \pm 3.3\end{array}$ & $\begin{array}{c}{[110.3-122.5]} \\
109 \pm 2.2\end{array}$ & $\begin{array}{c}{[5.1-11.5]} \\
7.6 \pm 2.6\end{array}$ & $\begin{array}{c}{[7.0-7.1]} \\
7.1 \pm 0.1\end{array}$ & $\begin{array}{c}{[326-485]} \\
424 \pm 62\end{array}$ \\
\hline 7 & $\begin{array}{c}{[142.3-170.8]} \\
155.6 \pm 3.3\end{array}$ & $\begin{array}{c}{[107.5-112.0]} \\
109.8 \pm 3.2\end{array}$ & $\begin{array}{c}{[7.8-13.9]} \\
11.8 \pm 2.8 \\
\end{array}$ & $\begin{array}{c}{[9.0-9.3]} \\
9.1 \pm 0.1\end{array}$ & $\begin{array}{c}{[734-784]} \\
769 \pm 23\end{array}$ \\
\hline 8 & $\begin{array}{c}{[145.8-168.9]} \\
154.4 \pm 11.0\end{array}$ & $\begin{array}{c}{[111.9-115.6]} \\
113.9 \pm 1.8\end{array}$ & $\begin{array}{c}{[2.2-5.3]} \\
3.6 \pm 1.3\end{array}$ & $\begin{array}{c}{[9.0-9.7]} \\
9.4 \pm 0.3\end{array}$ & $\begin{array}{c}{[650-1585]} \\
1115 \pm 435\end{array}$ \\
\hline 9 & $\begin{array}{c}{[144.1-170.6]} \\
160.9 \pm 7.0\end{array}$ & $\begin{array}{c}110.6-118.2] \\
113.4 \pm 1.4 \\
\end{array}$ & $\begin{array}{c}{[1.4-4.9]} \\
3.0 \pm 1.5 \\
\end{array}$ & $\begin{array}{c}{[9.5-9.8]} \\
9.6 \pm 0.2 \\
\end{array}$ & $\begin{array}{c}{[1081-1241]} \\
1147 \pm 76 \\
\end{array}$ \\
\hline 10 & $\begin{array}{c}{[126.3-128.1]} \\
127 \pm 0.7\end{array}$ & $\begin{array}{c}{[113-117]} \\
115.1 \pm 2.3\end{array}$ & $\begin{array}{c}{[1.2-1.8]} \\
1.5 \pm 0.3 \\
\end{array}$ & $\begin{array}{c}{[6.1-6.2]} \\
6.2 \pm 0.03\end{array}$ & $\begin{array}{c}{[398-467]} \\
437 \pm 27\end{array}$ \\
\hline 11 & $\begin{array}{c}{[147.6-154.7]} \\
151.2 \pm 3.1\end{array}$ & $\begin{array}{c}108.7-113.4] \\
111.5 \pm 2.0 \\
\end{array}$ & $\begin{array}{c}1.0-3.0] \\
1.8 \pm 0.9 \\
\end{array}$ & $\begin{array}{c}{[7.7-7.8]} \\
7.7 \pm 0.02 \\
\end{array}$ & $\begin{array}{c}{[851-860]} \\
857 \pm 4\end{array}$ \\
\hline
\end{tabular}


Table 4.42. Summary of Permeate Cleaning Parameters for UF2-R5 (Subruns 12 - 19)

\begin{tabular}{|c|c|c|c|c|c|}
\hline $\begin{array}{l}\text { Subrun } \\
\text { ID }\end{array}$ & $\begin{array}{c}\left.\text { Flux (gal/ft }{ }^{2}-d\right) \\
{[\min -\text { max }]} \\
\text { Avg } \pm \text { std }\end{array}$ & $\begin{array}{l}\text { Temperature }\left({ }^{0} \mathrm{~F}\right) \\
{[\mathrm{min}-\mathrm{max}]} \\
\text { Avg } \pm \text { std }\end{array}$ & $\begin{array}{c}\text { Turbidity (NTU) } \\
\text { [min - max] } \\
\text { Avg } \pm \text { std }\end{array}$ & $\begin{array}{c}\text { pH } \\
{[\min -\max ]} \\
\text { Avg } \pm \text { std } \\
\end{array}$ & $\begin{array}{c}\text { Conductivity }(\mu \mathrm{S} / \mathrm{cm}) \\
{[\mathrm{min}-\max ]} \\
\operatorname{Avg} \pm \text { std }\end{array}$ \\
\hline 12 & $\begin{array}{c}117.4-149.4] \\
131.5 \pm 4.5\end{array}$ & $\begin{array}{c}{[111.2-114.9]} \\
113.2 \pm 1.8\end{array}$ & $\begin{array}{c}{[0.6-1.5]} \\
0.9 \pm 0.3\end{array}$ & $\begin{array}{c}{[9.0-9.8]} \\
9.3 \pm 0.4\end{array}$ & $\begin{array}{c}1577-2190] \\
1884 \pm 279\end{array}$ \\
\hline 13 & $\begin{array}{c}{[102.3-112.1]} \\
107.6 \pm 4.5 \\
\end{array}$ & $\begin{array}{c}105.6-113.1] \\
109.6 \pm 3.3 \\
\end{array}$ & $\begin{array}{c}{[1.5-2.3]} \\
1.9 \pm 0.4 \\
\end{array}$ & $\begin{array}{c}{[7.5-7.6]} \\
7.6 \pm 0.1 \\
\end{array}$ & $\begin{array}{c}{[521-577]} \\
548 \pm 27\end{array}$ \\
\hline 14 & $\begin{array}{c}{[78.3-119.2]} \\
99.1 \pm 1.9\end{array}$ & $\begin{array}{c}{[106.5-109.5]} \\
108 \pm 2.1\end{array}$ & $\begin{array}{c}{[1.1-3.2]} \\
2.4 \pm 0.9\end{array}$ & $\begin{array}{c}{[9.3-9.4]} \\
9.4 \pm 0.02\end{array}$ & $\begin{array}{c}{[787-884]} \\
830 \pm 44\end{array}$ \\
\hline 15 & $\begin{array}{c}{[87.2-129.8]} \\
111.4 \pm 3.3\end{array}$ & $\begin{array}{c}{[107.1-111.7]} \\
109.3 \pm 1.4\end{array}$ & $\begin{array}{c}{[2.0-4.4]} \\
3.2 \pm 1.0\end{array}$ & $\begin{array}{c}{[7.5-7.7]} \\
7.6 \pm 0.1\end{array}$ & $\begin{array}{c}{[890-1077]} \\
976 \pm 81\end{array}$ \\
\hline 16 & $\begin{array}{c}{[106.7-124.5]} \\
116.6 \pm 3.0\end{array}$ & $\begin{array}{c}{[105.8-133.6]} \\
110.5 \pm 3.1\end{array}$ & $\begin{array}{c}{[0.5-3.9]} \\
1.5 \pm 1.2 \\
\end{array}$ & $\begin{array}{c}{[9.6-10.0]} \\
9.8 \pm 0.2 \\
\end{array}$ & $\begin{array}{c}{[864-986]} \\
921 \pm 39 \\
\end{array}$ \\
\hline 17 & $\begin{array}{c}{[129.8-140.5]} \\
134.5 \pm 1.9\end{array}$ & $\begin{array}{c}{[114.3-119.1]} \\
116.8 \pm 1.0\end{array}$ & $\begin{array}{c}{[0.8-1.9]} \\
1.5 \pm 0.4\end{array}$ & $\begin{array}{c}{[9.3-9.9]} \\
9.6 \pm 0.2\end{array}$ & $\begin{array}{c}{[1247-1534]} \\
1383 \pm 119\end{array}$ \\
\hline 18 & $\begin{array}{c}{[45.4-58.7]} \\
50.3 \pm 3.1\end{array}$ & $\begin{array}{c}{[113.8-121.1]} \\
116.6 \pm 3.3\end{array}$ & $\begin{array}{c}{[0.98-2.9]} \\
1.6 \pm 0.8 \\
\end{array}$ & $\begin{array}{c}{[8.3-9.7]} \\
8.9 \pm 0.7\end{array}$ & $\begin{array}{c}{[535-619]} \\
584 \pm 42\end{array}$ \\
\hline 19 & $\begin{array}{c}{[71.1-72.0]} \\
71.5 \pm 0.01 \\
\end{array}$ & $\begin{array}{c}109.8-115.9] \\
112.9 \pm 1.2 \\
\end{array}$ & $\begin{array}{c}{[1.3-2.9]} \\
2.1 \pm 0.7 \\
\end{array}$ & $\begin{array}{c}{[9.6]} \\
9.6 \\
\end{array}$ & $\begin{array}{c}{[585-1400]} \\
1089 \pm 98 \\
\end{array}$ \\
\hline
\end{tabular}


Table 4.43. Summary of Concentrate Cleaning Parameters for UF2-R5

\begin{tabular}{|c|c|c|c|}
\hline $\begin{array}{l}\text { Subrun } \\
\text { ID }\end{array}$ & $\begin{array}{l}\text { Temperature }\left({ }^{0} \mathbf{F}\right) \\
{[\min -\max ]} \\
\operatorname{Avg} \pm \text { std }\end{array}$ & $\begin{array}{c}\mathbf{p H} \\
{[\min -\max ]} \\
\text { Avg } \pm \text { std }\end{array}$ & $\begin{array}{c}\text { Conductivity }(\mu \mathrm{S} / \mathrm{cm}) \\
{[\mathrm{min}-\max ]} \\
\text { Avg } \pm \text { std }\end{array}$ \\
\hline 1 & $\begin{array}{c}{[117.8-124.0]} \\
121 \pm 2.2\end{array}$ & $\begin{array}{c}{[5.1-5.4]} \\
5.3 \pm 0.1\end{array}$ & $\begin{array}{c}{[660-1109]} \\
992 \pm 142\end{array}$ \\
\hline 2 & $\begin{array}{c}{[117.9-124]} \\
120.8 \pm 2.3\end{array}$ & NA & $\begin{array}{c}{[716-984]} \\
833 \pm 109\end{array}$ \\
\hline 3 & $\begin{array}{c}{[113.6-122.7]} \\
118.2 \pm 2.8\end{array}$ & $\begin{array}{c}5.7-5.9] \\
5.8 \pm 0.1\end{array}$ & $\begin{array}{c}{[712-845]} \\
781 \pm 49\end{array}$ \\
\hline 4 & $\begin{array}{c}{[67.0-88.0]} \\
80.2 \pm 4.4\end{array}$ & $\begin{array}{c}6.7-7.0] \\
6.8 \pm 0.1\end{array}$ & $\begin{array}{c}{[176-249]} \\
223 \pm 26\end{array}$ \\
\hline 5 & $\begin{array}{c}{[85.2-99.5]} \\
93.6 \pm 2.5\end{array}$ & $\begin{array}{c}{[6.9-7.1]} \\
7.0 \pm 0.1\end{array}$ & $\begin{array}{c}{[629-721]} \\
694 \pm 37\end{array}$ \\
\hline 6 & $\begin{array}{c}1113.3-122.8] \\
119.3 \pm 2.5\end{array}$ & $\begin{array}{c}7.3-7.8] \\
7.4 \pm 0.2\end{array}$ & $\begin{array}{c}{[938-1153]} \\
1039 \pm 116\end{array}$ \\
\hline 7 & $\begin{array}{c}{[118.8-123.0]} \\
120.9 \pm 1.3\end{array}$ & $\begin{array}{c}9.0-9.3] \\
9.2 \pm 0.1\end{array}$ & $\begin{array}{c}{[1241-1492]} \\
1350 \pm 105\end{array}$ \\
\hline 8 & $\begin{array}{c}{[120-126.6]} \\
123.5 \pm 1.8\end{array}$ & $\begin{array}{c}{[8.9-9.7]} \\
9.3 \pm 0.4\end{array}$ & $\begin{array}{c}{[1408-2540]} \\
2018 \pm 583\end{array}$ \\
\hline 9 & $\begin{array}{c}{[120.9-125.7]} \\
122.9 \pm 1.6\end{array}$ & $\begin{array}{c}9.4-9.9] \\
9.6 \pm 0.2\end{array}$ & $\begin{array}{c}1981-2120] \\
2038 \pm 60\end{array}$ \\
\hline 10 & $\begin{array}{c}{[121-126.7]} \\
124 \pm 1.9\end{array}$ & $\begin{array}{c}6.2-6.3] \\
6.3 \pm 0.01\end{array}$ & $\begin{array}{c}411-556] \\
499 \pm 77\end{array}$ \\
\hline 11 & $\begin{array}{c}116.3-124.5] \\
121.2 \pm 3.0\end{array}$ & $\begin{array}{c}{[7.8-7.9]} \\
7.8 \pm 0.01\end{array}$ & $\begin{array}{c}1427-1451] \\
1441 \pm 12\end{array}$ \\
\hline 12 & $\begin{array}{c}{[120.1-125.1]} \\
122.5 \pm 1.6\end{array}$ & $\begin{array}{c}9.0-9.8] \\
9.4 \pm 0.4\end{array}$ & $\begin{array}{c}{[2480-3120]} \\
2823 \pm 340\end{array}$ \\
\hline 13 & $\begin{array}{c}{[115.2-126.3]} \\
120.8 \pm 4.2\end{array}$ & $\begin{array}{c}7.7-7.8] \\
7.7 \pm 0.1\end{array}$ & $\begin{array}{c}995-1130] \\
1044 \pm 75\end{array}$ \\
\hline 14 & $\begin{array}{c}{[114.3-121.9]} \\
118.2 \pm 3.3\end{array}$ & $\begin{array}{c}9.6-9.7] \\
9.7 \pm 0.03\end{array}$ & $\begin{array}{c}{[1334-1533]} \\
1419 \pm 83\end{array}$ \\
\hline 15 & $\begin{array}{c}1115.3-121.5] \\
118.6 \pm 1.7\end{array}$ & $\begin{array}{c}7.6-7.8] \\
7.6 \pm 0.1\end{array}$ & $\begin{array}{c}{[1579-1866]} \\
1676 \pm 134\end{array}$ \\
\hline 16 & $\begin{array}{c}{[120.0-126.0]} \\
122.0 \pm 1.4\end{array}$ & $\begin{array}{c}{[9.5-9.9]} \\
9.7 \pm 0.2\end{array}$ & $\begin{array}{c}1451-1687] \\
1536 \pm 321\end{array}$ \\
\hline 17 & $\begin{array}{c}{[120.1-127.0]} \\
124.0 \pm 1.8\end{array}$ & $\begin{array}{c}{[9.3-9.9]} \\
9.6 \pm 0.3\end{array}$ & $\begin{array}{c}{[2120-2640]} \\
2375 \pm 260\end{array}$ \\
\hline 18 & $\begin{array}{c}{[120.0-128.0]} \\
124 \pm 3.3\end{array}$ & $\begin{array}{c}{[8.3-9.7]} \\
8.0 \pm 0.7\end{array}$ & $\begin{array}{c}{[692-812]} \\
728 \pm 56\end{array}$ \\
\hline 19 & $\begin{array}{c}119-125] \\
121 \pm 1.4\end{array}$ & $\begin{array}{c}{[9.6-9.7]} \\
9.64 \pm 0.3\end{array}$ & $\begin{array}{c}1065-2270] \\
1475 \pm 119\end{array}$ \\
\hline
\end{tabular}


Table 4.44 Summary of Permeate O/G Samples for UF2-R5

\begin{tabular}{|c|c|c|c|c|}
\hline \multirow[t]{2}{*}{ Subrun ID } & \multirow[t]{2}{*}{ Date/Time } & \multicolumn{3}{|c|}{ Sample Results $(\mathrm{mg} / \mathrm{L})$} \\
\hline & & $\# 1$ & $\# 2$ & $\# 3$ \\
\hline 1 & $2 / 21 / 98(01: 57)$ & 5 & & \\
\hline 2 & $2 / 23 / 98(01: 14)$ & 3 & & \\
\hline 3 & $2 / 25 / 98(01: 01)$ & 3 & & \\
\hline 4 & $3 / 2 / 98 \quad(01: 30)$ & 4 & & \\
\hline 5 & $3 / 4 / 98 \quad(00: 01)$ & 5 & 5 & 5 \\
\hline 6 & $3 / 5 / 98 \quad(23: 18)$ & 5 & & \\
\hline 7 & $3 / 9 / 98 \quad(02: 03)$ & 5 & & \\
\hline 8 & $3 / 15 / 98(02: 53)$ & 5 & & \\
\hline 9 & $3 / 16 / 98(06: 20)$ & 3 & & \\
\hline 10 & $3 / 16 / 98(21: 23)$ & 4 & & \\
\hline 10 & $3 / 23 / 98(08: 40)$ & 4 & & \\
\hline 10 & $3 / 29 / 98(10: 44)$ & 1 & & \\
\hline 11 & 4/3/98 (15:31) & 3 & 4 & 4 \\
\hline 11 & $4 / 6 / 98 \quad(19: 55)$ & 4 & & \\
\hline 12 & 4/10/98 (05:06) & 4 & & \\
\hline 12 & $4 / 12 / 98(23: 30)$ & 3 & & \\
\hline 13 & $4 / 13 / 98(23: 30)$ & 3 & & \\
\hline 13 & 4/15/98 (15:00) & 4 & & \\
\hline 14 & 4/18/98 (02:09) & 3 & & \\
\hline 14 & $4 / 21 / 98(05: 10)$ & 4 & & \\
\hline 15 & 4/25/98 (08:50) & 6 & & \\
\hline 15 & 4/27/98 (01:10) & 2 & & \\
\hline 16 & $4 / 30 / 98(23: 30)$ & 3 & 5 & 4 \\
\hline 16 & $5 / 2 / 98 \quad(06: 40)$ & 4 & & \\
\hline 16 & 5/4/98 (09:00) & 4 & & \\
\hline 16 & $5 / 6 / 98 \quad(15: 15)$ & 2 & & \\
\hline 17 & $5 / 8 / 98 \quad(12: 05)$ & 4 & & \\
\hline 17 & $5 / 11 / 98(14: 35)$ & 3 & & \\
\hline 17 & $5 / 15 / 98(05: 15)$ & 6 & & \\
\hline 18 & $5 / 22 / 98(07: 30)$ & 3 & & \\
\hline 18 & 5/28/98 (22:10) & 4 & & \\
\hline 18 & $6 / 1 / 98(19: 50)$ & 5 & & \\
\hline 18 & $6 / 4 / 98(03: 50)$ & 8 & & \\
\hline 18 & $6 / 10 / 98(12: 35)$ & 4 & 4 & 4 \\
\hline 18 & 6/13/98 (05:29) & 1 & & \\
\hline 19 & 6/26/98 (13:56) & 2 & & \\
\hline
\end{tabular}


Table 4.45 Summary of Concentrate Oil Content Samples for UF2-R5

\begin{tabular}{|c|c|c|c|c|}
\hline \multirow[t]{2}{*}{ Subrun ID } & \multirow[t]{2}{*}{ Date/Time } & \multicolumn{3}{|c|}{ Sample Results (\%) } \\
\hline & & $\# 1$ & $\# 2$ & $\# 3$ \\
\hline 1 & 2/21/98 (01:10) & 0.6 & 0.6 & 0.7 \\
\hline 1 & $2 / 21 / 98(17: 30)$ & 1.4 & & \\
\hline 2 & $2 / 23 / 98(05: 57)$ & 2.2 & & \\
\hline 3 & $2 / 26 / 98(07: 00)$ & 3.5 & & \\
\hline 4 & $3 / 3 / 98(10: 00)$ & 4.0 & & \\
\hline 5 & $3 / 5 / 98 \quad(14: 52)$ & 4.8 & 4.9 & 4.9 \\
\hline 6 & $3 / 7 / 98 \quad(21: 17)$ & 5.2 & & \\
\hline 7 & $3 / 11 / 98(05: 18)$ & 6.4 & & \\
\hline 8 & $3 / 15 / 98(11: 20)$ & 7.1 & & \\
\hline 9 & $3 / 16 / 98(12: 55)$ & 7.2 & & \\
\hline 10 & $4 / 3 / 98 \quad(07: 25)$ & 8.4 & & \\
\hline 11 & 4/7/98 (07:00) & 9.9 & & \\
\hline 12 & 4/10/98 (12:20) & 10.0 & & \\
\hline 12 & 4/13/98 (11:00) & 10.0 & & \\
\hline 13 & $4 / 14 / 98(11: 05)$ & 9.8 & 9.9 & 9.8 \\
\hline 13 & 4/17/98 (10:59) & 7.8 & & \\
\hline 14 & 4/18/98 (08:40) & 8.4 & & \\
\hline 14 & $4 / 24 / 98(06: 40)$ & 10.1 & & \\
\hline 15 & $4 / 24 / 98(19: 20)$ & 12.0 & & \\
\hline 15 & 4/30/98 (06:30) & 17.9 & & \\
\hline 16 & $4 / 30 / 98(20: 30)$ & 18.0 & & \\
\hline 16 & $5 / 2 / 98(09: 50)$ & 13.9 & & \\
\hline 16 & $5 / 7 / 98 \quad(06: 35)$ & 11.0 & & \\
\hline 17 & $5 / 7 / 98 \quad(20: 46)$ & 9.9 & & \\
\hline 17 & 5/9/98 (12:20) & 11.0 & 11.5 & 11.0 \\
\hline 17 & $5 / 12 / 98(11: 44)$ & 10.5 & & \\
\hline 17 & 5/18/98 (05:10) & 10.4 & & \\
\hline 18 & $5 / 20 / 98 \quad(20: 25)$ & 4.5 & & \\
\hline 18 & 5/28/98 (09:15) & 11.9 & & \\
\hline 18 & 6/11/98 (23:20) & 12.4 & & \\
\hline 18 & $6 / 16 / 98(10: 05)$ & 10 & & \\
\hline 18 & $6 / 22 / 98(10: 45)$ & 3.2 & 3.3 & 3.1 \\
\hline 19 & 6/28/98 (10:30) & 4.0 & & \\
\hline
\end{tabular}


Table 4.46 Summary of Skimming Samples for UF2-R5

\begin{tabular}{|c|c|c|c|c||}
\hline Subrun ID & Date/Time & \multicolumn{3}{|c|}{ Sample Results (mg/L) } \\
\cline { 3 - 5 } & & $\# \mathbf{1}$ & $\mathbf{\# 2}$ & $\mathbf{\# 3}$ \\
\hline 4 & $2 / 28 / 98(12: 20)$ & 100 & & \\
\hline 6 & $3 / 8 / 98(20: 20)$ & 100 & & \\
\hline 7 & $3 / 13 / 98(08: 45)$ & 100 & & \\
\hline 9 & $3 / 16 / 98(16: 00)$ & 98 & & \\
\hline 10 & $4 / 4 / 98(09: 30)$ & 100 & & \\
\hline 11 & $4 / 8 / 98(16: 50)$ & 100 & 99 & 100 \\
\hline 14 & $4 / 19 / 98(08: 59)$ & 100 & & \\
\hline 15 & $4 / 26 / 98(12: 12)$ & 100 & & \\
\hline 16 & $5 / 1 / 98(11: 10)$ & 99 & & \\
\hline 17 & $5 / 8 / 98(09: 35)$ & 99 & & \\
\hline 18 & $5 / 24 / 98(10: 20)$ & 100 & & \\
\hline 18 & $5 / 28 / 98(14: 25)$ & 98 & & \\
\hline 18 & $6 / 6 / 98(21: 09)$ & 100 & & \\
\hline 19 & $6 / 27 / 98(09: 50)$ & 100 & & \\
\hline
\end{tabular}


Table 4.47 Summary of Free Oil Productions for UF2-R5

\begin{tabular}{|c|c|c|c||}
\hline Subrun ID & Subrun Length, d & Total Free Oil, gal & Free Oil Production, gal/d \\
\hline \hline 1 & 0.68 & 0.0 & 0.0 \\
\hline 2 & 1.3 & 370 & 284.6 \\
\hline 3 & 2.8 & 272 & 97.1 \\
\hline 4 & 3.5 & 770 & 220 \\
\hline 5 & 2.0 & 420 & 210 \\
\hline 6 & 2.1 & 466 & 221.9 \\
\hline 7 & 3.2 & 593 & 185.3 \\
\hline 8 & 3.8 & 2,203 & 579.7 \\
\hline 9 & 0.93 & 166 & 166 \\
\hline 10 & 15.4 & 4,162 & 275.6 \\
\hline 11 & 3.4 & 1,508 & 343.5 \\
\hline 12 & 3.7 & 1,196 & 381.3 \\
\hline 13 & 3.0 & 1,144 & 381.2 \\
\hline 14 & 6.6 & 1,856 & 177.8 \\
\hline 15 & 5.4 & 960 & 798.3 \\
\hline 16 & 6.3 & 5,029 & 438.3 \\
\hline 17 & 9.3 & 4,076 & 397.3 \\
\hline 18 & 32.6 & 12,953 & 296.7 \\
\hline 19 & 3.0 & 890 & \\
\hline
\end{tabular}


Table 4.48 Summary of Pond Effluent O/G Samples for UF2-R5

\begin{tabular}{|c|c|c|c|c|}
\hline \multirow[t]{2}{*}{ Subrun ID } & \multirow[t]{2}{*}{ Date/Time } & \multicolumn{3}{|c|}{ Sample Results (mg/L) } \\
\hline & & $\# 1$ & $\# 2$ & $\# 3$ \\
\hline 1 & $2 / 8 / 98(11: 14)$ & 6,000 & & \\
\hline 2 & $2 / 21 / 98(23: 43)$ & 6,000 & & \\
\hline 3 & $2 / 25 / 98(00: 50)$ & 5,000 & & \\
\hline 3 & $2 / 26 / 98(06: 06)$ & 6,000 & & \\
\hline 4 & 3/2/98 (01:30) & 6,000 & & \\
\hline 5 & 3/3/98 (23:50) & 6,000 & & \\
\hline 6 & 3/7/98 (05:30) & 5,000 & & \\
\hline 8 & 3/15/98 (07:00) & 6,000 & & \\
\hline 10 & $3 / 17 / 98(07: 40)$ & 6,000 & 6,000 & 6,000 \\
\hline 10 & $3 / 28 / 98(08: 39)$ & 8,000 & & \\
\hline 11 & 4/5/98 (12:20) & 7,000 & & \\
\hline 12 & 4/11/98 (15:30) & 7,000 & & \\
\hline 13 & 4/14/98 (12:00) & 6,000 & & \\
\hline 13 & 4/16/98 (08:49) & 7,000 & & \\
\hline 14 & 4/19/98 (12:10) & 7,000 & & \\
\hline 15 & 4/25/98 (19:30) & 7,000 & & \\
\hline 15 & 4/28/98 (21:12) & 8,000 & & \\
\hline 16 & $5 / 1 / 98(17: 30)$ & 7,000 & & \\
\hline 16 & $5 / 5 / 98(09: 15)$ & 9,000 & & \\
\hline 17 & $5 / 8 / 98(12: 00)$ & 7,000 & & \\
\hline 17 & 5/11/98 (16:19) & 7,000 & & \\
\hline 17 & 5/13/98 (13:39) & 7,000 & & \\
\hline 18 & $5 / 21 / 98(15: 30)$ & 6,000 & & \\
\hline 18 & 5/24/98 (08:50) & 7,000 & 7,000 & 6,000 \\
\hline 18 & 5/28/98 (07:40) & 7,000 & & \\
\hline 18 & 6/1/98 (13:10) & 8,000 & & \\
\hline 18 & $6 / 4 / 98(13: 15)$ & 8,000 & & \\
\hline 18 & 6/10/98 (16:20) & 7,000 & & \\
\hline 18 & $6 / 13 / 98(09: 25)$ & 8,000 & & \\
\hline 18 & $6 / 17 / 98(11: 18)$ & 7,000 & & \\
\hline 18 & $6 / 20 / 98(16: 52)$ & 8,000 & & \\
\hline 19 & $6 / 26 / 98(18: 19)$ & 8,000 & & \\
\hline
\end{tabular}




\section{Permeate Flux and System Temperature}

Over the course of the subrun, the permeate flux ranged from 10.2 to $79.9 \mathrm{gal} / \mathrm{ft}^{2}-$

d. Permeate temperature was taken only once during the subrun and ranged around 68.7

${ }^{\circ} \mathrm{F}$. Concentrate temperature was taken once as well and ranged around $72.7^{\circ} \mathrm{F}$.

\section{Concentrate Oil Content and Free Oil Production}

Concentrate oil content started out at $0.6 \%$ and increased to $1.4 \%$ by the end of subrun \#2. The total volume of free oil that was produced during subrun \#1 was 0 gallons. The average daily free oil production was 0.0 gallons/day.

\section{Permeate Oil/Grease, Turbidity and Pond Effluent}

Permeate $\mathrm{O} / \mathrm{G}$ was constant around $5 \mathrm{mg} / \mathrm{L}$. Permeate turbidity ranged around 3.5 NTU. Pond effluent O/G was also constant at 6,000 mg/L.

\section{Conductivity and pH}

Permeate $\mathrm{pH}$ ranged at 4.5. Concentrate $\mathrm{pH} 4.6$ to 4.7 and averaged 4.6.

Permeate conductivity ranged at $442 \mu \mathrm{S} / \mathrm{cm}$. Concentrate conductivity's ranged from 206 to $360 \mu \mathrm{S} / \mathrm{cm}$ and averaged $283 \mu \mathrm{S} / \mathrm{cm}$.

\section{UF2-R5-SR1 Cleaning}


After UF2-R5-SR1 was shutdown on February 21, 1998 at 17:32 it was cleaned on February 21, 1998 at 19:10, with a $0.5 \%$ KLD cleaning solution. Once the cleaning water was heated to $\sim 115^{\circ} \mathrm{F}$, the system was cleaned for one hour under the regular cleaning cycle. After one hour elapsed, the system was shutdown and prepared for a spongeball sequence. Once the valves were adjusted on the system for spongeball retrieval, the system under went two spongeball passes. After the spongeball sequence was performed, the valves were readjusted to the normal mode setting. The system was then cleaned for an additional hour with the same cleaning solution. The total downtime for just the cleaning was 328 minutes.

\section{Permeate Flux and System Temperature}

During the first hour of cleaning the permeate flux ranged from 73.5 to 79.0 $\mathrm{gal} / \mathrm{ft}^{2}-\mathrm{d}$ and averaged $75.7 \mathrm{gal} / \mathrm{ft}^{2}-\mathrm{d}$. Permeate temperature during the first hour of cleaning ranged from 101 to $106^{\circ} \mathrm{F}$ and averaged $103{ }^{\circ} \mathrm{F}$. Concentrate temperature ranged from 118 to $124^{\circ} \mathrm{F}$ and averaged $121^{\circ} \mathrm{F}$.

After one hour, the system was shutdown and the valves were adjusted for the spongeball sequence. During the first pass of spongeballs, the permeate flux increased to $105.2 \mathrm{gal} / \mathrm{ft}^{2}-\mathrm{d}$. The second pass of spongeballs yielded a permeate flux of $117.3 \mathrm{gal} / \mathrm{ft}^{2}-$ d. After two spongeball passes were performed the system was cleaned for an additional hour.

In the second hour of regular cleaning, the permeate flux ranged from 93.9 to 98.5 $\mathrm{gal} / \mathrm{ft}^{2}-\mathrm{d}$ with an average of $95.8 \mathrm{gal} / \mathrm{ft}^{2}-\mathrm{d}$. Permeate temperature ranged from 108.6 to $114.8^{\circ} \mathrm{F}$ with an average of $111.2^{\circ} \mathrm{F}$. Concentrate temperature ranged from 117.8 to $124^{\circ} \mathrm{F}$ with an average of $121^{\circ} \mathrm{F}$.

\section{pH, Conductivity and Turbidity}


Permeate $\mathrm{pH}$ over the course of the cleaning ranged from 4.9 to 5.6 and averaged 5.2. Concentrate $\mathrm{pH}$ ranged from 5.1 to 5.4 and averaged 5.3. Permeate conductivity averaged $992 \mu \mathrm{S} / \mathrm{cm}$ and ranged from 660 to $1109 \mu \mathrm{S} / \mathrm{cm}$. Concentrate conductivity averaged $1369 \mu \mathrm{S} / \mathrm{cm}$ and ranged from 1049 to $1505 \mu \mathrm{S} / \mathrm{cm}$. Permeate turbidity ranged from 2.0 to 14.6 NTU and averaged 5.4 NTU.

\section{UF2-R5-SR2}

UF2-R5-SR2 was started on February 21, 1998 at 23:00 and ended on February 23, 1998 at 05:57. The length of the subrun lasted 0.68 days. The total permeate volume produced was 57,090 gal. Subrun \#2 was ended because the instantaneous permeate flow decreased to $17 \mathrm{gal} / \mathrm{min}$ with 1.29 days.

\section{Permeate Flux and System Temperature}

Over the course of the subrun, the permeate flux ranged from 15.8 to $103 \mathrm{gal} / \mathrm{ft}^{2}-$ d. Permeate temperature ranged from 74.5 to $78.2^{\circ} \mathrm{F}$. and averaged $76.4^{\circ} \mathrm{F}$. Concentrate temperature ranged from 78.2 to $93.6^{\circ} \mathrm{F}$ and averaged $80.9^{\circ} \mathrm{F}$. Permeate flux decreased rapidly during the duration of the subrun.

\section{Concentrate Oil Content and Free Oil Production}

Concentrate oil content started out at $1.4 \%$ and increased to $2.2 \%$ during subrun \#2. The total volume of free oil that was produced during subrun \#2 was 370 gallons. The average daily free oil production was 284.6 gallons/day.

\section{Permeate Oil/Grease, Turbidity and Pond Effluent}

Permeate $\mathrm{O} / \mathrm{G}$ remained constant at $5 \mathrm{mg} / \mathrm{L}$. Turbidity ranged from 1.7 to 5.7

NTU and averaged 3.7 NTU. Pond effluent also remained constant at 5,000 mg/L. 


\section{Conductivity and pH}

Permeate $\mathrm{pH}$ ranged from 4.5 to 6.5 with an average of 5.5. Concentrate $\mathrm{pH}$ was constant at 6.3. Permeate conductivity ranged from 442 to $605 \mu \mathrm{S} / \mathrm{cm}$ with an average of $524 \mu \mathrm{S} / \mathrm{cm}$. Concentrate conductivity was constant at $517 \mu \mathrm{S} / \mathrm{cm}$.

\section{UF2-R5-SR2 Cleaning}

After UF2-R5-SR2 was shutdown on February 23, 1998 at 05:57 it was cleaned at 07:50, with a $0.5 \%$ KLD cleaning solution. The total downtime for just the cleaning was 421 minutes.

\section{Permeate Flux and System Temperature}

During the first hour of cleaning the permeate flux ranged from 64.2 to 70.7 $\mathrm{gal} / \mathrm{ft}^{2}-\mathrm{d}$ and averaged $67.1 \mathrm{gal} / \mathrm{ft}^{2}-\mathrm{d}$. Permeate temperature during the first hour of cleaning ranged from 107.9 to $112.4^{\circ} \mathrm{F}$ and averaged $110.4{ }^{\circ} \mathrm{F}$. Concentrate temperature ranged from 117.9 to $123{ }^{\circ} \mathrm{F}$ and averaged $120.5^{\circ} \mathrm{F}$.

After one hour, the system was shutdown and the valves were adjusted for the spongeball sequence. During the first pass of spongeballs, the permeate flux increased to $121.4 \mathrm{gal} / \mathrm{ft}^{2}-\mathrm{d}$. The second pass of spongeballs yielded a permeate flux of $100.7 \mathrm{gal} / \mathrm{ft}^{2}-$ d. After two spongeball passes were performed the system was cleaned for an additional hour.

In the second hour of regular cleaning, the permeate flux ranged from 79.9 to $82.7 \mathrm{gal} / \mathrm{ft}^{2}-\mathrm{d}$ with an average of $81.4 \mathrm{gal} / \mathrm{ft}^{2}-\mathrm{d}$. Permeate temperature ranged from 110.9 to $112.9^{\circ} \mathrm{F}$ with an average of $111.9^{\circ} \mathrm{F}$. Concentrate temperature ranged from 118 to $124{ }^{\circ} \mathrm{F}$ with an average of $121^{\circ} \mathrm{F}$.

\section{pH, Conductivity and Turbidity}


Permeate and concentrate $\mathrm{pH}$ were not available during the cleaning because of the $\mathrm{pH}$ probe mal-functioning. Permeate conductivity averaged $833 \mu \mathrm{S} / \mathrm{cm}$ and ranged from 716 to $984 \mu \mathrm{S} / \mathrm{cm}$. Concentrate conductivity averaged $1414 \mu \mathrm{S} / \mathrm{cm}$ and ranged from 1174 to $2120 \mu \mathrm{S} / \mathrm{cm}$. Permeate turbidity ranged from 4.3 to $9.3 \mathrm{NTU}$ and averaged $6.1 \mathrm{NTU}$.

\section{UF2-R5-SR3}

UF2-R5-SR3 was started on February 23, 1998 at 12:38 and ended on February 26, 1998 at 07:04. The length of the subrun lasted 2.80 days. The total permeate volume produced was 45,880 gal. Subrun \#3 reached the $29 \mathrm{gal} / \mathrm{min}$ set less than a day into the subrun. The system was allowed to run because in reached the set point so fast. However the permeate flow did not level out. Subrun \#3 was ended because the instantaneous permeate flow decreased to $14 \mathrm{gal} / \mathrm{min}$.

\section{Permeate Flux and System Temperature}

Over the course of the subrun, the permeate flux ranged from 12.5 to $71.1 \mathrm{gal} / \mathrm{ft}^{2}-$

d. Permeate temperature ranged from 73.6 to $76.6^{\circ} \mathrm{F}$. and averaged $75.6^{\circ} \mathrm{F}$. Concentrate temperature ranged from 78.6 to $82.7^{\circ} \mathrm{F}$ and averaged $80.7^{\circ} \mathrm{F}$.

\section{Concentrate Oil Content and Free Oil Production}

Concentrate oil content started out at $2.2 \%$ and increased to $3.5 \%$ during subrun \#3. The total volume of free oil that was produced during subrun \#3 was 272 gallons. The average daily free oil production was 97.1 gallons/day.

\section{Permeate Oil/Grease, Turbidity and Pond Effluent}


Permeate $\mathrm{O} / \mathrm{G}$ remained constant at $3 \mathrm{mg} / \mathrm{L}$. Turbidity ranged from 1.1 to 3.7 NTU and averaged 2.4 NTU. Pond effluent O/G ranged from 5,000 to 6,000 mg/L and averaged 5,500 mg/L.

\section{Conductivity and pH}

Permeate $\mathrm{pH}$ ranged from 5.8 to 6.1 with an average of 5.9. Concentrate $\mathrm{pH}$ was constant at 4.8. Permeate conductivity ranged from 443 to $475 \mu \mathrm{S} / \mathrm{cm}$ with an average of $459 \mu \mathrm{S} / \mathrm{cm}$. Concentrate conductivity was constant at $490 \mu \mathrm{S} / \mathrm{cm}$.

\section{UF2-R5-SR3 Cleaning}

After UF2-R5-SR3 was shutdown on February 26, 1998 at 07:04 it was cleaned at 23:00, with a $0.5 \%$ KLD cleaning solution. The total downtime for just the cleaning was 1250 minutes.

\section{Permeate Flux and System Temperature}

During the first hour of cleaning the permeate flux ranged from 46.2 to 62.3 $\mathrm{gal} / \mathrm{ft}^{2}-\mathrm{d}$ and averaged $57.5 \mathrm{gal} / \mathrm{ft}^{2}-\mathrm{d}$. Permeate temperature during the first hour of cleaning ranged from 105.3 to $108.7^{\circ} \mathrm{F}$ and averaged $107.2^{\circ} \mathrm{F}$. Concentrate temperature ranged from 113.6 to $121.3{ }^{\circ} \mathrm{F}$ and averaged $117.4{ }^{\circ} \mathrm{F}$.

After one hour, the system was shutdown and the valves were adjusted for the spongeball sequence. During the first pass of spongeballs, the permeate flux increased to $140.2 \mathrm{gal} / \mathrm{ft}^{2}-\mathrm{d}$. The second pass of spongeballs yielded a permeate flux of $107.6 \mathrm{gal} / \mathrm{ft}^{2}-$

d. After two spongeball passes were performed the system was cleaned for an additional hour.

In the second hour of regular cleaning, the permeate flux ranged from 81.8 to 
$85.4 \mathrm{gal} / \mathrm{ft}^{2}-\mathrm{d}$ and averaged $83.2 \mathrm{gal} / \mathrm{ft}^{2}-\mathrm{d}$. Permeate temperature ranged from 108.2 to $110.6^{\circ} \mathrm{F}$ and averaged $109.4^{\circ} \mathrm{F}$. Concentrate temperature ranged from 117.4 to $122.7^{\circ} \mathrm{F}$ with an average of $119.4^{\circ} \mathrm{F}$.

\section{pH, Conductivity and Turbidity}

Permeate $\mathrm{pH}$ ranged from 5.5 to 5.7 and averaged 5.6. Concentrate $\mathrm{pH}$ ranged from 5.7 to 5.9 and averaged 5.8. Permeate conductivity averaged $781 \mu \mathrm{S} / \mathrm{cm}$ and ranged from 712 to $845 \mu \mathrm{S} / \mathrm{cm}$. Concentrate conductivity averaged $1530 \mu \mathrm{S} / \mathrm{cm}$ and ranged from 1407 to $1697 \mu \mathrm{S} / \mathrm{cm}$. Permeate turbidity ranged from 2.6 to $15.5 \mathrm{NTU}$ and averaged $7.7 \mathrm{NTU}$.

\section{UF2-R5-SR4}

UF2-R5-SR4 was started on February 27, 1998 at 19:50 and ended on March 3, 1998 at 10:01. The length of the subrun lasted 3.54 days. The total permeate volume produced was 162310 gal.

\section{Permeate Flux and System Temperature}

Over the course of the subrun, the permeate flux ranged from 16.0 to 103.2 $\mathrm{gal} / \mathrm{ft}^{2}$-d. Permeate temperature ranged from 73.2 to $77.9^{\circ} \mathrm{F}$. and averaged $76.2^{\circ} \mathrm{F}$. Concentrate temperature ranged from 75.7 to $83.6^{\circ} \mathrm{F}$ and averaged $80.8^{\circ} \mathrm{F}$.

\section{Concentrate Oil Content and Free Oil Production}

Concentrate oil content started out at $3.4 \%$ and increased to $4.0 \%$ during subrun \#4. The total volume of free oil that was produced during subrun \#4 was 770 gallons. The average daily free oil production was 220 gallons/day. 


\section{Permeate Oil/Grease, Turbidity and Pond Effluent}

Permeate $\mathrm{O} / \mathrm{G}$ ranged around $3 \mathrm{mg} / \mathrm{L}$. Turbidity ranged from 1.8 to $4.4 \mathrm{NTU}$ and averaged 2.7 NTU. Pond Effluent O/G ranged around 6,000 mg/L.

\section{Conductivity and pH}

Permeate $\mathrm{pH}$ ranged from 5.1 to 5.9 with an average of 5.4. Concentrate $\mathrm{pH}$ was constant at 5.7. Permeate conductivity ranged from 341 to $436 \mu \mathrm{S} / \mathrm{cm}$ with an average of $390 \mu \mathrm{S} / \mathrm{cm}$. Concentrate conductivity was constant at $556 \mu \mathrm{S} / \mathrm{cm}$.

\section{UF2-R5-SR4 Cleaning}

After UF2-R5-SR4 was shutdown on March 3, 1998 at 10:01 it was cleaned at 10:55, with a $0.5 \%$ KLD cleaning solution. The flush tank had to be used for the cleaning after subrun \#4, because the new CIP tank developed several holes. The holes developed after the tank was used once. The heater at the bottom of the CIP tank was found to be to powerful for the plastic tank. A stainless steel CIP tank has been ordered, as a result of the problem. The flush tank is going to be used until the new CIP tank arrives. As a result the water is not preheated before the cleaning, for there is no heater in the flush tank. The total downtime for just the cleaning was 253 minutes.

\section{Permeate Flux and System Temperature}

During the first hour of cleaning the permeate flux ranged from 37.4 to 72.0 $\mathrm{gal} / \mathrm{ft}^{2}-\mathrm{d}$ and averaged $51.1 \mathrm{gal} / \mathrm{ft}^{2}-\mathrm{d}$. Permeate temperature during the first hour of cleaning ranged from 62.6 to $72.8^{\circ} \mathrm{F}$ and averaged $69.2^{\circ} \mathrm{F}$. Concentrate temperature ranged from 67.0 to $81.0^{\circ} \mathrm{F}$ and averaged $74.3{ }^{\circ} \mathrm{F}$.

After one hour, the system was shutdown and the valves were adjusted for the spongeball sequence. During the first pass of spongeballs, the permeate flux increased to $115.6 \mathrm{gal} / \mathrm{ft}^{2}-\mathrm{d}$. The second pass of spongeballs yielded a permeate flux of $115.6 \mathrm{gal} / \mathrm{ft}^{2}-$ 
d. After two spongeball passes were performed the system was cleaned for an additional hour.

In the second hour of regular cleaning, the permeate flux ranged from 100.5 to $102.3 \mathrm{gal} / \mathrm{ft}^{2}-\mathrm{d}$ with an average of $101.6 \mathrm{gal} / \mathrm{ft}^{2}-\mathrm{d}$. Permeate temperature ranged from 79.1 to $82.9^{\circ} \mathrm{F}$ with an average of $81.0^{\circ} \mathrm{F}$. Concentrate temperature ranged from 84.0 to $88.0^{\circ} \mathrm{F}$ with an average of $86.0^{\circ} \mathrm{F}$.

\section{pH, Conductivity and Turbidity}

Permeate $\mathrm{pH}$ ranged from 5.3 to 6.6 and averaged 6.3. Concentrate $\mathrm{pH}$ ranged from 6.7 to 7.0 and averaged 6.8. Permeate conductivity averaged $223 \mu \mathrm{S} / \mathrm{cm}$ and ranged from 176 to $249 \mu \mathrm{S} / \mathrm{cm}$. Concentrate conductivity averaged $569 \mu \mathrm{S} / \mathrm{cm}$ and ranged from 537 to $597 \mu \mathrm{S} / \mathrm{cm}$. Permeate turbidity ranged from 4.1 to $9.1 \mathrm{NTU}$ and averaged 6.6 NTU.

\section{UF2-R5-SR5}

UF2-R5-SR5 was started on March 3, 1998 at 14:14 and ended on March 5, 1998 at 14:40. The length of the subrun lasted 2.03 days. The total permeate volume produced was 76,930 gal. Subrun \#5 was ended because the permeate running average reached the low set.

\section{Permeate Flux and System Temperature}

Over the course of the subrun, the permeate flux ranged from 17.8 to 115.6 gal/ft ${ }^{2}$-d. Permeate temperature ranged from 73.4 to $75.8^{\circ} \mathrm{F}$. and averaged $74.6^{\circ} \mathrm{F}$. Concentrate temperature ranged from 77.9 to $80.8^{\circ} \mathrm{F}$ and averaged $79.4^{\circ} \mathrm{F}$.

\section{Concentrate Oil Content and Free Oil Production}


Concentrate oil content started out at $4.0 \%$ and increased to $4.8 \%$ during subrun \#5. The total volume of free oil that was produced during subrun \#5 was 420 gallons. The average daily free oil production was 210 gallons/day.

\section{Permeate Oil/Grease, Turbidity and Pond Effluent}

Permeate $\mathrm{O} / \mathrm{G}$ ranged at $5 \mathrm{mg} / \mathrm{L}$. Turbidity ranged from 3.0 to $3.1 \mathrm{NTU}$ and averaged 3.1 NTU. Pond effluent O/G ranged at 6,000 mg/L.

\section{Conductivity and pH}

Permeate $\mathrm{pH}$ ranged from 5.4 to 5.5 with an average of 5.4. Concentrate $\mathrm{pH}$ was constant at 6.7. Permeate conductivity was constant at $331 \mu \mathrm{S} / \mathrm{cm}$. Concentrate conductivity was also constant at $486 \mu \mathrm{S} / \mathrm{cm}$.

\section{UF2-R5-SR5 Cleaning}

After UF2-R5-SR5 was shutdown on March 5, 1998 at 14:40 it was cleaned at 17:00, with a $0.5 \%$ KLD cleaning solution. The flush tank had to be used for the cleaning again. The water was recirculated for a few hour in order to raise the concentrate temperature, before adding the KLD. The total downtime for just the cleaning was 320 minutes.

\section{Permeate Flux and System Temperature}

During the first hour of cleaning the permeate flux ranged from 66.7 to 80.9 $\mathrm{gal} / \mathrm{ft}^{2}-\mathrm{d}$ and averaged $72.9 \mathrm{gal} / \mathrm{ft}^{2}-\mathrm{d}$. Permeate temperature during the first hour of cleaning ranged from 80.9 to $85.3^{\circ} \mathrm{F}$ and averaged $83.1^{\circ} \mathrm{F}$. Concentrate temperature ranged from 85.2 to $91.9^{\circ} \mathrm{F}$ and averaged $89.9{ }^{\circ} \mathrm{F}$.

After one hour, the system was shutdown and the valves were adjusted for the spongeball sequence. During the first pass of spongeballs, the permeate flux increased to 
$124.5 \mathrm{gal} / \mathrm{ft}^{2}-\mathrm{d}$. The second pass of spongeballs yielded a permeate flux of $151.1 \mathrm{gal} / \mathrm{ft}^{2}-$ d. After two spongeball passes were performed the system was cleaned for an additional hour.

In the second hour of regular cleaning, the permeate flux ranged from 92.5 to $142.3 \mathrm{gal} / \mathrm{ft}^{2}-\mathrm{d}$ with an average of $108.2 \mathrm{gal} / \mathrm{ft}^{2}-\mathrm{d}$. Permeate temperature ranged from 88.0 to $91.9^{\circ} \mathrm{F}$ with an average of $90.2^{\circ} \mathrm{F}$. Concentrate temperature ranged from 95.2 to $99.5^{\circ} \mathrm{F}$ with an average of $97.3^{\circ} \mathrm{F}$.

\section{pH, Conductivity and Turbidity}

Permeate $\mathrm{pH}$ ranged from 6.7 to 6.9 and averaged 6.8. Concentrate $\mathrm{pH}$ ranged from 6.9 to 7.1 and averaged 7.0. Permeate conductivity averaged $291 \mu \mathrm{S} / \mathrm{cm}$ and ranged from 267 to $309 \mu \mathrm{S} / \mathrm{cm}$. Concentrate conductivity averaged $694 \mu \mathrm{S} / \mathrm{cm}$ and ranged from 629 to $721 \mu \mathrm{S} / \mathrm{cm}$. Permeate turbidity ranged from 4.2 to $6.2 \mathrm{NTU}$ and averaged 5.2 NTU.

\section{UF2-R5-SR6}

UF2-R5-SR6 was started on March 5, 1998 at 20:00 and ended on March 7, 1998 at 21:17. The length of the subrun lasted 2.05 days. The total permeate volume produced was 93,570 gal. Subrun \#6 was ended because the permeate running average reached the low set.

\section{Permeate Flux and System Temperature}

Over the course of the subrun, the permeate flux ranged from 18.7 to 133.8 gal/ft ${ }^{2}-\mathrm{d}$. Permeate temperature ranged from 73.1 to $78.9^{\circ} \mathrm{F}$. and averaged $76.0{ }^{\circ} \mathrm{F}$. Concentrate temperature ranged from 78.2 to $82.9^{\circ} \mathrm{F}$ and averaged $80.4{ }^{\circ} \mathrm{F}$. 


\section{Concentrate Oil Content and Free Oil Production}

Concentrate oil content started out at $4.8 \%$ and increased to $5.2 \%$ during subrun \#6. The total volume of free oil that was produced during subrun \#6 was 466 gallons. The average daily free oil production was 221.9 gallons/day.

\section{Permeate Oil/Grease, Turbidity and Pond Effluent}

Permeate $\mathrm{O} / \mathrm{G}$ ranged at $5 \mathrm{mg} / \mathrm{L}$. Turbidity ranged from 2.1 to $16.6 \mathrm{NTU}$ and averaged 11.8 NTU. Pond effluent O/G ranged at 5,000 mg/L.

\section{Conductivity and pH}

Permeate $\mathrm{pH}$ ranged from 5.5 to 5.7 with an average of 5.6. Concentrate $\mathrm{pH}$ ranged from 5.5 to 6.0 and averaged 5.8. Permeate conductivity ranged from 238 to 349 $\mu \mathrm{S} / \mathrm{cm}$ and averaged $306 \mu \mathrm{S} / \mathrm{cm}$. Concentrate conductivity ranged from 212 to $422 \mu$ S/cm and averaged $317 \mu \mathrm{S} / \mathrm{cm}$.

\section{UF2-R5-SR6 Cleaning}

After UF2-R5-SR6 was shutdown on March 7, 1998 at 21:17 it was cleaned at 22:30, with a $0.5 \%$ KLD cleaning solution. The total downtime for just the cleaning was 163 minutes.

\section{Permeate Flux and System Temperature}

During the first 40 minutes of cleaning the permeate flux ranged from 62.3 to 73.8 $\mathrm{gal} / \mathrm{ft}^{2}-\mathrm{d}$ and averaged $68.3 \mathrm{gal} / \mathrm{ft}^{2}-\mathrm{d}$. Permeate temperature ranged from 105.4 to 111.6 ${ }^{\circ} \mathrm{F}$ and averaged $108.4^{\circ} \mathrm{F}$. Concentrate temperature ranged from 113.3 to $122.5^{\circ} \mathrm{F}$ and averaged $118^{\circ} \mathrm{F}$.

After 40 minutes, the system was shutdown and the valves were adjusted for the spongeball sequence. During the first pass of spongeballs, the permeate flux increased to 
131.6 gal/ $\mathrm{ft}^{2}-\mathrm{d}$. The second pass of spongeballs yielded a permeate flux of $133.4 \mathrm{gal} / \mathrm{ft}^{2}-$ d. After two spongeball passes were performed the system was cleaned for an additional 40 minutes.

In the second 40 minutes of regular cleaning, the permeate flux ranged from 110.3 to $115.6 \mathrm{gal} / \mathrm{ft}^{2}-\mathrm{d}$ with an average of $112.4 \mathrm{gal} / \mathrm{ft}^{2}-\mathrm{d}$. Permeate temperature ranged from 108.8 to $110.3^{\circ} \mathrm{F}$ with an average of $109.6^{\circ} \mathrm{F}$. Concentrate temperature ranged from 118.1 to $122.8^{\circ} \mathrm{F}$ with an average of $120.3^{\circ} \mathrm{F}$.

\section{pH and Conductivity}

Permeate $\mathrm{pH}$ ranged from 7.0 to 7.1 and averaged 7.1. Concentrate $\mathrm{pH}$ ranged from 7.3 to 7.8 and averaged 7.4. Permeate conductivity averaged $424 \mu \mathrm{S} / \mathrm{cm}$ and ranged from 326 to $485 \mu \mathrm{S} / \mathrm{cm}$. Concentrate conductivity averaged $1039 \mu \mathrm{S} / \mathrm{cm}$ and ranged from 938 to $1153 \mu \mathrm{S} / \mathrm{cm}$. Permeate turbidity ranged from 5.1 to $11.5 \mathrm{NTU}$ and averaged 7.6 NTU.

\section{UF2-R5-SR7}

UF2-R5-SR7 was started on March 8, 1998 at 00:00 and ended on March 11, 1998 at $05: 18$. The length of the subrun lasted 3.22 days. The total permeate volume produced was 105,990 gal. Subrun \#7 reached the $29 \mathrm{gal} / \mathrm{min}$ set point with in one days of operation. The running average did not exceed $29 \mathrm{gal} / \mathrm{min}$ though. As a result the system was allowed to stay in operation until the instantaneous permeate flow of 18 $\mathrm{gal} / \mathrm{min}$ was reached.

\section{Permeate Flux and System Temperature}

Over the course of the subrun, the permeate flux ranged from 17.1 to $86.3 \mathrm{gal} / \mathrm{ft}^{2}-$ d. Permeate temperature ranged from 75.3 to $78^{\circ} \mathrm{F}$. and averaged $76.5^{\circ} \mathrm{F}$. Concentrate temperature ranged from 79.0 to $81.6^{\circ} \mathrm{F}$ and averaged $80.3{ }^{\circ} \mathrm{F}$. 


\section{Concentrate Oil Content and Free Oil Production}

Concentrate oil content started out at $5.2 \%$ and increased to $6.4 \%$ during subrun \#7. The total volume of free oil that was produced during subrun \#7 was 593 gallons. The average daily free oil production was 185.3 gallons/day.

\section{Permeate Oil/Grease, Turbidity and Pond Effluent}

Permeate $\mathrm{O} / \mathrm{G}$ ranged from 3 to $5 \mathrm{mg} / \mathrm{L}$ and averaged $4 \mathrm{mg} / \mathrm{L}$. Turbidity ranged from 0.87 to 17.8 NTU and averaged 13.4 NTU. Pond effluent O/G ranged 7,000 mg/L.

\section{Conductivity and pH}

Permeate $\mathrm{pH}$ ranged from 5.0 to 6.0 with an average of 5.5. Concentrate $\mathrm{pH}$ ranged from 5.2 to 5.8 and averaged 5.6. Permeate conductivity ranged from 277 to 390 $\mu \mathrm{S} / \mathrm{cm}$ and averaged $354 \mu \mathrm{S} / \mathrm{cm}$. Concentrate conductivity ranged from 309 to $352 \mu$ S/cm and averaged $325 \mu \mathrm{S} / \mathrm{cm}$.

\section{UF2-R5-SR7 Cleaning}

After UF2-R5-SR7 was shutdown on March 11, 1998 at 05:18 it was cleaned at 11:30, with a $0.5 \%$ KLD cleaning solution. The total downtime for just the cleaning was 582 minutes.

\section{Permeate Flux and System Temperature}

During the first 40 minutes of cleaning the permeate flux ranged from 142.3 to 
$147.6 \mathrm{gal} / \mathrm{ft}^{2}-\mathrm{d}$ and averaged $145.1 \mathrm{gal} / \mathrm{ft}^{2}-\mathrm{d}$. Permeate temperature ranged from 107.5 to $112.0{ }^{\circ} \mathrm{F}$ and averaged $109.8^{\circ} \mathrm{F}$. Concentrate temperature ranged from 118.8 to $122.1{ }^{\circ} \mathrm{F}$ and averaged $120.6^{\circ} \mathrm{F}$.

After 40 minutes, the system was shutdown and the valves were adjusted for the spongeball sequence. During the first pass of spongeballs, the permeate flux increased to $169.2 \mathrm{gal} / \mathrm{ft}^{2}-\mathrm{d}$. The second pass of spongeballs yielded a permeate flux of $160 \mathrm{gal} / \mathrm{ft}^{2}-\mathrm{d}$. After two spongeball passes were performed the system was cleaned for an additional 40 minutes.

In the second 40 minutes of regular cleaning, the permeate flux ranged from 161.9 to $170.8 \mathrm{gal} / \mathrm{ft}^{2}-\mathrm{d}$ with an average of $166.1 \mathrm{gal} / \mathrm{ft}^{2}-\mathrm{d}$. Permeate temperature ranged from 110.1 to $110.8^{\circ} \mathrm{F}$ with an average of $110.5^{\circ} \mathrm{F}$. Concentrate temperature ranged from 121.3 to $119.7^{\circ} \mathrm{F}$ with an average of $121.3^{\circ} \mathrm{F}$.

\section{pH, Conductivity and Turbidity}

Permeate $\mathrm{pH}$ ranged from 9.0 to 9.3 and averaged 9.1. Concentrate $\mathrm{pH}$ ranged from 9.0 to 9.3 and averaged 9.2. Permeate conductivity averaged $769 \mu \mathrm{S} / \mathrm{cm}$ and ranged from 734 to $784 \mu \mathrm{S} / \mathrm{cm}$. Concentrate conductivity averaged $1350 \mu \mathrm{S} / \mathrm{cm}$ and ranged from 1241 to $1492 \mu \mathrm{S} / \mathrm{cm}$. Permeate turbidity ranged from 7.8 to $13.9 \mathrm{NTU}$ and averaged 11.8 NTU.

\section{UF2-R5-SR8}

UF2-R5-SR8 was started on March 11, 1998 at 15:00 and ended on March 15, 1998 at 10:30. The length of the subrun lasted 3.77 days. . The total permeate volume produced was 157,390 gal. Subrun \#8 reached the $29 \mathrm{gal} / \mathrm{min}$ set point with in a day and a half of operation. The running average did not exceed $29 \mathrm{gal} / \mathrm{min}$ though. As a result the system was allowed to stay in operation until the instantaneous permeate flow of $\sim 18$ $\mathrm{gal} / \mathrm{min}$ was reached. 


\section{Permeate Flux and System Temperature}

Over the course of the subrun, the permeate flux ranged from 17.9 to $97.8 \mathrm{gal} / \mathrm{ft}^{2}-$

d. Permeate temperature ranged from 70.0 to $75.7^{\circ} \mathrm{F}$. and averaged $73.4^{\circ} \mathrm{F}$. Concentrate temperature ranged from 75.0 to $80.7^{\circ} \mathrm{F}$ and averaged $77.9^{\circ} \mathrm{F}$.

\section{Concentrate Oil Content and Free Oil Production}

Concentrate oil content started out at $6.4 \%$ and increased to $7.1 \%$ during subrun \#8. The total volume of free oil that was produced during subrun \#8 was 2,203 gallons. The average daily free oil production was 579.7 gallons/day.

\section{Permeate Oil/Grease, Turbidity and Pond Effluent}

Permeate $\mathrm{O} / \mathrm{G}$ ranged at $4 \mathrm{mg} / \mathrm{L}$. Turbidity ranged from 2.8 to $4.9 \mathrm{NTU}$ and averaged 3.7 NTU. Pond effluent O/G ranged at 6,000 mg/L.

\section{Conductivity and pH}

Permeate $\mathrm{pH}$ ranged from 5.1 to 6.2 with an average of 5.5. Concentrate $\mathrm{pH}$ ranged from 5.0 to 6.4 and averaged 5.7. Permeate conductivity ranged from 278 to 388 $\mu \mathrm{S} / \mathrm{cm}$ and averaged $322 \mu \mathrm{S} / \mathrm{cm}$. Concentrate conductivity ranged from 234 to $352 \mu$ S/cm and averaged $307 \mu \mathrm{S} / \mathrm{cm}$.

\section{UF2-R5-SR8 Cleaning}

After UF2-R5-SR8 was shutdown on March 15, 1998 at 10:30 it was cleaned at 12:00, with a $0.5 \%$ KLD cleaning solution. The total downtime for just the cleaning was 230 minutes.

\section{Permeate Flux and System Temperature}


During the first 40 minutes of cleaning the permeate flux ranged from 145.8 to $168.9 \mathrm{gal} / \mathrm{ft}^{2}-\mathrm{d}$ and averaged $154.4 \mathrm{gal} / \mathrm{ft}^{2}-\mathrm{d}$. Permeate temperature ranged from 111.9 to $114.8^{\circ} \mathrm{F}$ and averaged $113.8^{\circ} \mathrm{F}$. Concentrate temperature ranged from 121.5 to $124.7^{\circ} \mathrm{F}$ and averaged $123.4^{\circ} \mathrm{F}$.

After 40 minutes, the system was shutdown and the valves were adjusted for the spongeball sequence. During the first pass of spongeballs, the permeate flux increased to $199.1 \mathrm{gal} / \mathrm{ft}^{2}-\mathrm{d}$. The second pass of spongeballs yielded a permeate flux of $188.5 \mathrm{gal} / \mathrm{ft}^{2}-$ d. After two spongeball passes were performed the system was cleaned for an additional 40 minutes.

In the second 40 minutes of regular cleaning, the permeate flux ranged from 112 to $142.3 \mathrm{gal} / \mathrm{ft}^{2}-\mathrm{d}$ with an average of $126.3 \mathrm{gal} / \mathrm{ft}^{2}-\mathrm{d}$. Permeate temperature ranged from 111.8 to $115.6^{\circ} \mathrm{F}$ and averaged $113.9^{\circ} \mathrm{F}$. Concentrate temperature ranged from 120 to $126.6^{\circ} \mathrm{F}$ and averaged $123.7^{\circ} \mathrm{F}$.

\section{pH, Conductivity and Turbidity}

Permeate $\mathrm{pH}$ ranged from 9.0 to 9.7 and averaged 9.4. Concentrate $\mathrm{pH}$ ranged from 8.9 to 9.7 and averaged 9.3 . Permeate conductivity averaged $1115 \mu \mathrm{S} / \mathrm{cm}$ and ranged from 650 to $1585 \mu \mathrm{S} / \mathrm{cm}$. Concentrate conductivity averaged $2018 \mu \mathrm{S} / \mathrm{cm}$ and ranged from 1408 to $2540 \mu \mathrm{S} / \mathrm{cm}$. Permeate turbidity ranged from 2.2 to $5.3 \mathrm{NTU}$ and averaged 3.6 NTU.

\section{UF2-R5-SR9}

UF2-R5-SR9 was started on March 15, 1998 at 14:20 and ended on March 16, 1998 at 12:35. The length of the subrun lasted 0.93 days. The total permeate volume produced was 36,900gal. Subrun \#9 never reached the $29 \mathrm{gal} / \mathrm{min}$ set point. The permeate flow dropped into the lower twenties a half a day into operation. The system was therefore, shutdown and recleaned. 


\section{Permeate Flux and System Temperature}

Over the course of the subrun, the permeate flux ranged from 19.6 to $64.0 \mathrm{gal} / \mathrm{ft}^{2}-$

d. Permeate temperature ranged from 76.1 to $77.3{ }^{\circ} \mathrm{F}$. and averaged $76.7^{\circ} \mathrm{F}$. Concentrate temperature ranged from 79.5 to $80^{\circ} \mathrm{F}$ and averaged $79.8^{\circ} \mathrm{F}$.

\section{Concentrate Oil Content and Free Oil Production}

Concentrate oil content started out at $7.1 \%$ and increased to $7.2 \%$ during subrun \#9. The total volume of free oil that was produced during subrun \#9 was 166 gallons. The average daily free oil production was 166 gallons/day.

\section{Permeate Oil/Grease, Turbidity and Pond Effluent}

Permeate $\mathrm{O} / \mathrm{G}$ ranged at $5 \mathrm{mg} / \mathrm{L}$. Turbidity ranged from 0.67 to $8.42 \mathrm{NTU}$ and averaged 2.2 NTU. Pond effluent O/G ranged at 6,000 mg/L.

\section{Conductivity and pH}

Permeate $\mathrm{pH}$ ranged from 4.9 to 5.4 with an average of 5.1. Concentrate $\mathrm{pH}$ ranged $\sim 5.7$. Permeate conductivity ranged from 352 to $378 \mu \mathrm{S} / \mathrm{cm}$ and averaged $365 \mu$ S/cm. Concentrate conductivity ranged $\sim 376 \mu \mathrm{S} / \mathrm{cm}$.

\section{UF2-R5-SR9 Cleaning}

After UF2-R5-SR9 was shutdown on March 16, 1998 at 12:35 it was cleaned at 17:30, with a $0.5 \%$ KLD cleaning solution. The total downtime for just the cleaning was 485 minutes.

\section{Permeate Flux and System Temperature}

During the first 30 minutes of cleaning the permeate flux ranged from 144.1 to 
$160.1 \mathrm{gal} / \mathrm{ft}^{2}-\mathrm{d}$ and averaged $151.2 \mathrm{gal} / \mathrm{ft}^{2}-\mathrm{d}$. Permeate temperature ranged from 113.6 to 118.2 ${ }^{\circ} \mathrm{F}$ and averaged $115.4^{\circ} \mathrm{F}$. Concentrate temperature ranged from 122.1 to $125.7{ }^{\circ} \mathrm{F}$ and averaged $123.9^{\circ} \mathrm{F}$.

After 30 minutes, the system was shutdown and the valves were adjusted for the spongeball sequence. During the first pass of spongeballs, the permeate flux increased to $220.3 \mathrm{gal} / \mathrm{ft}^{2}-\mathrm{d}$. The second pass of spongeballs yielded a permeate flux of $203.4 \mathrm{gal} / \mathrm{ft}^{2}-$ d. The third and fourth spongeball passes yielded flux of 203.4 and $199.1 \mathrm{gal} / \mathrm{ft}^{2}-\mathrm{d}$. After four spongeball passes were performed the system was cleaned for an additional 30 minutes.

In the second 30 minutes of regular cleaning, the permeate flux ranged $\sim 170.6$ $\mathrm{gal} / \mathrm{ft}^{2}$-d. Permeate temperature ranged from 110.6 to $112.0{ }^{\circ} \mathrm{F}$ and averaged $111.3{ }^{\circ} \mathrm{F}$. Concentrate temperature ranged from 120.9 to $123.3^{\circ} \mathrm{F}$ and averaged $121.9^{\circ} \mathrm{F}$.

\section{pH and Conductivity}

Permeate $\mathrm{pH}$ ranged from 9.5 to 9.8 and averaged 9.6. Concentrate $\mathrm{pH}$ ranged from 9.4 to 9.9 and averaged 9.6. Permeate conductivity averaged $1147 \mu \mathrm{S} / \mathrm{cm}$ and ranged from 1081 to $1241 \mu \mathrm{S} / \mathrm{cm}$. Concentrate conductivity averaged $2038 \mu \mathrm{S} / \mathrm{cm}$ and ranged from 1981 to $2120 \mu \mathrm{S} / \mathrm{cm}$. Permeate turbidity ranged from 1.4 to $4.9 \mathrm{NTU}$ and averaged 3.0 NTU.

\section{UF2-R5-SR10}

UF2-R5-SR10 was started on March 16, 1998 at 20:40 and ended on April 4, 1998 at 07:31. The length of the subrun lasted 15.4 days. . The total permeate volume produced was $557,460 \mathrm{gal}$. Subrun \#10 reached to $29 \mathrm{gal} / \mathrm{min}$ set point during the third day of operation. The system was allowed to stay in operation because the instantaneous permeate flow leveled out in the mid- twenties and did not decline for the rest of the subrun. 


\section{Permeate Flux and System Temperature}

Over the course of the subrun, the permeate flux ranged from 20 to $99 \mathrm{gal} / \mathrm{ft}^{2}-\mathrm{d}$. Permeate temperature ranged from 74.8 to $82.0^{\circ} \mathrm{F}$. and averaged $78.4^{\circ} \mathrm{F}$. Concentrate temperature ranged from 78.7 to $86.1^{\circ} \mathrm{F}$ and averaged $82.3^{\circ} \mathrm{F}$.

\section{Concentrate Oil Content and Free Oil Production}

Concentrate oil content during subrun \#10 started at $7.2 \%$ and increased to $9.9 \%$. The total volume of free oil that was produced during subrun \#10 was 4,162 gallons. The average daily free oil production was 275.6 gallons/day.

\section{Permeate Oil/Grease, Turbidity and Pond Effluent}

Permeate $\mathrm{O} / \mathrm{G}$ ranged from 1 to $4 \mathrm{mg} / \mathrm{L}$ and averaged $3 \mathrm{mg} / \mathrm{L}$. Turbidity ranged from 0.67 to 8.4 NTU and averaged 2.2 NTU. Pond Effluent Oil content ranged from 6,000 to $8,000 \mathrm{mg} / \mathrm{L}$ and averaged $7,500 \mathrm{mg} / \mathrm{L}$.

\section{Conductivity and pH}

Permeate $\mathrm{pH}$ ranged from 4.2 to 6.3 with an average of 5.0. Concentrate $\mathrm{pH}$ ranged from 4.7 to 5.4 and averaged 5.2. Permeate conductivity ranged from 120 to 392 $\mu \mathrm{S} / \mathrm{cm}$ and averaged $287 \mu \mathrm{S} / \mathrm{cm}$. Concentrate conductivity ranged 202 to $499 \mu \mathrm{S} / \mathrm{cm}$ and averaged $354 . \mu \mathrm{S} / \mathrm{cm}$.

\section{UF2-R5-SR10 Cleaning}


After UF2-R5-SR10 was shutdown on April, 11998 at 07:37 it was cleaned on April 3, 1998 at 19:00 with a 0.5\% KLD cleaning solution. Once the system temperature reached $\sim 115^{\circ} \mathrm{F}$. The cleaning lasted one hour without any spongeballs pass. The reason for the different cleaning method was because a new spongeball system was in the processes of installation. The spongeball section of the system was temporally disassembled.

\section{Permeate Flux and System Temperature}

During the 60 minute cleaning the permeate flux ranged from 142 to $144 \mathrm{gal} / \mathrm{ft}^{2}-\mathrm{d}$ and averaged $142.3 \mathrm{gal} / \mathrm{ft}^{2}$-d. Permeate temperature ranged from 113 to $117^{\circ} \mathrm{F}$ and averaged $115.1^{\circ} \mathrm{F}$. Concentrate temperature ranged from 121 to $126.7^{\circ} \mathrm{F}$ and averaged $124^{\circ} \mathrm{F}$.

\section{pH, Conductivity and Turbidity}

Permeate $\mathrm{pH}$ ranged from 6.1 to 6.2 and averaged 6.2. Concentrate $\mathrm{pH}$ ranged from 6.2 to 6.3 and averaged 6.3. In Table 4.28 conductivity of permeate and concentrate are presented. Permeate conductivity averaged $437 \mu \mathrm{S} / \mathrm{cm}$ and ranged from 398 to 467 $\mu \mathrm{S} / \mathrm{cm}$. Concentrate conductivity averaged $499 \mu \mathrm{S} / \mathrm{cm}$ and ranged from 411 to 556 $\mu \mathrm{S} / \mathrm{cm}$. Permeate turbidity ranged from 1.2 to $1.8 \mathrm{NTU}$ and averaged $1.5 \mathrm{NTU}$.

\section{UF2-R5-SR11}

UF2-R5-SR11 was started on April 3, 1998 at 20:38 and ended on April 7, 1998 at $07: 17$. The length of the subrun lasted 3.4 days. The total permeate volume produced was 154,590 gal. Subrun \#11 ended because additional work on the new spongeball tank was needed. The valve gaskets on the new header also needed replaced.

\section{Permeate Flux and System Temperature}


Over the course of the subrun, the permeate flux ranged from 19.6 to $40.9 \mathrm{gal} / \mathrm{ft}^{2}-$ d. Permeate temperature ranged from 74.0 to $79.4{ }^{\circ} \mathrm{F}$. and averaged $75.9^{\circ} \mathrm{F}$. Concentrate temperature ranged from 77.0 to $83.0^{\circ} \mathrm{F}$ and averaged $79.8^{\circ} \mathrm{F}$.

\section{Concentrate Oil Content and Free Oil Production}

Concentrate oil content during subrun \#11 started at $9.93 \%$ and increased to $10.0 \%$. The total volume of free oil that was produced during subrun \#11 was 1,508 gallons. The average daily free oil production was 443.2 gallons/day.

\section{Permeate Oil/Grease, Turbidity and Pond Effluent}

Permeate $\mathrm{O} / \mathrm{G}$ ranged from 3 to $4 \mathrm{mg} / \mathrm{L}$ and averaged $3.5 \mathrm{mg} / \mathrm{L}$. Turbidity ranged from 0.55 to 3.1 NTU and averaged 1.7 NTU. Pond Effluent Oil content ranged from 6,000 to $7,000 \mathrm{mg} / \mathrm{L}$ and averaged $6,500 \mathrm{mg} / \mathrm{L}$.

\section{Conductivity and pH}

Permeate $\mathrm{pH}$ ranged from 5.0 to 5.6 with an average of 5.3. Concentrate $\mathrm{pH}$ ranged from 5.0 to 5.3 and averaged 5.1. In Table 30 conductivity is presented. Permeate conductivity ranged from 202 to $434 \mu \mathrm{S} / \mathrm{cm}$ and averaged $306 \mu \mathrm{S} / \mathrm{cm}$. Concentrate conductivity ranged 304 to $444 \mu \mathrm{S} / \mathrm{cm}$ and averaged $356 . \mu \mathrm{S} / \mathrm{cm}$.

\section{UF2-R5-SR11 Cleaning}

After UF2-R5-SR11 was shutdown on April, 71998 at 07:17 it was cleaned on April 9, 1998 at 17:00 with a 0.5\% KLD cleaning solution. The total downtime for just the cleaning was 60 minutes, however the system was down for days due to the new spongeball system. 


\section{Permeate Flux and System Temperature}

During the 60 minute cleaning the permeate flux ranged from 147.6 to 154.7 $\mathrm{gal} / \mathrm{ft}^{2}-\mathrm{d}$ and averaged $151.2 \mathrm{gal} / \mathrm{ft}^{2}-\mathrm{d}$. Permeate temperature ranged from 108.7 to 113.4 ${ }^{\circ} \mathrm{F}$ and averaged $111.5^{\circ} \mathrm{F}$. Concentrate temperature ranged from 116.3 to $124.5^{\circ} \mathrm{F}$ and averaged $121.2^{\circ} \mathrm{F}$.

\section{pH, Conductivity and Turbidity}

Permeate $\mathrm{pH}$ ranged from 7.7 to 7.8 and averaged 7.7. Concentrate $\mathrm{pH}$ ranged from 7.8 to 7.9 and averaged 7.8. Permeate conductivity averaged $857 \mu \mathrm{S} / \mathrm{cm}$ and ranged from 851 to $860 \mu \mathrm{S} / \mathrm{cm}$. Concentrate conductivity averaged $1441 \mu \mathrm{S} / \mathrm{cm}$ and ranged from 1427 to $1451 \mu \mathrm{S} / \mathrm{cm}$. Permeate turbidity ranged from 1.0 to $3.0 \mathrm{NTU}$ and averaged 1.8 NTU.

\section{UF2-R5-SR12}

UF2-R5-SR12 was started on April 9, 1998 at 20:00 and ended on April 13, 1998 at 11:02. The length of the subrun lasted 3.7 days. The total permeate volume produced was 145,070 gal. Subrun \#12 was allowed to stay in concentration mode even though the permeate running average dropped below $29 \mathrm{gal} / \mathrm{min}$. The reason being, the system was going to be shutdown regardless, because of new spongeball tank work.

\section{Permeate Flux and System Temperature}

Over the course of the subrun, the permeate flux ranged from 16 to $54.2 \mathrm{gal} / \mathrm{ft}^{2}-\mathrm{d}$. Permeate temperature ranged from 74.3 to $80.7^{\circ} \mathrm{F}$. and averaged $78.5^{\circ} \mathrm{F}$. Concentrate temperature ranged from 77.7 to $86.2^{\circ} \mathrm{F}$ and averaged $82.8^{\circ} \mathrm{F}$.

\section{Concentrate Oil Content and Free Oil Production}


Concentrate oil content during subrun \#12 remained relatively constant starting out at $10.0 \%$ and ending at $9.8 \%$. The total volume of free oil that was produced during subrun \#12 was 1,196 gallons. The average daily free oil production was 323.2 gallons/day.

\section{Permeate Oil/Grease, Turbidity and Pond Effluent}

Permeate $\mathrm{O} / \mathrm{G}$ ranged from 3 to $4 \mathrm{mg} / \mathrm{L}$ and averaged $3.5 \mathrm{mg} / \mathrm{L}$. Turbidity ranged from 0.7 to $6.3 \mathrm{NTU}$ and averaged 1.7 NTU. Pond Effluent Oil content ranged at $0.7 \%$.

\section{Conductivity and pH}

Permeate $\mathrm{pH}$ ranged from 5.0 to 5.7 with an average of 5.3. Concentrate $\mathrm{pH}$ ranged from 5.1 to 5.7 and averaged 5.4. Permeate conductivity ranged from 352 to $449 \mu$ S/cm and averaged $416 \mu \mathrm{S} / \mathrm{cm}$. Concentrate conductivity ranged 324 to $442 \mu \mathrm{S} / \mathrm{cm}$ and averaged $401 . \mu \mathrm{S} / \mathrm{cm}$.

\section{UF2-R5-SR12 Cleaning}

After UF2-R5-SR12 was shutdown on April, 131998 at 11:02 it was cleaned on April 13, 1998 at 13:30 with a 0.5 \% KLD cleaning solution. The total downtime for just the cleaning and work performed on the spongeball tank was 1438 minutes.

\section{Permeate Flux and System Temperature}

During the first 40 minute cleaning the permeate flux ranged from 135.2 to 149.4 $\mathrm{gal} / \mathrm{ft}^{2}-\mathrm{d}$ and averaged $141.9 \mathrm{gal} / \mathrm{ft}^{2}-\mathrm{d}$. Permeate temperature ranged from 111.6 to 114.9 ${ }^{\circ} \mathrm{F}$ and averaged $113.4^{\circ} \mathrm{F}$. Concentrate temperature ranged from 120.1 to $123.9{ }^{\circ} \mathrm{F}$ and averaged $122.2^{\circ} \mathrm{F}$. 
The system was then set up for spongeballing. During the first spongeball pass the permeate flux increased to $177.8 \mathrm{gal} / \mathrm{ft}^{2}-\mathrm{d}$. The second pass yielded a permeate flux of $168.9 \mathrm{gal} / \mathrm{ft}^{2}-\mathrm{d}$. The third passes yield a permeate flux of $176.5 \mathrm{gal} / \mathrm{ft}^{2}-\mathrm{d}$.

During the second 40 minutes of regular cleaning, the permeate flux ranged from 117.4 to $124.5 \mathrm{gal} / \mathrm{ft}^{2}-\mathrm{d}$ and averaged $121 \mathrm{gal} / \mathrm{ft}^{2}-\mathrm{d}$. Permeate temperature ranged from 111.2 to $114.9^{\circ} \mathrm{F}$ and averaged $112.9^{\circ} \mathrm{F}$. Concentrate temperature ranged from 120.3 to $125.1^{\circ} \mathrm{F}$ and averaged $122.7^{\circ} \mathrm{F}$.

\section{pH, Conductivity and Turbidity}

Permeate $\mathrm{pH}$ ranged from 9.0 to 9.8 and averaged 9.3. Concentrate $\mathrm{pH}$ ranged from 9.0 to 9.8 and averaged 9.4. In Table 4.33 conductivity of permeate and concentrate are presented. Permeate conductivity averaged $1884 \mu \mathrm{S} / \mathrm{cm}$ and ranged from 1577 to $2190 \mu \mathrm{S} / \mathrm{cm}$. Concentrate conductivity averaged $2823 \mu \mathrm{S} / \mathrm{cm}$ and ranged from 2480 to $3120 \mu \mathrm{S} / \mathrm{cm}$. Permeate turbidity ranged from 0.6 to $1.5 \mathrm{NTU}$ and averaged $0.9 \mathrm{NTU}$.

\section{UF2-R5-SR13}

UF2-R5-SR13 was started on April 14, 1998 at 11:00 and ended on April 17, 1998 at 11:15. The length of the subrun lasted 3.0 days. The total permeate volume produced was $115,780 \mathrm{gal}$. Subrun \#13 never reached the $29 \mathrm{gal} / \mathrm{min}$ set point due to a rapid decline in permeate flux during the first day. The system was allowed to stay in operation because valve CV-1 was leaking. To prevent a long shutdown period, the system was allowed to keep running until pipe fitters were able to work on it.

\section{Permeate Flux and System Temperature}

Over the course of the subrun, the permeate flux ranged from 17.8 to $62.3 \mathrm{gal} / \mathrm{ft}^{2}-$ d. Permeate temperature ranged from 78.9 to $82.2^{\circ} \mathrm{F}$. and averaged $81.1^{\circ} \mathrm{F}$. Concentrate temperature ranged from 81.3 to $86.9^{\circ} \mathrm{F}$ and averaged $84.5^{\circ} \mathrm{F}$. 


\section{Concentrate Oil Content and Free Oil Production}

Concentrate oil content during subrun \#13 decreased starting out at $9.8 \%$ and ending at $7.8 \%$. The total volume of free oil that was produced during subrun \#13 was 1,144 gallons. The average daily free oil production was 381.3 gallons/day.

\section{Permeate Oil/Grease, Turbidity and Pond Effluent}

Permeate $\mathrm{O} / \mathrm{G}$ ranged from 3 to $4 \mathrm{mg} / \mathrm{L}$ and averaged $3.5 \mathrm{mg} / \mathrm{L}$. Turbidity ranged from 0.8 to 2.8 NTU and averaged 1.5 NTU. Pond Effluent Oil content ranged 6,000 to $7,000 \mathrm{mg} / \mathrm{L}$ and averaged 6,500 $\mathrm{mg} / \mathrm{L}$.

\section{Conductivity and pH}

Permeate $\mathrm{pH}$ ranged from 5.1 to 5.5 with an average of 5.3. Concentrate $\mathrm{pH}$ ranged from 5.3 to 5.6 and averaged 5.4. Permeate conductivity ranged from 348 to $428 \mu$ S/cm and averaged $388 \mu \mathrm{S} / \mathrm{cm}$. Concentrate conductivity ranged 401 to $484 \mu \mathrm{S} / \mathrm{cm}$ and averaged $460 \mu \mathrm{S} / \mathrm{cm}$.

\section{UF2-R5-SR13 Cleaning}

After UF2-R5-SR13 was shutdown on April, 171998 at 11:15 it was cleaned on April 17, 1998 at 17:30 with a 0.5\% KLD cleaning solution. Once the system temperature reached $\sim 115^{\circ} \mathrm{F}$. The system was not spongeball cleaned during this cleaning because the new spongeball screen inside the tank was being worked on. The cleaning consisted of just a one hour cleaning with a $0.5 \%$ KLD solution. The total downtime for just the cleaning and work performed on valve CV -1 was 550 minutes.

\section{Permeate Flux and System Temperature}


During the 60 minute cleaning the permeate flux ranged from 102.3 to 112.1 $\mathrm{gal} / \mathrm{ft}^{2}-\mathrm{d}$ and averaged $107.6 \mathrm{gal} / \mathrm{ft}^{2}-\mathrm{d}$. Permeate temperature ranged from 105.6 to 113.1 ${ }^{\circ} \mathrm{F}$ and averaged $109.6^{\circ} \mathrm{F}$. Concentrate temperature ranged from 115.2 to $126.3{ }^{\circ} \mathrm{F}$ and averaged $120.8^{\circ} \mathrm{F}$.

\section{pH, Conductivity and Turbidity}

Permeate $\mathrm{pH}$ ranged from 7.5 to 7.6 and averaged 7.6. Concentrate $\mathrm{pH}$ ranged from 7.7 to 7.8 and averaged 7.7. In Table 4.35 conductivity of permeate and concentrate are presented. Permeate conductivity averaged $548 \mu \mathrm{S} / \mathrm{cm}$ and ranged from 521 to $577 \mu$ S/cm. Concentrate conductivity averaged $1044 \mu \mathrm{S} / \mathrm{cm}$ and ranged from 995 to $1130 \mu \mathrm{S} / \mathrm{cm}$. Permeate turbidity ranged from 1.5 to $2.3 \mathrm{NTU}$ and averaged 1.9 NTU.

\section{UF2-R5-SR14}

UF2-R5-SR14 was started on April 17, 1998 at 20:25 and ended on April 24, 1998 at 06:46. The length of the subrun lasted 6.6 days. The total permeate volume produced was 283,070 gal. Subrun \#14 was shutdown because new actuators and valves needed to be installed on the new spongeball loop. The permeate running average was also at the $29 \mathrm{gal} / \mathrm{min}$ set point.

\section{Permeate Flux and System Temperature}

Over the course of the subrun, the permeate flux ranged from 20.5 to $63.1 \mathrm{gal} / \mathrm{ft}^{2}$ -

d. Permeate temperature ranged from 77.1 to $82.8^{\circ} \mathrm{F}$. and averaged $79.3^{\circ} \mathrm{F}$. Concentrate temperature ranged from 81.0 to $86.0^{\circ} \mathrm{F}$ and averaged $82.9^{\circ} \mathrm{F}$.

\section{Concentrate Oil Content and Free Oil Production}


Concentrate oil content during subrun \#14 started at $10.5 \%$ and decreased to 9.8

$\%$ by the end of the subrun. The total volume of free oil that was produced during subrun \#14 was 1,856 gallons. The average daily free oil production was 381.2 gallons/day.

\section{Permeate Oil/Grease, Turbidity and Pond Effluent}

Permeate $\mathrm{O} / \mathrm{G}$ ranged from 3 to $4 \mathrm{mg} / \mathrm{L}$ and averaged $3.5 \mathrm{mg} / \mathrm{L}$. Turbidity ranged from 0.2 to 1.6 NTU and averaged 0.6 NTU. Pond Effluent Oil content ranged at 7,000 $\mathrm{mg} / \mathrm{L}$.

\section{Conductivity and pH}

Permeate $\mathrm{pH}$ ranged from 5.0 to 5.5 with an average of 5.2. Concentrate $\mathrm{pH}$ ranged from 5.2 to 6.1 and averaged 5.4. Permeate conductivity ranged from 166 to $463 \mu$ $\mathrm{S} / \mathrm{cm}$ and averaged $345 \mu \mathrm{S} / \mathrm{cm}$. Concentrate conductivity ranged 207 to $481 \mu \mathrm{S} / \mathrm{cm}$ and averaged $360 \mu \mathrm{S} / \mathrm{cm}$.

\section{UF2-R5-SR14 Cleaning}

After UF2-R5-SR14 was shutdown on April, 241998 at 06:46 it was cleaned at 16:50 with a $0.5 \%$ KLD cleaning solution. The total downtime for just the cleaning and work performed on the spongeball tank was 195 minutes.

\section{Permeate Flux and System Temperature}

During the first 40 minute cleaning the permeate flux ranged from 78.3 to 83.6 $\mathrm{gal} / \mathrm{ft}^{2}-\mathrm{d}$ and averaged $80.7 \mathrm{gal} / \mathrm{ft}^{2}-\mathrm{d}$. Permeate temperature ranged from 106.5 to 109.5 ${ }^{\circ} \mathrm{F}$ and averaged $108^{\circ} \mathrm{F}$. Concentrate temperature ranged from 114.3 to $121.9{ }^{\circ} \mathrm{F}$ and averaged $118.2^{\circ} \mathrm{F}$. 
The system was then set up for spongeballing. During the first spongeball pass

the permeate flux increased to $124.5 \mathrm{gal} / \mathrm{ft}^{2}-\mathrm{d}$. The second pass yielded a permeate flux of $145.8 \mathrm{gal} / \mathrm{ft}^{2}-\mathrm{d}$. The third passes yield a permeate flux of $151.2 \mathrm{gal} / \mathrm{ft}^{2}-\mathrm{d}$.

During the second 40 minutes of regular cleaning, the permeate flux ranged from 115.6 to $119.2 \mathrm{gal} / \mathrm{ft}^{2}-\mathrm{d}$ and averaged $117.4 \mathrm{gal} / \mathrm{ft}^{2}-\mathrm{d}$. Permeate temperature ranged from 107.6 to $109.3^{\circ} \mathrm{F}$ and averaged $108.5^{\circ} \mathrm{F}$. Concentrate temperature ranged from 117.4 to $120.4^{\circ} \mathrm{F}$ and averaged $118.9^{\circ} \mathrm{F}$.

\section{pH, Conductivity and Turbidity}

Permeate $\mathrm{pH}$ ranged from 9.3 to 9.4 and averaged 9.4. Concentrate $\mathrm{pH}$ ranged from 9.6 to 9.7 and averaged 9.7. Permeate conductivity averaged $830 \mu \mathrm{S} / \mathrm{cm}$ and ranged from 787 to $884 \mu \mathrm{S} / \mathrm{cm}$. Concentrate conductivity averaged $1419 \mu \mathrm{S} / \mathrm{cm}$ and ranged from 1334 to $1533 \mu \mathrm{S} / \mathrm{cm}$. Permeate turbidity ranged from 1.1 to $3.2 \mathrm{NTU}$ and averaged 2.4 NTU.

\section{UF2-R5-SR15}

UF2-R5-SR15 was started on April 24, 1998 at 19:00 and ended on April 30, 1998 at 06:42. The length of the subrun lasted 5.4 days. The total permeate volume produced was 207,540 gal. Subrun \#15 was shutdown because additional valves and piping were being installed on the new spongeball loop.

\section{Permeate Flux and System Temperature}

Over the course of the subrun, the permeate flux ranged from 19.6 to $71.1 \mathrm{gal} / \mathrm{ft}^{2}$ -

d. Permeate temperature ranged from 78.7 to $81.8^{\circ} \mathrm{F}$. and averaged $80.4^{\circ} \mathrm{F}$. Concentrate temperature ranged from 82.3 to $86.3^{\circ} \mathrm{F}$ and averaged $84.5^{\circ} \mathrm{F}$. 


\section{Concentrate Oil Content and Free Oil Production}

Concentrate oil content during subrun \#15 started at $10.2 \%$ and increased to $18.0 \%$ by the end of the subrun. The total volume of free oil that was produced during subrun \#15 was 960 gallons. The average daily free oil production was 177.8 gallons/day.

\section{Permeate Oil/Grease, Turbidity and Pond Effluent}

Permeate O/G ranged from 2 to $6 \mathrm{mg} / \mathrm{L}$ and averaged $4 \mathrm{mg} / \mathrm{L}$. Turbidity ranged from 0.3 to 21.3 NTU and averaged 5.8 NTU. Pond Effluent Oil content ranged at 7,000 $\mathrm{mg} / \mathrm{L}$.

\section{Conductivity and pH}

Permeate $\mathrm{pH}$ ranged from 4.5 to 5.4 with an average of 5.0. Concentrate $\mathrm{pH}$ ranged from 5.2 to 5.4 and averaged 5.3. Permeate conductivity ranged from 279 to $398 \mu$ $\mathrm{S} / \mathrm{cm}$ and averaged $302 \mu \mathrm{S} / \mathrm{cm}$. Concentrate conductivity ranged 376 to $421 \mu \mathrm{S} / \mathrm{cm}$ and averaged $403 \mu \mathrm{S} / \mathrm{cm}$.

\section{UF2-R5-SR15 Cleaning}

After UF2-R5-SR15 was shutdown on April, 301998 at 06:42 it was cleaned at 17:50 with a $0.5 \%$ KLD cleaning solution. The total downtime for just the cleaning was 199 minutes.

\section{Permeate Flux and System Temperature}

During the first 30 minute cleaning the permeate flux ranged from 87.2 to 96.9 $\mathrm{gal} / \mathrm{ft}^{2}-\mathrm{d}$ and averaged $93.8 \mathrm{gal} / \mathrm{ft}^{2}-\mathrm{d}$. Permeate temperature ranged from 109.5 to 111.7 ${ }^{\circ} \mathrm{F}$ and averaged $110.6^{\circ} \mathrm{F}$. Concentrate temperature ranged from 117.7 to $121.5^{\circ} \mathrm{F}$ and averaged $119.9^{\circ} \mathrm{F}$. 
The system was then set up for spongeballing. During the first spongeball pass the permeate flux increased to $124.5 \mathrm{gal} / \mathrm{ft}^{2}-\mathrm{d}$. The second pass yielded a permeate flux of $142.3 \mathrm{gal} / \mathrm{ft}^{2}-\mathrm{d}$.

During the second 30 minutes of regular cleaning the permeate flux ranged from 128.1 to $129.8 \mathrm{gal} / \mathrm{ft}^{2}-\mathrm{d}$ and averaged $128.9 \mathrm{gal} / \mathrm{ft}^{2}-\mathrm{d}$. Permeate temperature ranged from 107.1 to $108.7^{\circ} \mathrm{F}$ and averaged $107.9^{\circ} \mathrm{F}$. Concentrate temperature ranged from 115.3 to $119.5^{\circ} \mathrm{F}$ and averaged $117.2^{\circ} \mathrm{F}$.

\section{pH, Conductivity and Turbidity}

Permeate $\mathrm{pH}$ ranged from 7.5 to 7.7 and averaged 7.6. Concentrate $\mathrm{pH}$ ranged from 7.6 to 7.8 and averaged 7.6. Permeate conductivity averaged $976 \mu \mathrm{S} / \mathrm{cm}$ and ranged from 890 to $1077 \mu \mathrm{S} / \mathrm{cm}$. Concentrate conductivity averaged $1676 \mu \mathrm{S} / \mathrm{cm}$ and ranged from 1579 to $1866 \mu \mathrm{S} / \mathrm{cm}$. Permeate turbidity ranged from 2.0 to $4.4 \mathrm{NTU}$ and averaged 3.2 NTU.

\section{UF2-R5-SR16}

UF2-R5-SR16 was started on April 30, 1998 at 20:04 and ended on May 7, 1998 at 06:45. The length of the subrun lasted 6.3 days. The total permeate volume produced was 351,070 gal. Subrun \#16 was shutdown because the new spongeball tank and screen were ready to be installed and tested.

\section{Permeate Flux and System Temperature}

Over the course of the subrun, the permeate flux ranged from 30.2 to 113.8 gal/ft ${ }^{2}$-d. Permeate temperature ranged from 77.8 to $81.1^{\circ} \mathrm{F}$. and averaged $79.6^{\circ} \mathrm{F}$. Concentrate temperature ranged from 81.6 to $84.8^{\circ} \mathrm{F}$ and averaged $83.1^{\circ} \mathrm{F}$. 


\section{Concentrate Oil Content and Free Oil Production}

Concentrate oil content during subrun \#16 started at $18.0 \%$ and decreased to $11.0 \%$ by the end of the subrun. The total volume of free oil that was produced during subrun \#16 was 5,029 gallons. The average daily free oil production was 798.3 gallons/day.

\section{Permeate Oil/Grease, Turbidity and Pond Effluent}

Permeate $\mathrm{O} / \mathrm{G}$ ranged from 2 to $4 \mathrm{mg} / \mathrm{L}$ and averaged $3 \mathrm{mg} / \mathrm{L}$. Turbidity ranged from 0.2 to 4.2 NTU and averaged 0.9 NTU. Pond Effluent Oil content ranged at 7,500 $\mathrm{mg} / \mathrm{L}$.

\section{Conductivity and pH}

Permeate $\mathrm{pH}$ ranged from 4.7 to 6.2 with an average of 5.1. Concentrate $\mathrm{pH}$ ranged from 4.9 to 6.4 and averaged 5.2. Permeate conductivity ranged from 196 to $361 \mu$ S/cm and averaged $281 \mu \mathrm{S} / \mathrm{cm}$. Concentrate conductivity ranged 188 to $462 \mu \mathrm{S} / \mathrm{cm}$ and averaged $309 \mu \mathrm{S} / \mathrm{cm}$.

\section{UF2-R5-SR16 Cleaning}

After UF2-R5-SR16 was shutdown on May 71998 at 06:45 it was cleaned at 12:50 with a $0.5 \%$ KLD cleaning solution and $\mathrm{pH}$ adjusted to 10 . The total downtime for just the cleaning was 493 minutes.

\section{Permeate Flux and System Temperature}

During the first 30 minute cleaning the permeate flux ranged from 106.7 to 113.8

$\mathrm{gal} / \mathrm{ft}^{2}-\mathrm{d}$ and averaged $111.2 \mathrm{gal} / \mathrm{ft}^{2}-\mathrm{d}$. Permeate temperature ranged from 105.8 to 113.6 ${ }^{\circ} \mathrm{F}$ and averaged $110.5^{\circ} \mathrm{F}$. Concentrate temperature ranged from 120 to $126^{\circ} \mathrm{F}$ and averaged $122.5^{\circ} \mathrm{F}$. 
The system was then set up for spongeballing. During the first spongeball pass the permeate flux increased to $160.1 \mathrm{gal} / \mathrm{ft}^{2}-\mathrm{d}$. The second pass yielded a permeate flux of $156.5 \mathrm{gal} / \mathrm{ft}^{2}-\mathrm{d}$. The third and fourth spongeball passes yielded permeate fluxes of 160.1 and $161.9 \mathrm{gal} / \mathrm{ft}^{2}-\mathrm{d}$ respectively.

During the second 30 minutes of regular cleaning the permeate flux ranged from 117.4 to $124.5 \mathrm{gal} / \mathrm{ft}^{2}-\mathrm{d}$ and averaged $122.0 \mathrm{gal} / \mathrm{ft}^{2}-\mathrm{d}$. Permeate temperature ranged from 111.4 to $111.7^{\circ} \mathrm{F}$ and averaged $111.6^{\circ} \mathrm{F}$. Concentrate temperature ranged from 120.4 to $122.0^{\circ} \mathrm{F}$ and averaged $121.3^{\circ} \mathrm{F}$.

\section{pH, Conductivity and Turbidity}

Permeate $\mathrm{pH}$ ranged from 9.6 to 10.0 and averaged 9.8. Concentrate $\mathrm{pH}$ ranged from 9.5 to 9.9 and averaged 9.7. Permeate conductivity averaged $921 \mu \mathrm{S} / \mathrm{cm}$ and ranged from 864 to $986 \mu \mathrm{S} / \mathrm{cm}$. Concentrate conductivity averaged $1536 \mu \mathrm{S} / \mathrm{cm}$ and ranged from 1451 to $1687 \mu \mathrm{S} / \mathrm{cm}$. Permeate turbidity ranged from 0.5 to $3.9 \mathrm{NTU}$ and averaged $1.5 \mathrm{NTU}$.

\section{UF2-R5-SR17}

UF2-R5-SR17 was started on May 7, 1998 at 20:23 and ended on May 18, 1998 at $05: 15$. The length of the subrun lasted 9.3 days. The total permeate volume produced was 360,880 gal. Subrun \#17 was shutdown because all of the valve seals for the whole system were being replaced. The original valve seals were not compatible with the oily waste the systems process.

\section{Permeate Flux and System Temperature}

Over the course of the subrun, the permeate flux ranged from 19.6 to $71.1 \mathrm{gal} / \mathrm{ft}^{2}-$ d. Permeate temperature ranged from 78.4 to $87.0^{\circ} \mathrm{F}$. and averaged $84.1^{\circ} \mathrm{F}$. Concentrate temperature ranged from 82.0 to $91.2^{\circ} \mathrm{F}$ and averaged $88.1^{\circ} \mathrm{F}$. 


\section{Concentrate Oil Content and Free Oil Production}

Concentrate oil content during subrun \#17 started at $11.0 \%$ and decreased to $9.9 \%$ by the end of the subrun. The total volume of free oil that was produced during subrun \#17 was 4,076 gallons. The average daily free oil production was 438.3 gallons/day.

\section{Permeate Oil/Grease, Turbidity and Pond Effluent}

Permeate $\mathrm{O} / \mathrm{G}$ ranged from 3 to $6 \mathrm{mg} / \mathrm{L}$ and averaged $4.3 \mathrm{mg} / \mathrm{L}$. Turbidity ranged from 0.75 to $14.3 \mathrm{NTU}$ and averaged 5.9 NTU. Pond Effluent O/G ranged from 7,000 to 9,000 $\mathrm{mg} / \mathrm{L}$ and averaged $8,000 \mathrm{mg} / \mathrm{L}$.

\section{Conductivity and pH}

Permeate $\mathrm{pH}$ ranged from 5.1 to 5.8 with an average of 5.5. Concentrate $\mathrm{pH}$ ranged from 5.3 to 5.8 and averaged 5.5. Permeate conductivity ranged from 120 to $403 \mu$ S/cm and averaged $287 \mu \mathrm{S} / \mathrm{cm}$. Concentrate conductivity ranged 217 to $433 \mu \mathrm{S} / \mathrm{cm}$ and averaged $350 \mu \mathrm{S} / \mathrm{cm}$.

\section{UF2-R5-SR17 Cleaning}

After UF2-R5-SR17 was shutdown on May 181998 at 05:15 it was cleaned on May 20, 1998 at 14:30 with a 0.5 \% KLD cleaning solution and $\mathrm{pH}$ adjusted to 10 . The total downtime for just the cleaning was 550 minutes not including the time for work on the valve replacement.

\section{Permeate Flux and System Temperature}

During the first 30 minute cleaning the permeate flux ranged from 129.8 to 133.4 $\mathrm{gal} / \mathrm{ft}^{2}-\mathrm{d}$ and averaged $131.3 \mathrm{gal} / \mathrm{ft}^{2}-\mathrm{d}$. Permeate temperature ranged from 116.7 to 119.1 
${ }^{\circ} \mathrm{F}$ and averaged $118.2^{\circ} \mathrm{F}$. Concentrate temperature ranged from 120.1 to $125.6^{\circ} \mathrm{F}$ and averaged $123.1^{\circ} \mathrm{F}$.

The system was then set up for spongeballing. During the first spongeball pass the permeate flux increased to $177.9 \mathrm{gal} / \mathrm{ft}^{2}-\mathrm{d}$. The second pass yielded a permeate flux of $172.5 \mathrm{gal} / \mathrm{ft}^{2}-\mathrm{d}$. The third spongeball pass yielded a permeate flux of $172.5 \mathrm{gal} / \mathrm{ft}^{2}-\mathrm{d}$.

During the second 30 minutes of regular cleaning the permeate flux ranged from 135.2 to $140.5 \mathrm{gal} / \mathrm{ft}^{2}-\mathrm{d}$ and averaged $137.7 \mathrm{gal} / \mathrm{ft}^{2}-\mathrm{d}$. Permeate temperature ranged from 114.3 to $115.9^{\circ} \mathrm{F}$ and averaged $115.3^{\circ} \mathrm{F}$. Concentrate temperature ranged from 122.1 to $127^{\circ} \mathrm{F}$ and averaged $124.6^{\circ} \mathrm{F}$.

\section{pH, Conductivity and Turbidity}

Permeate $\mathrm{pH}$ ranged from 9.3 to 9.9 and averaged 9.6. Concentrate $\mathrm{pH}$ ranged from 9.3 to 9.9 and averaged 9.6. Permeate conductivity averaged $1383 \mu \mathrm{S} / \mathrm{cm}$ and ranged from 1247 to $1534 \mu \mathrm{S} / \mathrm{cm}$. Concentrate conductivity averaged $2375 \mu \mathrm{S} / \mathrm{cm}$ and ranged from 2120 to $2640 \mu \mathrm{S} / \mathrm{cm}$. Permeate turbidity ranged from 0.8 to $1.9 \mathrm{NTU}$ and averaged 1.5 NTU.

\section{UF2-R5-SR18}

UF2-R5-SR18 was started on May 20, 1998 at 20:10 and ended on June 22, 1998 at 10:52. The length of the subrun lasted 32.6 days. The total permeate volume produced was 1,315,340 gal. Subrun \#18 was shutdown because all of the valve seals for the whole system were being replaced. The original valve seals were not compatible with the oily waste the systems process.

\section{Permeate Flux and System Temperature}


Over the course of the subrun, the permeate flux ranged from 19.6 to 113.8 $\mathrm{gal} / \mathrm{ft}^{2}$-d. Permeate temperature ranged from 80.1 to $89.8^{\circ} \mathrm{F}$. and averaged $85.3^{\circ} \mathrm{F}$. Concentrate temperature ranged from 84.0 to $93.6^{\circ} \mathrm{F}$ and averaged $89.9^{\circ} \mathrm{F}$.

\section{Concentrate Oil Content and Free Oil Production}

Concentrate oil content during subrun \#18 started at $4.5 \%$ and decreased to $3.2 \%$ by the end of the subrun. The total volume of free oil that was produced during subrun \#18 was 12,953 gallons. The average daily free oil production was 397.3 gallons/day.

\section{Permeate Oil/Grease, Turbidity and Pond Effluent}

Permeate $\mathrm{O} / \mathrm{G}$ ranged from 1 to $8 \mathrm{mg} / \mathrm{L}$ and averaged $3.8 \mathrm{mg} / \mathrm{L}$. Turbidity ranged from 0.19 to $17.7 \mathrm{NTU}$ and averaged 2.9 NTU. Pond Effluent O/G ranged from 6,000 to $8,000 \mathrm{mg} / \mathrm{L}$ and averaged $7,400 \mathrm{mg} / \mathrm{L}$.

\section{Conductivity and pH}

Permeate $\mathrm{pH}$ ranged from 5.2 to 6.2 with an average of 5.6. Concentrate $\mathrm{pH}$ ranged from 5.3 to 5.8 and averaged 5.6. Permeate conductivity ranged from 102 to $523 \mu$ S/cm and averaged $398 \mu \mathrm{S} / \mathrm{cm}$. Concentrate conductivity ranged 207 to $523 \mu \mathrm{S} / \mathrm{cm}$ and averaged $421 \mu \mathrm{S} / \mathrm{cm}$.

\section{UF2-R5-SR18 Cleaning}

After UF2-R5-SR18 was shutdown on June 22, 1998 at 10:52 it was cleaned on May 22, 1998 at 12:40 with a 0.5 \% KLD cleaning solution and $\mathrm{pH}$ adjusted to 10. The total downtime for just the cleaning was 215 minutes.

\section{Permeate Flux and System Temperature}


During the first 40 minute cleaning the permeate flux ranged from 45.4 to 51.6 $\mathrm{gal} / \mathrm{ft}^{2}-\mathrm{d}$ and averaged $47.1 \mathrm{gal} / \mathrm{ft}^{2}-\mathrm{d}$. Permeate temperature ranged from 114.6 to 121.1 ${ }^{\circ} \mathrm{F}$ and averaged $117.9^{\circ} \mathrm{F}$. Concentrate temperature ranged from 121 to $128^{\circ} \mathrm{F}$ and averaged $124^{\circ} \mathrm{F}$.

The system was then set up for spongeballing. During the first spongeball pass the permeate flux increased to $72.4 \mathrm{gal} / \mathrm{ft}^{2}-\mathrm{d}$. The second pass yielded a permeate flux of $79.8 \mathrm{gal} / \mathrm{ft}^{2}-\mathrm{d}$.

During the second 40 minutes of regular cleaning the permeate flux ranged from 51.6 to $58.7 \mathrm{gal} / \mathrm{ft}^{2}-\mathrm{d}$ and averaged $53.5 \mathrm{gal} / \mathrm{ft}^{2}-\mathrm{d}$. Permeate temperature ranged from 113.8 to $117.2^{\circ} \mathrm{F}$ and averaged $115.3^{\circ} \mathrm{F}$. Concentrate temperature ranged from 120 to $127.9^{\circ} \mathrm{F}$ and averaged $123.9^{\circ} \mathrm{F}$.

\section{pH, Conductivity and Turbidity}

Permeate $\mathrm{pH}$ ranged from 8.3 to 9.7 and averaged 8.9. Concentrate $\mathrm{pH}$ ranged from 8.3 to 9.7 and averaged 8.9 . Permeate conductivity averaged $584 \mu \mathrm{S} / \mathrm{cm}$ and ranged from 535 to $619 \mu \mathrm{S} / \mathrm{cm}$. Concentrate conductivity averaged $728 \mu \mathrm{S} / \mathrm{cm}$ and ranged from 692 to $812 \mu \mathrm{S} / \mathrm{cm}$. Permeate turbidity ranged from 0.98 to $2.89 \mathrm{NTU}$ and averaged 1.6 NTU.

\section{UF2-R5-SR19}

UF2-R5-SR19 was started on June 25, 1998 at 10:40 and ended on June 28, 1998 at 10:30. The length of the subrun lasted 3.0 days. The total permeate volume produced was 140,410 gal.

\section{Permeate Flux and System Temperature}


Over the course of the subrun, the permeate flux ranged from 24.9 to $49.8 \mathrm{gal} / \mathrm{ft}^{2}-$ d. Permeate temperature ranged from 87.2 to $90.1^{\circ} \mathrm{F}$. and averaged $88.4^{\circ} \mathrm{F}$. Concentrate temperature ranged from 93.2 to $94.5^{\circ} \mathrm{F}$ and averaged $94.1^{\circ} \mathrm{F}$.

\section{Concentrate Oil Content and Free Oil Production}

Concentrate oil content during subrun \#19 started at $3.2 \%$ and increased to $4.0 \%$ by the end of the subrun. The total volume of free oil that was produced during subrun \#19 was 890 gallons. The average daily free oil production was 296.7 gallons/day.

\section{Permeate Oil/Grease, Turbidity and Pond Effluent}

Permeate $\mathrm{O} / \mathrm{G}$ ranged at $5 \mathrm{mg} / \mathrm{L}$. Turbidity ranged from 1.9 to $5.4 \mathrm{NTU}$ and averaged 2.3 NTU. Pond Effluent O/G ranged from 8,000 mg/L.

\section{Conductivity and pH}

Permeate $\mathrm{pH}$ ranged from 4.8 to 5.1 with an average of 5.0. Concentrate $\mathrm{pH}$ ranged from 5.1 to 5.2 and averaged 5.1. Permeate conductivity ranged from 234 to $351 \mu$ S/cm and averaged $394 \mu \mathrm{S} / \mathrm{cm}$. Concentrate conductivity ranged 422 to $432 \mu \mathrm{S} / \mathrm{cm}$ and averaged $427 \mu \mathrm{S} / \mathrm{cm}$. 


\section{CHAPTER 5}

\section{DISCUSSION}

In this chapter the following topics will be discussed: 1) the development of an operating plan for the systems, 2) the effect on free oil production with in the concentration tanks, 3) the development of the mass balance model on oil, 4) and the role of concentration polarization and membrane fouling on permeate flux.

\section{DEVELOPMENT OF AN OPERATING PLAN FOR THE TUBULAR UNITS}

System operation is described in detail in Chapter 3. In the following section, the method used to assure that the system was operating at maximum efficiency is discussed. Permeate Flux Set Points

Each system was design to produce 40,000 gallons of permeate per day to meet the demands of the plant. This corresponded to a permeate flow of $29 \mathrm{gal} / \mathrm{min}(25.8$ $\left.\mathrm{gal} / \mathrm{ft}^{2}-\mathrm{d}\right)$. A permeate running average was used to track the average permeate flow throughout a subrun. The running average takes into consideration; the time the system was down or not producing permeate, the total length of the subrun and the total volume of permeate produced. In Figure 5.1 a typical running permeate average is presented. The equation that was used to determine the permeate running average throughout a subrun is as follows: 


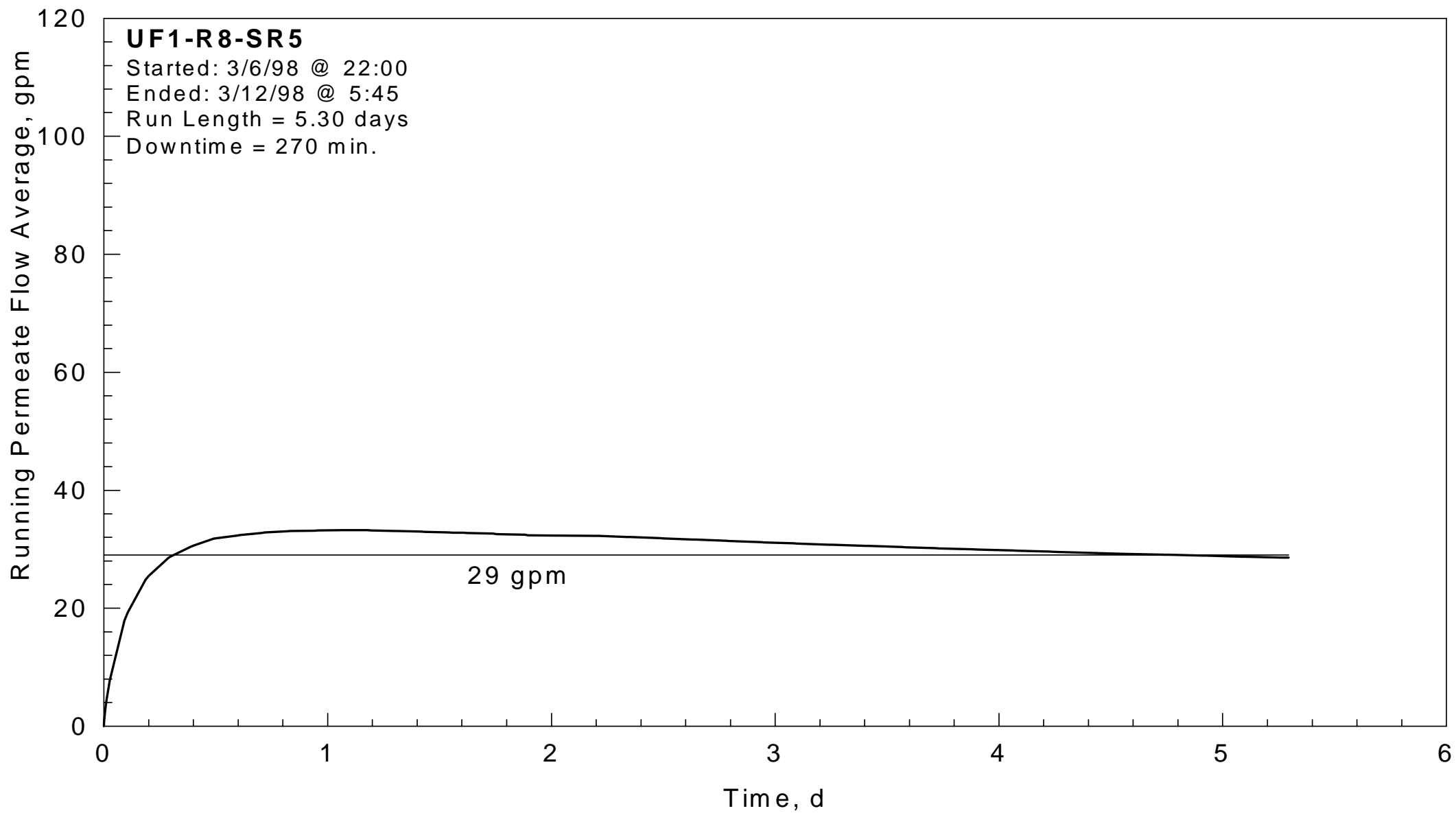

Figure 5.1 Running Permeate Average versus Time 


$$
\mathrm{Q}_{\text {permeate }}=\mathrm{V}_{\text {permeated }} /\left(\mathrm{T}_{\text {operation }}+\mathrm{T}_{\text {downtime }}\right)
$$

Where:

$\mathrm{Q}_{\text {permeate }}=$ Running permeate flow average $(\mathrm{gal} / \mathrm{min})$

$\mathrm{V}_{\text {permeated }}=$ Total volume of permeate produce from $\mathrm{t}$ to $\mathrm{t}+1$ (gallons)

$\mathrm{T}_{\text {operation }}=$ Total amount of time the system was operating $\mathrm{t}=$ minutes

$\mathrm{T}_{\text {downtime }}=$ amount of time the system was down for routine cleanings $\mathrm{t}=$ minutes

The system was shutdown and cleaned if the permeate running average was significantly less than $29 \mathrm{gal} / \mathrm{min}$.

Another set point that was established was the instantaneous permeate flow. The instantaneous permeate flow was not allowed to decrease below $18 \mathrm{gpm}\left(16.0 \mathrm{gal} / \mathrm{ft}^{2}-\mathrm{d}\right)$. The set point was based on advice from the membrane manufacturer who said that operating the system at low permeate flow could decrease membrane life.

\section{MODIFIED TREATMENT PROCESS}

The modified treatment plan is present in Figure 5.2. The Proposed treatment plan is present in Figure 3.1 Many changes were made to the original treatment plan due to the performance of the full-scale tubular UF system. These changes were the result of water quality, free oil production and concentrate oil content. 


\section{River}

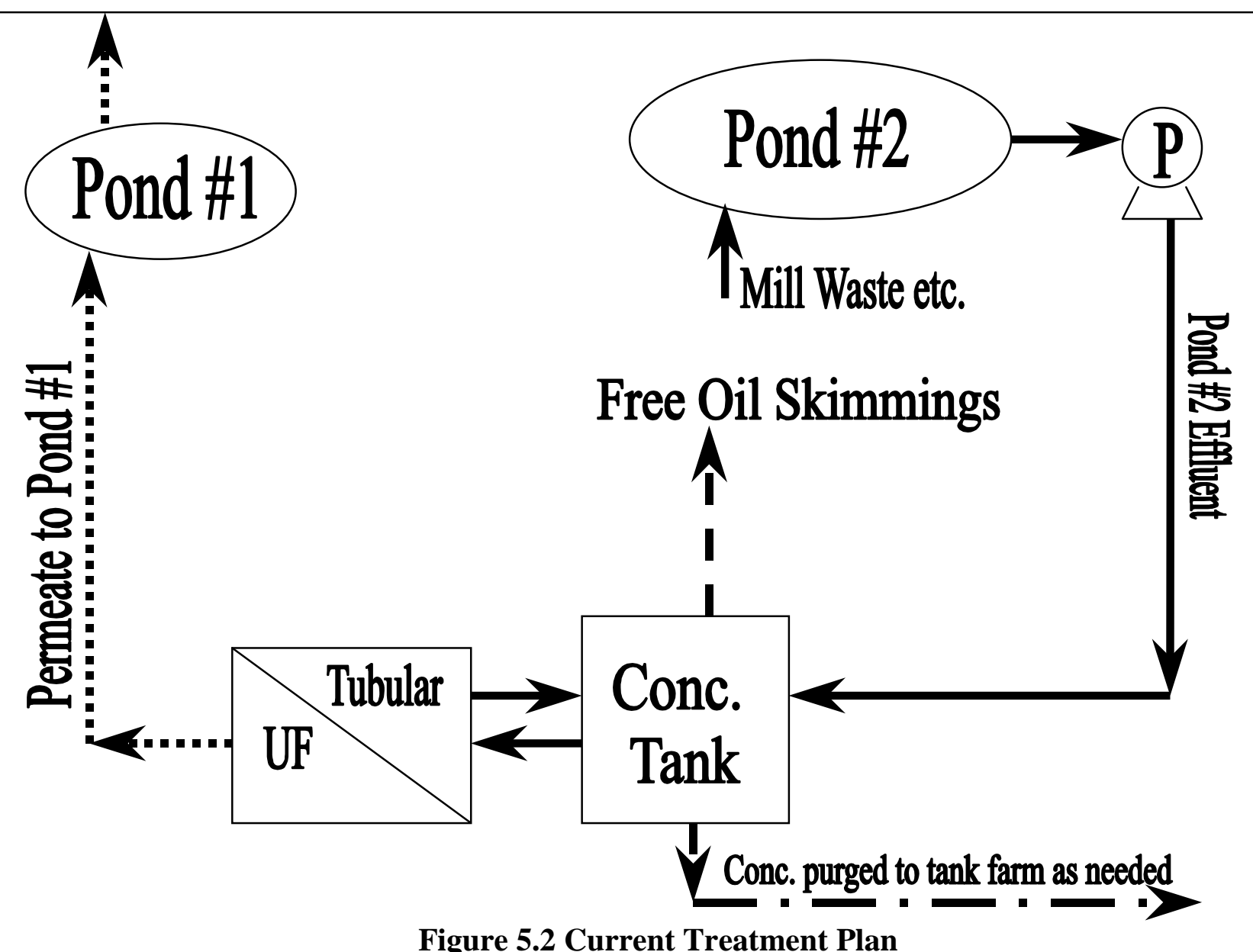

Figure 5.2 Current Treatment Plan 


\section{Water Quality}

In Tables 4.1, 4.10, 4.19, 4.28, 4.37, a summary of the results from UF1-R8, UF2-R3, UF2-R4 and UF2-R5 are presented. For all runs, permeate $(\mathrm{O} / \mathrm{G})$ was consistently low, ranging from 1 to $9 \mathrm{mg} / \mathrm{L}$ and averaging $3.1 \mathrm{mg} / \mathrm{L}$.

The pilot-scale UF system significantly reduced O/G concentrations, however concentrations were still above the discharge limits. Thus, the wetlands were necessary in the preliminary design to further degrade the remaining $\mathrm{O} / \mathrm{G}$ in the UF effluent. However, the full-scale system produced permeate that was of high quality and did not require further polishing. Removal efficiencies were consistently above $99.9 \%$. As a result the wetlands were deemed unnecessary and the permeate could be directly discharged into the river.

\section{Free Oil Production}

As concentration occurred, an unexpectedly large amount of free oil separated out of the concentrate and accumulated at the top of the concentration tanks. The total amount of free oil collected during UF1-R8 was 49,484 gallons with a daily average of 394 gallons. The total amount of free oil collected during UF2-R5 was 39,034 gallons with a daily average of 355 gallons. Daily averages were similar for all other runs. The volume that formed was far beyond what was expected. In the original plan, coalescers were too dewater any free oil that might form at the top of the concentration tanks. The oil content of the free oil was consistently above $98 \%$ oil. As a result, the skimmed free oil could be directly transferred to the storage facility for offsite recycling. Thus, the coalscers were no longer needed. 
Due to the volume and oil content of the free oil forming at the top of concentration tanks, the concentrate oil content typically remained below the $16 \%$ oil content set point for a vast majority of the runs. Recall in the preliminary design, the residual from the tubular was to be sent to a HSR-UF when the oil content reached $16 \%$. However, because of the free oil formation, the oil content within the tubular seldom reached a high enough level to warrant purging. Thus, the HSR-UF system was not needed.

\section{Concentrate Oil Content}

An oil mass balance was performed on the UF system in order to note any change in the system. In Figure 5.3, the oil mass balance diagram is presented. The mass balance equation was calculated as follows:

$$
\begin{aligned}
\left(\mathrm{OC}_{\mathrm{n}+1}\right)= & {\left[\left(\mathrm{V}_{\text {perm }}\right)\left(\mathrm{OC}_{\text {pond }}\right)-\left(\mathrm{V}_{\text {perm- }}\right)\left(\mathrm{OC}_{\text {perm }}\right)-\left(\mathrm{V}_{\text {skim }}\right)(0.00349 \mathrm{~kg} / \mathrm{gal})(\% \text { oil })-\right.} \\
& \left.\left(\mathrm{V}_{\text {leak }}\right)\left(\mathrm{OC}_{\text {leak }}\right)+\left(\mathrm{V}_{\text {sys }}\right)\left(\mathrm{OC}_{\mathrm{n}}\right)\right] / \mathrm{V}_{\text {sys }}
\end{aligned}
$$

where,

$\mathrm{V}_{\text {sys }}=$ System volume at 11.0 feet in concentration tanks (14,561 gallons)

$\mathrm{OC}_{\mathrm{n}+1}=$ Concentrate oil content for current day $(\mathrm{kg} / \mathrm{gal})$

$\mathrm{OC}_{\text {pond }}=$ Pond effluent oil content $(\mathrm{kg} / \mathrm{gal})$

$\mathrm{V}_{\text {perm }}=$ Volume permeate removed from system from $t_{1}$ to $t_{2}$ (gallons)

$\mathrm{OC}_{\text {perm }}=$ Permeate oil content $(\mathrm{kg} / \mathrm{gal})$

$\mathrm{V}_{\text {skim }}=$ Volume oil skimmed from concentrate tank (gallons)

$\%$ oil $=\%$ oil of skimmings

$\mathrm{V}_{\text {leak }}=$ Volume of leaks (gallons)

$\mathrm{OC}_{\text {leak }}=$ Oil content of leaks $(\mathrm{kg} / \mathrm{gal})$

$\mathrm{OC}_{\mathrm{n}}=$ Concentrate oil content for previous day $\mathrm{kg} / \mathrm{gal}$

$0.00349 \mathrm{~kg} / \mathrm{gal}=$ density of oil package.

The predicted oil content was calculated daily during a run, after the free oil was

skimmed from concentration tanks. In Figure 5.4, actual and predicted oil contents for 


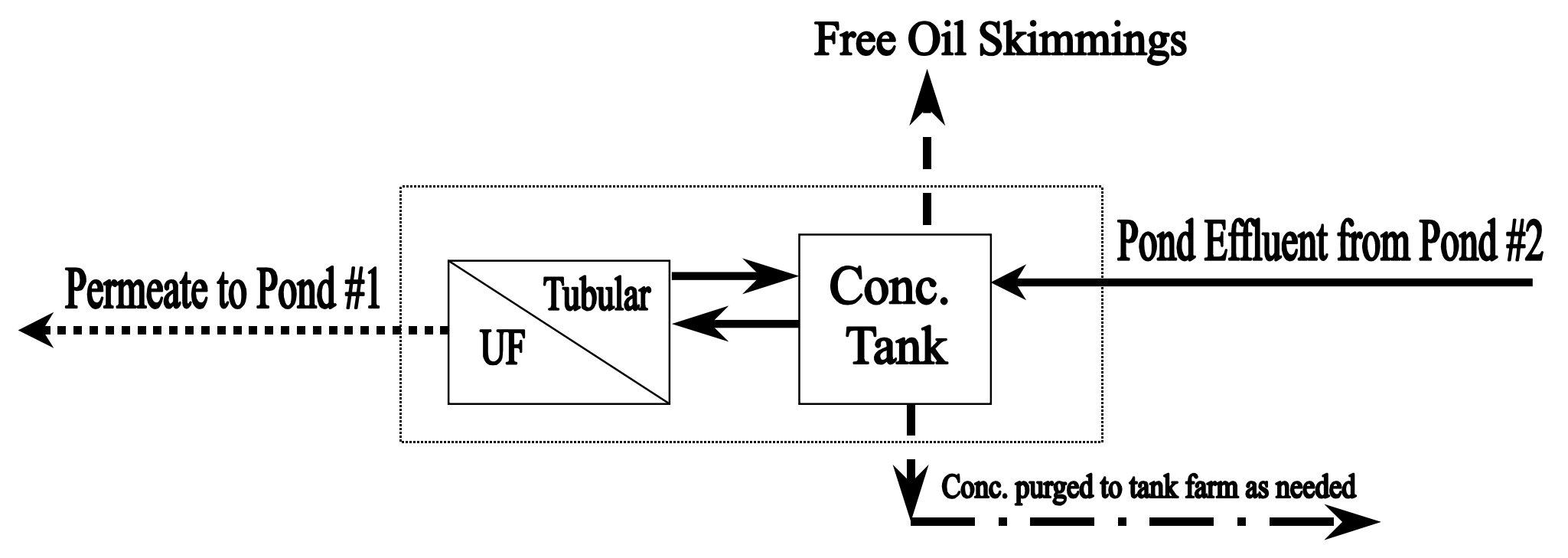

Figure 5.3 Mass Balance Diagram 
UF1-R7 mass balance are presented. In Figure 5.5, actual and predicted oil contents for UF1-R8 mass balance are presented. In Figure 5.6, actual and predicted oil contents for UF2-R3 mass balance are presented. In Figure 5.7, actual and predicted oil contents for UF2-R4 mass balance are presented. In Figure 5.8, actual and predicted oil contents for UF2-R5 mass balance are presented.

Also presented in Figures 5.4, 5.5, 5.6, 5,7, and 5.8, is the oil content of the concentrate solution if no free oil formed in the concentration tanks. The oil content would have reached the $16 \%$ set point in less than 10 days for both UF1-R8 and UF2-R5. However, because of free oil formation, the concentrate almost always remained at an oil content below $16 \%$.

In UF1-R7, UF2-R3 and UF2-R4 the predicted oil mass balance model adequately predicted the actual oil content. Unfortunately, the runs did not last long. The systems were designed to concentrate the waste to $32 \mathrm{X}$ or $16 \%$ oil content. During the runs UF1R7, UF2-R3 and UF2-R4, the systems were shutdown due to either logistical reasons or system malfunction (e.g. valve replacement or pipe rupture) and the $32 \mathrm{X}$ set point was never reached. Consequently, for all three runs the systems had to be drained to repair the problems and the systems were down for long periods of time. As a result, it was decided that a new run should be started after the system was repaired and cleaned.

UF1-R8 on the other hand, lasted significantly longer than previous runs. UF1-R8 lasted for 125 days. Similar to past runs an oil mass balance was calculated daily, to monitor changes in the systems. During UF1-R8, the actual oil content increased to $12 \%$ oil after the first 35 days of operation. Over a period of the next 40 days of 


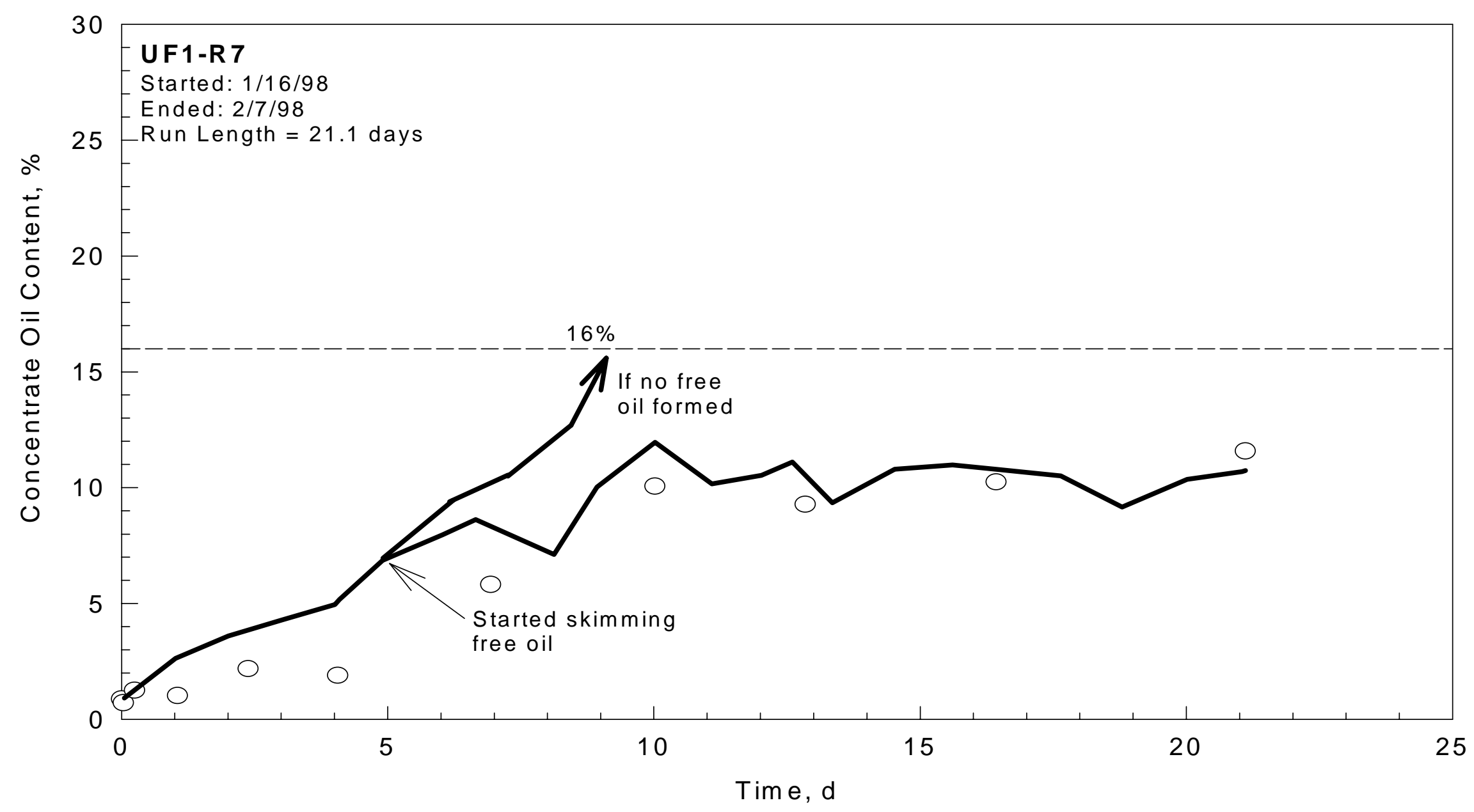

Figure 5.4 Actual and Predicted Oil Contents for UF1-R7 Mass Balance 


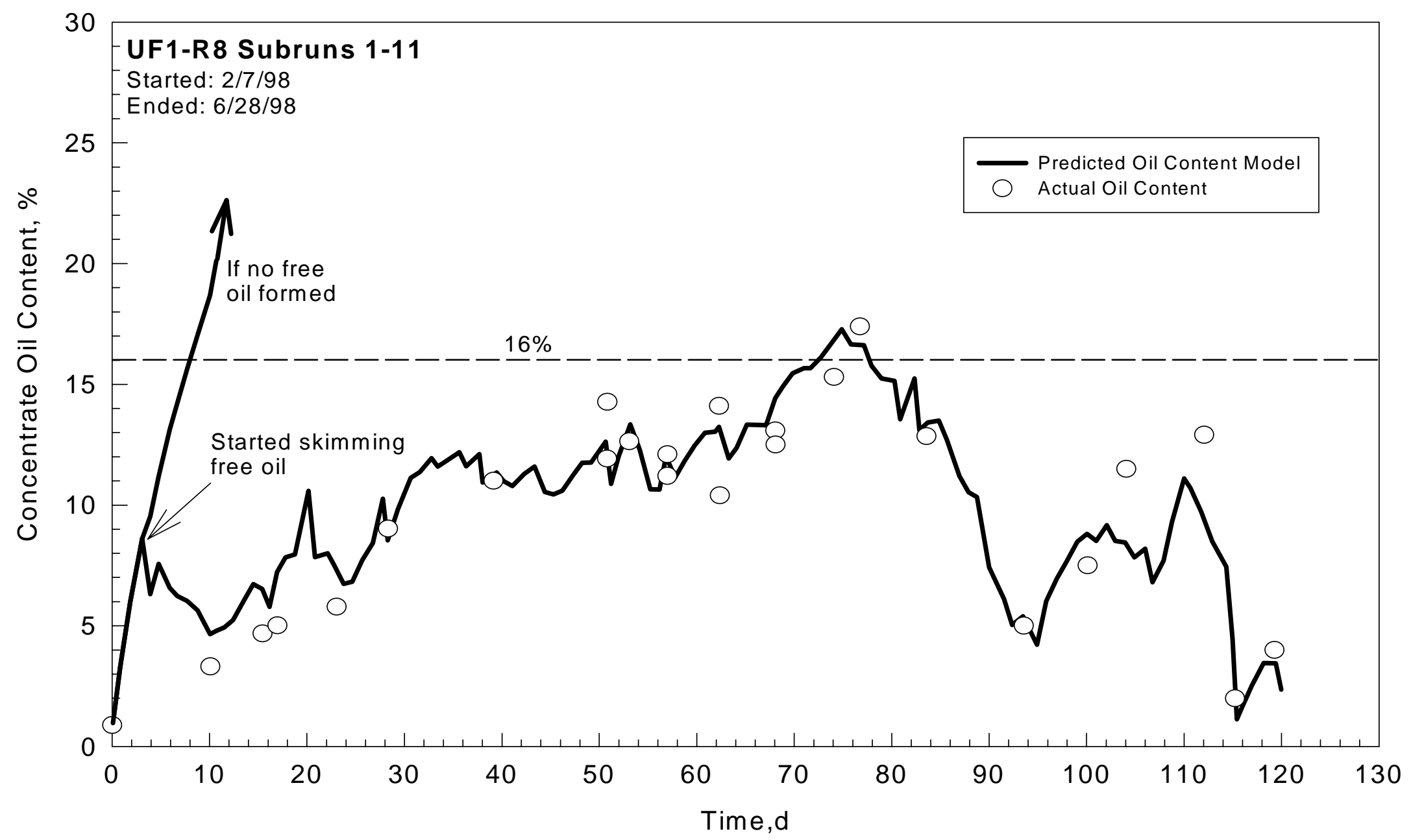

Figure 5.5 Actual and Predicted Oil Contents for UF1-R8 Mass Balance 


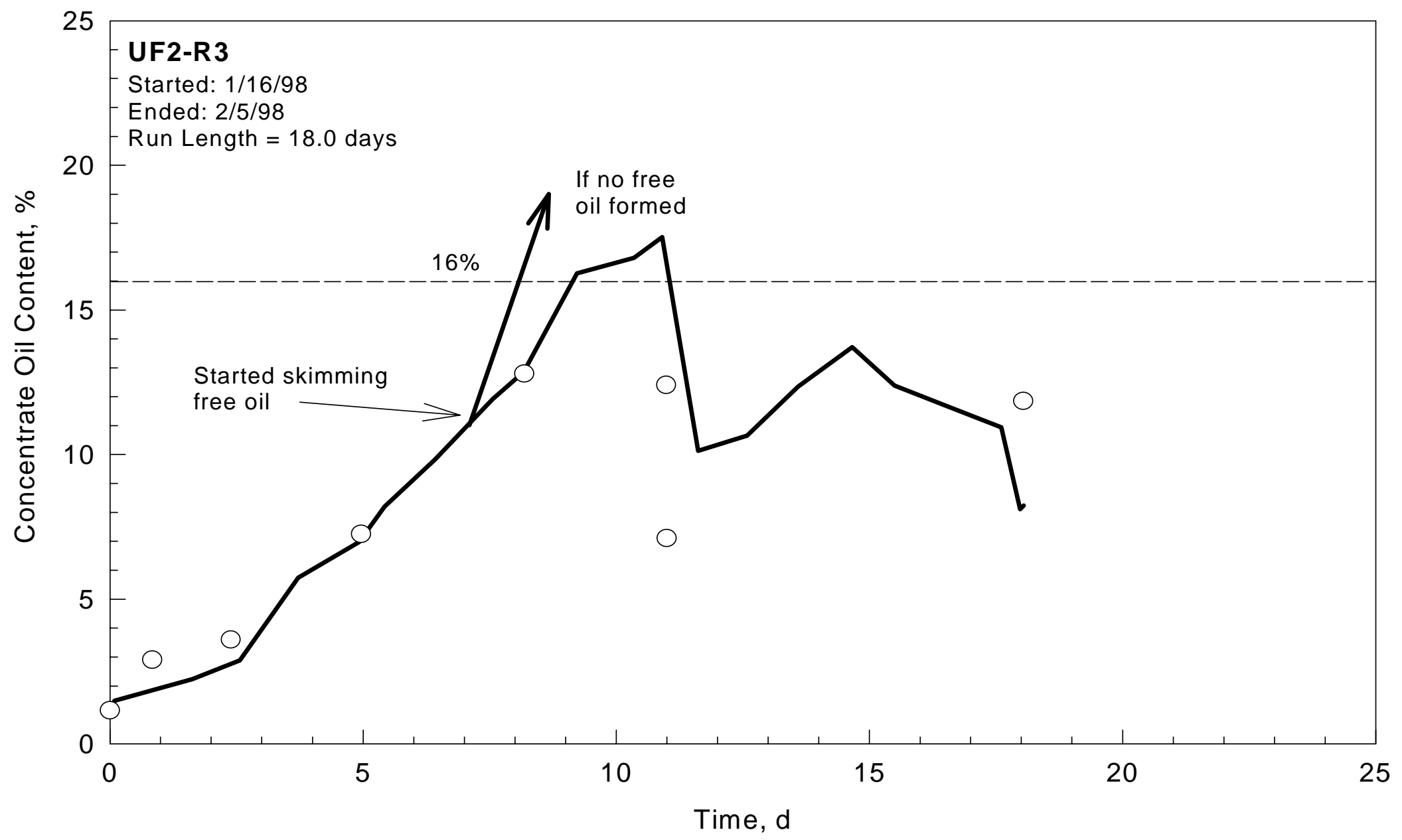

Figure 5.6 Actual and Predicted Oil Contents for UF2-R3 Mass Balance 


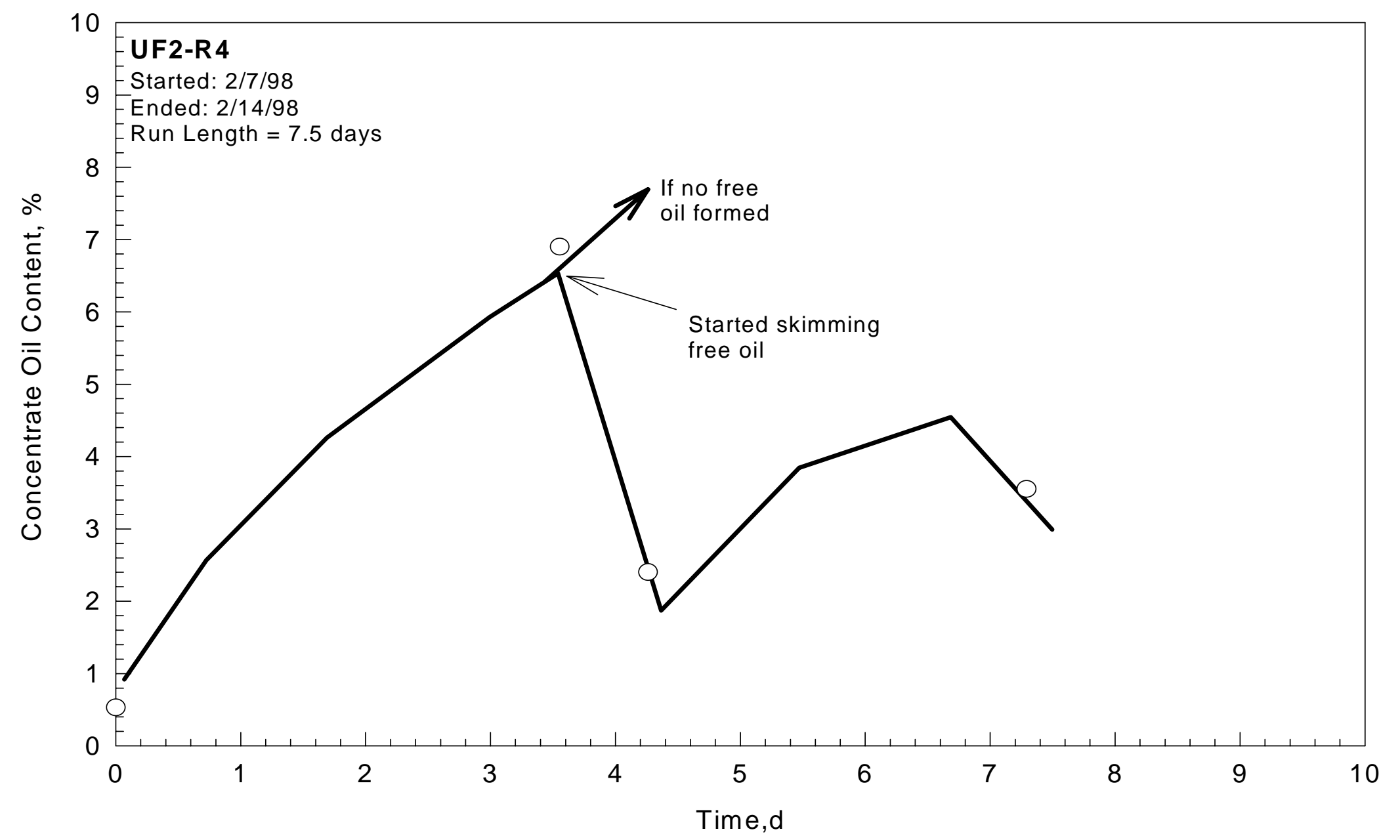

Figure 5.7 Actual and Predicted Oil Contents for UF2-R4 Mass Balance 


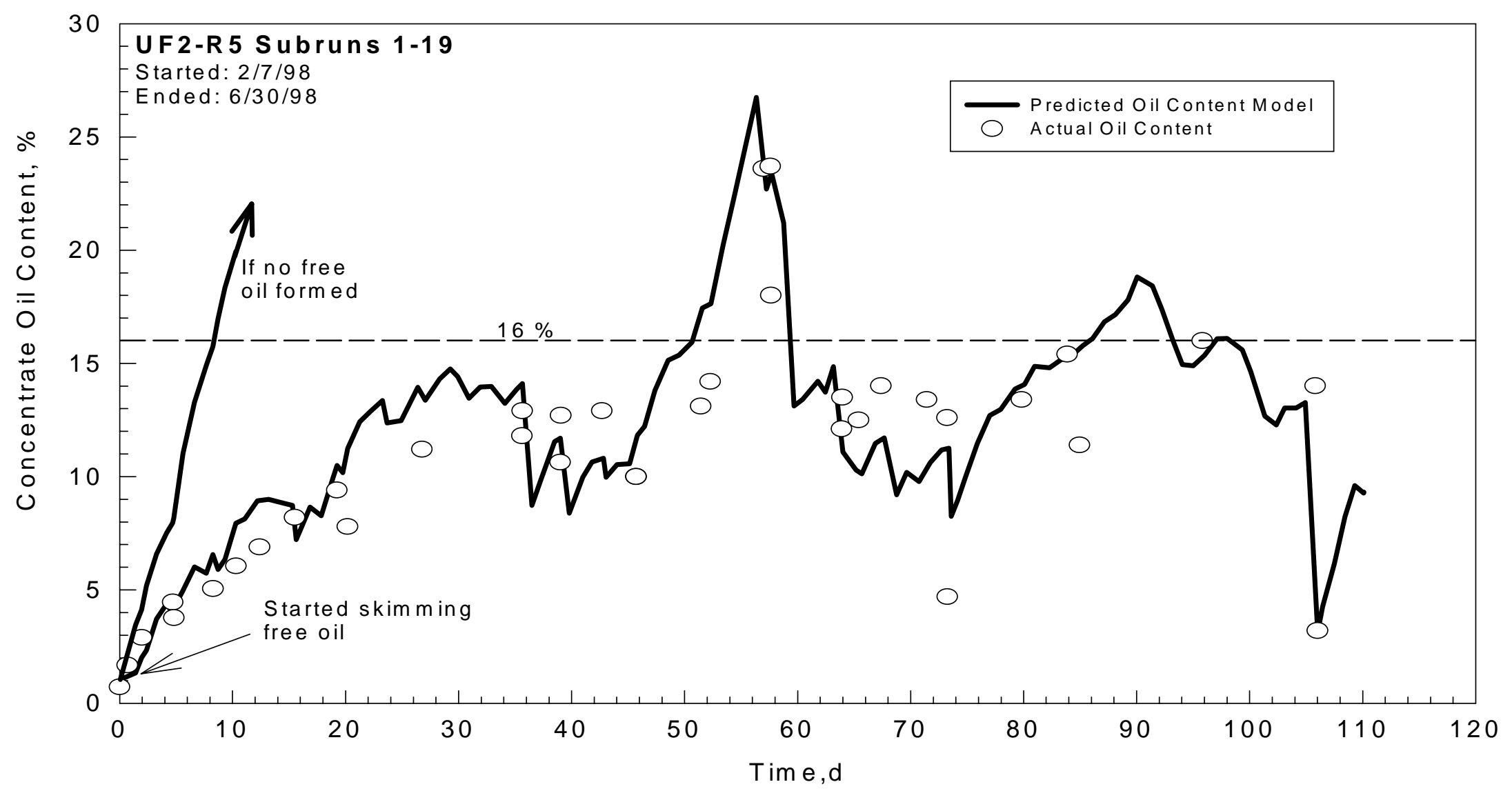

Figure 5.8 Actual and Predicted Oil Contents for UF2-R5 Mass alance 
operation, the oil content remained within the range of 10 to $15 \%$ oil. The oil content peaked above $16 \%$ oil only once around 79 days into UF1-R8, however declined and remained below the $16 \%$ set point the remainder of the run. As presented in Figure 5.4, the oil content of the concentrate solution would have reached the $16 \%$ oil content set point in less than 10 days if no free oil was formed and removed in the concentration tanks. However, because of free oil formation, the concentrate almost always remained at an oil content below $16 \%$ oil.

UF2-R5 also was in operation for a long period of time. UF2-R5 lasted for 109 days. During the first 35 days of operation, the oil content increased to $~ 12 \%$ oil. Similar to UF1-R8, the oil content remained constant between 10 and $15 \%$ for a period of about 20 days. The concentrate oil content increased to $18 \%$ when the oil skimmer was not functioning and oil was not removed from the concentration tank. After repairs were made, skimming resumed and the oil content dropped to a constant concentration of $\sim 12 \%$ oil. It was theorized that because the free oil was not being removed, the oil layer began to accumulate. The accumulating oil decreased the amount of available space for the concentrate in the concentration tank. As the volume decreased, the quiescent conditions in the concentration tank, which normally favor free oil formation, also decreased and the concentrate mixed more readily. Thus, the rate of free oil breaking out of the concentrate decreased, allowing for a net increase in oil content

\section{THE ROLE OF CONCENTRATION POLARIZATION AND MEMBRANE FOULING ON PERMEATE FLUX}

Concentration Polarization is the build up of solute molecules close to or on the membrane's surface. Solute is brought to the membrane's surface by convective 
transport. As water permeates the membrane, solute molecule larger than the MWCO of the membrane are retained. The retained solute, builds up causing a decline in flux due to either an increased resistance in the boundary layer or an increased osmotic pressure decreasing the driving force. Concentration polarization is effected by operating parameters, such as cross-flow velocity, temperature, pressure, and feed concentration. The effects of operating parameters in concentration polarization are presented in Figure 2.10 .

Membrane Fouling on the other hand is due to the deposition of particles on the membrane's surface or precipitation of particles within the membrane pores. Similar to concentration polarization, membrane-fouling results in a decrease in permeate flux. However, concentration polarization is not membrane fouling. Membrane fouling is primarily time-dependent and partially concentration dependent. Depending on the system flux decline may occur in one or more stages. Typically, a rapid decline in flux is observed followed by a more gradual decline with time. Since fouling is the result of interactions between the membrane and feed solutes and perhaps between adsorbed solute and other solutes in the concentrate stream, it is difficult to establish general rules about the nature and extent of the fouling (Cheryan, 1986).

During the full-scale operation of the tubular UF systems, permeate flux over time typically had an exponential decline in nature. It was hypothesized that concentration polarization had the majority of influence on flux decline, however, there was uncertainty whether membrane fouling was also occurring. In order to determine if membrane fouling was occurring five fouling models were applied to the data to determine the 
degree of fouling if any. The simplest models relate permeate flux to time and or the volume permeated. The models were as follows:

\section{Model \#1 - Kuo and Cheryan (1983)}

$$
\mathrm{J}=\mathrm{J}_{\mathrm{o}}\left(\mathrm{t}^{-\mathrm{b}}\right)
$$

Where: $\mathrm{J}=$ flux at any time $\mathrm{t}$

$\mathrm{t}=$ time in days

$\mathrm{J}_{\mathrm{o}}=$ initial permeate flux at time $=0$

$\mathrm{b}=$ fouling index

\section{Model \#2 - Merin and Cheryan (1980)}

$$
\mathrm{J}=\mathrm{J}_{\mathrm{o}}\left(\mathrm{V}^{-\mathrm{b}}\right)
$$

Where: $\mathrm{J}=$ flux at any time $\mathrm{t}$

$\mathrm{J}_{\mathrm{o}}=$ initial permeate flux at time $=0$

$\mathrm{V}=$ volume permeated

$\mathrm{b}=$ fouling index

\section{Model \#3 - Pore Plugging}

$$
\mathrm{J}=\mathrm{J}_{\mathrm{o}}\left(\mathrm{e}^{-\mathrm{bt}}\right)
$$

Where: $\mathrm{J}=$ flux at any time $\mathrm{t}$

$\mathrm{J}_{\mathrm{o}}=$ initial permeate flux at time $=0$

$\mathrm{t}=$ time in days

$\mathrm{b}=$ fouling index

\section{Model \#4 - Concentration Polarization and Adsorption}

$$
\mathrm{J}=\mathrm{J}_{\mathrm{ss}}+\operatorname{Bexp}(-\mathrm{kt})
$$

Where: $\mathrm{J}=$ flux at any time $\mathrm{t}$

$\mathrm{J}_{\mathrm{ss}}=$ steady state permeate flux

$\mathrm{t}=$ time in days

$\mathrm{B}=$ constant determined by linearization $(\mathrm{y}$ int)

$\mathrm{k}=$ fouling index 


\section{Model \#5 Cake Formation}

$$
\mathrm{J}=\mathrm{J}_{\mathrm{o}} /\left(1+\mathrm{J}_{\mathrm{o}} \mathrm{kt}\right)
$$

Where: $\mathrm{J}=$ flux at any time $\mathrm{t}$

$\mathrm{J}_{\mathrm{o}}=$ initial permeate flux at time $=0$

$\mathrm{t}=$ time in days

$\mathrm{k}=$ fouling index

\section{Modeling Flux Decline}

Of the five models, model \#4 fit the data the best. In Figure 5.9 the actual and predicted permeate flux for UF1-R7 using Model \#4 is presented. In Figure 5.10 the actual and predicted permeate flux for UF1-R8 (subruns 1-6) using Model \#4 is presented. In Figure 5.11 the actual and predicted permeate flux for UF1-R8 using Model \#4 (subruns 7-10) is presented. In Figure 5.12 the actual and predicted permeate flux for UF2-R3 using Model \#4 is presented. In Figure 5.13 the actual and predicted permeate flux for UF2-R4 using Model \#4 is presented. In Figure 5.14 the actual and predicted permeate flux for UF2-R5(subruns 1-6) using Model \#4 is presented. In Figure 5.15 the actual and predicted permeate flux for UF2-R5(subruns 7-12) using Model \#4 is presented. In Figure 5.16 the actual and predicted permeate flux for UF2-R5 (subruns 1318) using Model \#4 is presented. In Table 5.1, model index values (k) for all subruns are presented. The model index characterizes the declining nature of permeate flux over time. The concentration polarization and adsorption-fouling model consistently fit the actual data and predicted the steady-state fluxes. However, a single average model index could not predict the behavior over the entire run, due to the wide range of model index values. 

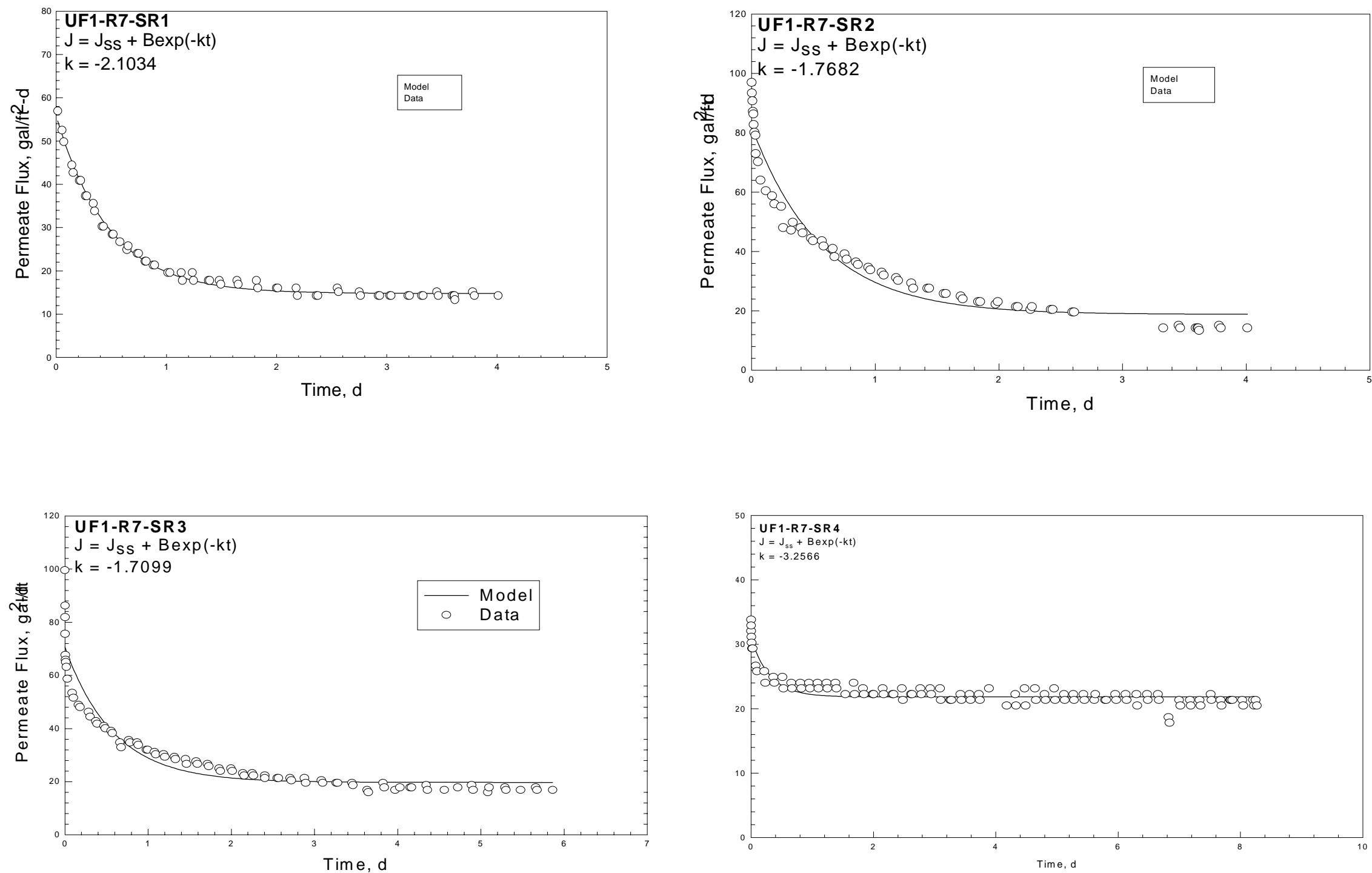

Figure 5.9 Actual and Predicted Permeate Flux for UF1-R7 using Model \#4 

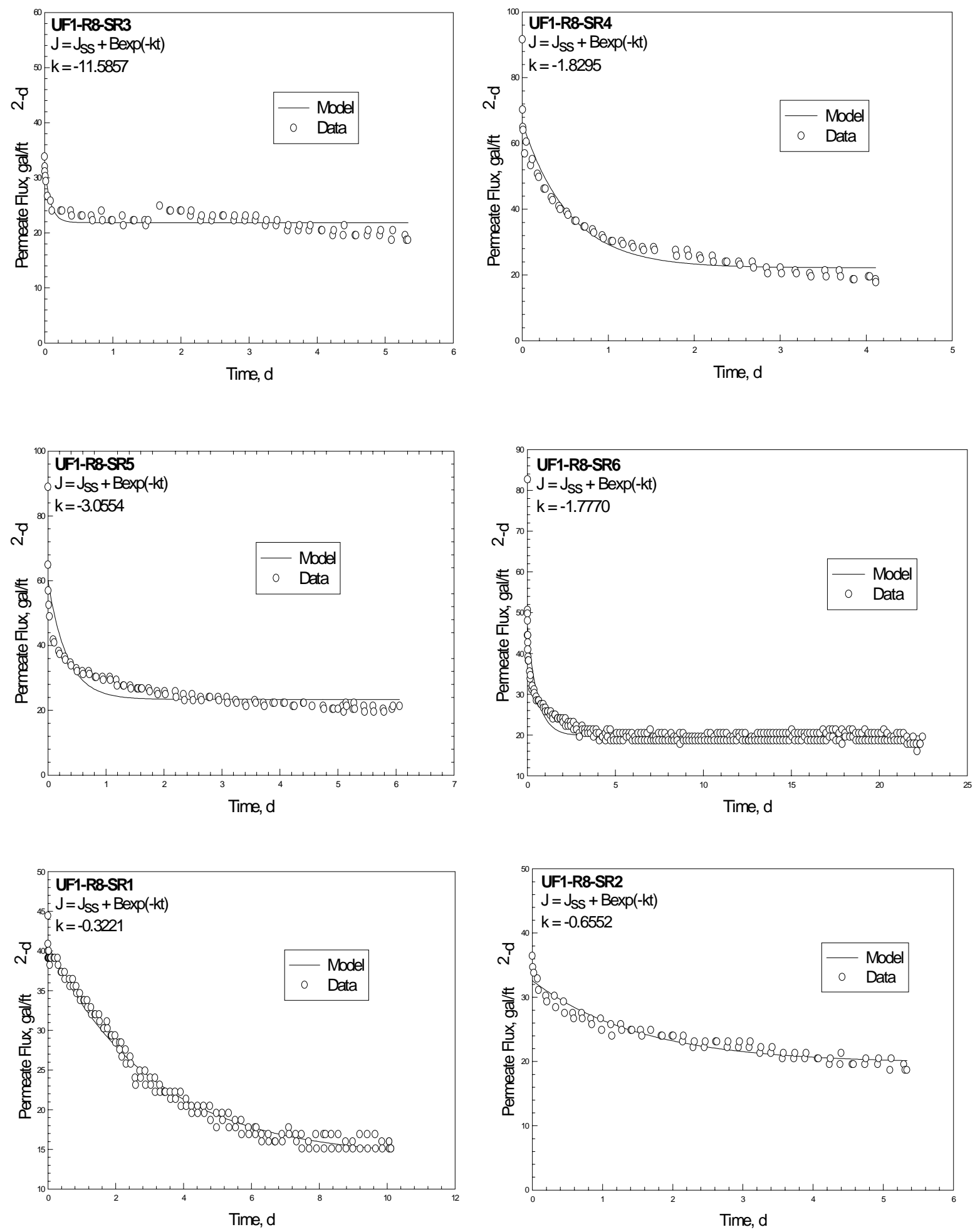

Figure 5.10 Actual and Predicted Permeate Flux for UF1-R8 (subrun 1-6) using Model \#4 

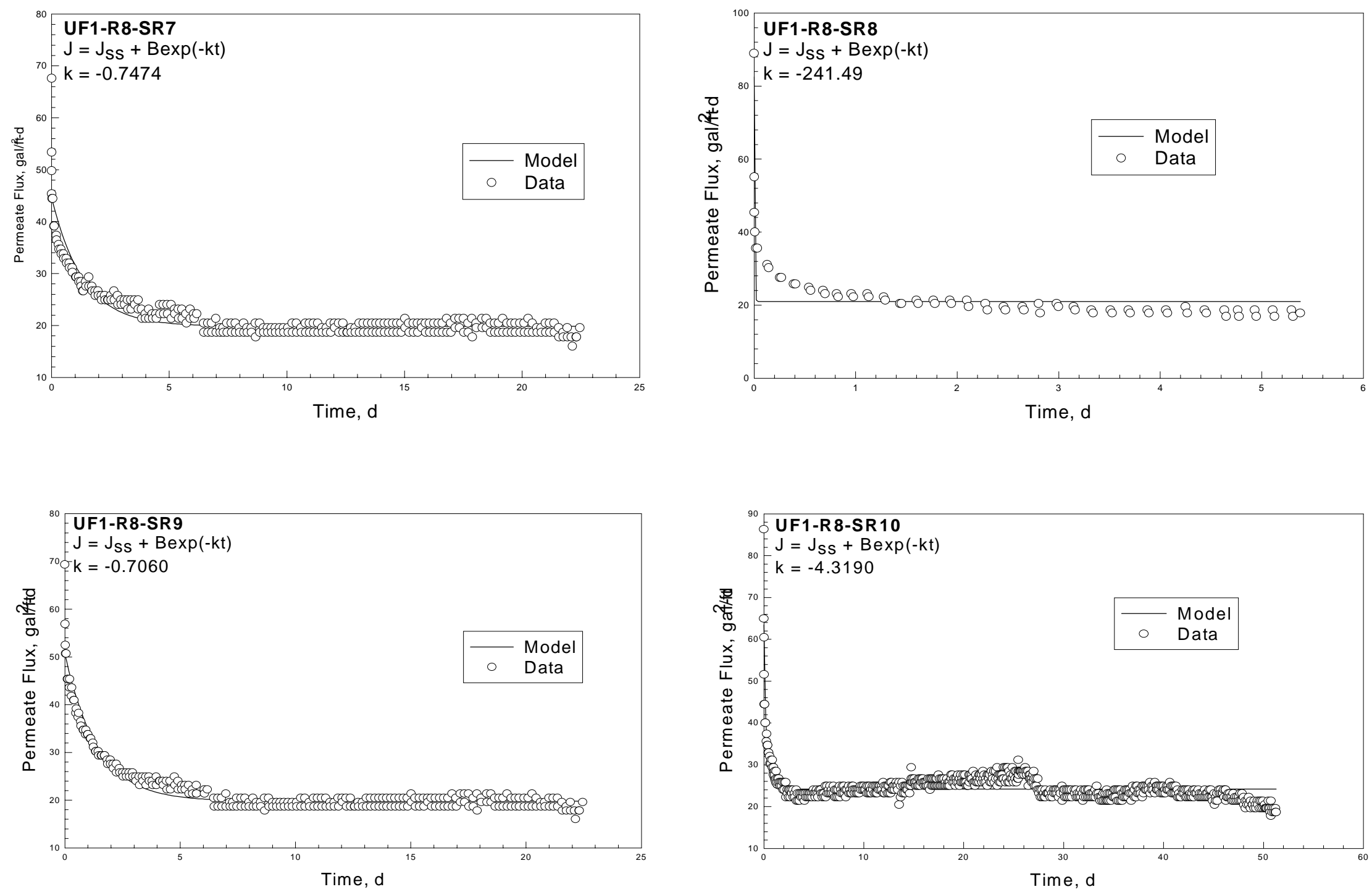

Figure 5.11 Actual and Predicted Permeate Flux for UF1-R8 (subrun 7-10) using Model \#4 

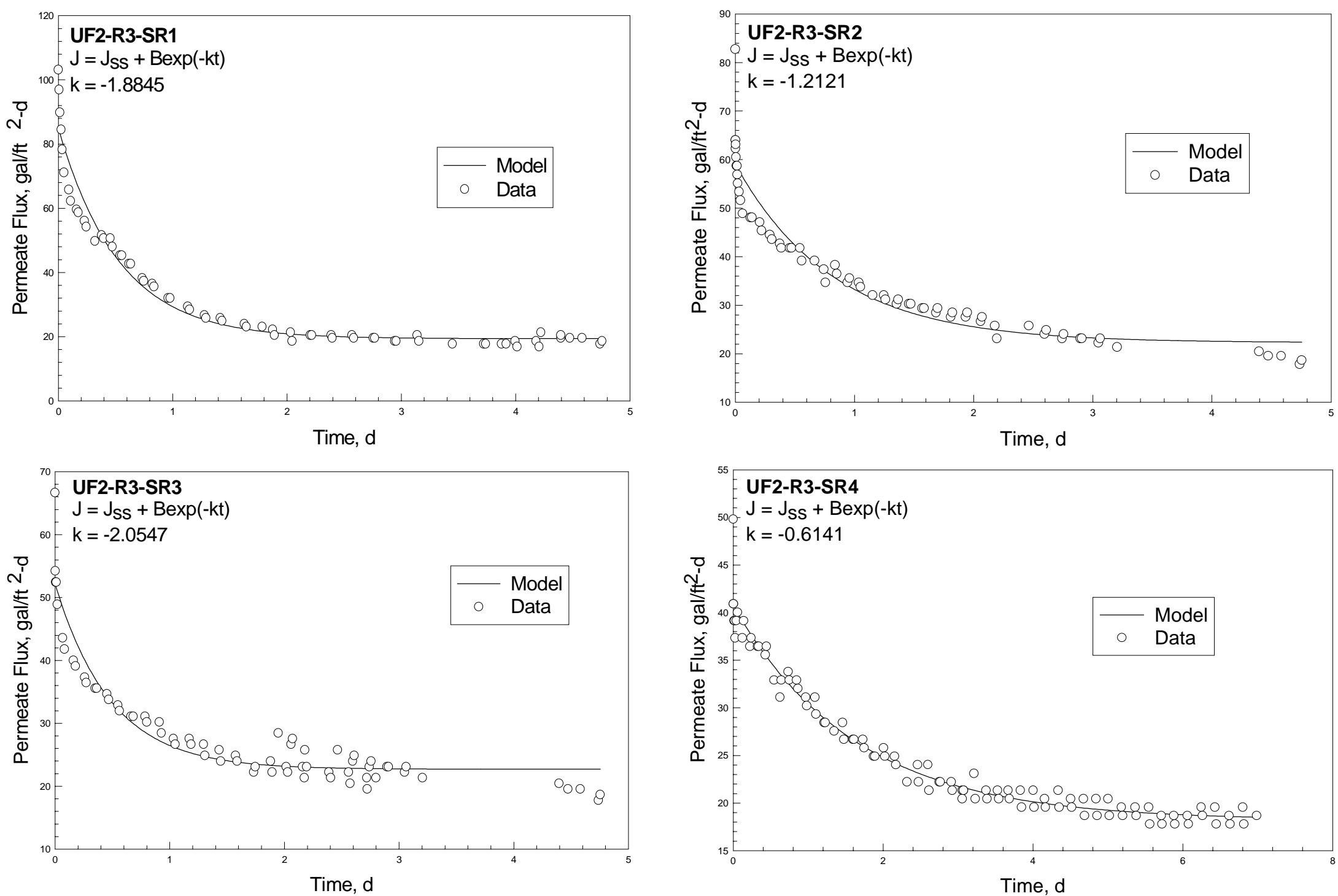

Figure 5.12 Actual and Predicted Permeate Flux for UF2-R3 using Model \#4 

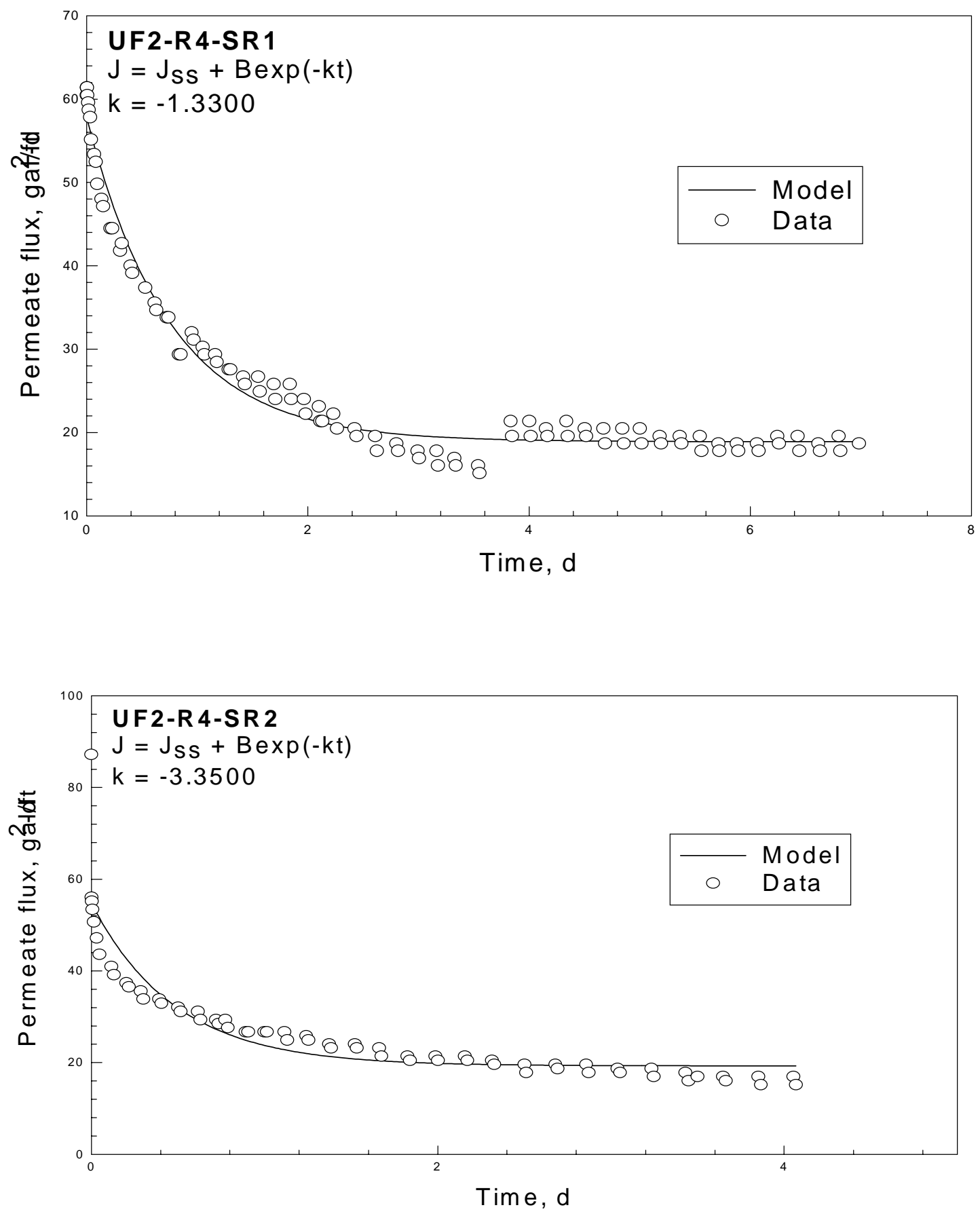

Figure 5.13 Actual and Predicted Permeate Flux for UF2-R4 using Model \#4 

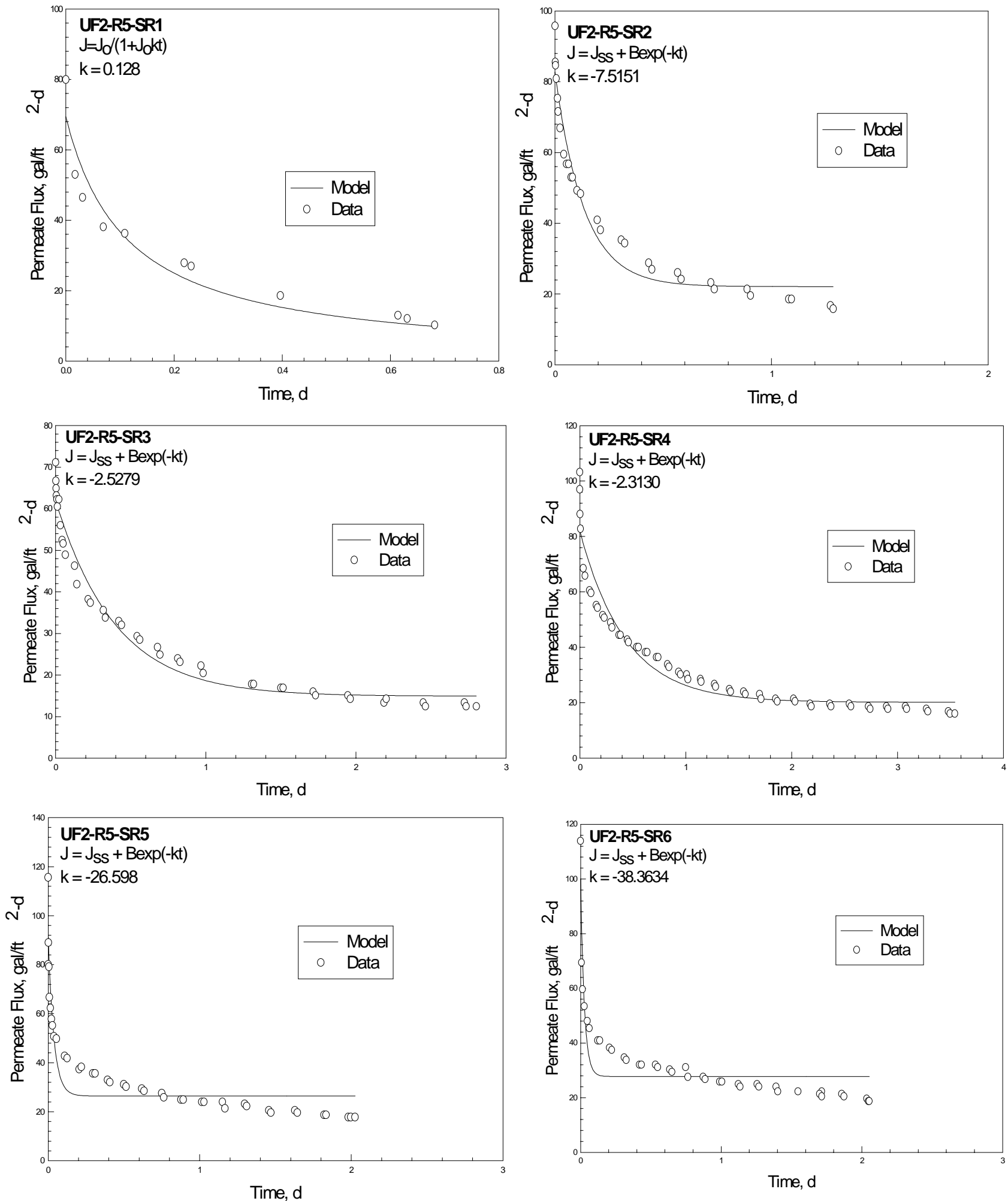

Figure 5.13 Actual and Predicted Permeate Flux for UF2-R5 (Subrun 1-6) using Model \#4 

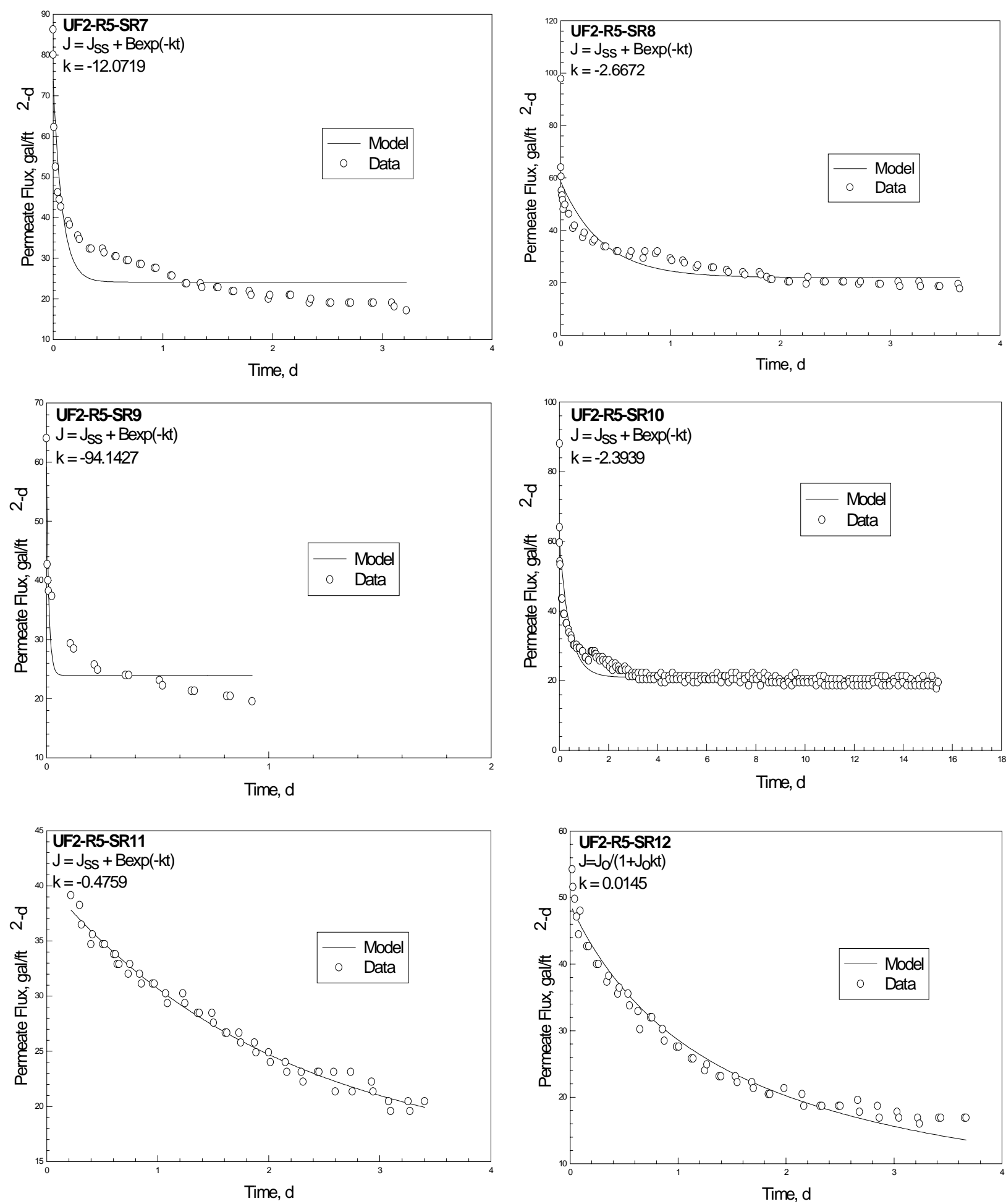

Figure 5.15 Actual and Predicted Permeate Flux for UF2-R5 (Subrun 7-12) using Model \#4 

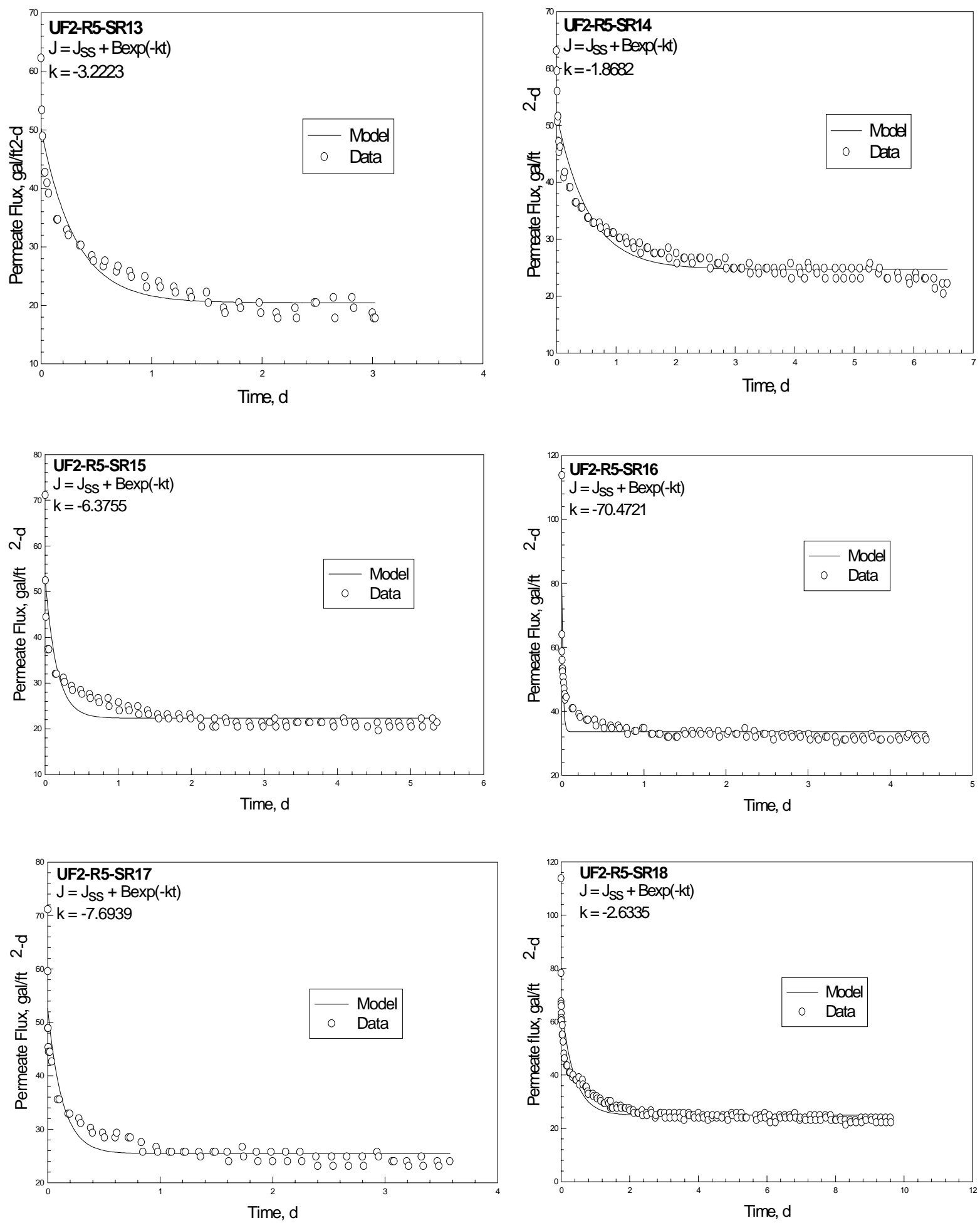

Figure 5.16 Actual and Predicted Permeate Flux for UF2-R5 (Subrun 13-18) using Model \#4 
Table 5.1 List of Model Indexes (k) for All Subruns

\begin{tabular}{|c|c|c|}
\hline Run ID & Subrun ID & Model Index, $\mathrm{k}$ \\
\hline \multirow[t]{4}{*}{ UF1-R7 } & 1 & -2.10 \\
\hline & 2 & -1.77 \\
\hline & 3 & -1.71 \\
\hline & 4 & -3.21 \\
\hline \multirow[t]{11}{*}{ UF1-R8 } & 1 & -0.32 \\
\hline & 2 & -0.66 \\
\hline & 3 & -11.59 \\
\hline & 4 & -1.83 \\
\hline & 5 & -3.06 \\
\hline & 6 & $\begin{array}{l}-1.78 \\
\end{array}$ \\
\hline & 7 & -0.75 \\
\hline & 8 & -2.88 \\
\hline & 9 & -0.71 \\
\hline & 10 & -4.32 \\
\hline & 11 & -3.56 \\
\hline \multirow[t]{4}{*}{ UF2-R3 } & 1 & -1.88 \\
\hline & 2 & -1.21 \\
\hline & 3 & -2.05 \\
\hline & 4 & -0.61 \\
\hline \multirow[t]{2}{*}{ UF2-R4 } & 1 & -1.33 \\
\hline & 2 & -3.35 \\
\hline \multirow[t]{19}{*}{ UF2-R5 } & 1 & -9.88 \\
\hline & 2 & -7.52 \\
\hline & 3 & -2.53 \\
\hline & 4 & -2.31 \\
\hline & 5 & -26.60 \\
\hline & 6 & -38.36 \\
\hline & 7 & -12.07 \\
\hline & 8 & -2.67 \\
\hline & 9 & -94.14 \\
\hline & 10 & -2.39 \\
\hline & 11 & -0.48 \\
\hline & 12 & -1.18 \\
\hline & 13 & -3.22 \\
\hline & 14 & -1.87 \\
\hline & 15 & -6.38 \\
\hline & 16 & -70.47 \\
\hline & 17 & -7.69 \\
\hline & 18 & -2.63 \\
\hline & 19 & -1.27 \\
\hline
\end{tabular}


The predicted initial permeate flux was consistently lower than the actual permeate flux. This difference was due to the cleaning solution present in the system during the start up of a subrun. The cleaning solution decreases the surface tension at the membrane pores allowing water to pass through more readily, thus a high permeate flux occurs. Within a few minutes of the subrun, the concentrate circulating through the system diluted the cleaning solution. When the concentrate diluted the cleaning solution adequately, the predicted permeate fluxes closely resembled the actual data. In Figure 5.16, actual and predicted permeate flux for models $1,2,3$ and 5 are presented for UF2R5-SR3. The results presented in Figure 5.16 were similar in all subruns. 


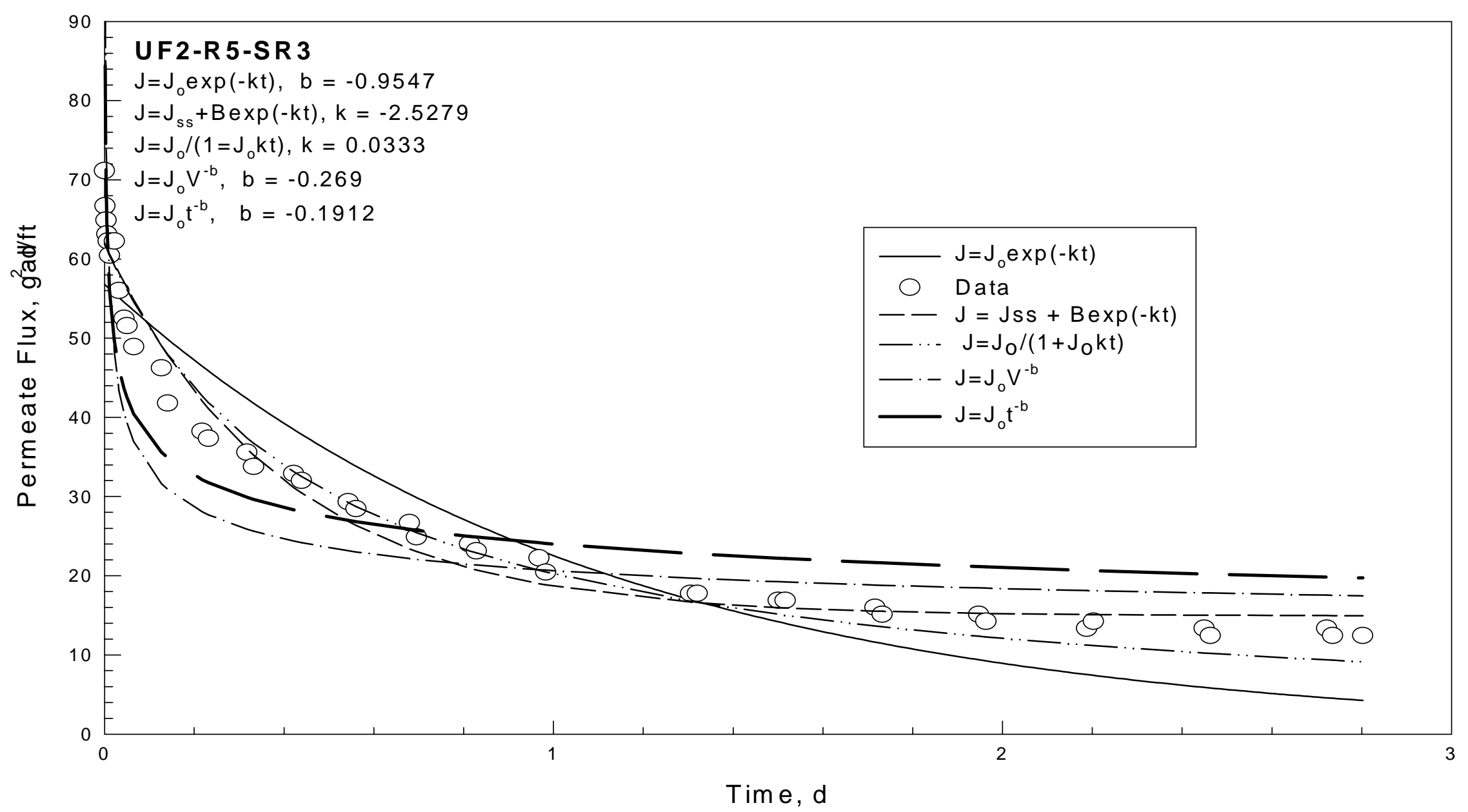

Figure 5.17, Actual and Predicted Permeate Flux for UF2-R5-SR3 using Models 1, 2, 3, and 5 


\section{CHAPTER 6}

\section{CONCLUSION}

In starting up and optimizing performance of the tubular UF systems the following tasks were completed. The objective of the entire study was to develop a standard operating plan for the entire oily-waste system. In partial fulfillment of this objective, the following goals were achieved:

5. Development of an operating plan for tubular UF system that optimizes system performance.

6. Determined free oil production rates.

7. Developed a mass balance model on oil for tubular UF system.

8. Investigated the role of concentration polarization on permeate flux.

Several positive outcomes occurred from the implementation of the full-scale tubular UF system to treat oily waste. Effluent $\mathrm{O} / \mathrm{G}$ concentrations were consistently low, yielding 99.9\% removal efficiencies. Thus, the wetlands treatment process were not required. Due to the unexpected purity and large volumes of free oil forming at the top of the concentration tanks, system oil content remained below $16 \%$. As a result, there was no need to purge and treat the concentrate. Thus, installation of the HSR-UF system was deemed unnecessary. The concentration polarization and adsorption fouling model consistently fit and predicted steady-state fluxes, however, was unable to predict the behavior of an entire run using a single average fouling index value. 
Future research is going to be preformed on the system during the winter months in order to verify that the high shear rotary UF systems are not needed. It is hypothesized that the amount of free oil separating from the concentrate will be significantly less causing the concentrate oil content to increase beyond $16 \%$ set point. Thus purging the concentrate to the HSR-UF system might have to be implemented. 


\section{CHAPTER 7}

\section{REFERENCES}

Applegate, Lynn E. (1984). “Membrane Separation Processes.” Chemical Engineering, 91(12), PP. 64-89.

Belfort, G. (1988). "Membrane Modules: Comparison of Different Configurations Using Fluid Mechanics.” Journal of Membrane Science, 35, pp. 245-270.

Burke, John. (1991). "Waste Treatment of Metalworking Fluids, A Comparison of Three Common Methods." Journal of Lubrication Engineers, pp. 236-248.

Cheryan, Munir PhD. (1986). Ultrafiltration Handbook. Technomic Publishing Company, Inc. Lancaster, PA.

Cheryan Munir and Merin, Uzi, “ A Study of the Fouling Phenomenon during Ultrafiltration of Cottage Cheese Whey." Journal of dairy Science, pp. 619-629.

Eringis, A., Brady, F., and R. Blank (1993). "Wastewater Treatment in the Die Casting Industry Using Cross-Flow Membrane Filtration." Transaction of the North American Die Casting Association.

Goldsmith,R., Roberts, D., and D., Burre (1974). "Ultrafiltration of Soluble Oil Wastes." Journal of Water pollution Control Federation, 46(9), 2183-2192.

Jonnson, Ann Sofi and Gun Tragardh. (1990). "Fundamental Principles of Ultrafiltration." Chemical Engineering Processes, 27, pp. 67-81.

Jonsson, G., and C. E. Boesen (1984). " Polarization Phenomena in Membrane Processes." Synthetic Membrane Processes. Academic Press Inc., pp. 101-129.

Kuo and Cheryan, "Ultrafiltration of Acid Whey in a Spiral-Wound Unit: effect of operating parameters on Membrane Fouling." Journal of food Science. pp. 1113-1118

Laemmle, Joseph. “Metalworking Lubricants.” American Petroleum institute.

Lee, S., Aurelle, Y., H. Roques (1984). "Concentration Polarization, Membrane Fouling, and Cleaning of Ultrafiltration of Soluble Oil," Journal of Membrane Science,19,23-38. 
MacNeil, J. and D. McCoy (1989). "Membrane Separation Technologies." Standard Handbook of Hazardous Waste Treatment and Disposal. McGraw-Hill Book Co., New York, 6.91-6.106.

Mahdi, S. and R. Skold (1991). "Membrane Filtration for the Recycling of Water-Based Synthetic Metalworking Fluids." Filtration and Separation, 28 (6), pp. 407-414.

Mallevialle, Joel, Odendaal, P., Wiesner, M. (1996). Water Treatment: Membrane Processes. McGraw Hill. New York.

Matthiasson, E. (1983). "The Role of Macromolecular Adsorption in Fouling of Ultrafiltration Membranes.” Journal of Membrane Science, 16, pp. 23-26.

Perry, R. and D. Green (1997). Perry's Chemical Engineering Handbook, $7^{\text {th }}$ ed. McGrall-Hill, New York.

Pinto, Stevens D. (1978). "Ultrafiltration for Dewatering of Waste Emulsified Oils." Proceedings, $1^{\text {st }}$ International Conference. IIT Research Institute, Chicago, Ill. pp. 1-4.

Reed, Brian E., Wei Lin, Chris Dunn, Patrick Carriere and Gary Roark (1997). "Treatment of an Oil/Grease Wastewater Using Ultrafiltration: Pilot-scale Results." Separation Science and Technology, 32(9), pp. 1493-1511.

Reed, Brian E., Member, ASCE, Wei Lin, Roger Viadero Jr., and Joseph Young (1997). "Treatment of Oily Wastes Using High-Shear Ultrafiltration." Journal of Environmental Engineering, pp. 1234-1242.

Sheppard, John and Thomas, David, (1970). "Control of Concentration Polarization and Arrest of Fouling of Cellulose Actetate Hyperfiltration Membranes By High Axial Velocity." Membranes from Cellulose and Cellulose Derivatives. A. F. Turburk (ed.), American Chemical society, Washington, D.C., pp. 289-331.

Toyomoto, Kazuo and Akon Higuchi (1992). "Microfiltration and Ultrafiltration." Membrane Science and Technology. Marcel Dekker, Inc.

Wahl, J.R. et al. (1979). Ultrafiltration for Today's Oily Wastewaters: A Survey of Current Ultrafiltration Systems. Proceedings of the $34^{\text {th }}$ Annual Industrial Waste Conference. Purdue University. West Lafayetter, IN., pp. 719-733.

Yukel, L., et al. (1991). A New Concept in the Economical Treatment of Waste Emulsions: Chemical Emulsion Breaking and Membrane Filtration. Mines ET Carrieres: Les Techiques, March, pp. 126-131. 
Zaidi, A., Simms, K., and S. Kok (1992). "The Use of Micro/Ultrafiltration for the Removal of Oil and Suspended Solids From Oilfield Brines." Water Science and Technology, 25(10), pp. 163-176. 